UNIVERSIDADE DE SÃO PAULO

FACULADADE DE FILOSOFIA, LETRAS E CIÊNCIAS HUMANAS DEPARTAMENTO DE LINGÜÍSTICA

\title{
DESCRIÇÃO DE DISTORÇÕES DOS SONS DA FALA EM CRIANÇAS COM E SEM TRANSTORNO FONOLÓGICO
}

São Paulo

2006 
UNIVERSIDADE DE SÃO PAULO

FACULADADE DE FILOSOFIA, LETRAS E CIÊNCIAS HUMANAS DEPARTAMENTO DE LINGÜÍSTICA

\section{DESCRIÇÃO DE DISTORÇÕES DOS SONS DA FALA EM CRIANÇAS COM E SEM TRANSTORNO FONOLÓGICO}

São Paulo

2006 


\section{BANCA EXAMINADORA}

Presidente

$1^{\circ}(*)$ Examinador

$2^{\circ}(*)$ Examinador 
Aos meus queridos pais ANTONIO e ANTONIA

Pelo amor incondicional, incentivo e companheirismo em todos os momentos. 


\section{AGRADECIMENTOS}

Com a concretização do Mestrado tenho a agradecer muitas pessoas que souberam me dar apoio, me ajudando em todos os momentos de angústia, indecisões e incertezas.

Dedico a todos que participaram deste processo e que fizera acreditar que com companheirismo e amor as tarefas ficam menos árduas.

A todos que se fizeram presentes neste momento tão importante na minha vida profissional deixo meus sinceros agradecimentos:

A DEUS, pela oportunidade de concretizar todos os objetivos e colocar no meu caminho pessoas que me fizeram acreditar que a trajetória fica mais leve quando somos rodeados de pessoas sinceras e que nos fazem ver que sem compreensão e amor nada é possível.

Aos meus maravilhosos pais ANTONIO e ANTONIA, pelo grande exemplo de dedicação, sabedoria e paciência, por sempre acreditarem no meu esforço, e doar todo amor e incentivo, me apoiando em todas as minhas decisões.

À minha querida irmã MÁRCIA, por toda dedicação, colaboração, disponibilidade, companheirismo, incentivo e "paciência".

Ao meu irmãozinho GUILHERME, por demonstrar a importância do carinho e amor, me ajudando a enfrentar os momentos de cansaço e desânimo.

Ao meu cunhado ALEXANDRE, pela colaboração, "ajudas" e "socorros".

À TIA ROSANA, pelo grande carinho, sempre espalhando alegria e otimismo.

À amiga-irmã MIRELLA, por sua intensa amizade, sempre compartilhando dificuldades e alegrias. 
À querida orientadora Professora Livre Docente HAYDÉE FISZBEIN WERTZNER pela dedicação, carinho e atenção, por seu grande exemplo de responsabilidade e competência. Obrigada pela oportunidade, confiança e incentivo.

Às professoras ZELITA GUEDES e SANDRA PALOMO pelas tão valiosas contribuições e sugestões.

À amiga DANIELA GALEA pelo companheirismo, amizade e importante colaboração na tradução.

Às amigas do Laboratório de Investigação Fonoaudiológica em Fonologia do Curso de Fonoaudiologia do Departamento de Fisioterapia, Fonoaudiologia e Terapia Ocupacional da Faculdade de Medicina da Universidade de São Paulo: VANESSA, mÁrciA CASTRO, AMÁliA, ANNE CAROLINE, FRANCINE, LUCIANA, ANA CAROLINA, ADRIANA, FELISA, MÁRCIA SIMÕES e SIMONE por estarem sempre presentes, ajudando a superar as dificuldades e contribuindo para a realização de todas as tarefas com alegria e amor.

Às amigas LEILA e RENATA pelo incentivo, força e valiosa colaboração na coleta e análise dos dados.

Às amigas da Turma XXIV, em especial à VANESSA, LUCIENE, ÉRIKA e JAMILE pela amizade e apoio.

Ao professor DIDIER DEMOLIN pela importante contribuição na aplicação e análise da palatografia e linguografia.

Aos FUNCIONÁRIOS do Centro de Docência e Pesquisa do Departamento de Fisioterapia, Fonoaudiologia e Terapia Ocupacional da Faculdade de Medicina da Universidade de São Paulo por toda disponibilidade e atenção. 
Aos FUNCIONÁRIOS do Departamento de Lingüística da Faculdade de Filosofia, Letras e Ciências Humanas da Universidade de São Paulo pelos esclarecimentos de dúvidas e atenção.

Aos FUNCIONÁRIOS e PROFESSORAS das escolas "EMEF Guilherme de Almeida" e "EMEI José Rubens Peres Fernandes", em especial ás coordenadoras pedagógicas MÀRCIA e SUELY por toda receptividade e confiança que depositaram em mim e no meu trabalho.

Às CRIANÇAS e FAMÍLIAS das escolas "EMEF Guilherme de Almeida" e “EMEI José Rubens Peres Fernandes” e Laboratório de Investigação Fonoaudiológica em Fonologia do Curso de Fonoaudiologia pela confiança e aceite em participar deste trabalho.

Ao estatístico MARCOS MAEDA pela preciosa colaboração na análise dos resultados.

À SUMAYA LIMA pela valiosa ajuda na revisão deste trabalho.

Ao CNPq pela concessão da bolsa de mestrado que possibilitou a realização da pesquisa. 


\section{SUMÁRIO}

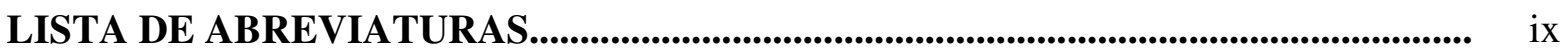

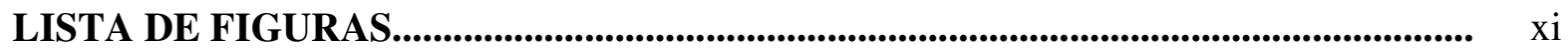

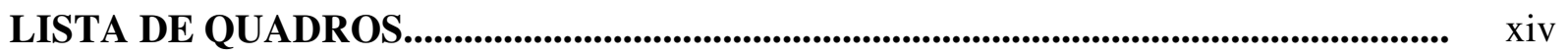

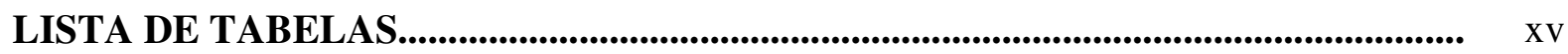

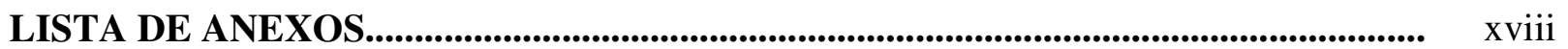

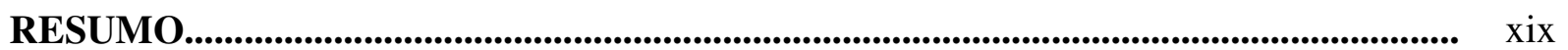

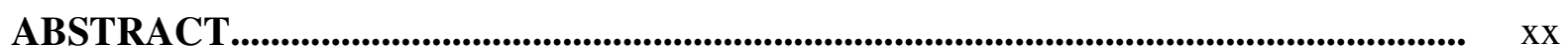

APRESENTAÇÃ

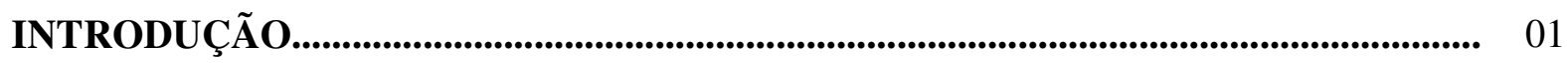

A Interdependência entre Fonologia e Fonética..................................................... 03

Fonética Articulatória...................................................................................... 04

Desenvolvimento do Sistema Fonológico e Fonético................................................... 07

Transtorno Fonológico.......................................................................................... 10

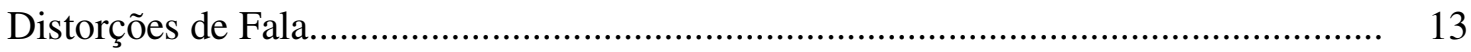

Gravidade do Transtorno Fonológico.......................................................................... 17

Provas e Instrumentos Usados no Transtorno Fonológico.......................................... 20

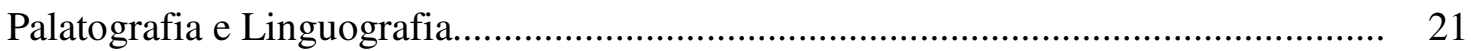

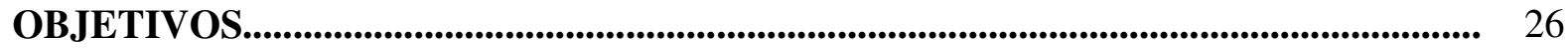

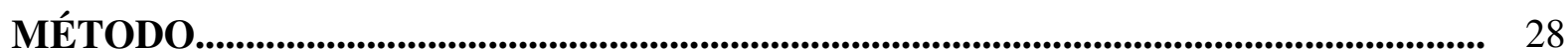

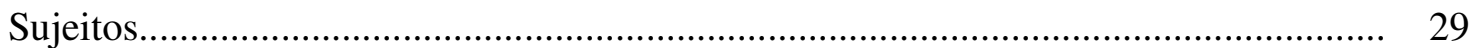

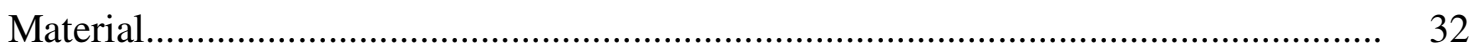

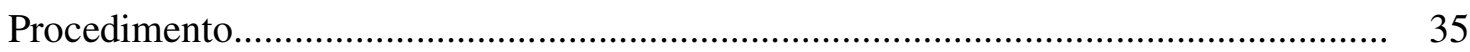

Seleção das Escolas e dos Sujeitos Sem Transtorno Fonológico...................... 35

Seleção dos Sujeitos Com Transtorno Fonológico......................................... 36

Análise Perceptiva Auditiva e Visual da Distorção........................................ 37

Composição, Aplicação e Critérios de Análise da Prova para Verificação de

Distorção dos Sons em Sílabas e Palavras....................................................... 38

Critérios de Análise da Prova de Verificação de Distorção de Fala................ 39

Palatografia e Linguografia.......................................................................... 40 
Avaliação da Motricidade Orofacial............................................................... 44

Provas de Fonologia, Fala Espontânea e Índices de Gravidade....................... 44

Cálculo dos Índices de Gravidade................................................................... 45

Método Estatístico........................................................................................ 47

$\begin{array}{ll}\text { RESULTADOS } & 48\end{array}$

Descrição da População Quanto ao Gênero e Idade........................................................ 49

Descrição da Ocorrência de Distorções em Crianças Com e Sem Transtorno

Fonológico nas Provas de Imitação e Nomeação (WERTZNER, 2004) e Fala

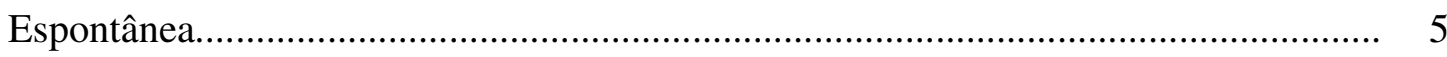

Descrição das Distorções na Prova Específica para Verificação de Distorções em

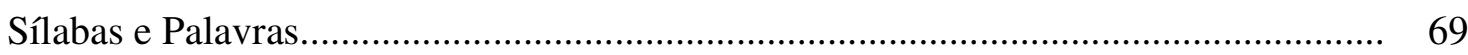

Classificação Perceptiva das distorções de Fala na Prova Específica para Verificação de Distorções em Sílabas e Palavras.......................................................................... 74

Análise da Motricidade Orofacial.............................................................................. 79

Descrição da Articulação dos Sons Líquidos Laterais e Vibrantes Simples e de

Fricativos Alveolares e Palatais pela Palatografia e Linguografia............................... 80

Comparação entre os Pontos de Contato da Articulação na Palatografia e

Linguografia e Classificação Perceptiva das Distorções............................................... 82

Comparação dos Índices de Gravidade nas Provas de Imitação e Nomeação

(WERTZNER, 2004) e Fala Espontânea................................................................... 98

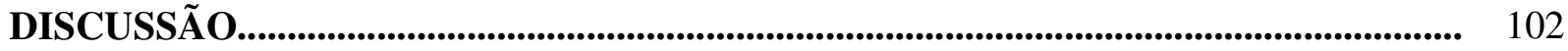

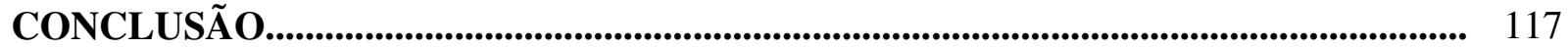

REFERÊNCIAS BIBLIOGRÁFICAS........................................................................ 120

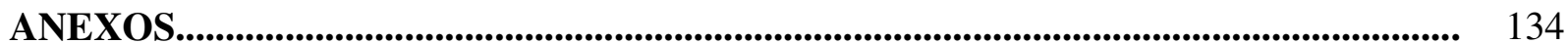

(CD) 


\section{LISTA DE ABREVIATURAS}

$\begin{array}{ll}\text { A } & \text { Alveolar } \\ \text { ABFW } & \text { Teste de Linguagem Infantil } \\ \text { ACI } & \text { Articulation Competence Index } \\ \text { Ap } & \text { Ápice } \\ \text { A-L } & \text { Ápico-laminar } \\ \text { A-P } & \text { Alvéolo-palatal } \\ \text { CAPPesq } & \text { Comissão de Ética para Análise de Projetos de Pesquisa } \\ \text { D } & \text { Dental } \\ \text { DN } & \text { Data de Nascimento } \\ \text { DP } & \text { Desvio Padrão } \\ \text { D-A } & \text { Dento-alveolar } \\ \text { D-P } & \text { Dento-palatal } \\ \text { DSM } & \text { Diagnostic and Statistical Manual } \\ \text { F } & \text { Feminino } \\ \text { GSTF } & \text { Grupo sem Transtorno Fonológico } \\ \text { GSTF 1 } & \text { Grupo sem Transtorno Fonológico - crianças entre 5:01 a 5:11 anos } \\ \text { GSTF 2 } & \text { Grupo sem Transtorno Fonológico - crianças entre 6:01 a 6:11 anos } \\ \text { GSTF 3 } & \text { Grupo sem Transtorno Fonológico - crianças entre 7:00 a 7:11 anos } \\ \text { GTF } & \text { Grupo com Transtorno Fonológico } \\ \text { GTF 1 } & \text { Grupo com Transtorno Fonológico - crianças entre 5:02 a 5:11 anos } \\ \text { GTF 2 } & \text { Grupo com Transtorno Fonológico - crianças entre 6:01 a 6:11 anos } \\ \text { GTF 3 } & \text { Grupo com Transtorno Fonológico - crianças entre 7:00 a 7:09 anos } \\ \text { GSTFCD } & \text { Grupo sem Transtorno Fonológico com Distorção } \\ \text { GSTFSD } & \text { Grupo sem Transtorno Fonológico sem Distorção } \\ \text { GTFCD } & \text { Grupo com Transtorno Fonológico com Distorção } \\ \text { GTFSD } & \text { Grupo com Transtorno Fonológico sem Distorção } \\ \text { LIF } & \text { Laboratório de Investigação Fonoaudiológica em Fonologia } \\ \text { M } & \text { Masculino } \\ \text { MAA } & \text { Mordida Aberta Anterior } \\ \text { MCA } & \text { Mordida Cruzada Anterior } \\ \text { MCP } & \text { Mordida Cruzada Posterior } \\ \text { N } & \text { Número } \\ \text { PCC } & \text { Percentage of Consonants Correct } \\ \text { PCC-A } & \text { Percentage of Consonants Correct - Adjustment } \\ \text { PCC-R } & \text { Percentage of Consonants Correct - Revised } \\ \text { PDI } & \text { Process Density Index } \\ \text { RDI } & \text { Relative Distortion Index } \\ & \end{array}$




\section{Distorções}

SD Sem Distorção

Som [1]

PLSD

Projeção de lingual sem distorção acústica

Som $[r]$

PoCD

Posteriorização com distorção acústica

Som $[\Lambda]$

$\mathrm{RM}$

Ruído molhado (ruído de saliva)

Som [s]

PLSD

PALCD

PLLCD

Som $[z]$

PLSD

PALCD

PLLCD

Som [S]

ESD

Projeção de língua sem distorção acústica

Projeção anterior de língua com distorção acústica

ECD

Som [3]

ESD

Projeção lateral de língua com distorção acústica

ECD

Projeção de língua sem distorção acústica

Projeção anterior de língua com distorção acústica

Projeção lateral de língua com distorção acústica

Esforço articulatório sem distorção acústica

Esforço articulatório com distorção acústica

Esforço articulatório sem distorção acústica

Esforço articulatório com distorção acústica 


\section{LISTA DE FIGURAS}

Figura 1. Materiais utilizados na palatografia e linguografia ......................................... 41

Figura 2. Mistura de carvão digestivo pulverizado e azeite de oliva.............................. 41

Figura 3. Aplicação da mistura no palato duro e na língua............................................ 41

Figura 4. Introdução do espelho entre os molares superiores e obtenção

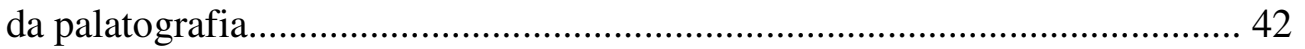

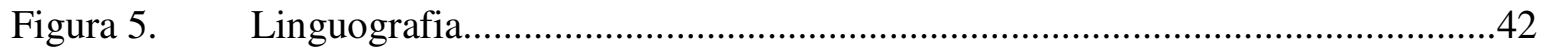

Figura 6. Distribuição dos sujeitos do GSTF de acordo com a idade.............................. 49

Figura 7. Distribuição dos Sujeitos do GTF de acordo com a idade................................ 50

Figura 8. Distribuição dos sujeitos do GTF de acordo com o gênero............................... 51

Figura 9. Presença de distorção de fala nos sujeitos do GSTF........................................ 56

Figura 10. Distribuição por faixa etária dos sujeitos do GSTFCD ...................................... 57

Figura 11. Distribuição por gênero dos sujeitos do GSTFCD............................................ 57

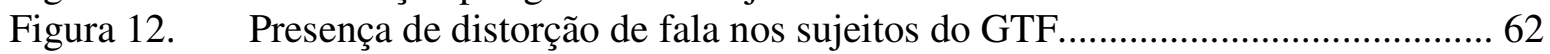

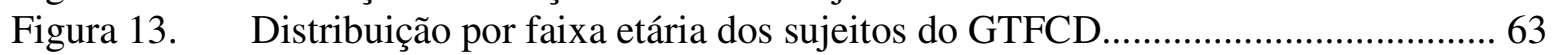

Figura 14. Distribuição por gênero dos sujeitos do GTFCD............................................ 63

Figura 15. Comparação da média de porcentagem na prova específica

Figura 16. Con

Figura 16. Comparação da média de porcentagem na prova específica

para verificação de distorção em sílabas - GSTFCD na faixa etária

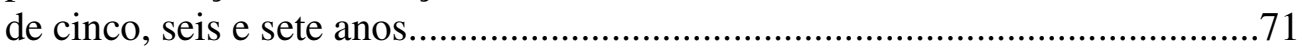

Figura 17. Comparação da média de porcentagem na prova específica

para verificação de distorção em palavras - GSTFCD na faixa etária

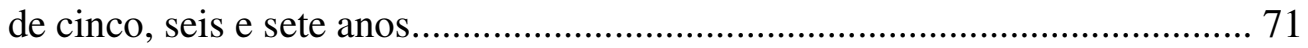

Figura 18. Comparação da média de porcentagem na prova específica

para verificação de distorção em sílabas e palavras - GTFCD......................... 73

Figura 19. Comparação das médias dos sons distorcidos na prova

para verificação de distorção em sílabas e palavras - GSTFCD e GTFCD....... 73

Figura 20. Comparação das médias de porcentagem da classificação das

distorções em sílabas e palavras da prova específica para

verificação de distorção de fala - GSTFCD....................................................... 74

Figura 21. Comparação das médias de porcentagem da classificação das

distorções em sílabas e palavras da prova específica para

verificação de distorção de fala - faixas etárias do GSTFCD.

Figura 22. Comparação das médias de porcentagem da classificação das

distorções em sílabas e palavras da prova específica para

verificação de distorção de fala - GTFCD.

Figura 23. Comparação das médias de porcentagem da classificação das

distorções em sílabas e palavras da prova específica para

verificação de distorção de fala - GTFCD e GSTFCD................................... 78

Figura 24. Tipos de dentição do GSTFSD, GSTFCD, GTFSD, GTFCD.......................... 79

Figura 25. Porcentagem média dos tipos de maloclusões -

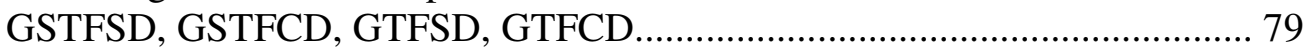

Figura 26. Palatografia e Linguografia do som [s] - GSTFSD ...................................... 81

Figura 27. Palatografia e Linguografia do som [s] - GSTFCD ........................................... 83

Figura 28. Boxplot do PCC na Nomeação.......................................................................... 90 
Figura 29. Boxplot do PCC na Imitação....................................................................... 91

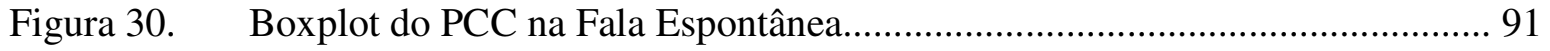

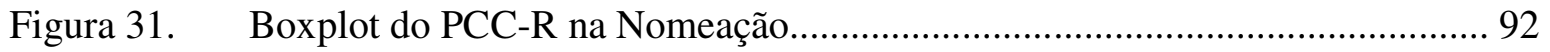

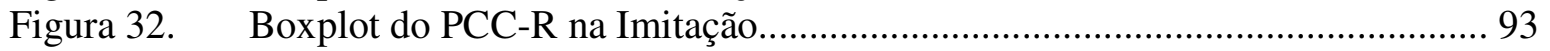

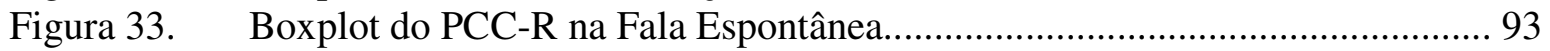

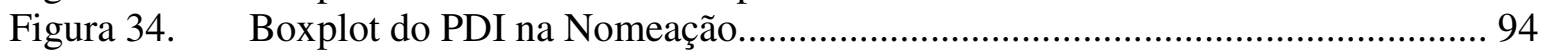

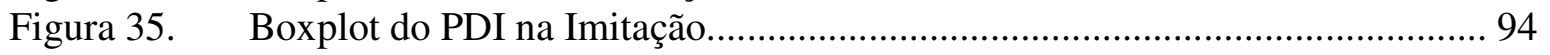

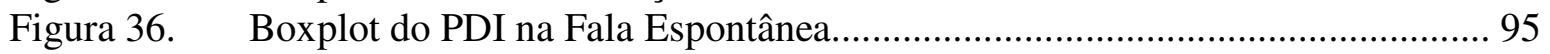

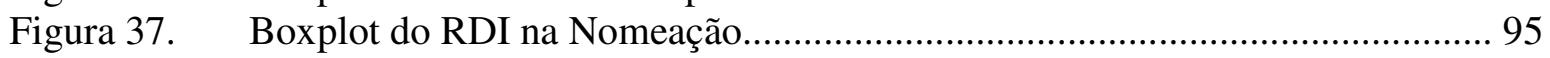

Figura 38. Boxplot do RDI na Imitação...................................................................... 96

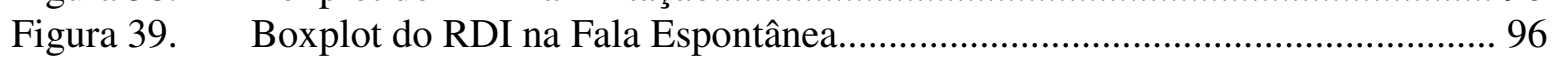

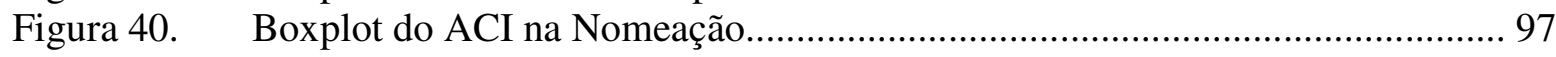

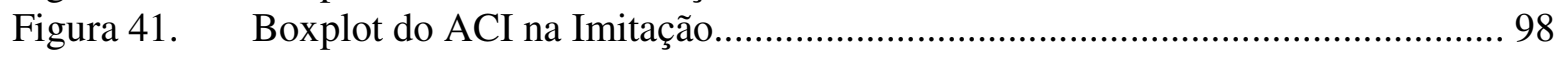

Figura 42. Boxplot do ACI na Fala Espontânea................................................................ 98 
Figura A. Palatografia e Linguografia [s] - GSTFSD 5:10 anos............................ 166

Figura B. Palatografia e Linguografia [z] - GSTFSD 5:10 anos............................. 166

Figura C. Palatografia e Linguografia [S] - GSTFSD 5:10 anos............................. 166

Figura D. Palatografia e Linguografia [3] - GSTFSD 5:10 anos............................ 167

Figura E. Palatografia e Linguografia [1] - GSTFSD 5:10 anos............................. 167

Figura F. Palatografia e Linguografia $[\Lambda]$ - GSTFSD 5:10 anos............................. 167

Figura G. Palatografia e Linguografia [ᄃ] - GSTFSD 5:10 anos............................ 168

Figura H. Palatografia e Linguografia [s] - GSTFSD 7:00 anos............................ 168

Figura I. Palatografia e Linguografia [z] - GSTFSD 7:00 anos............................. 168

Figura J. Palatografia e Linguografia [S] - GSTFSD 7:00 anos........................... 169

Figura L. Palatografia e Linguografia [3] - GSTFSD 7:00 anos............................. 169

Figura M. Palatografia e Linguografia [1] - GSTFSD 7:00 anos............................ 169

Figura N. Palatografia e Linguografia $[\Lambda]$ - GSTFSD 7:00 anos............................ 170

Figura O. Palatografia e Linguografia [ᄃ] - GSTFSD 7:00 anos............................ 170

Figura P. Palatografia e Linguografia [s] - GSTFCD 5:09 anos........................... 170

Figura Q. Palatografia e Linguografia [s] - GSTFCD 6:02 anos............................ 171

Figura R. Palatografia e Linguografia [s] - GSTFCD 7:05 anos............................ 171

Figura S. Palatografia e Linguografia [s] - GSTFSD 7:11 anos........................... 171

Figura T. Palatografia e Linguografia [z] - GSTFCD 5:09 anos........................... 172

Figura U. Palatografia e Linguografia [z] - GSTFCD 7:05 anos.......................... 172

Figura V. Palatografia e Linguografia [z] - GSTFCD 7:11 anos.......................... 172

Figura X. Palatografia e Linguografia [S] - GSTFCD 6:02 anos............................ 173

Figura Z. Palatografia e Linguografia [1] - GSTFCD 5:09 anos........................... 173

Figura AA. Palatografia e Linguografia [1] - GSTFCD 7:11 anos........................... 173

Figura AB. Palatografia e Linguografia [s] - GSTFCD 7:04 anos............................ 174

Figura AC. Palatografia e Linguografia [s] - GSTFCD 7:09 anos............................. 174

Figura AD. Palatografia e Linguografia [z] - GSTFCD 7:09 anos............................ 174

Figura AE. Palatografia e Linguografia $[\ulcorner]$ - GSTFCD 7:04 anos............................. 175 


\section{LISTA DE QUADROS}

Quadro 1. Palavras utilizadas na prova específica para verificação

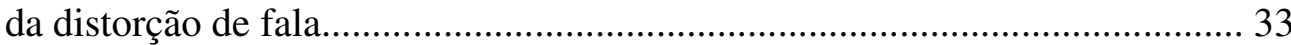

Quadro 2. Palavras empregadas para a coleta da palatografia e linguografia................... 33

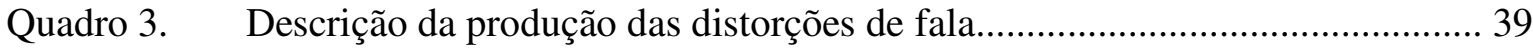

Quadro 4. Componentes estudados na palatografia e linguografia................................... 43

Quadro 5. Produções consideradas como erros na contagem do PCC

(WERTZNER, 2002).

Quadro 6. Descrição dos pontos de contato do palatograma e linguograma

nos sons [s], [z] [S], [3], [1], [ $\Gamma]$ e $[\Lambda]$ em sujeitos do

GSTFSD nas faixas etárias de cinco e sete anos de idade.....

Quadro 7. Descrição da análise perceptiva da distorção de fala e pontos

de contato no palatograma e linguograma no som [s] - GSTFCD.

Quadro 8. Descrição da análise perceptiva da distorção de fala e pontos de contato no palatograma e linguograma no som [z] - GSTFCD

Quadro 9. Descrição da análise perceptiva da distorção de fala e pontos de contato no palatograma e linguograma no som [S] - GSTFCD

Quadro 10. Descrição da análise perceptiva da distorção de fala e pontos de contato no palatograma e linguograma no som [1] - GSTFCD

Quadro 11. Descrição da análise perceptiva da distorção de fala e pontos de contato no palatograma e linguograma no som [s] - GTFCD.

Quadro 12. Descrição da análise perceptiva da distorção de fala e pontos de contato no palatograma e linguograma no som [z] - GTFCD

Quadro 13. Descrição da análise perceptiva da distorção de fala e pontos de contato no palatograma e linguograma no som $[\ulcorner]$ - GTFCD.

Quadro 14. Descrição dos pontos de contato no palatograma e linguograma, dentição, oclusão e análise perceptiva da distorção de fala no som [s] - GSTFSD, GSTFCD e GTFCD.

Quadro 15. Descrição dos pontos de contato no palatograma e linguograma, dentição, oclusão e análise perceptiva da distorção de fala no som [z] - GSTFSD, GSTFCD e GTFCD

Quadro 16. Descrição dos pontos de contato no palatograma e linguograma, dentição, oclusão e análise perceptiva da distorção de fala no som [1] - GSTFSD e GSTFCD.

Quadro 17. Descrição dos pontos de contato no palatograma e linguograma, dentição, oclusão e análise perceptiva da distorção de fala no som $\left[\int\right]$ - GSTFSD e GSTFCD

Quadro 18. Descrição dos pontos de contato no palatograma e linguograma, dentição, oclusão e análise perceptiva da distorção de fala no som $[\ulcorner]-$ GSTFSD e GSTFCD 


\section{LISTA DE TABELAS}

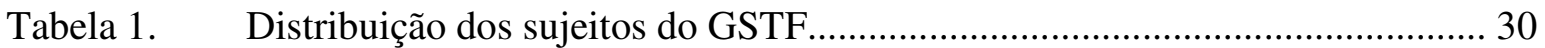

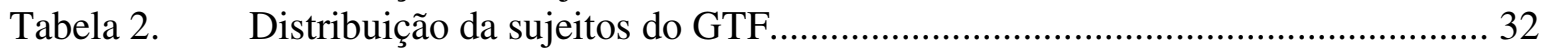

Tabela 3. Distribuição da idade dos sujeitos no

GSTF1, GSTF2 e GSTF3 e GSTF.......................................................... 50

Tabela 4. Distribuição da idade dos sujeitos no GTF1, GTF2 e GTF3 e GTF................................................................. 50

Tabela 5. Porcentagem média de distorção nos sons [s], [z], [ $\quad$ ] e [1] nas provas de nomeação, imitação e fala espontânea no GSTF........................ 52

Tabela 6. Número de sujeitos que apresentaram distorção no [s], [z], [S] e [1] - GSTF1, GSTF2, GSTF3.

Tabela 7. Comparação da ocorrência de distorção e produção correta entre as faixas etárias de cinco, seis e sete anos nas provas de imitação e nomeação e fala espontânea para os sons [s] e [z] no GSTF.......... 54

Tabela 8. Comparação entre a ocorrência de distorção e produção correta nas provas de imitação e nomeação e fala espontânea para [s] - GSTF........... 55

Tabela 9. Comparação entre a ocorrência de distorção e produção correta nas provas de imitação e nomeação e fala espontânea para [z] - GSTF........... 55

Tabela 10. Comparação entre a ocorrência de distorção e produção correta nas provas de imitação e nomeação e fala espontânea para [S] - GSTF.......... 55

Tabela 11. Comparação entre a ocorrência de distorção e produção correta nas provas de imitação e nomeação e fala espontânea para [1] - GSTF........... 56

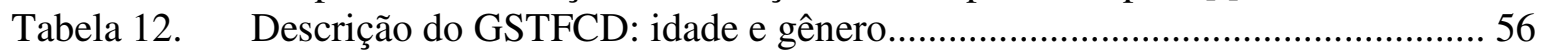

Tabela 13. Número de sujeitos do GSTFCD que apresentaram distorção -

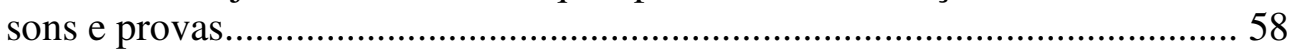

Tabela 14. Porcentagem de distorção nos sons [s], [z] e [ $\Gamma]$ nas provas de nomeação, imitação e fala espontânea no GTF.

Tabela 15. Número de sujeitos que apresentaram distorção no [s] GTF1, GTF2, GTF3

Tabela 16. Sons distorcidos - GTF1, GTF2 e GTF3 ..................................................... 59

Tabela 17. Comparação da ocorrência de distorção e produção correta entre as provas de imitação e nomeação e fala espontânea para os sons [s] e [z] no GTF.....

Tabela 18. Comparação de ocorrência de distorção e produção correta nas provas de imitação e nomeação e fala espontânea para [s] - GTF

Tabela 19. Comparação de ocorrência de distorção e produção correta entre as provas de imitação e nomeação e fala espontânea para [z] - GTF.

Tabela 20. Comparação de ocorrência de distorção e produção correta entre as provas de imitação e nomeação e fala espontânea para [ $[$ ] - GTF.

Tabela 21. Descrição do GTFCD: idade e gênero. 62

Tabela 22. Número de sujeitos do GTFCD que apresentaram distorção sons e provas.

Tabela 23. Comparação do número de sujeitos com e produção correta no GSTF e GTF.

Tabela 24. Comparação da ocorrência de distorção e produção correta entre os grupos GSTF e GTF nas provas de nomeação, imitação e fala espontânea nas faixas etária de cinco anos - [s].. 
Tabela 25. Comparação da ocorrência de distorção e produção correta entre os grupos GSTF e GTF nas provas de nomeação, imitação e

fala espontânea nas faixas etária de seis anos - [s]

Tabela 26. Comparação da ocorrência de distorção e produção correta entre os grupos GSTF e GTF nas provas de nomeação, imitação e

fala espontânea nas faixas etária de sete anos - [s]....

Tabela 27. Comparação da ocorrência de distorção e produção correta entre os grupos GSTF e GTF nas provas de nomeação, imitação

e fala espontânea na faixa etária de cinco anos para o som $[\mathrm{z}]$.

Tabela 28. Comparação da ocorrência de distorção e produção correta entre os grupos GSTF e GTF nas provas de nomeação, imitação e fala espontânea na faixa etária de seis anos para o som [z]...

Tabela 29. Comparação da ocorrência de distorção e produção correta entre os grupos GSTF e GTF nas provas de nomeação, imitação

e fala espontânea na faixa etária de sete anos para o som $[\mathrm{z}]$

Tabela 30. Ocorrência de distorção do GSTFCD na Prova Específica

para Verificação de Distorção - Imitação de Sílabas.

Tabela 31. Porcentagem de distorção do GSTFCD na Prova Específica para

Verificação de Distorção - Imitação de Palavras.

Tabela 32. Porcentagem de distorção do GSTFCD na Prova Específica para

Verificação de Distorção - Imitação de Sílabas.

Tabela 33. Desempenho dos sujeitos do GTFCD na prova de

imitação de palavras - porcentagem de distorção

Tabela 34. Média de porcentagem na classificação perceptiva das distorções

de fala na prova de imitação de sílabas e palavras - GSTFCD.

Tabela 35. Média de porcentagem na classificação perceptiva das distorções de fala na prova de imitação de sílabas e palavras -

faixa etária de cinco anos do GSTFCD.

Tabela 36. Média de porcentagem na classificação perceptiva das distorções de fala na prova de imitação de sílabas e palavras -

faixa etária de seis anos do GSTFCD.

Tabela 37. Média de porcentagem na classificação perceptiva das distorções de fala na prova de imitação de sílabas e palavras faixa etária de sete anos do GSTFCD.

Tabela 38. Média de porcentagem na classificação perceptiva das distorções de fala na prova de imitação de sílabas e palavras - GTFCD.....

Tabela 39. Comparação dos grupos GTFSD, GTFCD, GSTFCD e GSTFSD nos índices de gravidade na prova de nomeação

Tabela 40. Comparação dos grupos GTFSD, GTFCD, GSTFCD e GSTFSD nos índices de gravidade na prova de imitação.

Tabela 41. Comparação nos grupos GTFSD, GTFCD, GSTFCD e GSTFSD nos índices de gravidade na prova de fala espontânea. 
Tabela A. Relação de livros de história pesquisados..................................................... 154

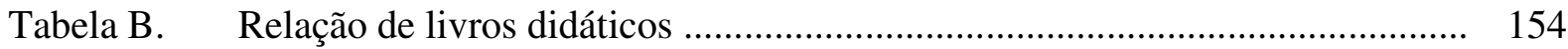

Tabela C. Entrevistas - ocorrência do fonema /s/ ..................................................... 155

Tabela D. Entrevistas - ocorrência do fonema /z/ ...................................................... 155

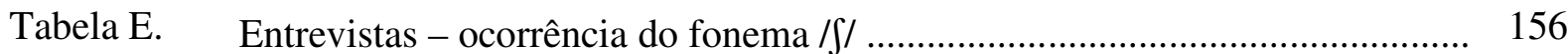

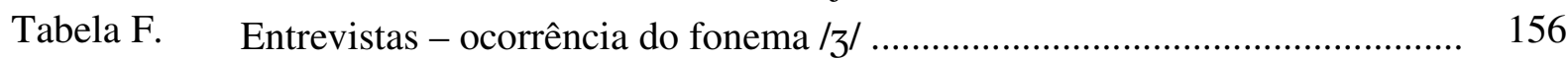

Tabela G. Livros Infantis - ocorrência do fonema /s/ ................................................... 156

Tabela H. $\quad$ Livros Infantis - ocorrência do fonema /z/ .................................................. 157

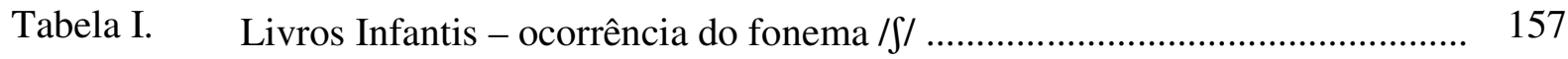

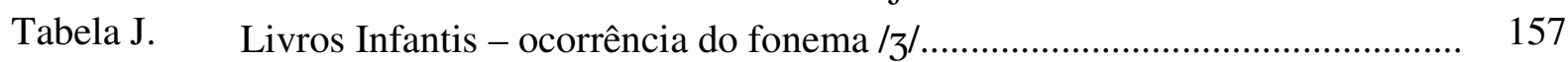

Tabela L. Livros Didáticos - ocorrência do fonema /s/............................................... 158

Tabela M. Livros Didáticos - ocorrência do fonema /z/ ............................................ 160

Tabela N. Livros Didáticos - ocorrência do fonema $/ / /$.................................................. 161

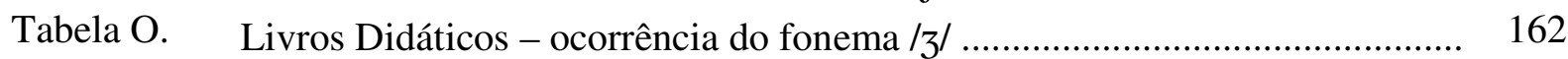

Tabela P. Proporção de distorção nos sons [s], [z], [S] e [1] nas provas de nomeação, imitação e fala espontânea no GSTF.......................................................... 163

Tabela Q. Proporção de distorção nos sons [s], [z] e [ᄃ] nas provas de nomeação, imitação e fala espontânea no GTF................................................................ 164

Tabela R. Proporção de distorção nos sons [s], [z], [S], [l] e [r] nas provas de nomeação, imitação e fala espontânea no GTF e GSTF nas faixas etárias de cinco, seis e sete anos. 


\section{LISTA DE ANEXOS}

Anexo 1. Aprovação do Comitê de Ética.............................................................. 135

Anexo 2. Questionário sobre o Desenvolvimento Neuropsicomotor 136 do GSTF.

Anexo 3. Termo de Consentimento Pós-Informação para o Grupo Sem 138 Transtorno Fonológico

Anexo 4. Roteiro de Avaliação da Motricidade Orofacial................................... 140

Anexo 5a. Protocolo de Registro da Prova Específica para Distorção de Fala 141 em Sílabas e Palavras - [s]....

Anexo 5b. Protocolo de Registro da Prova Específica para Distorção de Fala em Sílabas e Palavras - [z]

Anexo 5c. Protocolo de Registro da Prova Específica para Distorção de Fala em Sílabas e Palavras - [3]

Anexo 5d. Protocolo de Registro da Prova Específica para Distorção de Fala em Sílabas e Palavras - [ $]$ ]....

Anexo 5e. Protocolo de Registro da Prova Específica para Distorção de Fala em Sílabas e Palavras - [ \ulcorner]

Anexo 5f. Protocolo de Registro da Prova Específica para Distorção de Fala em Sílabas e Palavras - [1]

Anexo 5g. Protocolo de Registro da Prova Específica para Distorção de Fala em Sílabas e Palavras - $[\Lambda]$

Anexo 6. Termo de Consentimento Pós-Informação para o Grupo Com Transtorno Fonológico.

Anexo 7. Protocolo para cálculo dos índices de gravidade

Anexo 8a. Carta de Encaminhamento à escola de Educação Fundamental...........

Anexo 8b. Carta de Encaminhamento à escola de Educação Infantil....................

Anexo 9. Construção do Teste de Súlabas e Palavras para Verificação da Distorção de Fala

Anexo 10. Proporção de distorção nos [s], [z], [S] e [l] nas provas de nomeação, imitação e fala espontânea no GSTF.

Anexo 11. Proporção de distorção nos [s], [z] e [r] nas provas de nomeação, imitação e fala espontânea no GTF.

Anexo 12. Proporção de distorção nos [s], [z], [S], [1] e [ᄃ] nas provas de nomeação, imitação e fala espontânea no GTF e GSTF nas faixas etárias de cinco, seis e sete anos.

Anexo 13. Fotos das palatografias e linguografias dos sujeitos do GSTFSD, 


\section{RESUMO}

AMARO, L. Descrição de distorções de fala em crianças com e sem transtorno fonológico. 2006, 177f. Dissertação (Mestrado) - Faculdade de Filosofia, Letras e Ciências Humanas, Universidade de São Paulo, São Paulo, 2006.

No transtorno fonológico podem ocorrer concomitantemente alterações fonéticas e fonológicas, que comprometem a articulação e o conhecimento internalizado do sistema de sons da língua. As alterações fonéticas podem acontecer também em crianças com desenvolvimento típico de linguagem. Várias pesquisas têm mostrado a importância de se utilizar técnicas objetivas durante o diagnóstico bem como da aplicação de índices de gravidade. O objetivo desta pesquisa é identificar a ocorrência de distorções de fala e aplicar e comparar os índices de gravidade em crianças entre cinco e sete anos de idade com e sem transtorno fonológico. Para isso, foram avaliadas 30 crianças com desenvolvimento típico de linguagem (GSTF) e 15 crianças com transtorno fonológico (GTF). Foram aplicadas provas experimentais de fonologia, fala espontânea e avaliação da motricidade orofacial e calculados os índices PCC, PCC-R, PDI, RDI e ACI nas provas de fonologia e fala espontânea. Se detectada qualquer tipo de distorção em quaisquer umas das provas de fonologia nos sons $[\mathrm{s}],[\mathrm{z}],\left[\int\right],[3],[1],[\varsigma]$ e $[\Lambda]$ era aplicada a prova para verificação específica de distorção, além da palatografia e linguografia.Os resultados apontaram que no GSTF, 23,3\% das crianças apresentou distorção nas provas de fonologia e fala espontânea nos sons [s], [z], [S] e [1]; no GFT 20\% das crianças apresentou distorção nas provas de fonologia e fala espontânea nos sons [s], [z] e [ᄃ]; não houve evidências de diferença significativa entre o número de sujeitos que apresentaram distorção no GSTF e GTF. Houve diferença significante apenas nas provas de imitação e fala espontânea na faixa etária de sete anos, com maior ocorrência de distorção do [s] no grupo GTF do que no GSTF. Apenas o GTF apresentou distorção no [ $\varsigma$, parece que a distorção deste som está mais relacionada ao transtorno fonológico. A análise da palatografia confirmou a análise perceptiva, oferecendo a vantagem de mostrar o local exato da produção. No GSTF e no GTF, os sujeitos que não apresentaram distorção obtiveram todos os índices melhores do que os sujeitos com distorção. O índice ACI indicou que o GSTF sem distorção teve o melhor desempenho, mostrando-se adequado para medir a competência articulatória.

Palavras-chaves: Fonoaudiologia, Transtorno Fonológico, Diagnóstico, Alterações Fonéticas, Palatografia. 


\begin{abstract}
AMARO, L. Description of speech distortions in children with and without phonological disorders. 2006, 175 f. Dissertation (master) - Faculty of Humanities, University of São Paulo, São Paulo, 2006.

Phonological and phonetic alterations can occur together in the phonological disorder compromising the articulation and the internal knowledge of the speech sounds of a language. Phonetic alterations can occur in children with typical phonological development. Several researches have shown the importance of the use of objective techniques during both the diagnosis of disorder and application of severity indexes. The aim of this research is to identify the occurrence of distortions in the speech. Also, to apply and compare severity indexes in children between five and seven years old with and without phonological disorders. 30 children with typical language development (GSTF) and 15 phonologically-disordered children (GTF) were assessed. Experimental test of Phonology (nomeation, imitation and continuous speech) and the oral motricity were applied. The PCC, PPC-R, PDI, RDI and ACI indexes were calculated based on Phonology tests. If any kind of distortion as detected in any Phonology test related to the sounds $[\mathrm{s}],[\mathrm{z}],\left[\int\right],[3],[1],[\Gamma]$ and $[\Lambda]$, the specific test to verify distortion was used, for confirmation and perceptual classification of kind distortion, besides the palatography and tongue graph. The results pointed that in the GSTF, $23,3 \%$ of the children presented distortion in the Phonology tests and continuous speech in the $[\mathrm{s}],[\mathrm{z}]$ and $[\ulcorner]$ sounds; there was no evidence of statistic differences between number of subjects that presented distortion in the GSTF and in the GTF. There was significant difference only in the imitation and continuous speech tests in the age range of seven years, with more occurrence of [s] distortion in the GTF compared to the GSTF. Only the GTF presented [] distortions. It seems that this distortion is more related to the phonological disorder. The palatography and the tongue graph confirmed the perceptive analysis, offering the advantage of showing the exact place of production. All subjects from the GSTF and GTF that did not present distortions had better severity indexes compared to the subjects that presented it. The ACI index indicated that the GSTF without distortion had better performance, showing that it is adequate to measure articulatory competence.
\end{abstract}

Key words: Speech Language and Hearing Sciences, Phonological Disorder, Diagnosis, Phonetic Alterations, Palatography. 
APRESENTAÇÃO 
O transtorno fonológico, por ser um distúrbio muito freqüente na clínica fonoaudiológica, é sempre bastante estudado, tanto em suas manifestações lingüísticas quanto em causas correlacionadas, o que vem contribuindo para grandes avanços nos procedimentos de avaliação, diagnóstico e tratamento.

Desde a Iniciação Científica realizada no período da graduação, o transtorno fonológico tem sido o tema central dos estudos da pesquisadora. Na Iniciação Científica, o tema foi a gravidade e a inteligibilidade do transtorno fonológico, tema ainda desenvolvido durante a bolsa de Capacitação Técnica. Isto possibilitou uma visão mais abrangente dos aspectos envolvidos nessa alteração, além da realização de artigos e trabalhos apresentados em congressos.

Além disso, atendendo crianças no Laboratório de Investigação Fonoaudiológica em Fonologia, do Curso de Fonoaudiologia da Universidade de são Paulo, muitas vezes foram encontradas dificuldades para detectar se a alteração presente era apenas fonológica ou também fonética.

Com este estudo, pretende-se colaborar na descrição de distorções de fala, tendo em vista a escassez de trabalhos realizados sobre a diferenciação das alterações fonéticas e fonológicas do transtorno fonológico no Português Brasileiro, como será observado na introdução. Desta maneira, a necessidade desse tipo de informação, para auxiliar no diagnóstico do transtorno fonológico motivou o tema da pesquisa desenvolvida.

$\mathrm{Na}$ Introdução, encontra-se a revisão da literatura sobre a interdependência entre Fonologia e Fonética: fonética articulatória, desenvolvimento do sistema fonológico e fonético; transtorno fonológico, distorções de fala, gravidade do transtorno fonológico, provas e instrumentos usados no transtorno fonológico, palatografia e linguografia. Em seguida, são apontados os objetivos gerais e específicos deste estudo.

No capítulo seguinte, descreve-se a metodologia utilizada na coleta e análise dos dados. $\mathrm{Na}$ sequiência, encontram-se os resultados; o quinto capítulo relaciona os achados da pesquisa com os demais estudos na área de distorção de fala e palatografia e linguografia.

O capítulo final expõe as conclusões pertinentes a esta pesquisa, seguido pelas referências bibliográficas.

Por meio da realização deste trabalho, pretende-se fornecer mais um instrumento que colabore para um diagnóstico fonoaudiológico diferenciado, bem como auxiliar na elaboração de um planejamento terapêutico adequado aos casos de crianças que apresentam, concomitantemente, alterações fonéticas e fonológicas, proporcionando uma intervenção precisa e eficaz. 


\section{INTRODUÇãO}


O transtorno fonológico é definido como uma alteração de fala caracterizada pela produção incorreta dos sons e uso inadequado das regras fonológicas da língua quanto à distribuição do som e ao tipo de sílaba, que resultam no colapso de contrastes fonêmicos e que afetam o significado (PEÑA-BROOKS e HEDGE, 2000; WERTZNER, 2002). É sabido que tais dificuldades na produção dos sons podem interferir no rendimento escolar, profissional e na comunicação (DSM-IV, 1995).

No transtorno fonológico as alterações fonéticas e fonológicas podem ocorrer simultaneamente, comprometendo tanto a articulação como o conhecimento internalizado do sistema de sons da língua (CASTRO, 2004).

No entanto, as alterações fonéticas podem ocorrer também em crianças com desenvolvimento típico de fala e linguagem. A literatura americana relata que, entre seis e nove anos de idade, predominam, na fala das crianças, as distorções (SHRIBERG, 1993).

No Português brasileiro, alguns estudos mostraram que essas alterações ocorrem principalmente nos sons alveolares [s] e [z], plosivos [t] e [d], líquido [1] e nasal [n], que são produzidos na posição interdental da língua (WERTZNER et al., 2005 a).

No presente estudo foram analisadas as alterações fonéticas, ou distorção de fala nos sons [1], [r], $[K][\mathrm{s}],[\mathrm{z}],\left[\int\right]$ e [3], em crianças com e sem transtorno fonológico. A escolha desses sons apoiou-se no fato de os fonemas líquidos serem os últimos a serem adquiridos (WERTZNER, 1992; 1998; GALEA 2003), bem como no transtorno fonológico serem freqüentemente comprometidos (WERTZNER, 2002). Os fonemas fricativos são aqueles que apresentam bastante produção distorcida, que muitas vezes, além da alteração visual da produção, também manifestam comprometimento auditivo.

Para detectar as alterações fonéticas e fonológicas no diagnóstico do transtorno fonológico, é muito importante considerar alguns aspectos, como: índices de gravidade do transtorno, tipos de provas usadas na avaliação, técnicas e instrumentos objetivos utilizados para diagnóstico. 


\section{A Interdependência entre Fonologia e Fonética}

Ao realizar a descrição lingüística dos sons, percebe-se que fonética e fonologia são inseparáveis. A fonética estuda a composição material dos sons lingüísticos; descreve o material sonoro em agrupamentos como sílabas, grupos fônicos e orações; além de enfatizar e discutir a problemática da discriminação auditiva (compreensão da fala) e da articulação vocal (emissão da fala). A fonologia se ocupa dos sons lingüísticos sob o ponto de vista da sua distribuição e função; estuda os fonemas e os modelos acústico-articulatórios; o valor dos agrupamentos como signo lingüístico; por fim, enfatiza os critérios de funcionalidade e de pertinência (COSERIU, 1979; PAIS, 1981).

O objeto de estudo da fonologia é a forma sistemática como cada língua organiza os sons. A partir da apresentação dos sons distintivos, é possível chegar a afirmações mais gerais sobre a natureza dos sistemas dos sons das línguas do mundo. Atém-se nos sons capazes de distinguir significados, os fonemas, e na forma como se organizam e se combinam para formar unidades lingüísticas maiores, além das variações combinatórias que esses fonemas podem apresentar. Pelo processo de substituição de sons em contextos lingüísticos semelhantes, pode-se observar a existência de contrastes de significado, e desse modo, identificar os fonemas de uma língua (PAIS, 1981; CRYSTAL, 2000; HERNANDORENA, 2001).

A função da fonética é de apreender os sons efetivamente realizados pelos falantes da língua em toda a sua diversidade, enquanto a fonologia abstrai essa diversidade para captar o sistema que caracteriza a língua. Sendo assim, por tratar dos sons enquanto realidade diretamente apreendida, os estudos fonéticos colaboram no auxílio da fonologia (HERNANDORENA, 2001).

A fonética é uma ciência histórica que designa a evolução dos sons, analisa acontecimentos e transformações que se movem (ou se modificam) no tempo (SAUSSURE, 1969). Ela fornece métodos para descrição, classificação e transcrição dos sons usados na fala. De modo geral, é dividida em três campos: fonética acústica, que estuda as propriedades físicas dos sons da fala, durante a transmissão que ocorre entre emissão e recepção; a fonética auditiva, que estuda a reação da percepção aos sons da fala, mediada pela orelha, o nervo auditivo e o cérebro; e a fonética articulatória, que tem por objetivo estudar a maneira como os sons da fala são produzidos pelos órgãos da fala (PAIS, 1981; CASAES, 1990; CRYSTAL, 2000).

Malmberg (1954) também descreve a fonética combinatória, em que os sons influenciamse uns aos outros e modificam-se de várias maneiras. Assim, as consoantes estão sujeitas à influência acústica das vogais, além dos espectros vocálicos poderem se modificar em contato 
com as consoantes. É a vogal da sílaba que determina se as consoantes que a rodeiam devem ser mais palatizadas, velarizadas ou labializadas.

$\mathrm{Na}$ fonética combinatória pode existir o fenômeno sincrônico que ocorre no interior de um sistema fonético em conseqüência dos hábitos próprios da língua, os quais divergem de uma língua para a outra.

A sincronia é definida como o eixo das simultaneidades, no qual devem ser estudadas as relações entre os fatos existentes ao mesmo tempo num determinado momento do sistema lingüístico, que pode ser tanto no presente quanto no passado. É vista como o estudo de funcionamento da língua (CARVALHO, 2003).

Pode-se, assim, perceber que as representações mentais que os falantes têm dos sons não são idênticas às propriedades físicas, mas sim vinculadas aos fonemas da língua. Conclui-se, assim, que a fonologia e a fonética apresentam campos de estudo interdependentes (HERNANDORENA, 2001).

Qualquer separação muito rígida entre a Fonética e a Fonologia não parece realista, já que não se podem manter considerações fonológicas fora de uma análise fonética (CRYSTAL, 1977). Dessa maneira, a diferença fonética nem sempre é acompanhada por uma diferença fonológica. Como exemplo, os falantes do Português entendem os sons [t] e [t $\left.\int\right]$ como uma só unidade, o fonema /t/, pois esses sons constituem variação de um mesmo fonema. A ocorrência de [t $\left.\int\right]$ é previsível no Português, porque não passa de uma variação alofônica antes do [i].

\section{Fonética Articulatória}

A fonética articulatória, também conhecida como fonética fisiológica, empresta seus métodos de estudo da anatomia e fisiologia humana (PAIS, 1981; CASAES, 1990; CRYSTAL, 2000).

De acordo com Pais (1981) e Casaes (1990), os órgãos fisiológicos que participam da produção dos sons são chamados de órgãos fonadores, controlados pelo cérebro. Para que os sons da fala sejam realizados é necessária a integridade dos órgãos de fala. Assim, alterações na forma ou tonicidade desses órgãos poderão interferir na dinâmica da fala e provocar ajustes motores compensatórios inadequados, resultando numa produção incorreta. 
Segundo Cagliari (1981), a língua é uma massa de tecidos e músculos capaz de se moldar de inúmeras formas, produzindo várias configurações nas cavidades faríngea e oral. É considerada como o órgão mais importante na modulação dos sons, tanto que a descrição fonética se baseia muito nas posturas assumidas pela língua durante a produção sonora.

Nos últimos anos houve muito progresso na elaboração de técnicas instrumentais para observar e medir os movimentos dos órgãos da fala. Alguns desses instrumentos são: palatografia e eletropalatografia, que mostram o contato da língua com o palato; eletroaerômetro, que mede o fluxo relativo de ar entre a boca e o nariz; e eletromiógrafo, que mede o movimento muscular durante a fala. $\mathrm{O}$ uso dessas técnicas proporcionou uma compreensão mais fidedigna e detalhada da articulação do que os métodos tradicionais visuais e cinestésicos (CRYSTAL, 2000).

Em relação à articulação das consoantes, é de conhecimento que se inicia no momento da passagem do ar pela cavidade oral, quando o ar é comprimido ou detido, sendo pronunciadas com um ruído audível. A articulação de um som pode ser classificada em função do lugar e modo de articulação, além da vibração das pregas vocais.

As consoantes são classificadas de acordo com o nome do lugar onde ocorre o maior fechamento dos articuladores, obstruindo a corrente aérea (CAGLIARI, 1981). De acordo com Silva (2001), a partir da posição do articulador ativo em relação ao articulador passivo, pode-se definir o lugar de articulação dos segmentos consonantais, que pode ser bilabial, labiodental, dental, alveolar, palatal, velar ou glotal.

Também é importante identificar o modo de articulação de um segmento, a qual está relacionada ao tipo de obstrução de ar oferecida pelos articuladores durante a produção de um segmento, podendo ser oclusiva, nasal, fricativa, africada, vibrante, retroflexa e lateral (SILVA, 2001).

Dentre alguns sons do Português, as líquidas [1], [r] e [K] bem como as fricativas [s], [z], [S] e [3] são estudadas na presente pesquisa, e na sequiência são descritas as suas produções articulatórias.

$\mathrm{Na}$ produção das líquidas laterais a corrente de ar, ao passar pela cavidade oral, pode encontrar uma obstrução central e um escape lateral. No Português, as laterais não são fricativas nem constritivas (CAGLIARI, 1981). O articulador ativo, língua, toca o passivo, palato duro, ocorrendo então a obstrução da corrente aérea na linha central do trato vocal; e o ar é expelido por ambos os lados da obstrução, com saída lateral entre a língua e a bochecha (SILVA, 2001). 
São consideradas líquidas laterais no Português brasileiro o [1] que é dental, e o, [ $\Lambda$ ] considerada palatal.

Segundo Cagliari (1974), o som [1] tende a ser mais dental do que alveolar. Com relação ao comportamento da língua, o som [1] difere-se das oclusivas alvéolo-dentais, pois é articulado com a própria ponta da língua, enquanto as oclusivas alvéolo-dentais são articuladas com a parte de cima de frente da língua. A lateral palatal $[\Lambda]$ é articulada com o começo do dorso da língua sobre a região pré-palatal. $\mathrm{O}[1]$ e o $[\Lambda]$ diferem-se porque o $[\Lambda]$ apresenta um contato muito mais largo entre língua e palato, bem como pelo comportamento da ponta da língua, que fica atrás dos incisivos inferiores, enquanto para o [1] mantém-se elevada.

De acordo com Silva (2001), na líquida vibrante simples a vibração ocorre pelo toque do articulador ativo com o passivo. As vibrantes são articuladas com a ponta da língua, de tal forma que ocorre vibração da ponta da língua contra a área alveolar da abóbada palatina atrás dos dentes incisivos. O [r] do dialeto paulistano é considerado uma alveolar sonora (CAGLIARI, 1974).

Em relação à produção dos fricativos, ocorre um estreitamento da passagem da corrente de ar entre dois articuladores, de tal modo que o ar passando produz um ruído de fricção, sibilo ou chiado, sendo considerado um som contínuo.

Os fricativos alveolares que são [s]e [z] são produzidos pelo estreitamento da ponta da língua contra os alvéolos. Já os fricativos palatais, [3] e [ $\left.\int\right]$, são produzidos no estreitamento do dorso da língua contra o palato duro (CASAES, 1990).

Segundo Cagliari (1974), as consoantes alveolares se caracterizam, do ponto de vista articulatório, pelas seguintes propriedades: o estreitamento do canal do aparelho fonador ocorre na região denominada alveolar, elevação da língua, com a ponta da língua apoiada atrás dos incisivos inferiores. Do ponto de vista articulatório, as palatais se caracterizam pela zona de articulação que é feita na região palatal, pré-palatal ou central e o modo de articulação que ocorre com contato linguodental bem largo, maior elevação da língua (dorso), ponta da língua abaixada, atrás dos incisivos inferiores, articulação de grande esforço muscular e duração.

As fricativas alveolares [s] e [z] e as palatais [3] e [ $\left.\int\right]$ diferem entre si pela ausência de vibração de pregas vocais em [s] e [S] e presença de vibração de pregas vocais em [z] e $[3]$. 


\section{Desenvolvimento do Sistema Fonológico e Fonético}

A produção dos sons da fala envolve aspectos lingüísticos, motores, cognitivos, orgânicos e ambientais. Durante o desenvolvimento considera-se que entre dois a quatro anos ocorre maior expansão do sistema fonológico (INGRAM, 1976; WERTZNER, 1994).

O desenvolvimento fonológico relaciona-se aos demais aspectos da linguagem e com a cognição.

Wertzner (1994) estudou a aquisição fonológica de crianças falantes do Português brasileiro e verificou que: até os 3:6 anos de idade as crianças adquirem os seguintes fonemas: /p/, /b/, /t/, /d/, /k/, g/, /f/, /v/, /s/, /z/, /3/, / / /, /l/, /r/, /m/, /n/; aos 4:0 anos, o arquifonema /S/, o $/ \Lambda /$; aos 5:6, o arquifonema /R/; os encontros consonantais são adquiridos entre 4:0 a 6:6 anos.

Como principais características durante o desenvolvimento fonológico notam-se os processos fonológicos, que são simplificações sistemáticas das regras fonológicas que afetam uma classe ou seqüências de sons. São observados durante o desenvolvimento típico: redução de sílaba, harmonia consonantal, plosivação de fricativa, posteriorização para velar, posteriorização para palatal, frontalização de velar, frontalização de palatal, simplificação de líquida, simplificação do encontro consonantal e simplificação da consoante final (WERTZNER, 2000).

Kent (1992) apresenta um modelo de fatores perceptivos e motores no desenvolvimento fonológico. Com isso, existiria um canal de entrada (auditivo ou auditivo integrado ao visual) e um canal de saída (regulação motora do aparato de fala). Os sistemas de entrada e saída seriam geneticamente determinados. A exposição ao ambiente lingüístico selecionaria algumas categorias auditivas para preservação ou para negligência, os mecanismos envolvidos nesse processo seriam os de atenção e orientação. Esses fatores genéticos, audição, atenção e reconhecimento, orientariam os subsistemas para o funcionamento da produção motora da fala, que dependeria do desenvolvimento do aparato anatômico para fala e sinergia dos movimentos, da modificação pela experiência perceptual e do desenvolvimento sensório motor que levaria a ajustes de padrões motores para produção fonética.

Já as estabilizações das produções fonéticas estão relacionadas ao crescimento físico. Sabe-se que a variabilidade no controle motor diminui com o crescimento, gerando aumento progressivo na estabilidade da produção e diminuindo as variações articulatórias (KENT, 1976). 
O autor op. cit. descreve que a transição de vocalizações pré-lingüísticas para a fala do adulto representa uma maestria na coordenação de múltiplos subsistemas da fala. Este notável comportamento emerge num contexto com rápidas mudanças no crescimento do músculo esqueletal e no desenvolvimento motor.

Em relação ao desenvolvimento fonético, de acordo com Green et al. (2000) o desenvolvimento motor pode envolver a diferenciação dos movimentos, como a modificação de um comportamento pré-existente em outros mais especializados e/ou a integração de novos comportamentos com a prévia estabilização de outros.

Wertzner et al. (2005 a) relatam que semelhante a outras línguas, entre seis e nove anos de idade predominam, ocorrem ou são detectadas nas crianças alterações fonéticas, ou seja, as distorções de fala. No Português as distorções ocorrem principalmente nos sons alveolares [s] e [z], plosivos [t] e [d], líquido [1] e nasal [n], que são produzidos na posição interdental da língua.

De acordo com Launay e Borel-Maisonny (1989), no Inglês o [s] é com freqüência produzido distorcido, por exigir na produção o estreitamento do orifício oral durante a constrição da corrente aérea entre a ponta da língua e o alvéolo; além disso, há a necessidade de forma e precisão de posição da língua.

Além da complexidade da produção, Ingram (1976) descreve que o número de sílabas, tonicidade, assimilação e posição afetam a precisão na produção de fricativas. As fricativas são produzidas com maior precisão em posição final ou pós-vocálica.

Durante o desenvolvimento fonético, ocorre a dentição mista. Sabe-se que esta é uma fase complexa, em que as falhas dentárias podem contribuir para que ocorra alteração fonética. Alguns indivíduos, após essa fase, podem permanecer ainda com o mesmo tipo de alteração.

A dentição mista se inicia com a erupção dos primeiros molares permanentes e se completa com a erupção dos segundos molares permanentes. Essa é uma fase muita dinâmica, cujas transformações exibem rápidas remodelações na face (ISSÁO e GUEDES-PINTO, 1994).

Os eventos que ocorrem durante a dentição mista são: irrompimento dos primeiros molares aos seis anos, dos incisivos dos seis aos sete anos, dos caninos e pré-molares aos dez anos, dos segundos molares aos doze e dos terceiros molares aos dezoito anos aproximadamente. São características desta fase a presença de diastemas, principalmente na arcada superior, crescimento das arcadas em sentido transversal e erupções dos dentes permanentes anteriores com inclinação vestibular.

$\mathrm{Na}$ fase de dentição mista é possível observar períodos de desarmonia entre o crescimento facial e o desenvolvimento da dentição, uma vez que o desenvolvimento da face ocorre de um 
modo mais moderado do que o da dentição, acarretando prejuízo temporário da aparência, a denominada fase do "patinho feio", que coincide com o início das trocas dentárias (ISSÁO e GUEDES-PINTO, 1994).

As transformações na cavidade oral ocorrem por volta dos seis anos, principalmente pelo ganho da dimensão vertical, devido à erupção dos primeiros molares permanentes (ANTUNES et al., 2000). É de se esperar que após essas modificações estruturais associadas ao crescimento craniofacial ocorra correção espontânea da produção distorcida para as crianças que o apresentam. No entanto, a permanência de alterações nas estruturas ósseas e dentárias que estão envolvidas com a produção da fala pode afetar a produção dos sons da língua, justificando a necessidade de verificar a ocorrência de alterações fonéticas em diferentes faixas etárias (ALABARSE e WERTZNER, 1998).

Em relação à interdependência no desenvolvimento entre a Fonologia e a Fonética, Kent (2000) explica que o controle motor da fala se refere a sistemas e estratégias que regulam a produção da fala, incluindo o planejamento, a preparação dos movimentos e a execução dos planos de movimentos que resultam na contração muscular e substituição estrutural. Tradicionalmente, o controle motor da fala distingue-se de operações fonológicas, mas em algumas teorias fonológicas recentes há uma névoa entre as fronteiras das representações fonológicas e funções motoras.

Peterson e Shoup (1966) enfatizam que existe uma razão considerável para acreditar que aspectos fonológicos são organizados primeiramente em termos das possibilidades e forças do mecanismo no qual a fala é produzida.

Os processos motores da fala são moldados por múltiplos sistemas intrínsecos, como maturação cognitiva, lingüística e sensório-motora, e extrínsecos, como estimulação auditiva e visual e percepção das diferenças. A evolução da comunicação verbal pode ser limitada pelo desenvolvimento lento de algum fator. A proporção dos efeitos limitantes do desenvolvimento fisiológico na aquisição fonológica ainda não está bem determinada, no entanto, a relação entre imaturidade da coordenação e ininteligibilidade no desenvolvimento da fala é óbvia (GREEN et al., 2000).

Assume-se que a entrada para o sistema de controle motor da fala é uma representação fonológica da linguagem, uma seqüência de unidades abstratas, como os fonemas. A saída do controle motor da fala é uma série de movimentos articulados que transporta por meio da mensagem lingüística um sinal que pode ser interpretado pelo ouvinte. Por isso, os processos do 
controle motor da fala ocorrem entre a formulação da linguagem e dos sinais acústicos por meio dos quais a mensagem é usualmente recebida (KENT, 2000).

Green et al. (2000) sugerem que o estudo do início da coordenação motora da fala pode trazer um amplo entendimento do desenvolvimento fonológico. Por uma perspectiva do desenvolvimento do controle motor, tem-se que as influências fonológicas no início do desenvolvimento podem ser afetadas por um número de fatores, incluindo uma organização préexistente muscular, experiências prévias e necessidades de espaço e tempo de um dado fonema.

\section{Transtorno Fonológico}

O transtorno fonológico é definido como uma alteração de fala caracterizada pela produção inadequada dos sons, bem como pelo uso inadequado das regras fonológicas da língua quanto à distribuição do som e ao tipo de sílaba, que resultam no colapso de contrastes fonológicos e afetam o significado. A causa do transtorno é desconhecida, sendo a gravidade e a inteligibilidade de fala de grau variado (PEÑA-BROOKS e HEDGE, 2000; WERTZNER, 2002). Essas dificuldades na produção dos sons interferem no rendimento escolar, profissional ou na comunicação (DSM-IV, 1995).

O transtorno fonológico é descrito geralmente em função das características relacionadas ao gênero, idade, gravidade, inteligibilidade de fala e aspectos fonológicos (WERTZNER e OLIVEIRA, 2000; WERTZNER, 2002).

Shirberg (2004) refere que os processos etiológicos do transtorno fonológico podem ser genéticos ou ambientais, sendo que alterações no controle motor da fala podem induzir a um transtorno com envolvimento motor de fala e atraso de fala.

As simplificações sistemáticas das regras fonológicas, que afetam uma classe ou sequiências de sons, recebem o nome de processos fonológicos. Os processos fonológicos são esperados dentro do desenvolvimento típico, no entanto, à medida que a criança cresce e se desenvolve, deixa de usá-los e adquire as regras do adulto (WERTZNER, 2004).

Os processos fonológicos que ocorrem no desenvolvimento típico no transtorno fonológico são mantidos por um tempo maior, podendo co-ocorrer vários processos no mesmo segmento, os quais podem ser usados em ordem cronológica invertida. Além disso, em alguns casos também ocorrem processos fonológicos idiossincráticos (INGRAM, 1976; STOELGAMMON e DUNN, 1985; WERTZNER, 2004; CROSBIES et al., 2005). 
No transtorno fonológico estão incluídos erros de produção, ou seja, de articulação, que envolvem o fracasso em formar corretamente os sons da fala, e problemas fonológicos de base cognitiva, que envolvem um déficit na categorização lingüística dos sons. As omissões são consideradas mais severas do que as substituições de sons, que por sua vez são mais severas do que as distorções (DSM-IV, 1995).

Dessa forma, existe uma diferenciação quanto à localização funcional da origem dos tipos de erros, levando a uma hierarquização do grau de gravidade dos erros que afetam diretamente a inteligibilidade de fala. As crianças que apresentam mais omissões e substituições têm maior dificuldade de serem entendidas pelo interlocutor, mas as que apresentam distorções serão mais inteligíveis, gerando menor ambigüidade de fala (SHRIBERG e KWIATKOWSKI, 1982 b).

De acordo com Shriberg et al. (1986), a classificação do tipo de alteração encontrada no transtorno fonológico é muito importante para diagnóstico e planejamento do tratamento, pois a identificação de alguns critérios, como os padrões de alterações de fala, restritos a distorções articulatórias, geralmente são considerados leves, enquanto que padrões de alterações envolvendo eliminações e substituições de numerosos sons da fala são consideradas de graus moderado a severo.

Shriberg (1993) fez uma representação do transtorno fonológico de desenvolvimento em oito domínios de envolvimento, que seriam: cognitivo psicolingüístico, compreensão da linguagem, produção da linguagem, compreensão da Fonologia, produção, distorções múltiplas, distorções com características limitadas (erros que envolvem dois ou mais tipos de distorções dentro de uma única classe de som) e distorções com fonemas limitados (que ocorrem com maior freqüência em crianças mais velhas e em adultos). Conclui-se que as distorções não apresentam envolvimento da cognição, linguagem e Fonologia.

Conclui-se que os erros de omissão e substituição ocorrem quase sempre devido aos erros nos contrastes fonológicos nos níveis cognitivos de organização lingüística e no processamento psicolingüístico (acesso e recuperação lexical). Porém, podem ocorrer também por uma dificuldade fonética. Já o locus dos erros de distorção envolve dificuldades no nível periférico da produção, relacionando-se ao processamento sensório-motor da fala (SHRIBERG, 1993).

Assim, os erros fonológicos e fonéticos envolvem níveis de processamento diferentes, levando também à diferença no tratamento. Para o tratamento da eliminação dos erros fonológicos exige-se um planejamento focalizado na linguagem, enquanto que para os erros fonéticos o planejamento envolve aspectos relacionados à fala. 
A literatura aponta como variáveis correlacionadas ao transtorno fonológico: gênero, idade, otite e alterações de vias aéreas superiores, problemas pré e peri natais e a familiaridade. Porém, os estudos não são conclusivos a respeito dos dados, uma vez que parte encontra relação com o transtorno e parte não (FOX et al., 2002; WERTZNER, 2002).

A caracterização fonológica do transtorno fonológico é bastante estudada na medida em que é o suporte para o diagnóstico e planejamento da intervenção. A análise tradicional é uma forma bastante comum de descrição do transtorno fonológico, pois nela verifica-se o inventário fonético apontando os acertos, omissões, substituições e distorções.

A análise fonológica por meio dos processos fonológicos permite verificar quais são aqueles mais observados no transtorno fonológico. Pesquisas com crianças falantes do Português brasileiro indicam que os processos fonológicos de simplificação de líquidas, simplificação do encontro consonantal, ensurdecimento de plosiva e ensurdecimento de fricativas são os que mais ocorrem (WERTZNER, 2002; PAGAN, 2003; CASTRO, 2004).

Em meio a crianças falantes do Português brasileiro, Wertzner (2002) estudou 50 crianças com transtorno fonológico; observou que as principais características fonológicas do transtorno estão no uso dos processos fonológicos de simplificação do encontro consonantal, simplificação de líquidas, eliminação da consoante final, frontalização da palatal, ensurdecimento de fricativas, ensurdecimento de plosivas, plosivação de fricativas, frontalização de velar e posteriorização para palatal. Além disso, a maioria dos sujeitos estudados usou somente processos fonológicos de desenvolvimento, sendo que muitas vezes apareceram processos do início do desenvolvimento com outros mais tardios. Um menor número de sujeitos usou processos fonológicos não de desenvolvimento, mas sempre em conjunto com os de desenvolvimento.

Destaca-se que em alguns casos há a combinação desses processos com a ocorrência de alguns idiossincráticos.

\section{Distorções de Fala}

O diagnóstico diferencial entre os tipos de alterações fonéticas e fonológicas é de grande importância para o tratamento, visto que os procedimentos terapêuticos são distintos. O que diferencia esses quadros é o estabelecimento de contrastes entre os sons da fala. Assim, nas alterações fonológicas, tem-se a eliminação do contraste, e os erros são expressos por meio de omissão e substituição. A omissão caracteriza-se pela ausência do som-alvo na produção de um 
vocábulo. A substituição é identificada quando um som-alvo é trocado por outro na produção de um vocábulo. Essas duas modalidades de alterações são em geral mais facilmente identificadas pelo fonoaudiólogo (SHRIBERG e KWIATKOWSKI, 1982a).

A distorção do som em geral é uma alteração fonética que não envolve as regras fonológicas da língua. Caracteriza-se por alguma dificuldade nas habilidades motoras envolvidas na produção dos sons, tais como imprecisão de local, tempo, pressão e velocidade, que resulta em um som não padrão da fala. Em geral, é considerada uma alteração leve e que apesar de comprometer a inteligibilidade de fala, não compromete os contrastes fonológicos da língua e, portanto, não afeta o significado das palavras.

A literatura aponta alguns relatos de grande incidência de distorção na faixa etária de três anos, com decréscimo até os seis anos, que pode estar relacionada a fatores como: amadurecimento geral da criança, tipo de alimentação, crescimento crânio-facial na faixa etária de três a seis anos, como troca dentária e crescimento da arcada dentária, além da fase de aquisição e estabilização das fricativas (MOURA, 1994; PEREIRA et al., 1998; FONSECA et al., 2003).

Alguns estudos referem que em crianças em fase de desenvolvimento da articulação a produção do som com projeção da ponta da língua para uma posição mais anterior da cavidade oral produzida contra os dentes, ou até mesmo entre as arcadas dentárias durante as produções do [s], [t] e [d], podem ser aceitas como normal no início da aquisição e será corrigida quando a criança aprender a melhor posicioná-la (TOMÉ et al., 2004). O sigmatismo, que é a perturbação na articulação das sibilantes, é particularmente comum (DSM-IV, 1995).

Quanto ao gênero, há evidências de que a população masculina é a mais acometida em relação à ocorrência de distorção de fala, com maior freqüência na faixa etária de três a seis anos de idade (TOMÉ et al., 1998). Verifica-se que a maior incidência de distorção ocorre na fase de dentição mista, estando relacionada às falhas dentárias (RODRIGUES et al., 1999).

Sabe-se que as alterações fonéticas encontradas no transtorno fonológico são variáveis. Portanto, os pesquisadores buscam formas de realizarem melhores distinções entre os tipos de alterações encontradas na fala de crianças com este transtorno. Dessa maneira, para o diagnóstico é necessária tanto a análise fonológica como a fonética.

Quanto ao tipo de distorção, a literatura indica a existência da distorção comum. A distorção comum é observada no decorrer do desenvolvimento normal, podendo ocorrer em crianças com desenvolvimento típico de fala e linguagem. Já a distorção incomum, definida como qualquer tipo de distorção não observada no desenvolvimento típico, ocorre nos sujeitos com 
dificuldades específicas de produção de fala (SHRIBERG et al., 1986; SHRIBERG, 1993; SHRIBERG et al.,1997; WERTZNER, 2002; PEREIRA et al., 2003).

Shriberg (1993) refere que a lista de distorções incomuns é arbitrária e são consideradas como erros para todas as idades. Em sujeitos que apresentam esse tipo de distorções são freqüentemente encontrados casos de transtorno estrutural, sensitivo e motor, incluindo fissura palatina, deficiência auditiva e disartria. São consideradas quatro classes de distorções clínicas incomuns: consoantes fracas, consoantes e vogais imprecisas, falha para manter contrastes oral/nasal e falha notável para manter a sonorização apropriada.

A identificação de distorções comuns e incomuns é muito importante para propósitos de avaliação e diagnóstico; além disso, as distorções incomuns acarretam consequiências mais negativas para a inteligibilidade e aceitabilidade da fala em contextos acadêmicos e sociais (SHRIBERG, 1993).

No Inglês americano os cinco tipos de distorções clínicas comuns em ordem de prevalência são as seguintes: labializada [1] e [r], velarizada [1] e [r], sonora lateralizada ou fricativa sibilante surda ou africada, derrotização, sonora dentalizada ou fricativa sibilante ou fricativa sibilante surda ou africada (SHRIBERG, 1993, LOWE, 1996; PEÑA-BROOKS e HEDGE, 2000).

Em relação à distorção como erro residual do transtorno fonológico, Gruber (1999) calculou as idades prováveis para remissão espontânea em 24 crianças com atraso de fala, usando análises de Kaplan-Meier e a pontuação limiar de 85\% das medidas do PCC, PCC-A e PCC-R. Os resultados mostraram que há dois caminhos distintos para a remissão espontânea, mas ainda não é possível, durante o intervalo de remissão espontânea, determinar qual caminho a criança vai seguir. Se seguir o caminho A, as alterações de eliminação, substituição e omissão declinarão com o aumento das produções corretas, enquanto que se seguir o caminho B, distorções clínicas comuns aumentarão, mas haverá o decréscimo das eliminações e substituições. As distorções são comuns nas consoantes com desenvolvimento tardio, mas raro para as consoantes com desenvolvimento precoce e médio. $\mathrm{O}$ autor conclui que omissão-substituição-distorção-correção reflete a hierarquização do desenvolvimento fonológico.

Há ainda que se considerar que os aspectos fonéticos característicos dos sons da fala na criança têm uma relação com o processo de maturação do sistema miofuncional oral enquanto mecanismo de produção motora dos sons. Assim, as alterações da fala devem ser investigadas cuidadosamente em relação à morfofisiologia, pois muitos casos de alterações fonéticas são 
decorrentes da forma ou função alterada das estruturas estomatognáticas (MARCHESAN, 1993; WERTZNER, 1997).

No entanto, as alterações na forma ou função das estruturas estomatognáticas podem não levar à alteração fonética se o indivíduo fizer uma adaptação eficiente. Seifert et al. (1997) referem que prejuízos no sistema miofuncional, como devido a trauma, perda de dentes decíduos e erupção da dentição permanente, induzem a má formações estruturais dos maxilares e dentição. Mas, se existe uma capacidade adaptativa insuficiente e uma difunção dos órgãos da fala, poderá ocorrer uma produção sonora incorreta, com a tendência a movimentos anteriores de língua.

Algumas anomalias orais estão relacionadas à alteração na articulação, como: palato ogival, mordida aberta anterior e lateral, espessura do rebordo alveolar, grau de protrusão, rotação dos dentes e espaços, como diastemas (DOUGLAS, 1998).

Com base na literatura, Cunha et al. (2003) correlacionaram as alterações do sistema estomatognático e as alterações na articulação. Observaram que as alterações da articulação da fala estão relacionadas a maloclusões, características craniofaciais específicas e alterações do sistema estomatognático. Dentre as alterações de fala, relacionaram as distorções com o incorreto posicionamento da língua, onde os sons linguodentais são articulados como interdentais, gerando o ceceio anterior.

Em uma pesquisa para verificar a ocorrência de ceceio anterior e alterações de oclusão no plano vertical anterior, foram estudadas 132 crianças falantes do Português brasileiro de três a seis anos de idade. Os resultados mostraram que a presença de alterações na oclusão pode representar risco para ceceio, mas não é determinante, já que o ceceio pode estar relacionado a outros fatores, como cavidade oral pequena para o tamanho da língua, fase de aquisição e desenvolvimento do sistema fonológico e articulatório (TOMÉ et al., 2004).

Para Mota e Guedes (2000), a presença de mordida aberta anterior, devido à alteração da oclusão ou por ausência dos incisivos na troca dentária, pode levar a elevação, protrusão ou interposição lingual como mecanismo adaptativo, visando efetivar a produção de sons alveolares.

A literatura também aponta que o posicionamento interdental da língua na produção dos sons $[\mathrm{t}],[\mathrm{d}],[\mathrm{l}],[\mathrm{n}],[\mathrm{s}]$ e [z] está freqüentemente associado a um padrão de deglutição com interposição de língua (BRAGA e MACHADO, 1992; PEREIRA et al. 1998); alterações respiratórias (MARCHESAN, 2005); alterações do sistema sensório-motor oral, como alterações na praxia lingual e produção do /r/ (FONSECA et al., 2003); aleitamento artificial e hábitos de sucção não-nutritiva (FELÍCIO et al., 2003), anquiloglossia (MESSNER e LALAKEA, 2002, 2003; MARCHESAN, 2003), entre outros. 
Para o Português brasileiro, segundo Tomé et al. (2004), as fricativas são mais fáceis de serem distorcidas, provavelmente por serem contínuas. De acordo com Felício (1994), em sons linguodentais as alterações não são audíveis, no entanto, em fonemas línguo-alveolares podem ocorrer desvios audíveis, caracterizando o ceceio anterior e o lateral.

Wertzner et al. (2005 a) mostraram que crianças com transtorno fonológico apresentam mais distorções do que crianças com desenvolvimento típico de linguagem, e que os sons mais distorcidos para ambos os grupos foram [s], [z] e [3]. Para estes sons, os exemplos no Português brasileiro são o ceceio anterior ou lateral produzido com interposição de língua, como em /sapo/, que é representado foneticamente [s*apu]. Indicou também que as líquidas laterais $[1]$ e $[\Lambda]$ e a vibrante $[\ulcorner]$ foram distorcidas apenas no grupo com transtorno fonológico e que em geral as distorções levam a produções em que a língua é posteriorizada.

\section{Gravidade do Transtorno Fonológico}

A classificação da gravidade do transtorno fonológico é uma questão muito discutida na literatura, devido à necessidade de existirem procedimentos que quantifiquem a gravidade e o impacto dos distúrbios da comunicação no sistema de classificação diagnóstica, na realização de planejamentos de intervenção mais dirigidos às dificuldades do sujeito e no controle terapêutico (SHRIBERG e KWIATKOWSKI, 1982b).

$\mathrm{Na}$ literatura são descritas algumas medidas de análise padronizadas de cálculo de gravidade. São exemplos de medidas: Percentage of Consonants Correct (PCC) (SHRIBERG e KWIATKOWSKI, 1982b); Process Density Index (PDI) (EDWARDS, 1992), Relative Distortion Index (RDI) e o Articulation Competence Index (ACI) (SHRIBERG, 1993), Percentage of Consonants Correct-Revised (PCC-R), Percentage of Consonants Correct-Adjusted (PCC-A) (SHRIBERG et al. 1997).

A medida Percentage of Consonants Correct (PCC) (SHRIBERG e KWIATKOWSKI, 1982 b) é derivada de amostras de fala espontânea. Reflete uma escala crescente do grau de gravidade que engloba os conceitos de inaptidão, prejuízo e inteligibilidade. A medida de valores do PCC inclui quatro graus de gravidade, que são: leve, mais de $85 \%$ de acerto; entre $65 \%$ e $85 \%$, levemente-moderado; de 50 a $65 \%$, moderadamente severo; e abaixo de $50 \%$, severo. É obtida 
dividindo-se o número total de consoantes produzidas numa amostra de fala pelo número total de consoantes, multiplicadas por $100 \%$. São considerados erros omissões, substituições e distorções.

A medida PCC permite ao fonoaudiólogo ter uma base sólida para o diagnóstico, prognóstico e planificação do tratamento (GARRET e MORAN, 1992).

Foram realizados alguns estudos para classificação da medida PCC em crianças falantes do Português brasileiro. Entre eles, existe o de Wertzner et al. (2001), que estudaram 22 crianças com idades entre 4:5 a 6:1. Houve apenas uma ocorrência de grau severo (4,5\%), a maior ocorrência foi do grau levemente moderado, com oito sujeitos (36,3\%), seguidos do moderadamente-severo, com sete sujeitos $(31,8 \%)$ e do grau leve, com seis sujeitos $(27,2 \%)$.

Em outro estudo, Wertzner (2002) encontrou resultados semelhantes em 50 crianças com transtorno fonológico nas provas de Fonologia do teste de Linguagem Infantil ABFW (WERTZNER, 2000), sendo que na prova de imitação 48\% dos sujeitos foram classificados como leve, $42 \%$ como levemente-moderado, $8 \%$ como moderadamente-severo e $2 \%$ como severo. Na prova de nomeação do mesmo teste, $50 \%$ dos sujeitos foram classificados como leve, $42 \%$ como levemente-moderado, $6 \%$ como moderadamente-severo e $2 \%$ como severo.

Wertzner et al. (2004a) analisaram o julgamento de 60 juízes, entre graduandos do curso de Fonoaudiologia e fonoaudiólogos experientes, em relação aos critérios que utilizaram para enquadrar 50 sujeitos com transtorno fonológico nas categorias de gravidade após ouvirem as amostras de fala. Concluíram que os juízes utilizaram critérios semelhantes no julgamento perceptivo de gravidade. Os descritores mais usados como justificativas do grau de gravidade foram: Fonologia, idade, inteligibilidade de fala, voz e fala.

A medida de gravidade Relative Distortion Index (RDI) é um valor que reflete a proporção de erros de distorção numa amostra de fala, sendo independente do PCC. É obtido pela divisão do número total de erros de distorção da amostra pelo número total de erros da fala, multiplicados por $100 \%$ (SHRIBERG, 1993).

O PCC não se destina a crianças mais velhas ou adultos que apresentam apenas distorções clínicas comuns ou incomuns relevantes. Para estes, a medida Articulation Competence Index (ACI) foi desenvolvida para suprir a necessidade da pontuação de gravidade ajustada à proporção relativa de erros de distorção. Tal medida proporciona uma pontuação que reflete com exatidão as medidas de gravidade de articulação. Este índice é baseado em duas características da fala conversacional: porcentagem de consoantes corretamente articuladas (PCC) e porcentagem de todas as consoantes produzidas incorretamente devido à distorção de fala (RDI). É obtido pela somatória dos índices PCC e RDI, dividida por dois e multiplicada por $100 \%$. 
Em 1997, Shriberg et al. propuseram uma revisão da medida PCC de acordo com o tipo de erro considerado. Na medida PCC, distorções comuns ou não, omissões e substituições são considerados erros; PCC - Ajusted (PCC-A) não considera distorções comuns como erro, enquanto PCC - Revised (PCC-R) não aceita qualquer tipo de distorção como erro. Para testar essas medidas, os autores utilizaram 836 fitas de sujeitos entre três e 40 anos com fala normal ou com distúrbio, tendo como objetivo uma classificação diagnóstica baseada no instrumento titulado como Sistema de Classificação de Distúrbios de Fala (SDCS). O artigo sugeriu que o PCC-R é a melhor medida de competência articulatória em crianças de três a oito anos, pois proporciona melhor separação entre as crianças com aquisição de fala normalizada e as com atraso de fala. Observaram que crianças com aquisição normalizada apresentaram $37 \%$ de erros de eliminação e substituição, enquanto as crianças com atraso tiveram 82\% de erros desta ordem.

Cada uma das medidas descritas no parágrafo anterior tem uma aplicação mais apropriada. A medida PCC é indicada para crianças de três a seis anos. O PCC-A é uma medida comparativa quando todos os sujeitos analisados apresentam comprometimento de fala, porém com diferentes idades. O PCC-R é utilizado para comparações entre falantes de idades e características de falas variadas.

Uma outra medida de gravidade do transtorno fonológico é o Process Density Index (PDI), na qual é calculada a média de processos fonológicos presentes em uma palavra. Esta medida não está associada a uma amostra específica de fala. É uma medida baseada em produções incorretas e leva em consideração o fato de que um único som incorreto pode resultar na aplicação de um ou mais processos. Embora necessite de maior refinamento e mais testes, o PDI pode ser visto como uma medida de grande potencial clínico para gravidade e/ou inteligibilidade fonológica (EDWARDS, 1992).

Wertzner (2002) analisou o PDI de 50 crianças com diagnóstico de transtorno fonológico e observou que a maior parte dos sujeitos foi classificada nos graus leve e levemente-moderado. Comparando os índices obtidos pelos 50 sujeitos no PCC e PDI nas provas de imitação e nomeação verificou-se a existência de associação, porém, a correlação entre PCC e PDI foi negativa, indicando que quando um índice aumentou o outro diminuiu.

Wertzner et al. (2004b) estudaram 20 sujeitos com desenvolvimento típico de fala e linguagem e 20 sujeitos com transtorno fonológico pareados em relação a idade e gênero, aplicando-se as provas de: nomeação, imitação e fala espontânea composta de um discurso e de uma entrevista. Em seguida, calculou-se para cada sujeito as medidas PCC, PCC-R e PDI. Os resultados indicaram que existem diferenças entre os dois grupos, com correlação negativa entre 
as medidas PDI e PCC-R. As médias dos índices PCC-R foram maiores que as médias do PCC nas quatro provas aplicadas

\section{Provas e Instrumentos usados no Transtorno Fonológico}

O tipo de provas utilizado durante a avaliação do transtorno fonológico é um fator de grande importância, podendo interferir na análise da fala. Existem três tipos de testes mais utilizados para a coleta dos dados, que são: imitação, nomeação e fala espontânea. O tipo de teste a ser usado pelo fonoaudiólogo depende do tipo de informação desejada e do tempo disponível para a aplicação do teste (STOEL-GAMMON e DUNN, 1985; WERTZNER, 2000).

De acordo com Wertzner (1992), nas provas de nomeação e imitação pode-se direcionar a produção dos fonemas e contextos que se deseja testar. Na fala espontânea isso não é possível, pois as amostras são próximas do uso coloquial do sujeito testado. Apesar de ser considerada a prova mais adequada por alguns autores, pode ocorrer a evitação de palavras que indiquem as alterações fonológicas que a criança possua.

Sabe-se que o ouvido humano é usado como instrumento final para determinação e interpretação dos efeitos dos distúrbios de comunicação. Ainda assim, é conveniente usar técnicas instrumentais para uma análise mais detalhada e objetiva do que se escuta (DARLEY et al., 1978).

Com a tecnologia e, conseqüentemente, com a melhoria dos equipamentos, essa detecção pode ser realizada de maneira objetiva e fidedigna. Atualmente existem vários instrumentos que podem contribuir objetivamente para essa identificação, tais como: espectrografia acústica, eletromiógrafo, cine-radiografia, palatografia, palatografia dinâmica ou eletropalatografia, EMA, raios-X, laringografias, entre outros.

Uma das formas mais utilizadas atualmente é a espectrografia acústica, que caracteriza os sons da fala em termos acústicos. É uma análise muito segura e bastante conveniente na avaliação das características de fala de crianças, principalmente quando comparada a outros métodos de avaliação, tais como a eletromiografia ou o raio-X (KENT, 1976).

Existem muitas técnicas para registrar e analisar o sinal de fala, entre elas as análises de freqüência fundamental e variações de amplitude e as relações temporais e composição das ondas. Os aspectos relacionados com o espectro (composição da onda) do sinal de fala podem ser estudados por meio de espectrógrafo do som, que é uma amostra gráfica das regiões de concentração de energia característica de diversos fonemas. As relações temporais entre os 
acontecimentos fisiológicos e acústicos podem ser estudadas nos registros espectrográficos (DARLEY et al., 1978).

Deve-se destacar que vários estudos usaram a análise espectrográfica para complementar a identificação e classificação das distorções. Assim, a análise acústica da fala de crianças com transtorno fonológico complementa a análise fonológica descritiva, pois fornece dados mais objetivos e claros sobre a produção de fala (CHANEY, 1988). Vários autores demonstram grande importância para o diagnóstico e intervenção do transtorno fonológico (GURGUEIRA, 2000; PAGAN, 2003).

A análise acústica tem como objetivos auxiliar no diagnóstico, na busca da etiologia e no tratamento dos distúrbios de fala, linguagem, voz e audição. Permite relacionar esses distúrbios com os processos fisiológicos envolvidos em sua ocorrência (GURGUEIRA, 2000), como Pagan (2003), que analisou acusticamente as consoantes líquidas laterais e vibrante simples de crianças com transtorno fonológico e encontrou que a líquida vibrante simples foi o som mais alterado para essas crianças.

\section{Palatografia e Linguografia}

A fonética articulatória pode ser corroborada pelo exame dos órgãos fisiológicos que entram em contato para a produção dos sons. Para que isso ocorra, existem alguns instrumentos, entre eles a palatografia e a linguografia, que permitem a realização do registro dos contatos articulatórios da língua com o palato (CASAES, 1990). O princípio básico é que um articulador deposita um material em uma superfície contatada (LADEFOGED, 2001).

A palatografia e a linguografia são técnicas que se complementam, visto que revelam pontos de contato em diferentes estruturas, colaborando para a realização de um diagnóstico fidedigno.

De acordo com Cagliari (1974), a palatografia começou a ser usada em 1872 por Oakley Coles, cuja preocupação era ensinar pacientes com fissura palatina a falarem corretamente. Cagliari também refere que a palatografia foi sendo aperfeiçoada em função dos novos equipamentos disponíveis, principalmente pela fotografia. Dessa maneira, foi utilizada por vários autores, como: Claes Witting (1953); Ladefoged (1957), que apresentou uma conclusão um tanto parcial a respeito da impossibilidade de se associar dados palatográficos com dados acústicos; e 
Scully (1971), que aproveitou o método direto palatográfico para detectar características fisiológicas das fricativas inglesas, a fim de compará-las com dados acústicos.

A literatura indica que quando a palatografia começou a ser aplicada, o material utilizado para fazer a palatografia e linguografia consistia de pó de chocolate, que era espanado na superfície da língua ou palato duro respectivamente, criando ao mesmo tempo um registro da palatografia e um da linguografia. A presença de pó de chocolate possibilitava o aumento de salivação, causando diminuição de contrastes. Atualmente, para a obtenção dos dados é utilizada uma mistura de azeite de oliva e carvão digestivo pulverizado. Esse material permite que sejam criados registros dos dados separadamente, gerando menos confusão e imagens contratadas que resultam em análises mais fidedignas (LADEFOGED, 1993; LADEFOGED, 1997; LADEFOGED, 2001).

Os objetivos destes instrumentos, palatografia e linguografia, segundo Pais (1999), são: análise e descrição da articulação oral dos sons de línguas naturais; análise e descrição das variações sócio e psicolingüísticas da articulação dos sons de uma língua natural; análise contrastiva da articulação dos sons de duas línguas naturais e suas implicações no ensino/aprendizagem de línguas; e análise e descrição de distúrbios e patologias da linguagem, quanto a articulação e auxílio para o diagnóstico e acompanhamento da terapia.

A palatografia e a linguografia são instrumentos usados na diferenciação de alterações fonéticas e fonológicas, sendo métodos tradicionais para se obter dados articulatórios. São considerados como alguns dos melhores métodos para determinar a região de contato entre a língua e a região superior do trato vocal durante a produção de sons isolados, em sílabas ou palavras. Requerem pouca tecnologia, além de serem ferramentas de baixo custo que podem ser facilmente usadas para descrição articulatória (DARLEY et al., 1978; CASAES, 1993; LADEFOGED, 1997; LADEFOGED, 2001).

Além disso, há a grande vantagem de que todo o procedimento pode ser fotografado ou filmado. A filmagem traz muitas vantagens, como baixo custo, gravação toda a face do sujeito a certa distância, intimidando-o menos, além de a imagem poder ser passada e processada por um computador (LADEFOGED, 2001).

As desvantagens do método consistem em: não poderem ser examinadas as consoantes bilabiais, lábio-dentais, uvulares, faringais e as vogais; pode refletir a soma dos contatos articulatórios que ocorrem na produção da palavra investigada, não mostrando a posição da língua em nenhum momento particular; o uso de substâncias para marcar os contatos pode causar incômodo, provocando uma fala de maneira pouco natural; as fotografias da maneira como são 
tiradas podem revelar pouco a respeito da anatomia da cavidade oral e das variações reais dos contatos; e irregularidades do palato, presença de maloclusão, ou seja, os contatos sem simetria, unilaterais ou mesmo causados por movimentos incontrolados da língua ou dos maxilares dificultam a análise dos dados (MALMBERG, 1971; CAGLIARI, 1974; CASAES, 1992; LADEFOGED, 1997).

Além dos aspectos já citados, existe a dificuldade da realização de testes em condições de igualdade de produção surda e sonora, principalmente com relação à energia articulatória, que é tão difícil para a palatografia e linguografia como para qualquer outra técnica.

A tradicional objeção com relação ao caráter estático da palatografia, dada a dinâmica da fala, ficou superada, graças aos projetos de palatografia dinâmica ou eletropalatografia (CAGLIARI, 1974). A eletropalatografia pode ser usada na Fonoaudiologia para realizar medidas dinâmicas das funções da língua, com propósitos de diagnóstico, terapia e de pesquisa (CAYLEY et al., 2000).

De acordo com Cagliari (1974), é possível esquematizar os métodos e as técnicas palatográficas utilizadas pela Fonética da seguinte maneira:

Método Direto: pintura da língua ou do palato para se obter os contatos línguo-palatais;

> Método Indireto: uso de placas ou pseudopalatos recobertos de uma substância que marque os contatos línguo-palatais;

Palatografia Dinâmica: registro eletrônico de seqüência de contatos obtidos sem a superposição dos mesmos na fala contínua.

De um modo geral, pode-se dizer que a palatografia registra os contatos feitos pela língua contra o palato duro e os dentes superiores. Esses contatos são reveladores do modo e lugar da articulação, bem como da formação das cavidades ressonadoras orais, das constrições e da pressão articulatória. O palatograma, que é o registro da palatografia é obtido de várias maneiras, como: observação dos pontos de contatos seguida do desenho; uso de placas (palatos artificiais), seguido de análise ou transferência destes dados para modelos de gessos ou para papel; e fotografia como forma de registro (CAGLIARI, 1974).

A linguografia mostra os contatos do palato pela língua. O linguograma é a forma de registro da linguografia que pode ser obtido por meio da observação dos pontos de contato, seguida do desenho ou pela fotografia.

Os palatogramas e linguogramas podem ser acompanhados por diagramas que mostram a forma da boca do sujeito numa secção sagital. A forma mais antiga, mas de grande eficácia, é desenhar com todos os detalhes em papel vegetal quadriculado (CASAES, 1993). Diagramas 
deste tipo podem ser obtidos por meio da passagem de imagens refletidas pelo espelho para o computador, que poderá aplicar escalas e programas para uma melhor análise ou pela fotografia.

Outra forma de se obter o palatograma é pela impressão das superfícies dos dentes e do palato duro feita em campo com alginato, para obtenção de molde, que será analisado por meio de diagramas (LADEFOGED, 1993; LADEFOGED, 1997; LADEFOGED, 2001).

A utilização destes dois registros, palatograma e linguograma, permitem obter com maior precisão as áreas de contato dos órgãos fonoarticulatórios (SPAJIC et al., 1993).

De acordo com Cagliari (1974), a análise de interpretação dos dados nem sempre é fácil. É preciso conhecimento a respeito da anatomia do aparelho fonador, das características fisiológicas da produção dos sons e dos aspectos metodológicos implícitos nas técnicas experimentais.

Casaes (1992) examinou por meio de 114 palatografias de adultos falantes do Português brasileiro os pontos de contato dos órgãos fonoarticulatórios de realizações sonoras das seguintes consoantes: $[\mathrm{k}],[\mathrm{r}],[\mathrm{l}],[\mathrm{r}],[\mathrm{s}],[\mathrm{z}],\left[\int\right],[\Lambda],[\mathrm{y}],[\mathrm{k}]$ e $[\mathrm{g}]$. Os palatogramas mostraram que o contato entre a língua e o palato ocorre no contorno da arcada dentária, na produção de $[1],[\Lambda]$ e $\left[\ulcorner]\right.$, enquanto que na de $[\mathrm{s}],[\mathrm{z}],\left[\int\right],[\mathrm{r}]$ há presença de um pequeno canal entre a língua e o palato. Na produção do [k], [g] e [פ] ocorre contato entre as porções mais posteriores da língua e palato.

Em relação às distorções de fala obtidas pela palatografia, a literatura mostra que as pequenas variações de contato são consideradas irrelevantes, desde que não recaiam dentro das características do som seguinte. Esse caráter de irrelevância ou de mudança é dado, em geral, pelos sistemas fonéticos utilizados para descrever os segmentos falados das línguas, cuja base são as possibilidades articulatórias do homem.

Em um estudo realizado com 17 crianças americanas, diagnosticadas com transtorno fonológico, Gibbon (1999) verificou através da eletropalatografia desses sujeitos que a lateralização das sibilantes [s] e [z] foi a forma de distorção que mais ocorreu. Também foram observadas posteriorização destes sons, alteração do ponto articulatório de alveolar para palatal e anteriorização dos mesmos para a região dental.

A palatografia, além de contribuir no diagnóstico, pode ser considerada uma técnica voltada à reabilitação articulatória, podendo atuar como recurso valioso caso a capacidade adaptativa do paciente esteja comprometida. Troia et al. (2005) relataram o uso da palatografia na recuperação fonética de um paciente usuário de próteses totais duplas, portador de apraxia 
ideomotora, e que após sucessivos tratamentos continuava a apresentar dificuldades de articulação. A aplicação da técnica facilitou sobremaneira a reeducação fonética do paciente, além de proporcionar maior segurança e aceitação do novo tratamento.

Tendo em vista a escassez de trabalhos realizados no Português brasileiro sobre a diferenciação das alterações fonéticas e fonológicas no transtorno fonológico, espera-se que esta pesquisa possa contribuir para o diagnóstico preciso e objetivo da diferenciação dessas alterações, colaborando para melhores procedimentos terapêuticos. 


\section{OBJETIVOS}


O objetivo geral desta pesquisa é identificar a ocorrência de distorções de fala em crianças entre cinco e sete anos de idade com e sem transtorno fonológico.

São objetivos específicos:

descrever a ocorrência de distorções de fala em crianças com e sem transtorno fonológico;

verificar se existe diferença entre a ocorrência de distorção entre crianças com e sem transtorno fonológico;

verificar o tipo de prova de Fonologia mais adequada para identificar as distorções;

realizar a classificação perceptiva das distorções detectadas pela prova específica para verificação de distorção da fala;

descrever a articulação das distorções dos sons líquidos laterais e vibrantes simples, bem como dos fricativos alveolares e palatais pela palatografia e linguografia;

aplicar e comparar os índices de gravidade em sujeitos com e sem transtorno fonológico com e sem distorção. 
MÉTODO 
Esta pesquisa foi aprovada pela Comissão de Ética para Análise de Projetos de Pesquisa (CAPPesq) do Hospital das Clínicas da Faculdade de Medicina da Universidade de São Paulo sob o número 1090/04, em 27 de janeiro de 2005 (Anexo 1).

\section{Sujeitos}

Fizeram parte desta pesquisa 45 crianças, sendo 15 diagnosticadas com transtorno fonológico, formando o Grupo com Transtorno Fonológico (GTF) e 30 crianças com desenvolvimento típico de fala e linguagem, compondo o Grupo Sem Transtorno Fonológico (GSTF). A Tabela 1 mostra a composição do GSTF e a Tabela 2 a composição do GTF.

As 30 crianças do GSTF tinham entre 5:01 e 7:11 anos de idade e foram distribuídas em três grupos. O subgrupo GSTF1 foi composto por dez crianças entre 5:01 e 5:11, o GSTF2 por dez crianças entre 6:01 e 6:11 e o GSTF3 por dez crianças entre 7:00 e 7:11 anos de idade. Ainda no GSTF, 15 (50\%) das crianças eram do gênero masculino e 15 (50\%) do gênero feminino, sendo então cada um dos três subgrupos constituídos por cinco meninos e cinco meninas.

Todas as crianças do GSTF frequientavam a Escola Municipal de Educação Infantil José Rubens Peres Fernandes ou a Escola Municipal de Ensino Fundamental Guilherme de Almeida, ambas localizadas na Zona Leste da cidade de São Paulo, no bairro da Penha.

O critério de inclusão dos sujeitos do GSTF foi, além da idade, a ausência de alterações no desenvolvimento de linguagem em todos os sistemas lingüísticos, inclusive no fonológico, registradas por meio do questionário aplicado aos pais (Anexo anexo 2), juntamente com os resultados dos Testes de Fonologia (WERTZNER, 2004) e Vocabulário (BEFI-LOPES, 2004) do Teste de Linguagem Infantil ABFW. Ainda os sujeitos do GSTF poderiam ou não apresentar distorção de fala.

Os critérios de inclusão das 15 crianças do GTF foram: diagnóstico de transtorno fonológico; idades entre 5:0 2 e 7:09 anos, de ambos gêneros; residentes na cidade de São Paulo; sem obrigatoriedade de apresentar qualquer tipo de distorção de fala. Todos foram provenientes do Laboratório de Investigação Fonoaudiológica (LIF) em Fonologia do Curso de Fonoaudiologia do Departamento de Fisioterapia, Fonoaudiologia e Terapia Ocupacional da Faculdade de Medicina da Universidade de São Paulo ou do Centro de Saúde Escola Samuel Barnsley Pessoa. 
Tabela 1. Distribuição dos sujeitos do GSTF.

\begin{tabular}{|c|c|c|c|c|}
\hline $\begin{array}{c}\text { Sujeitos } \\
\text { GSTF }\end{array}$ & D.N. & Idade & Gênero & Distorção \\
\hline 1 & $14 / 09 / 00$ & $05: 01$ & $\mathrm{~F}$ & 0 \\
\hline 2 & $28 / 08 / 00$ & 05:02 & M & 0 \\
\hline 3 & $13 / 07 / 00$ & 05:03 & F & 1 \\
\hline 4 & 09/05/00 & 05:06 & M & 0 \\
\hline 5 & $24 / 04 / 00$ & 05:05 & F & 0 \\
\hline 6 & $26 / 03 / 00$ & 05:06 & M & 0 \\
\hline 7 & $19 / 02 / 00$ & 05:08 & F & 0 \\
\hline 8 & $29 / 01 / 00$ & 05:09 & M & 1 \\
\hline 9 & $07 / 01 / 05$ & $05: 10$ & M & 0 \\
\hline 10 & $18 / 11 / 99$ & $05: 11$ & $\mathrm{~F}$ & 0 \\
\hline 11 & 28/09/99 & 06:01 & F & 0 \\
\hline 12 & $19 / 08 / 99$ & 06:02 & M & 1 \\
\hline 13 & $15 / 06 / 99$ & 06:04 & $\mathrm{F}$ & 0 \\
\hline 14 & $07 / 06 / 99$ & 06:04 & M & 0 \\
\hline 15 & 03/04/99 & 06:06 & M & 0 \\
\hline 16 & 08/03/99 & 06:07 & $\mathrm{F}$ & 0 \\
\hline 17 & $16 / 02 / 99$ & 06:08 & M & 0 \\
\hline 18 & $05 / 02 / 99$ & $06: 10$ & $\mathrm{~F}$ & 0 \\
\hline 19 & $16 / 11 / 98$ & 06:11 & F & 0 \\
\hline 20 & $16 / 11 / 98$ & 06:11 & M & 0 \\
\hline 21 & $22 / 10 / 98$ & 07:00 & M & 0 \\
\hline 22 & $26 / 09 / 98$ & 07:00 & $\mathrm{F}$ & 1 \\
\hline 23 & $22 / 05 / 98$ & 07:05 & $\mathrm{F}$ & 0 \\
\hline 24 & $15 / 05 / 98$ & 07:05 & M & 1 \\
\hline 25 & $12 / 03 / 98$ & 07:07 & M & 0 \\
\hline 26 & 03/03/98 & 07:07 & $\mathrm{F}$ & 1 \\
\hline 27 & $10 / 02 / 98$ & 07:08 & $\mathrm{F}$ & 0 \\
\hline 28 & $31 / 01 / 98$ & 07:08 & M & 0 \\
\hline 29 & $05 / 12 / 97$ & $07: 10$ & $\mathrm{~F}$ & 0 \\
\hline 30 & $31 / 10 / 97$ & 07:11 & M & 1 \\
\hline
\end{tabular}

Legenda: GSTF - grupo sem transtorno fonológico; D.N. - data de nascimento; F - feminino; M - masculino; 0 - não apresentou distorção; 1 - apresentou distorção. 
Tabela 2. Distribuição dos sujeitos do GTF.

\begin{tabular}{ccccc}
\hline $\begin{array}{c}\text { Sujeitos } \\
\text { GTF }\end{array}$ & D.N. & Idade & Gênero & Distorção \\
\hline 1 & $13 / 08 / 99$ & $05: 02$ & $\mathrm{~F}$ & 0 \\
2 & $03 / 06 / 00$ & $05: 04$ & $\mathrm{M}$ & 0 \\
3 & $08 / 08 / 98$ & $05: 08$ & $\mathrm{M}$ & 0 \\
4 & $17 / 10 / 99$ & $05: 11$ & $\mathrm{M}$ & 1 \\
5 & $09 / 09 / 99$ & $06: 01$ & $\mathrm{M}$ & 0 \\
6 & $18 / 02 / 99$ & $06: 01$ & $\mathrm{~F}$ & 0 \\
7 & $14 / 05 / 99$ & $06: 04$ & $\mathrm{M}$ & 0 \\
8 & $25 / 02 / 99$ & $06: 08$ & $\mathrm{~F}$ & 0 \\
9 & $04 / 06 / 97$ & $06: 09$ & $\mathrm{~F}$ & 0 \\
10 & $06 / 11 / 97$ & $06: 09$ & $\mathrm{~F}$ & 0 \\
11 & $06 / 04 / 98$ & $06: 11$ & $\mathrm{~F}$ & 0 \\
12 & $23 / 09 / 98$ & $07: 00$ & $\mathrm{~F}$ & 1 \\
13 & $09 / 04 / 98$ & $07: 00$ & $\mathrm{~F}$ & 0 \\
14 & $28 / 04 / 98$ & $07: 06$ & $\mathrm{~F}$ & 0 \\
15 & $10 / 10 / 98$ & $07: 09$ & $\mathrm{M}$ & 1 \\
\hline
\end{tabular}

Legenda: GTF - grupo com transtorno fonológico; D.N. - data de nascimento; F - feminino; M - masculino; 0 - não apresentou distorção; 1 - apresentou distorção.

O diagnóstico do transtorno fonológico foi realizado por meio das aplicações e análises de provas específicas realizadas no LIF em Fonologia. Todos os sujeitos estavam em fase de processo diagnóstico e não haviam realizado tratamento fonoaudiológico.

Das sete crianças com distorção que fizeram parte do GSTF, uma do gênero feminino com 7:00 anos, que havia apresentado produção distorcida no som [s] e [z] nas provas de imitação, nomeação (WERTZNER, 2004), prova específica para verificação da distorção em imitação de sílabas e [s] na prova de fala espontânea, não conseguiu realizar a palatografia e a linguografia devido a intenso enjôo ao passar o material nos órgãos articuladores.

Um outro sujeito também do GSTF do gênero feminino com 5:3 anos, que havia apresentado nas provas de imitação, nomeação (WERTZNER, 2004), fala espontânea e específica para verificação das distorções produção distorcida no som [s], foi transferida de escola antes da realização da palatografia e linguografia com este mesmo som.

No GTF uma criança do gênero masculino com 5:11 anos, que havia apresentado distorção no [s] e [z] nas de nomeação, imitação (WERTZNER, 2004) e fala espontânea, realizou apenas substituição por [S] durante a realização da prova específica para verificação da distorção destes sons. 


\section{Material}

Para a seleção e coleta de dados dos sujeitos do GSTF, foram utilizados: questionários aplicados aos responsáveis pelas crianças, composto por questões sobre o desenvolvimento neuropsicomotor incluindo a linguagem e a fala (Anexo 2); o Termo de Consentimento Livre e Esclarecido para o GSTF (Anexo 3); o Teste de Fonologia composto por provas de nomeação e imitação (WERTZNER, 2004) e de Vocabulário (BEFI-LOPES, 2004) do Teste de Linguagem ABFW para avaliar o vocabulário e o sistema fonológico dos sujeitos; o roteiro de avaliação da motricidade orofacial (Anexo 4) utilizado no LIF de Fonologia para verificar a anatomia e morfologia dos órgãos articulatórios e as funções neurovegetativas; coleta da fala espontânea, obtida pelo livro de história infantil Esconde-Esconde (FURNARI, 1999).

Foram usadas como provas experimentais para ambos os grupos avaliação de motricidade orofacial, as avaliações de Fonologia (WERTZNER, 2004), a fala espontânea, a prova específica para verificar a distorção de fala e a palatografia e a linguografia, para casos em que o sujeito apresentasse distorção em algum dos sons estudados.

A prova específica para verificar a distorção de fala é composta por listas de sílabas e palavras para serem imitadas, sendo 21 sílabas para cada som ([s], [z], [S], [3], $[\ulcorner],[\Lambda]$ e $[1])$ que foi combinado com as vogais a, e, $\varepsilon, \mathrm{i}, \mathrm{o}, \mathrm{o}$ e u três vezes. Nas palavras procurou-se utilizar combinações com as vogais, na posição inicial, medial e final.

As estruturas silábicas das palavras variaram de acordo com o som. Para o som [s] foram utilizadas oito palavras dissílabas, oito trissílabas e duas polissílabas. Já para o som [z] foram selecionadas três dissílabas e cinco trissílabas. A lista de palavras para o [ $\left.\int\right]$ foi composta de seis palavras dissílabas, cinco trissílabas e duas polissílabas. Para o [3] foram seis palavras dissílabas, sete trissílabas e uma polissílaba. O [ $\ulcorner$ ] foi avaliado por oito palavras trissílabas. Para o $[\Lambda]$ foram cinco trissílabas e duas polissílabas e para o [1] foram utilizadas uma monossílaba, sete palavras dissílabas e quatro trissílabas.

Nos Anexos 5a a $5 \mathrm{~g}$ encontram-se os protocolos dessa prova, com as sílabas e as palavras. No Quadro 1 estão as palavras que foram utilizadas para cada som para a prova específica, para verificação da distorção de fala. 
Quadro 1. Palavras utilizadas na prova específica para verificação da distorção de fala.

\begin{tabular}{|c|c|c|c|c|c|c|c|}
\hline FONEMAS & $/ \mathrm{s} /$ & $|z|$ & $/ 3 /$ & $/ S /$ & $|\alpha|$ & $/ / /$ & $/ \mathcal{L}$ \\
\hline PALAVRAS & $\begin{array}{c}\text { Sapo } \\
\text { Cena } \\
\text { Seta } \\
\text { Cidade } \\
\text { Sopa } \\
\text { Sólido } \\
\text { Suco } \\
\text { Pássaro } \\
\text { Pêssego } \\
\text { Inseto } \\
\text { Bicicleta } \\
\text { Professora } \\
\text { Caçula } \\
\text { Paçoca } \\
\text { Cabeça } \\
\text { Doce } \\
\text { Saci } \\
\text { Urso }\end{array}$ & $\begin{array}{c}\text { Zabumba } \\
\text { Zebra } \\
\text { Zunido } \\
\text { Casaco } \\
\text { Desenho } \\
\text { Casinha } \\
\text { Casa } \\
\text { Vaso }\end{array}$ & $\begin{array}{c}\text { Janela } \\
\text { Geladeira } \\
\text { Jipe } \\
\text { Jogo } \\
\text { Juba } \\
\text { Pijama } \\
\text { Objeto } \\
\text { Mágico } \\
\text { Tijolo } \\
\text { Jujuba } \\
\text { Laranja } \\
\text { Hoje } \\
\text { Anjo } \\
\text { Caju }\end{array}$ & $\begin{array}{c}\text { Xale } \\
\text { Chegada } \\
\text { Chefe } \\
\text { Chinelo } \\
\text { Chuva } \\
\text { Enxada } \\
\text { Bexiga } \\
\text { Cachorro } \\
\text { Caixote } \\
\text { Caixa } \\
\text { Peixe } \\
\text { Abacaxi } \\
\text { Bicho }\end{array}$ & $\begin{array}{c}\text { Girafa } \\
\text { Coroa } \\
\text { Coruja } \\
\text { Cadeira } \\
\text { Árvore } \\
\text { Jacaré } \\
\text { Chuveiro } \\
\text { Canguru }\end{array}$ & $\begin{array}{c}\text { Lata } \\
\text { Leão } \\
\text { Leque } \\
\text { Lixo } \\
\text { Lobo } \\
\text { Loja } \\
\text { Lua } \\
\text { Polegar } \\
\text { Galinha } \\
\text { Janela } \\
\text { Xale } \\
\text { Cavalo }\end{array}$ & $\begin{array}{c}\text { Palhaço } \\
\text { Folhinha } \\
\text { Toalha } \\
\text { Vermelho } \\
\text { Filhote }\end{array}$ \\
\hline
\end{tabular}

No Quadro 2 encontram-se as palavras empregadas para a coleta da palatografia e linguografia.

Para a palatografia e linguografia foram selecionadas para cada som uma palavra, de preferência monossilábica e que continha apenas o som que se pretendia estudar, precedido e seguido da vogal a, por ser uma vogal central. As palavras foram retiradas de Paes (1999).

Quadro 2. Palavras empregadas para a coleta da palatografia e linguografia.

\begin{tabular}{cc}
\hline SONS ESTUDADOS & PALAVRAS \\
\hline$[\mathrm{s}]$ & ASSA \\
{$[\mathrm{z}]$} & ASA \\
{$[3]$} & AJA \\
{$[S]$} & CHEIA \\
{$[r]$} & ERA \\
[]$]$ & ALA \\
{$[\Lambda]$} & ALHO \\
\hline
\end{tabular}

Todas as provas foram filmadas e gravadas. As aplicações das provas foram registradas por aparelho de mini DVD da marca Sony modelo Handycam DCR - DVD 403, um notebook Semp Thoshiba Satelitte 605 e um microfone Sennheiser evolution 817 acoplado ao notebook, 
além de mini DVD-RW 30 minutos 1.4 GB/Go da Sony, para possibilitar uma melhor análise dos dados coletados. As provas foram realizadas em ambiente tratado acusticamente para o GTF e em ambiente silencioso para o GSTF.

Para a avaliação audiológica foi utilizado audiômetro da marca Grason-Stadler modelo GSI-68, fone supra aurais modelo TDH-50 (ANSI S3.6 -1989, IEC 1998) e cabina acústica com quantidade de ruído ambiental, atendendo à norma ANSI S3.1 - 1991.

Todas as provas foram transcritas em protocolos específicos. Para o GTF mantiveram-se os protocolos, exceto o questionário aplicado aos pais, que foi substituído pela anamnese utilizada no LIF de Fonologia, e o Termo de Consentimento Livre Esclarecido dirigido ao grupo com transtorno fonológico (Anexo 6).

Para os sujeitos dos dois grupos foram calculados em protocolos específicos os índices de gravidade: PCC (SHRIBERG e KWIATKOSWKI, 1982b), PCC-R (SHRIBERG et al. 1997), ACI (SHIBERG, 1993) e RDI (SHIBERG, 1993) (Anexo 7).

Para análise da fonética articulatória realizada por meio da palatografia, foram utilizadas fotos obtidas pela câmera de DVD, luva descartável, carvão digestivo pulverizado, pincel chato $\mathrm{n}^{\mathrm{o}}$ 8, espelho arredondado com cinco centímetros de altura e três centímetros de largura, impressora HP Officejet 7310, computador, folha específica para impressão fotográfica. Destacase que tanto o espelho como o pincel foram de uso individual para cada sujeito, sendo em seguida descartados. 


\section{Procedimento}

Todas as provas específicas da pesquisa foram aplicadas pela pesquisadora, assim como as análises dos dados. Para garantir a fidedignidade das transcrições fonéticas, cálculos dos índices de gravidade, classificação perceptiva das distorções e análise das palatografias, $20 \%$ dos sujeitos foram analisados por um juiz pertencente ao LIF de Fonologia.

Seleção das Escolas e dos Sujeitos Sem Transtorno Fonológico

As escolas escolhidas para a coleta dos dados de crianças do GSTF pertenciam à mesma região e eram públicas. As escolas da região da Penha na cidade de São Paulo foram receptivas para a realização da pesquisa. Após o contato telefônico com a direção ou coordenação pedagógica da escola, marcava-se um dia para a visita. Neste momento, entregava-se uma carta explicativa sobre o projeto (Anexos $8 \mathrm{a}$ e 8b) e discutia-se a viabilidade da execução do trabalho.

Depois de autorizada a pesquisa, a secretaria das escolas fornecia as listas de alunos do jardim II e pré da escola de educação infantil e da $1^{\mathrm{a}}$ e $2^{\mathrm{a}}$ séries do ensino fundamental, com nomes completos e datas de nascimento, para facilitar a seleção dos sujeitos da pesquisa.

Primeiramente, os professores e os coordenadores pedagógicos indicaram os alunos que apresentaram os melhores conceitos obtidos nas avaliações realizadas semestralmente e que não apresentavam alteração de linguagem oral e/ou escrita e de fala. Com base nas indicações dos professores e coordenadores, foi realizada uma seleção pela pesquisadora, com o objetivo de escolher os sujeitos da pesquisa com as idades necessárias para compor os subgrupos GSTF1, GSTF2 e GSTF3.

O Termo de Consentimento Livre e Esclarecido, juntamente com uma carta explicativa sobre a pesquisa e um questionário a respeito do histórico de desenvolvimento da criança, foi enviado aos pais dos alunos selecionados.

Os sujeitos cujos responsáveis relataram histórico de trocas ou omissões na fala, dificuldades na leitura, escrita e/ou aprendizagem não condizentes com a idade foram descartados da pesquisa e foram encaminhados para o LIF em Fonologia do Curso de Fonoaudiologia do Departamento de Fisioterapia, Fonoaudiologia e Terapia Ocupacional da Faculdade de Medicina 
da Universidade de São Paulo, para a realização da avaliação diagnóstica. Destaca-se que após o questionário aplicado ao GSTF não foram eliminadas as crianças com histórico de otites.

Após o retorno dos questionários preenchidos e dos Termos de Consentimento assinados, foram aplicadas as provas do Teste de Fonologia (WERTZNER, 2004) e Vocabulário (BEFILOPES, 2004) do Teste de Linguagem Infantil - ABFW, avaliação da fala espontânea e da motricidade orofacial para eliminar qualquer alteração de linguagem. A partir da análise dos dados da avaliação da Fonologia, os sujeitos foram então divididos em GSTF com distorção (GSTFCD) e GSTF sem distorção (GSTFSD).

O acordo entre as duas transcrições para a amostra analisada foi de $90 \%$ para nomeação e imitação (WERTZNER, 2004) e fala espontânea.

\section{Seleção dos Sujeitos com Transtorno Fonológico}

Após os sujeitos serem submetidos ao processo diagnóstico, que constou das provas do Teste de Linguagem Infantil - ABFW nas áreas de Vocabulário, Fonologia, Pragmática e Fluência (ANDRADE et al. 2004), avaliação da fala espontânea e motricidade orofacial, foi constatada a presença do transtorno fonológico, independente de apresentar concomitantemente distorções de fala em qualquer som.

Todas as crianças do GTF foram encaminhadas para exame audiológico no Setor de Audiologia do Curso de Fonoaudiologia da Faculdade de Medicina da Universidade de São Paulo.

As provas da avaliação diagnóstica dos sujeitos do GTF foram aplicadas pela pesquisadora, ou por fonoaudiólogas pós-graduandas do LIF em Fonologia, ou por alunas estagiárias do quarto ano da graduação ou do Centro de Saúde Escola Samuel Barsnley Pessoa, sob a supervisão do professor responsável pelo LIF de Fonologia e do Centro de Saúde, durante o ano letivo de 2004 e 2005.

As pós-graduandas ou alunas estagiárias realizaram a primeira transcrição das provas de Fonologia e fala espontânea nos sujeitos avaliados, e a pesquisadora realizou a segunda transcrição das provas. A pesquisadora realizou a primeira transcrição em sujeitos que avaliou e a segunda transcrição foi feita por uma aluna de graduação de Fonoaudiologia, bolsista de iniciação científica no LIF em Fonologia. O cálculo de acordo entre as primeiras e segundas transcrições foi de $95 \%$. 
Posteriormente, as 15 crianças com diagnóstico de Transtorno Fonológico foram divididas em GTF que apresentaram distorção de fala (GTFCD) e GTF que não apresentaram distorção de fala (GTFSD).

\section{Análise Perceptiva Auditiva e Visual da Distorção}

Para a análise perceptiva da presença de distorção foram consideradas as palavras do teste de Fonologia (WERTZNER, 2004) e da fala espontânea, que continham fonemas líquidos laterais e vibrantes simples e fricativos. O registro da presença de distorções ocorreu por meio da transcrição das fitas ou no momento da realização da prova, realizada com apoio na percepção auditiva e visual da pesquisadora. Uma aluna da graduação do curso de Fonoaudiologia, bolsista de iniciação científica, realizou a segunda análise assistindo as gravações, obtendo-se um acordo de $90 \%$.

Após a classificação perceptiva da ausência ou presença da distorção de fala, por meio dos julgamentos auditivo e/ou visual durante a aplicação da prova e na transcrição da prova, os sujeitos do GSTF e GTF foram redistribuídos em quatro grupos independentemente da idade. Dessa maneira, foi formado o Grupo Sem Transtorno Fonológico Com Distorção (GSTFCD), Grupo Sem Transtorno Fonológico Sem Distorção (GSTFSD), Grupo Com Transtorno Fonológico Com Distorção (GTFCD) e Grupo Com Transtorno Fonológico Sem Distorção (GTFSD). 
Composição, Aplicação e Critérios de Análise da Prova para Verificação de Distorção dos Sons em Sílabas e Palavras

A prova utilizada para a verificação de distorção em líquidas foi elaborada por Castro (2004) e a de fricativas foi preparada especificamente para esta pesquisa. No Anexo 9 encontrase a pré-pesquisa realizada para a obtenção da lista de palavras com fricativas alveolares e palatais.

Para os sons fricativos a lista constou de 21 sílabas para cada um dos sons [s, z, 3, $]$ e de 18 palavras com [s], oito palavras com [z], 14 para [3] e 12 palavras com [J] (Anexos 5a a 5d).

A prova de verificação de distorção para os sons líquidos constou de 21 sílabas para cada um dos sons $[\varsigma, 1, \kappa]$ e oito palavras para $[\varsigma], 13$ palavras para $[1]$, cinco para $[\kappa]$ (Anexos 5 e a $5 \mathrm{~g})$.

Posteriormente à subdivisão dos grupos, aos sujeitos do GSTFCD e GTFCD foi aplicada a prova para verificação da distorção, com o som que a criança havia apresentado com distorção durante a realização das provas de Fonologia (WERTZNER, 2004) e/ou fala espontânea.

Foi solicitado à criança que repetisse a sílaba ou palavra imediatamente após a produção do examinador.

Para evitar viés na pesquisa, as provas do teste para verificação de distorção de fala foram aplicadas em ordem diferente para os sujeitos, dentro de cada um dos grupos para um determinado som. Para ambos os grupos a forma A constava da aplicação inicial de repetição de sílabas seguidas de repetição de palavras; já para a forma $\mathrm{B}$, eram aplicada inicialmente as palavras do final para o início, e depois as sílabas, também do final para o início.

A primeira transcrição foi realizada no momento da aplicação do teste. A concordância de identificação de distorção visual e auditiva entre a pesquisadora e a aluna bolsista de iniciação científica foi realizada por amostragem para ambos os grupos. O acordo foi de $85 \%$. 
Critérios de Análise da Prova de Verificação de Distorção de Fala

A análise das distorções na prova de verificação permitiu a descrição de algumas variações para cada som. Para as liquidas partiu-se da descrição feita por Castro (2004), porém, foram necessárias algumas adaptações. O Quadro 3 mostra as categorias analisadas já adaptadas e que foram utilizadas nesta pesquisa. Para as fricativas foram criadas categorias para os sons conforme o encontrado no estudo. Deve-se salientar que nem todas as descrições de distorções, tanto para fricativos quanto para líquidas, foram encontradas nos sujeitos desta pesquisa.

Quadro 3. Descrição da produção das distorções de fala.

\begin{tabular}{lll}
\hline Som & \multicolumn{1}{c}{ Descrição da produção } & Abreviatura \\
\hline$[l]$ & $\begin{array}{l}\text { Projeção de língua sem distorção acústica: quando o sujeito interpõe a língua } \\
\text { entre os dentes anteriores ou lateralmente, podendo ser notado apenas visual e } \\
\text { auditivamente. }\end{array}$ & $\begin{array}{l}\text { Posteriorização com distorção acústica: no momento da produção o sujeito PoCD } \\
\text { posterioriza a língua, com distorção notada auditivamente. }\end{array}$ \\
\hline$[\mathrm{r}]$ & $\begin{array}{l}\text { Ruído molhado: definido como a produção em que parece haver acúmulo RM } \\
\text { exagerado de saliva. }\end{array}$ & $\begin{array}{l}\text { Projeção de língua sem distorção acústica: quando o sujeito interpõe a língua } \\
\text { entre os dentes anteriores ou lateralmente, não podendo ser notado auditivamente. }\end{array}$ \\
\hline$[\mathrm{s}]$ &
\end{tabular}

Projeção de língua anterior com distorção acústica: quando o sujeito interpõe a PLACD língua entre os dentes anteriores, podendo ser notado visualmente e auditivamente.

Projeção de língua lateral com distorção acústica: quando o sujeito interpõe a PLLCD língua entre os dentes laterais, podendo ser notado visual e auditivamente.

[z] Projeção de língua sem distorção acústica: quando o sujeito interpõe a língua PLSD entre os dentes anteriores ou lateralmente, não podendo ser notado auditivamente.

Projeção de língua anterior com distorção acústica: quando o sujeito interpõe a PLACD língua entre os dentes anteriores, podendo ser notado visualmente e auditivamente.

Projeção de língua lateral com distorção acústica: quando o sujeito interpõe a PLLCD língua entre os dentes laterais, podendo ser notado visual e auditivamente.

[S] Esforço articulatório sem distorção acústica: quando o sujeito realizou ESD visualmente exagero na produção articulatória, causando chiado forte.

Esforço articulatório com distorção acústica: quando o sujeito realizou ECD visualmente e/ou acusticamente exagero na produção articulatória, podendo ser notado visual e auditivamente.

[3] Esforço articulatório sem distorção acústica: quando o sujeito realizou ESD visualmente exagero na produção articulatória, causando chiado forte.

Esforço articulatório com distorção acústica: quando o sujeito realizou visual e ECD auditivamente exagero na produção articulatória. 
Foi realizada a palatografia e a linguografia para todos os sons estudados, ou seja, [s], [z], [S], [3], [1], $[\ulcorner]$ e $[\Lambda]$, em dois sujeitos com desenvolvimento típico de fala e linguagem nas faixas etárias de cinco e sete anos, no dia da coleta de dados, não estava presente nenhum sujeito na faixa etária de seis anos, que pudesse realizar a técnica. Estes sujeitos fizeram parte do estudo, mas não apresentaram distorção, pertencendo ao GSTFSD. Foram escolhidos aleatoriamente dentro deste grupo. A palatografia e a linguografia possibilitaram uma comparação visual das produções adequadas e das com distorção.

Todos os sujeitos com distorção de fala confirmada na prova para verificação de distorção foram submetidos à palatografia e à linguografia para análise do som distorcido.

Explicava-se à criança o procedimento para a obtenção da palatografia. A ordem dada à criança foi: "vou pintar sua língua com uma mistura preta que não tem gosto nem cheiro, logo depois vou pedir para você falar uma palavra. Depois de falar você deve abrir a boca para que eu coloque o espelho para ver como ficou seu 'céu da boca', e então vou tirar uma foto".

Para a linguografia, a ordem dada foi: "vou pintar seu 'céu da boca', com uma mistura preta que não tem gosto nem cheiro, e logo depois vou pedir para você falar uma palavra. Depois de falar você deve abrir a boca e colocar a língua para fora, e em seguida vou tirar uma foto da língua".

Para a palatografia, a língua dos sujeitos foi revestida com uma mistura de partes iguais de azeite de oliva e carvão de lenha digestivo pulverizado (o azeite de oliva não tem sabor ruim e o carvão é insípido), com um pincel largo e macio. Em seguida o sujeito deveria produzir uma palavra que contivesse o som a ser investigado.

Após a produção da palavra, era solicitado que o sujeito abrisse a boca para a introdução de um espelho com cantos arredondados, que refletia a região entre os molares esquerdos e direitos da arcada dentária superior que foi contatada pela língua. Logo após, a imagem refletida no espelho foi fotografada e todo o processo filmado. Ao término do registro fotográfico, o sujeito foi instruído a utilizar a escova de dente e enxaguar a boca para que não ficasse nenhum resíduo da mistura. A seguir, são mostradas as Figuras do material, mistura, aplicação da mistura para realização da palatografia e linguografia, introdução do espelho entre os molares e palatografia e linguografia. 
Figura 1. Materiais utilizados na palatografia e linguografia.

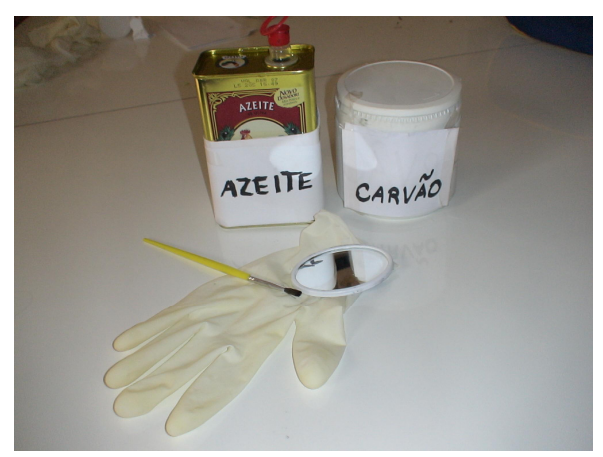

Figura 2. Mistura de carvão digestivo pulverizado e azeite de oliva.

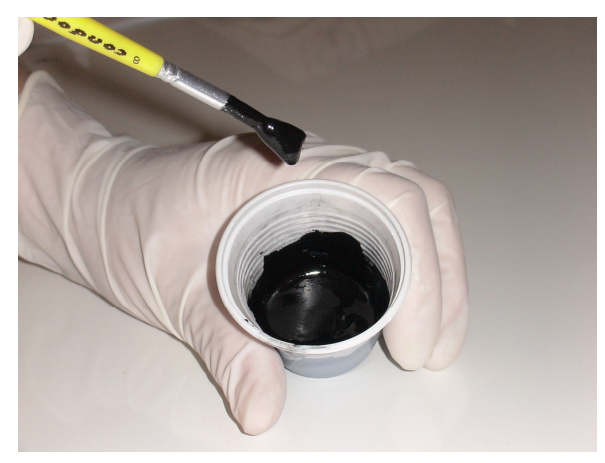

Figura 3. Aplicação da mistura no palato duro e na língua.
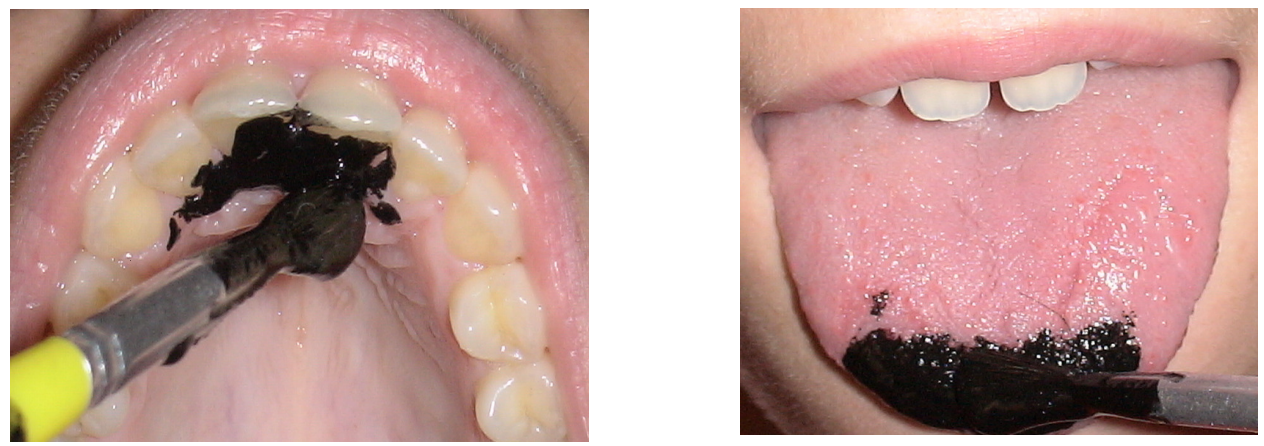
Figura 4. Introdução do espelho entre os molares superiores e obtenção da palatografia.

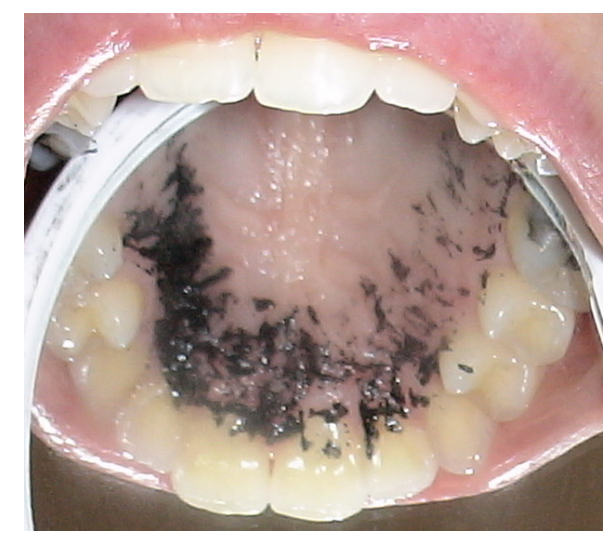

Figura 5. Linguografia.

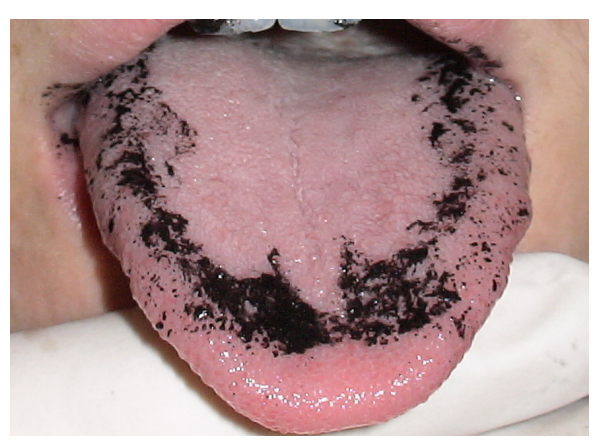

Após a obtenção da palatografia, procedimento semelhante foi realizado para a linguografia. A mesma mistura foi aplicada no palato duro, e após a produção da mesma palavra utilizada na palatografia, o sujeito colocava a língua para fora para ser fotografada e filmada para posterior análise (CASAES, 1992; LADEFOGED, 2001).

O tempo gasto para a realização de cada palatografia e/ou linguografia entre instrução, aplicação da mistura, produção e enxágüe foi ao redor de dois minutos. No entanto, $40 \%$ das crianças referiram enjôo. Em alguns casos, na hora de fotografar a palatografia o espelho embaçava enquanto procurava-se o melhor foco para fotografar a imagem. Além disso, para as crianças menores houve dificuldade em se posicionar o espelho entre os molares, devido ao tamanho reduzido da arcada dentária.

Para a análise do palatograma e do linguograma foram usadas as fotografias. Nesta análise estudou-se a arcada dentária, o palato duro e a mancha observada. O Quadro 4 mostra as medidas analisadas para cada um dos componentes estudados. 
Durante a análise a criança poderia apresentar concomitantemente mais de um ponto de contato (CASAES, 1990). As manchas poderiam ocorrer também em mais de uma região do palato, sendo considerada como exemplo dento-alveolar, dento-palatal e dento-alvéolo-palatal. Da mesma forma, mais de uma região da língua também poderia estar manchada, sendo classificada como ápico-laminar (AVELINO e KIM, 2006).

Para 20\% das palatografias e linguografias foram realizadas, além da análise da pesquisadora, uma segunda análise das fotos, por uma fonoaudióloga mestre, que obteve $95 \%$ de acordo.

Quadro 4. Componentes estudados na palatografia e linguografia.

\begin{tabular}{|c|c|c|c|}
\hline \multirow{2}{*}{$\begin{array}{l}\text { ESTRUTURA } \\
\text { ARCADA } \\
\text { DENTÁRIA }\end{array}$} & \multicolumn{3}{|c|}{ ASPECTOS ANALISADOS } \\
\hline & \multicolumn{2}{|l|}{ Simetria } & $\begin{array}{l}\text { Simétrica se as duas hemiarcadas fossem } \\
\text { semelhantes em forma e tamanho. }\end{array}$ \\
\hline & \multicolumn{2}{|l|}{ Aberta ou Estreita } & $\begin{array}{l}\text { Aberta se os dentes estivessem dispostos } \\
\text { harmonicamente e estreita se visualmente } \\
\text { estivesse apertada. }\end{array}$ \\
\hline & \multicolumn{2}{|c|}{ Completa ou Incompleta } & $\begin{array}{l}\text { Completa se todos os dentes estivessem presentes } \\
\text { na arcada; nos casos de dentição mista, se pelo } \\
\text { menos } 75 \% \text { do dente estivesse erupcionado; ou } \\
\text { incompleta pela ausência de dentes anteriores } \\
\text { (incisivos e caninos). }\end{array}$ \\
\hline \multirow[t]{3}{*}{$\begin{array}{l}\text { PALATO } \\
\text { DURO }\end{array}$} & \multicolumn{2}{|l|}{ Homogêneo } & $\begin{array}{l}\text { Se na extensão não apresentasse saliências ou } \\
\text { reentrâncias. }\end{array}$ \\
\hline & \multicolumn{2}{|l|}{ Fissura } & Presença de algum tipo de fissura palatina. \\
\hline & \multicolumn{2}{|l|}{ Rugosidades } & 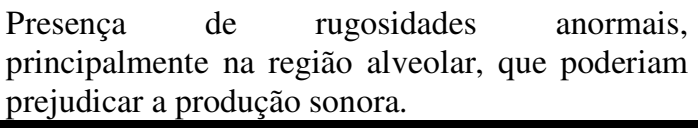 \\
\hline \multirow[t]{9}{*}{ MANCHA } & \multicolumn{2}{|l|}{ Simétrica } & $\begin{array}{l}\text { Simetria entre as partes direita e esquerda, tanto } \\
\text { da língua quanto do palato duro. }\end{array}$ \\
\hline & \multicolumn{2}{|l|}{ Interrupção } & Ausência do material em algum ponto da mancha. \\
\hline & \multicolumn{2}{|l|}{ Tensão: forte ou fraca } & $\begin{array}{l}\text { Fraca se a mancha fosse visualmente clara e forte } \\
\text { quando foi escura. }\end{array}$ \\
\hline & \multirow[t]{2}{*}{ LINGUOGRAMA } & Ápice & $\begin{array}{l}\text { Mancha na porção mais fina da língua que } \\
\text { repousa atrás dos dentes. }\end{array}$ \\
\hline & & Laminar & $\begin{array}{l}\text { Região da língua manchada logo atrás da ponta. } \\
\text { Maior área da língua, faz contato com o palato } \\
\text { duro e mole. }\end{array}$ \\
\hline & \multirow[t]{4}{*}{ PALATOGRAMA } & Dental & Mancha na região oclusal ou lingual dos dentes. \\
\hline & & Alveolar & Mancha na região alveolar do palato duro. \\
\hline & & Palatal & Contato com a região palatal do palato duro. \\
\hline & & Velar & Mancha sobre a região velar da cavidade oral. \\
\hline
\end{tabular}




\section{Avaliação da Motricidade Orofacial}

Para o presente trabalho foi considerado o tipo de oclusão e dentição por ser importante na análise da palatografia.

$\mathrm{Na}$ avaliação de motricidade orofacial, foi considerada maloclusão quando se observou um desvio na forma natural da oclusão, tais como: mordida aberta anterior, caso existisse uma falta de sobreposição vertical entre quaisquer dos incisivos antagonistas, sem estimar a quantidade de mordida aberta; topo a topo, com os bordos incisais dos incisivos superiores tocando nos bordos incisais dos incisivos inferiores; sobremordida, os dentes em oclusão cêntrica apresentavam sobrepasse dos dentes anteriores superiores acima de $3 \mathrm{~mm}$ aproximadamente sobre os inferiores; mordida cruzada, com os dentes em oclusão cêntrica. A mordida cruzada anterior foi registrada quando um ou mais de um dos incisivos superiores apresentavam uma inclinação axial anormal, ocluindo lingualmente, em relação aos seus antagonistas, os incisivos inferiores. A mordida cruzada posterior foi registrada, considerando quando dois ou mais dentes posteriores, incluindo-se também os caninos, apresentavam um problema oclusal em que as cúspides vestibulares dos dentes superiores ocluíam lingualmente em relação às cúspides vestibulares dos dentes inferiores. Foi considerada a mordida cruzada posterior uni ou bilateral; o overjet foi observado quando os dentes anteriores superiores se encontravam numa posição protrusiva (EMMERICH et al., 2004).

Devido à idade dos sujeitos, a dentição foi classificada como decídua, quando a criança tinha todos os dentes decíduos, e mista, na ausência de um ou mais dentes decíduos, podendo ou não estar erupcionado dentes permanentes e presença ou não do primeiro molar permanente.

\section{Provas de Fonologia, Fala Espontânea e Índices de Gravidade}

As provas de Fonologia (WERTZNER, 2004) e fala espontânea foram analisadas por meio do inventário fonético e a análise dos processos fonológicos.

No inventário fonético foram analisadas e quantificadas todas as substituições, omissões e distorções realizadas por cada sujeito. $\mathrm{Na}$ análise dos processos fonológicos, foram classificados os processos fonológicos e quantificada a produtividade de cada processo, além de verificados se estavam ou não adequados à idade do sujeito. 
Os dados das provas de Fonologia foram anotados no momento da coleta e conferidos posteriormente por meio da gravação feita pela pesquisadora e por um juiz graduado em Fonoaudiologia, com $90 \%$ de acordo.

Após as análises foram aplicados os índices PCC (SHRIBERG e KWIATKOWSKI, 1982 b), PCC-R (SHRIBERG et al., 1997), PDI (EDWARDS,1992), ACI (SHIBERG, 1993) e RDI (SHIBERG, 1993) para a classificação da gravidade do transtorno fonológico e das distorções.

\section{Cálculo dos Índices}

Percentage of Correct Consonants (PCC): são considerados erros, qualquer tipo de substituições, omissões e/ou distorções. O cálculo é realizado pela divisão das consoantes corretas pelo total de consoantes da prova multiplicado por $100 \%$. O Quadro 5 indica as produções consideradas como erros na contagem do PCC de acordo com Wertzner (2002).

Quadro 5. Produções consideradas como erros na contagem do PCC (WERTZNER, 2002).

\begin{tabular}{|c|c|}
\hline - Eliminação da consoante & Exemplo: /lapiS/ - [lapi] \\
\hline $\begin{array}{ll}\text { - } & \begin{array}{l}\text { Substituição da consoante por } \\
\text { outra }\end{array} \\
\end{array}$ & Exemplo: /sapo/ - [tapu] \\
\hline $\begin{array}{l}\text { - Sonorização ou ensurdecimento } \\
\text { parcial da consoante }\end{array}$ & Exemplo: /meza/ - [mesa] \\
\hline $\begin{array}{l}\text { - Distorção do som não importa o } \\
\text { quanto seja sutil; consideram-se } \\
\text { as distorções comuns e incomuns }\end{array}$ & Exemplo: /sapo/ - [s*apu] \\
\hline $\begin{array}{l}\text { - Adição de um som a um padrão } \\
\text { consonantal }\end{array}$ & Exemplo: /prata/ - [parata] \\
\hline
\end{tabular}

Percentage of Consonants Correct - Revised (PCC-R): é calculado por meio da divisão das consoantes corretas emitidas pelo total de consoantes da prova multiplicado por $100 \%$. São considerados erros somente omissões e substituições. Por exemplo, se uma criança produzir [s*apu], com distorção do /s/, não será considerado erro, mas sim se produzir [tapu], pois houve a substituição de um som por outro. 
Process Density Index (PDI): valor que reflete a ocorrência de processos fonológicos numa amostra de fala. É obtido pela divisão do número total de processos fonológicos da amostra pelo número total de palavras da amostra.

$>$ Relative Distortion Index (RDI): valor que reflete a proporção de erros de distorção numa amostra de fala. É obtido pela divisão do número total de erros de distorção da amostra pelo número total de erros da fala, multiplicado por $100 \%$. Desta forma, se a criança produziu no total da amostra de fala estudada dez erros entre substituições, omissões e distorções, sendo seis distorções, o índice RDI será: 6/10 x 100\% $=60 \%$.

Articulation Competence Index (ACI): é baseado em duas características da fala conversacional, a porcentagem de consoantes corretas corretamente articuladas (PCC) e a porcentagem de todas as consoantes produzidas incorretamente, devido à distorção de fala. É obtido pela soma dos índices PCC e RDI, dividido por dois e multiplicado por 100\%. Quando o sujeito não apresentar distorções de fala e, portanto, obtiver o RDI igual a zero, o ACI será considerado igual ao PCC. 


\section{Método estatístico}

O método estatístico deste estudo constou de análises descritivas e inferenciais.

A parte descritiva foi realizada através dos cálculos de média, desvio padrão, mínimo, máximo, quartis. Esses resultados foram apresentados em gráficos do tipo boxplot, nos quais é possível verificar o retângulo construído com os quartis e os valores extremos (mínimo, máximo e valores discrepantes) de variáveis quantitativas, além de gráficos de barras, colunas, pizza e rosca construídos com base nos valores das médias.

Para a análise inferencial foi utilizado o teste paramétrico ANOVA (análise de variância), sendo realizadas as comparações múltiplas pelo método Bonferroni quando se observou diferenças entre as diferenças médias dos grupos e os testes não-paramétricos $\chi^{2}$ (qui-quadrado) e teste de Fisher (MAXWELL e SATAKE, 1997). 


\section{RESULTADOS}


Os resultados deste estudo são mostrados de acordo com as seguintes análises: descrição da população quanto ao gênero e idade; descrição da ocorrência de distorções em crianças com e sem transtorno fonológico nas provas de imitação e nomeação (WERTZNER, 2004) e fala espontânea; descrição das distorções na prova específica para verificação de distorções em sílabas e palavras; classificação perceptiva das distorções de fala na prova específica para verificação de distorções em sílabas e palavras; análise da motricidade orofacial; descrição da articulação dos sons líquidos laterais e vibrantes simples e de fricativos alveolares e palatais pela palatografia e linguografia; comparação entre os pontos de contatos da articulação na palatografia e linguografia e classificação perceptiva das distorções; comparação dos índices de gravidade nas provas de imitação e nomeação (WERTZNER, 2004) e fala espontânea.

\section{Descrição da População quanto ao Gênero e Idade}

\section{Grupo Sem Transtorno Fonológico}

O Grupo Sem Transtorno Fonológico (GSTF) foi composto por 30 crianças. Na Figura 6 e e na Tabela 3 podem ser observados os dados de acordo com a faixa etária do GSTF1, GSTF2 e GSTF3 e GSTF.

Figura 6. Distribuição dos sujeitos do GSTF de acordo com a idade.

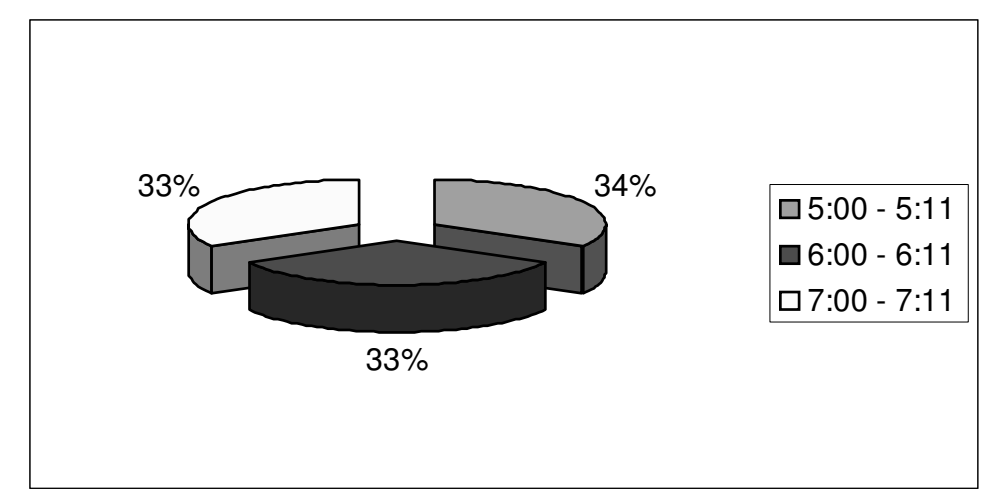


Tabela 3. Distribuição da idade dos sujeitos no GSTF1, GSTF2 e GSTF3 e GSTF.

\begin{tabular}{ccccccc}
\hline & N & MÉDIA & MEDIANA & DP & MÍNIMO & MÁXIMO \\
\hline GSTF1 & 10 & $5: 06$ & $5: 06$ & $0: 3$ & $5: 01$ & $5: 11$ \\
GSTF2 & 10 & $6: 06$ & $6: 06$ & $0: 3$ & $6: 01$ & $6: 11$ \\
GSTF3 & 10 & $7: 06$ & $7: 07$ & $0: 3$ & $7: 00$ & $7: 11$ \\
GSTF & 30 & $6: 06$ & $6: 06$ & $0: 7$ & $5: 01$ & $7: 11$ \\
\hline
\end{tabular}

Legenda: GSTF - Grupo sem transtorno fonológico, GSTF1 - Grupo sem transtorno fonológico na faixa etária de cinco anos, GSTF2 - Grupo sem transtorno fonológico na faixa etária de seis anos, GSTF3 - Grupo sem transtorno fonológico na faixa etária de sete anos, N- número, DP -desvio padrão.

\section{Grupo Com Transtorno Fonológico}

O GTF foi composto por 15 sujeitos. As idades dos sujeitos do GTF variaram entre 5:02 anos a 7:9 anos, sendo que a faixa etária de maior concentração foi de seis anos, com 7 sujeitos, seguida de cinco anos e sete anos, com 4 sujeitos em cada faixa etária (Figura 7). Na Tabela 4 observa-se a distribuição da idade dos sujeitos no GTF1, GTF2 e GTF3 e GTF.

Figura 7. Distribuição dos Sujeitos do GTF de acordo com a idade.

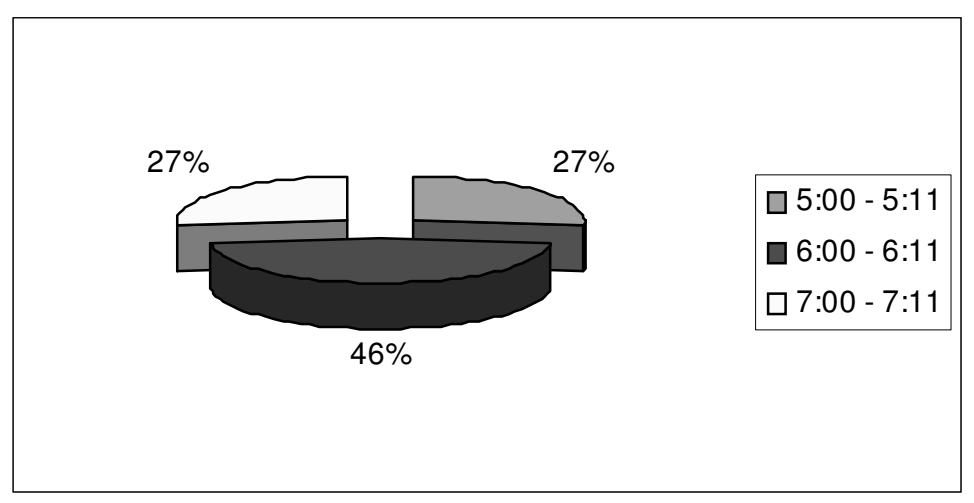

Tabela 4. Distribuição da idade dos sujeitos no GTF1, GTF2 e GTF3 e GTF.

\begin{tabular}{ccccccc}
\hline & N & MÉDIA & MEDIANA & DP & MÍNIMO & MÁXIMO \\
\hline GTF1 & 4 & $5: 06$ & $5: 06$ & $0: 4$ & $5: 02$ & $5: 11$ \\
GTF2 & 7 & $6: 05$ & $6: 06$ & $0: 4$ & $6: 01$ & $6: 11$ \\
GTF3 & 4 & $7: 03$ & $7: 03$ & $0: 4$ & $7: 00$ & $7: 09$ \\
GTF & 15 & $6: 05$ & $6: 06$ & $0: 7$ & $5: 02$ & $7: 09$ \\
\hline
\end{tabular}

Legenda: GTF - Grupo com transtorno fonológico, GTF1 - Grupo com transtorno fonológico na faixa etária de cinco anos, GTF2 - Grupo com transtorno fonológico na faixa etária de seis anos, GTF3 - Grupo com transtorno fonológico na faixa etária de sete anos, DP -desvio padrão.

Em relação ao gênero, no GTF houve predominância do gênero feminino (60\%), como pode ser observado na Figura 8. 
O GTF1 foi composto por $75 \%$ dos sujeitos do gênero masculino e $25 \%$ do feminino; o GSTF2 por $71,4 \%$ do gênero feminino e $28,6 \%$ do masculino; o GSTF3 por $75 \%$ do gênero feminino e $25 \%$ do masculino. Desta forma, o GSTF1 foi o único subgrupo composto mais por sujeitos do gênero masculino do que feminino.

Figura 8. Distribuição dos sujeitos do GTF de acordo com o gênero.

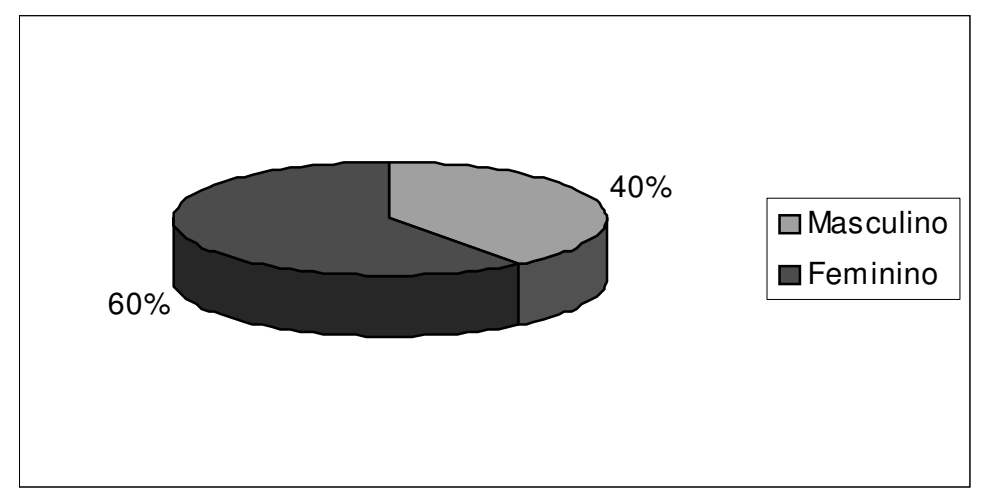




\section{Descrição da Ocorrência de Distorções em Crianças com e sem Transtorno Fonológico nas Provas de Imitação, Nomeação (WERTZNER, 2004) e Fala Espontânea.}

A seguir será feita a descrição da ocorrência de distorções nas provas de imitação e nomeação (WERTZNER, 2004) e fala espontânea e nas diferentes faixas etárias, primeiramente no GSTF seguido do GTF e por fim a comparação da ocorrência de distorção dos sons nestes dois grupos.

\section{Grupo Sem Transtorno Fonológico}

No GSFT os sujeitos apresentaram distorção nas provas de nomeação, imitação e fala espontânea nos sons [s], [z], [S] e [1].

Para cada som calculou-se a possibilidade de ocorrência no grupo e a porcentagem de casos observados em cada uma das três provas (nomeação, imitação e fala espontânea). A Tabela 5 indica a porcentagem de distorção em cada um dos sons [s], [z], [ $]$ e [1] nestas provas no GSTF

No Anexo 10 se encontram as proporções de ocorrências das distorções para cada som nas provas de imitação, nomeação e fala espontânea nos sujeitos do GSTF.

Tabela 5. Porcentagem média de distorção nos sons [s], [z], [S] e [1] nas provas de nomeação, imitação e fala espontânea no GSTF.

\begin{tabular}{ccccc}
\hline PROVAS & {$[\mathbf{s}]$} & {$[\mathbf{z}]$} & {$[\mathbf{S}]$} & {$[\mathbf{l}]$} \\
\hline IMITAÇÃ̃O & $17,7 \%$ & $13,3 \%$ & $1,1 \%$ & $8,3 \%$ \\
NOMEAÇÃO & $17,7 \%$ & $14,2 \%$ & $1,1 \%$ & $16,1 \%$ \\
FALA ESPONTÂANA & $13,8 \%$ & $0 \%$ & $0 \%$ & $0 \%$ \\
\hline
\end{tabular}

Na Tabela 6 podem ser observados os números de sujeitos do GSTF1, GSTF2 e GSTF3 que apresentaram distorções nos sons $[\mathrm{s}],[\mathrm{z}],\left[\int\right]$ e $[1]$ independentemente da prova. No entanto, não há fortes indícios de diferenças entre os grupos GSTF1, GSTF2 e GSTF3 quanto ao número de sujeitos que apresentaram distorção em cada som, apesar da pequena incidência não permitir a aplicação de teste estatístico específico.

O GSTF3 foi o grupo que mais apresentou sujeitos com distorção de fala, com a ocorrência de três sons distorcidos ([s], [z], [1]). 
O GSTF1 foi o segundo grupo em que mais sujeitos realizaram produção distorcida. Os sons distorcidos foram os mesmos do GSTF3, ou seja, [s], [z], [1]. Por fim, no GSTF2 ocorreu o menor número de sujeitos que apresentaram distorção, além de apresentar distorção em apenas dois sons, [s] e [S].

Tabela 6. Número de sujeitos que apresentaram distorção no [s], [z], [S] e [l] - GSTF1, GSTF2, GSTF3.

\begin{tabular}{ccccc} 
& & \multicolumn{3}{c}{ Número de Sujeitos } \\
\cline { 3 - 6 } & & GSTF1 & GSTF2 & GSTF3 \\
\cline { 3 - 6 }$[\mathrm{s}]$ & com distorção & 2 & 1 & 4 \\
& produção correta & 8 & 9 & 6 \\
\hline$[\mathrm{z}]$ & com distorção & 1 & 0 & 4 \\
& produção correta & 9 & 10 & 6 \\
\hline$\left[\int\right]$ & com distorção & 0 & 1 & 0 \\
& produção correta & 10 & 9 & 10 \\
\hline$[1]$ & com distorção & 1 & 0 & 9 \\
& produção correta & 9 & 10 & 1 \\
\hline
\end{tabular}

Legenda: GSTF1 - Grupo sem transtorno fonológico na faixa etária de cinco anos, GSTF2 - Grupo sem transtorno fonológico na faixa etária de seis anos, GSTF3 - Grupo sem transtorno fonológico na faixa etária de sete anos.

Na Tabela 7 pode ser observada a comparação entre os grupos de acordo com as faixas etárias quanto à ocorrência de distorção ou produção correta para os sons [s] e [z] no GSTF, nas provas de nomeação, imitação e fala espontânea. Para tanto foi aplicado o teste de qui-quadrado (n.sig.0,05). Houve diferença significante na prova de nomeação tanto para o som $[\mathrm{s}]$ como [z] e para imitação no som [s], com maior ocorrência de distorção para a faixa etária de sete anos. 
Tabela 7. Comparação da ocorrência de distorção e produção correta entre as faixas etárias de cinco, seis e sete anos nas provas de imitação e nomeação e fala espontânea para os sons [s] e [z] no GSTF.

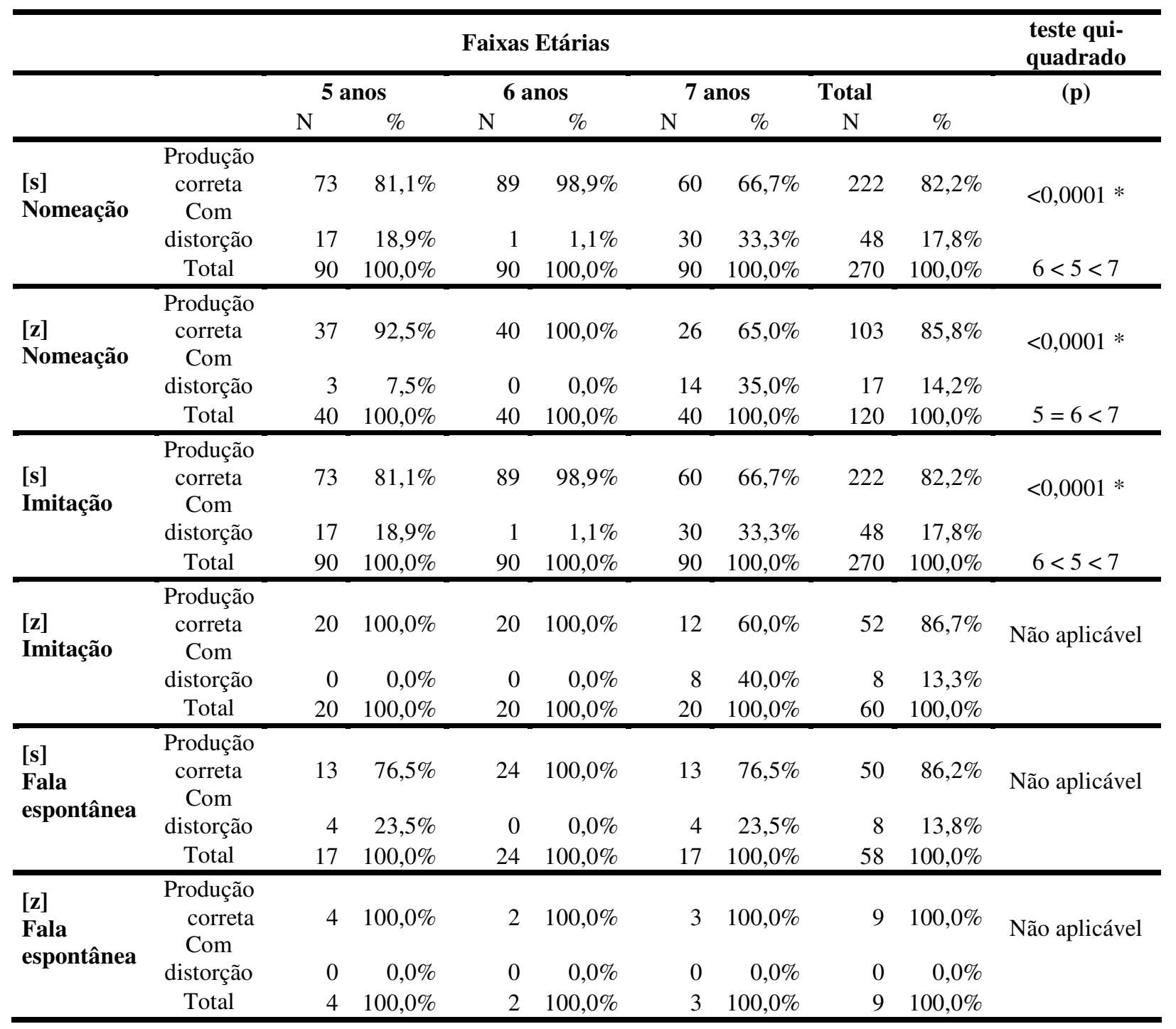

As Tabelas 8, 9, 10 e 11 permitem observar a comparação entre as provas quanto ao número de ocorrências de distorção e de produção correta nos sons $[\mathrm{s}],[\mathrm{z}],\left[\int\right]$ e $[1]$ no GSTF. Por meio do teste de qui-quadrado com nível de significância de 5\%. Não houve diferença significante na distribuição do som [s] entre as provas de nomeação, imitação e fala espontânea no GSTF. Para os sons [z], [ $]$ e [1] não foi possível aplicar o teste, mas não há indícios de diferenças entre as provas. 
Tabela 8. Comparação entre a ocorrência de distorção e produção correta nas provas de imitação e nomeação e fala espontânea para [s] - GSTF.

\begin{tabular}{|c|c|c|c|c|c|c|c|c|c|}
\hline \multicolumn{10}{|c|}{ Provas } \\
\hline & & \multicolumn{2}{|c|}{ Imitação } & \multicolumn{2}{|c|}{ Nomeação } & \multicolumn{2}{|c|}{$\begin{array}{c}\text { Fala } \\
\text { espontânea }\end{array}$} & \multicolumn{2}{|c|}{ Total } \\
\hline \multirow{3}{*}{ [s] } & & $\mathrm{N}$ & $\%$ & $\mathrm{~N}$ & $\%$ & $\mathrm{~N}$ & $\%$ & $\mathrm{~N}$ & $\%$ \\
\hline & $\begin{array}{c}\text { Produção } \\
\text { correta } \\
\text { Com } \\
\text { distorção }\end{array}$ & $\begin{array}{r}222 \\
48\end{array}$ & $\begin{array}{l}82,2 \% \\
17,8 \%\end{array}$ & $\begin{array}{r}222 \\
48\end{array}$ & $82,2 \%$ & 50 & $\begin{array}{l}86,2 \% \\
13,8 \%\end{array}$ & 494 & $\begin{array}{l}82,6 \% \\
17,4 \%\end{array}$ \\
\hline & Total & 270 & $100,0 \%$ & 270 & $100,0 \%$ & 58 & $100,0 \%$ & 598 & $100,0 \%$ \\
\hline
\end{tabular}

Teste de qui-quadrado $(\mathrm{p})=0,749$

Tabela 9. Comparação entre a ocorrência de distorção e produção correta nas provas de imitação e nomeação e fala espontânea para [z] - GSTF.

\begin{tabular}{|c|c|c|c|c|c|c|c|c|c|}
\hline \multicolumn{10}{|c|}{ Provas } \\
\hline & & \multicolumn{2}{|c|}{ Imitação } & \multicolumn{2}{|c|}{ Nomeação } & \multicolumn{2}{|c|}{$\begin{array}{c}\text { Fala } \\
\text { espontânea }\end{array}$} & \multicolumn{2}{|c|}{ Total } \\
\hline \multirow{4}{*}[\mathbf{z}]{} & & $\mathrm{N}$ & $\%$ & $\mathrm{~N}$ & $\%$ & $\mathrm{~N}$ & $\%$ & $\mathrm{~N}$ & $\%$ \\
\hline & $\begin{array}{c}\text { Produção } \\
\text { correta } \\
\text { Com }\end{array}$ & 52 & $86,7 \%$ & 103 & $85,8 \%$ & 9 & $100,0 \%$ & 164 & $86,8 \%$ \\
\hline & distorção & 8 & $13,3 \%$ & 17 & $14,2 \%$ & 0 & $0,0 \%$ & 25 & $13,2 \%$ \\
\hline & Total & 60 & $100,0 \%$ & 120 & $100,0 \%$ & 9 & $100,0 \%$ & 189 & $100,0 \%$ \\
\hline
\end{tabular}

Tabela 10. Comparação entre a ocorrência de distorção e produção correta nas provas de imitação e nomeação e fala espontânea para [S] - GSTF.

\begin{tabular}{|c|c|c|c|c|c|c|c|c|c|}
\hline \multicolumn{10}{|c|}{ Provas } \\
\hline & & \multicolumn{2}{|c|}{ Imitação } & \multicolumn{2}{|c|}{ Nomeação } & \multicolumn{2}{|c|}{$\begin{array}{c}\text { Fala } \\
\text { espontânea }\end{array}$} & \multicolumn{2}{|c|}{ Total } \\
\hline \multirow{3}{*}[\int]{} & & $\mathrm{N}$ & $\%$ & $\mathrm{~N}$ & $\%$ & $\mathrm{~N}$ & $\%$ & $\mathrm{~N}$ & $\%$ \\
\hline & $\begin{array}{c}\text { Produção } \\
\text { correta } \\
\text { Com } \\
\text { distorção }\end{array}$ & 89 & $\begin{array}{r}98,9 \% \\
1,1 \%\end{array}$ & 89 & $98,9 \%$ & 7 & $100,0 \%$ & 185 & $\begin{array}{r}98,9 \% \\
1,1 \%\end{array}$ \\
\hline & Total & 90 & $100,0 \%$ & 90 & $100,0 \%$ & 7 & $100,0 \%$ & 187 & $100,0 \%$ \\
\hline
\end{tabular}


Tabela 11. Comparação entre a ocorrência de distorção e produção correta nas provas de imitação e nomeação e fala espontânea para [l] - GSTF.

\begin{tabular}{cccccccccc}
\hline & \multicolumn{9}{c}{ Provas } \\
\hline & \multicolumn{1}{c}{ Imitação } & \multicolumn{2}{c}{ Nomeação } & \multicolumn{2}{c}{ Fala } \\
espontânea & \multicolumn{2}{c}{ Total } \\
\hline & $\mathrm{N}$ & $\%$ & $\mathrm{~N}$ & $\%$ & $\mathrm{~N}$ & $\%$ & $\mathrm{~N}$ & $\%$ \\
\cline { 2 - 12 } & $\begin{array}{c}\text { Produção } \\
\text { correta } \\
\text { Com }\end{array}$ & 238 & $99,2 \%$ & 236 & $98,3 \%$ & 7 & $100,0 \%$ & 481 & $98,8 \%$ \\
distorção & 2 & $0,8 \%$ & 4 & $1,7 \%$ & 0 & $0,0 \%$ & 6 & $1,2 \%$ \\
\hline Total & 240 & $100,0 \%$ & 240 & $100,0 \%$ & 7 & $100,0 \%$ & 487 & $100,0 \%$ \\
\hline
\end{tabular}

A partir desses dados o GSTF foi subdivido em GSTFSD e GSTFCD. No GSTF, sete crianças $(23,3 \%)$ apresentaram distorção de fala, como pode ser observado na Figura 9. Essas crianças constituíram o subgrupo GSTFCD.

A descrição dos sete sujeitos do GSTFCD quanto à idade e ao gênero encontra-se na Tabela 12.

Figura 9. Presença de distorção de fala nos sujeitos do GSTF.

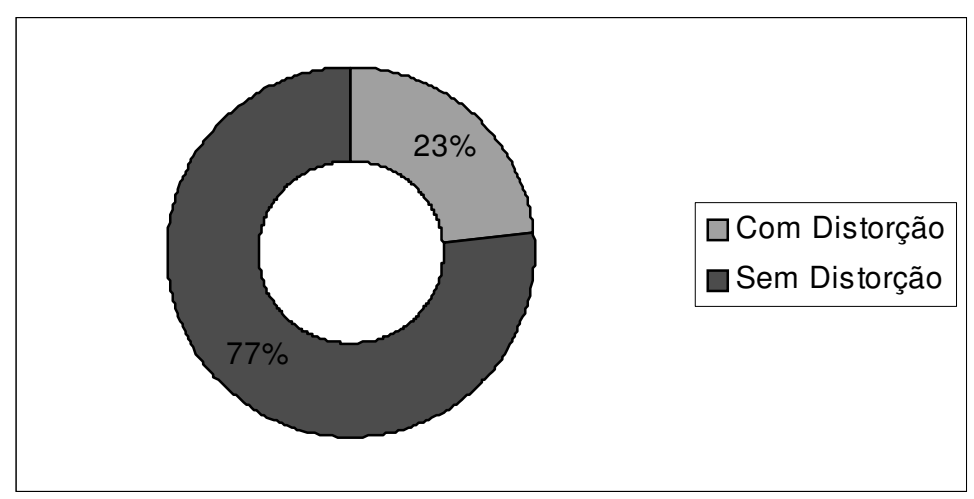

Tabela 12. Descrição do GSTFCD: idade e gênero.

\begin{tabular}{cc}
\hline GÊNERO & IDADE \\
\hline F & $5: 03$ \\
M & $5: 09$ \\
M & $6: 02$ \\
F & $7: 00$ \\
M & $7: 05$ \\
F & $7: 07$ \\
F & $7: 11$ \\
\hline
\end{tabular}


No GSTFCD a faixa etária que mais apresentou distorção independente da prova foi a faixa de sete anos (57,1\%), seguida por cinco anos $(28,6 \%)$ e seis anos (14,3\%) (Figura 10). O gênero que mais apresentou distorção no GSTFCD foi o feminino (57\%) (Figura 11).

Figura 10. Distribuição por faixa etária dos sujeitos do GSTFCD.

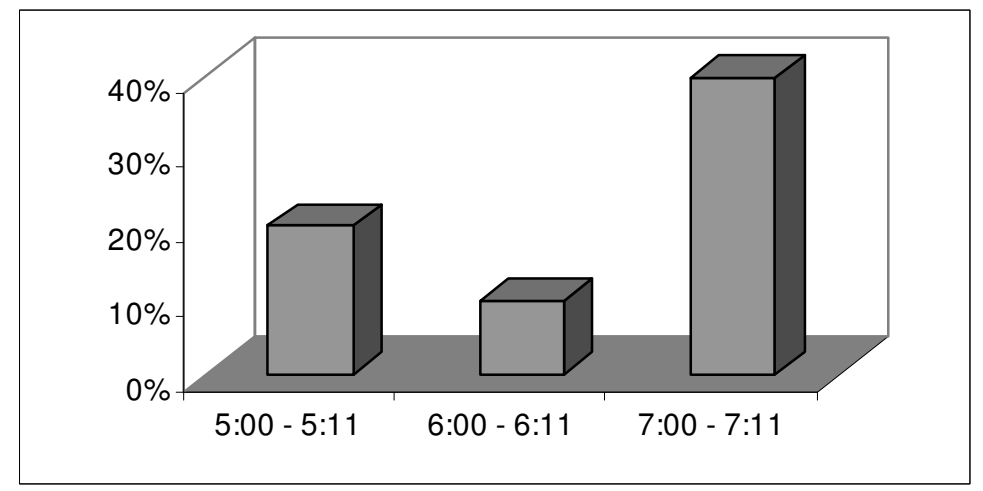

Figura 11. Distribuição por gênero dos sujeitos do GSTFCD.

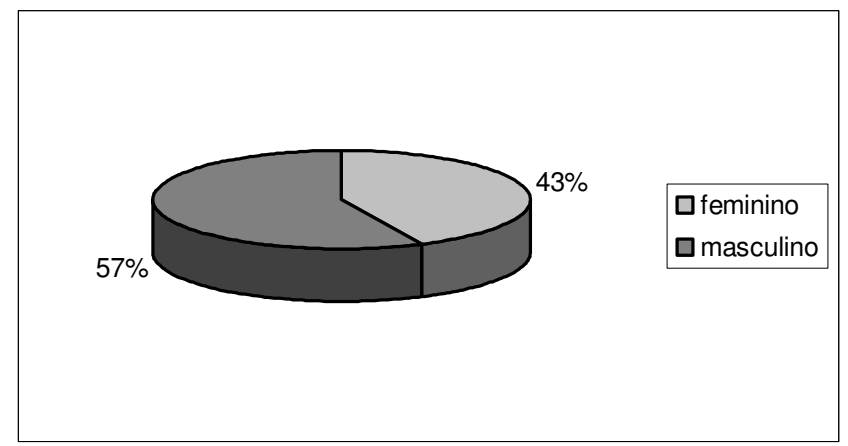

Em relação ao número de sujeitos do GSTFCD que apresentaram distorção nas provas de nomeação, imitação e fala espontânea, independente do número de produções distorcidas, pode ser observado na Tabela 13 que as provas de nomeação e imitação foram as provas que apresentaram maior número de sujeitos que realizaram distorção de fala, enquanto a fala espontânea foi a prova em que menos sujeitos realizaram produção com distorção.

Como pode ser verificado apenas o som [s] foi produzido com distorção nas três provas, enquanto para os demais somente ocorreram distorções nas provas de imitação e nomeação. 
Tabela 13. Número de sujeitos do GSTFCD que apresentaram distorção - sons e provas.

\begin{tabular}{cccccccc}
\hline PROVAS/SONS & {$[\mathbf{s}]$} & {$[\mathbf{z}]$} & {$[\mathbf{[}]$} & {$[3]$} & {$[\mathbf{l}]$} & {$[\mathbf{r}]$} & {$[\mathbf{K}]$} \\
\hline NOMEAÇ्̃̃O & 7 & 5 & 1 & 0 & 1 & 0 & 0 \\
IMITAÇÃO & 7 & 4 & 1 & 0 & 2 & 0 & 0 \\
FALA ESPONTÂNEA & 5 & 0 & 0 & 0 & 0 & 0 & 0 \\
\hline
\end{tabular}

\section{Grupo Com Transtorno Fonológico}

No GFT os sujeitos apresentaram distorção nas provas de nomeação, imitação e fala espontânea nos sons $[\mathrm{s}],[\mathrm{z}]$ e $[r]$.

O Anexo 10 indica a proporção de distorção nos [s], [z] e [r] nas provas de nomeação, imitação e fala espontânea em todos os sujeitos do GTF.

Para cada uma das três provas (nomeação, imitação e fala espontânea) foi calculada separadamente a porcentagem de ocorrência de distorção destes sons. A porcentagem de distorção em cada um nos sons $[\mathrm{s}],[\mathrm{z}]$ e $[\ulcorner]$ nas provas de nomeação, imitação e fala espontânea no GTF pode ser observada na Tabela 14.

Tabela 14. Porcentagem de distorção nos sons [s], [z] e [r] nas provas de nomeação, imitação e fala espontânea no GTF.

\begin{tabular}{cccc}
\hline PROVAS & {$[\mathbf{s}]$} & {$[\mathbf{z}]$} & {$[\ulcorner]$} \\
\hline IMITAÇÃ̃O & $7,1 \%$ & $10 \%$ & $0 \%$ \\
NOMEAÇÃA & $7,4 \%$ & $6,6 \%$ & $1 \%$ \\
FALA ESPONTÂNEA & $14,6 \%$ & $0 \%$ & $0 \%$ \\
\hline
\end{tabular}

Na Tabela 15 podem ser observados os números de sujeitos do GTF1, GTF2 e GTF3 que apresentaram distorção nos sons $[\mathrm{s}],[\mathrm{z}]$ e $[\ulcorner]$ independentemente da prova. Observa-se que nenhum sujeito na faixa etária de seis anos apresentou distorção. 
Tabela 15. Número de sujeitos que apresentaram distorção no [s], [z] e [r] - GTF1, GTF2, GTF3.

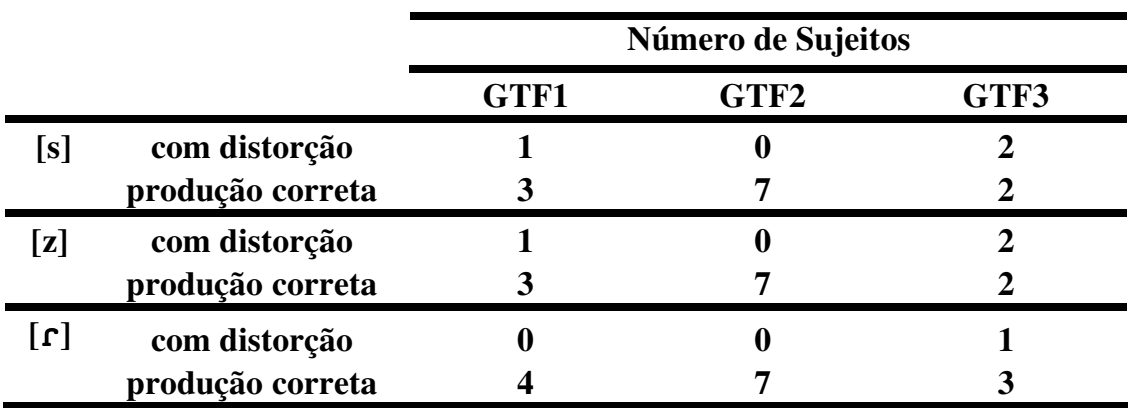

Legenda: GTF1 - Grupo com transtorno fonológico na faixa etária de cinco anos, GTF2 - Grupo com transtorno fonológico na faixa etária de seis anos, GTF3 - Grupo com transtorno fonológico na faixa etária de sete anos.

A Tabela 16 demonstra quais sons foram produzidos com distorção no GTF1, GTF2 e GTF3.

Tabela 16. Sons distorcidos - GTF1, GTF2 e GTF3.

\begin{tabular}{cc}
\hline GRUPOS & SONS DISTORCIDOS \\
\hline GTF1 & {$[\mathrm{s}],[\mathrm{z}]$} \\
GTF2 & Nenhum som foi distorcido \\
GTF3 & {$[\mathrm{s}],[\mathrm{z}],[r]$} \\
\hline
\end{tabular}

Legenda: GTF1 - Grupo com transtorno fonológico na faixa etária de cinco anos, GTF2 - Grupo com transtorno fonológico na faixa etária de seis anos, GTF3 - Grupo com transtorno fonológico na faixa etária de sete anos.

A comparação entre os grupos das faixas etárias de cinco, seis e sete anos nas provas de imitação e nomeação e fala espontânea para os sons [s] e [z] no GTF, quanto à presença de distorção e produção correta pode ser observada na Tabela 17. Para tal comparação foi aplicado o teste de qui-quadrado (n.sig.0,05). No entanto, não foi aplicável em todos os casos, devido a baixo emprego de distorções e produções corretas, mas há indícios de maior ocorrência de distorção do som [s] na faixa etária de sete anos em todas as provas. 
Tabela 17. Comparação da ocorrência de distorção e produção correta entre as provas de imitação e nomeação e fala espontânea para os sons [s] e [z] no GTF.

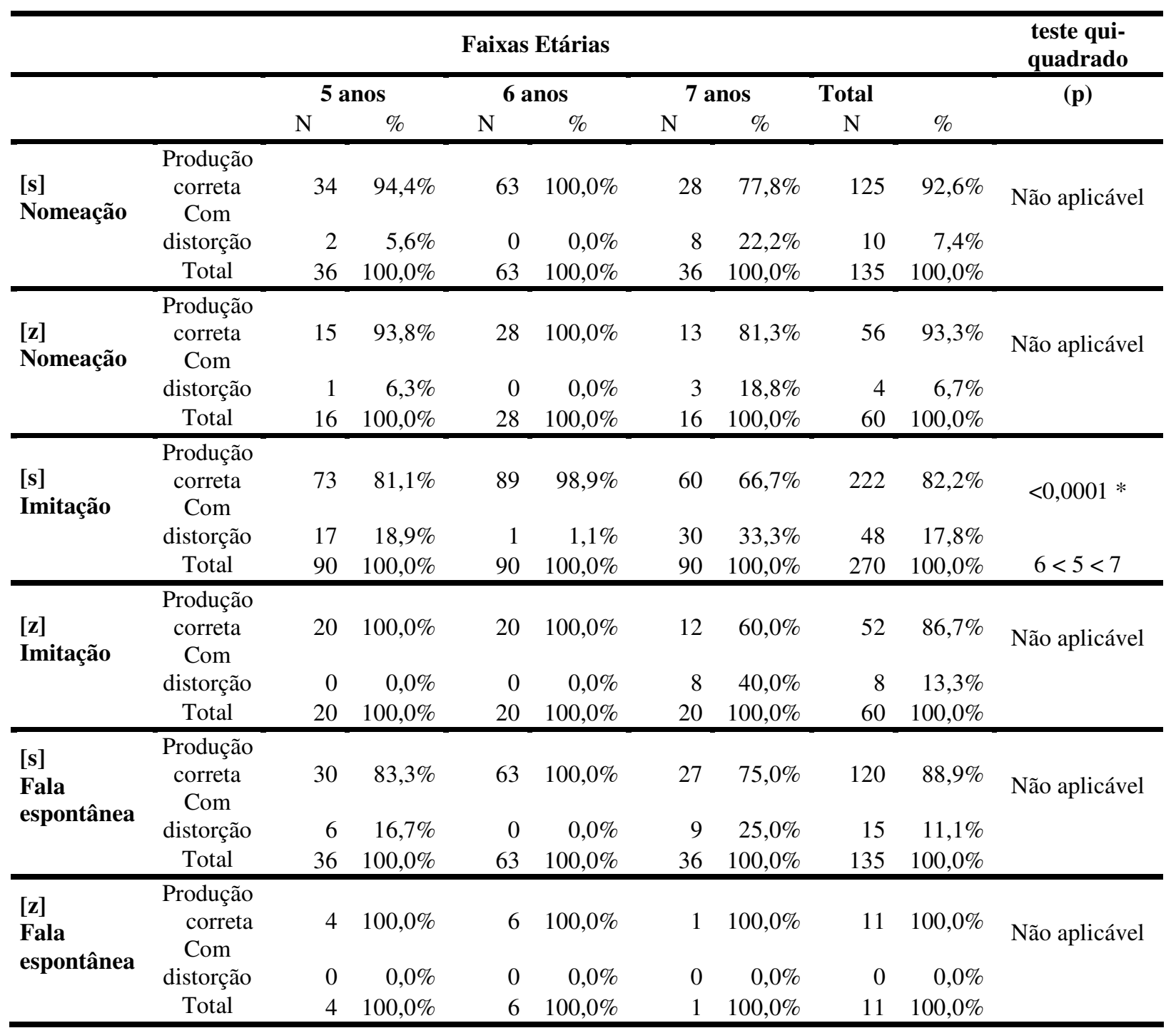

As Tabelas 18, 19 e 20 permitem observar a comparação entre as provas quanto ao número de ocorrências com distorção e produção correta nos sons $[\mathrm{s}],[\mathrm{z}]$ e $[\ulcorner]$ no GTF. Para avaliar essas comparações foi aplicado o teste de qui-quadrado com nível de significância de 5\%. Não houve diferença significante na distribuição do som [s] entre as provas de nomeação, imitação e fala espontânea no GTF. Para os sons [z] e [ᄃ] não foi possível aplicar o teste, mas não há indícios de diferenças entre as provas. 
Tabela 18. Comparação de ocorrência de distorção e produção correta nas provas de imitação e nomeação e fala espontânea para [s] - GTF.

\begin{tabular}{|c|c|c|c|c|c|c|c|c|c|}
\hline \multicolumn{10}{|c|}{ Provas } \\
\hline & & \multicolumn{2}{|c|}{ Imitação } & \multicolumn{2}{|c|}{ Nomeação } & \multicolumn{2}{|c|}{$\begin{array}{c}\text { Fala } \\
\text { espontânea }\end{array}$} & \multicolumn{2}{|c|}{ Total } \\
\hline \multirow{4}{*}{ [s] } & & $\mathrm{N}$ & $\%$ & $\mathrm{~N}$ & $\%$ & $\mathrm{~N}$ & $\%$ & $\mathrm{~N}$ & $\%$ \\
\hline & $\begin{array}{c}\text { Produção } \\
\text { correta } \\
\text { Com }\end{array}$ & 120 & $88,9 \%$ & 125 & $92,6 \%$ & 35 & $85,4 \%$ & 280 & $90,0 \%$ \\
\hline & distorção & 15 & $11,1 \%$ & 10 & $7,4 \%$ & 6 & $14,6 \%$ & 31 & $10,0 \%$ \\
\hline & Total & 135 & $100,0 \%$ & 135 & $100,0 \%$ & 41 & $100,0 \%$ & 311 & $100,0 \%$ \\
\hline
\end{tabular}

Teste de qui-quadrado $(\mathrm{p})=0,337$

Tabela 19. Comparação de ocorrência de distorção e produção correta entre as provas de imitação e nomeação e fala espontânea para [z] - GTF.

\begin{tabular}{|c|c|c|c|c|c|c|c|c|c|}
\hline \multicolumn{10}{|c|}{ Provas } \\
\hline & & \multicolumn{2}{|c|}{ Imitação } & \multicolumn{2}{|c|}{ Nomeação } & \multicolumn{2}{|c|}{$\begin{array}{c}\text { Fala } \\
\text { espontânea }\end{array}$} & \multicolumn{2}{|c|}{ Total } \\
\hline \multirow{4}{*}[\mathbf{z}]{} & & $\mathrm{N}$ & $\%$ & $\mathrm{~N}$ & $\%$ & $\mathrm{~N}$ & $\%$ & $\mathrm{~N}$ & $\%$ \\
\hline & $\begin{array}{c}\text { Produção } \\
\text { correta } \\
\text { Com }\end{array}$ & 27 & $90,0 \%$ & 56 & $93,3 \%$ & 11 & $100,0 \%$ & 94 & $93,1 \%$ \\
\hline & distorção & 3 & $10,0 \%$ & 4 & $6,7 \%$ & 0 & $0,0 \%$ & 7 & $6,9 \%$ \\
\hline & Total & 30 & $100,0 \%$ & 60 & $100,0 \%$ & 11 & $100,0 \%$ & 101 & $100,0 \%$ \\
\hline
\end{tabular}

Tabela 20. Comparação de ocorrência de distorção e produção correta entre as provas de imitação e nomeação e fala espontânea para [r] - GTF.

\begin{tabular}{|c|c|c|c|c|c|c|c|c|c|}
\hline \multicolumn{10}{|c|}{ Provas } \\
\hline & & \multicolumn{2}{|c|}{ Imitação } & \multicolumn{2}{|c|}{ Nomeação } & \multicolumn{2}{|c|}{$\begin{array}{c}\text { Fala } \\
\text { espontânea }\end{array}$} & \multicolumn{2}{|c|}{ Total } \\
\hline & & $\mathrm{N}$ & $\%$ & $\mathrm{~N}$ & $\%$ & $\mathrm{~N}$ & $\%$ & $\mathrm{~N}$ & $\%$ \\
\hline [r] & $\begin{array}{c}\text { Produção } \\
\text { correta } \\
\text { Com } \\
\text { distorção }\end{array}$ & 195 & $\begin{array}{r}100,0 \% \\
0,0 \% \\
\end{array}$ & 208 & $99,0 \%$ & 31 & $100,0 \%$ & 434 & $\begin{array}{r}99,5 \% \\
0,5 \% \\
\end{array}$ \\
\hline & Total & 195 & $100,0 \%$ & 210 & $100,0 \%$ & 31 & $100,0 \%$ & 436 & $100,0 \%$ \\
\hline
\end{tabular}

O GTF foi subdivido em GTFSD e GTFCD, abaixo segue a descrição do subgrupo com distorção, ou seja, do GTFCD. 
No GTF, das 15 crianças estudadas, três (20\%) apresentaram distorção de fala, como pode ser observado na Figura 12. Essas crianças constituíram o subgrupo GTFCD.

Figura 12. Presença de distorção de fala nos sujeitos do GTF.

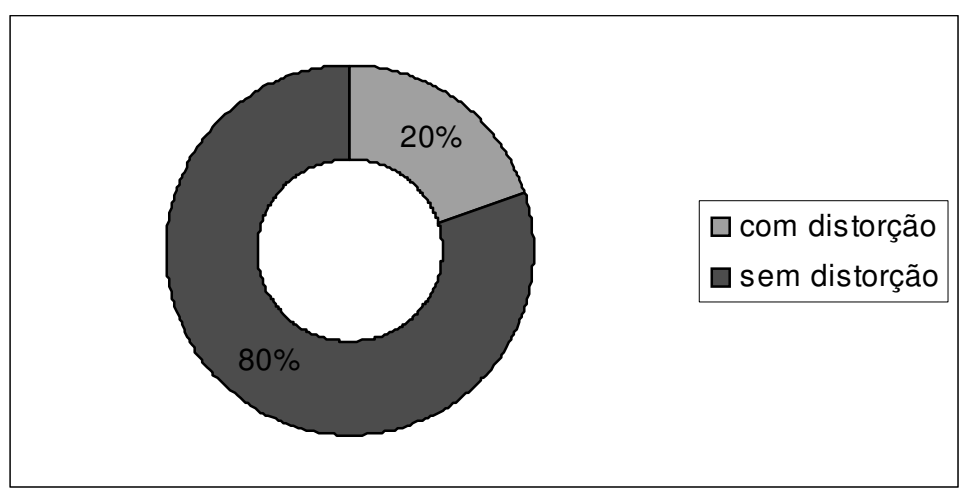

A Tabela 21 apresenta a descrição da idade e do gênero dos sujeitos que formaram o GTFCD.

Tabela 21. Descrição do GTFCD: idade e gênero.

\begin{tabular}{cc}
\hline GÊNERO & IDADE \\
\hline M & $5: 11$ \\
F & $7: 02$ \\
M & $7: 09$ \\
\hline
\end{tabular}

A faixa etária que mais apresentou distorção no GTFCD foi de sete anos $(66,6 \%)$, seguida por cinco anos $(33,3 \%)$, nenhum sujeito com seis anos apresentou distorção de fala, podendo ser observado na Figura 13. 
Figura 13. Distribuição por faixa etária dos sujeitos do GTFCD.

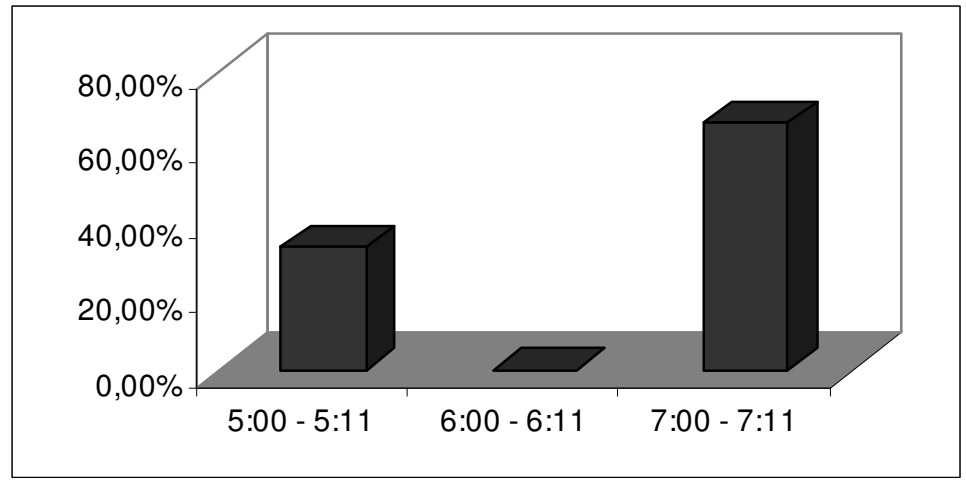

O gênero que mais apresentou distorção foi o masculino (67\%), como observado na Figura 14.

Figura 14. Distribuição por gênero dos sujeitos do GTFCD.

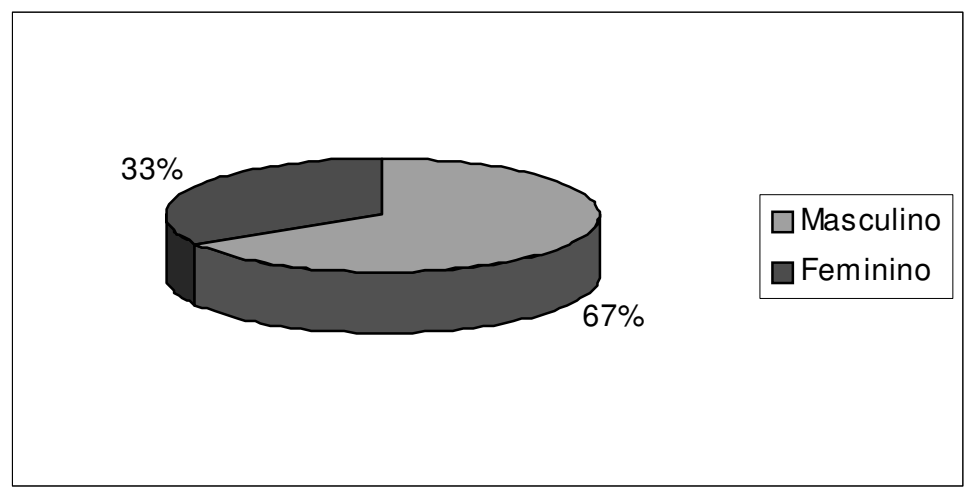

Em relação ao número de sujeitos do GTFCD que apresentaram distorção nas provas de nomeação, imitação e fala espontânea, independente do número de produções distorcidas, pode ser observado na Tabela 22 que a prova de nomeação foi a com maior número de sujeitos com distorção de fala, seguida da imitação e da fala espontânea. Todos os sujeitos do GTFCD apresentaram distorção no som [s] nas provas de nomeação, imitação e fala espontânea.

O som [s] foi o som no qual o maior número de sujeitos apresentou distorção, seguido do som [z], sendo que ambos ocorreram nas provas de nomeação e imitação. Por fim o som [r] foi o que teve menor número de sujeitos com presença de distorção, ocorrendo distorção apenas na prova de nomeação. 
Tabela 22. Número de sujeitos do GTFCD que apresentaram distorção - sons e provas

\begin{tabular}{cccccccc}
\hline PROVAS/SONS & {$[\mathbf{s}]$} & {$[\mathbf{z}]$} & {$[\mathbf{S}]$} & {$[3]$} & {$[\mathbf{l}]$} & {$[\mathbf{r}]$} & {$[\mathbf{K}]$} \\
\hline NOMEAÇÃO & 3 & 2 & 0 & 0 & 0 & 1 & 0 \\
IMITAÇÃO & 3 & 2 & 0 & 0 & 0 & 0 & 0 \\
FALA ESPONTÂNEA & 3 & 0 & 0 & 0 & 0 & 0 & 0 \\
\hline
\end{tabular}

Comparação entre a presença de distorção no GSTF e GTF.

Para verificar a distribuição de distorções dos sons entre os grupos, aplicou-se o teste de qui-quadrado com nível de significância de 5\% (MAXWELL e SATAKE, 1997). Não houve evidências de diferença significante entre o número de sujeitos que apresentaram distorção nos grupos de estudo GSTF e GTF, independente da faixa etária e da prova, como observado na Tabela 23.

Tabela 23. Comparação do número de sujeitos com e produção correta no GSTF e GTF.

\begin{tabular}{ccc}
\hline DISTORÇÃO & GSTF & GTF \\
\hline SIM & 7 & 3 \\
NÃO & 23 & 12 \\
TOTAL & 30 & 15 \\
\hline
\end{tabular}

Teste de qui-quadrado $(\mathrm{p})=1,000$

Legenda: GSTF - Grupo sem transtorno fonológico, GTF - Grupo com transtorno fonológico.

Os sons mais distorcidos em ambos os grupos foram [s] e [z]. Como as ocorrências de distorções foram baixas não foi possível aplicar teste estatístico para verificar a diferença entre os sons.

No Anexo 12 pode ser observada a proporção de distorções de fala nos sons [s], [z], [S], [1] e [r] nas faixas etárias de cinco, seis e sete anos no GTF e GSTF.

Nas Tabelas 24, 25 e 26 observam-se as comparações da ocorrência de distorção e produção correta entre os grupos GSTF e GTF nas provas de imitação e nomeação e fala espontânea no som [s], nas faixas etárias de cinco, seis e sete anos pelo teste de qui-quadrado ou teste de Fisher conforme a necessidade (n. sig. 0,05). Houve diferença significante apenas nas provas de imitação e fala espontânea na faixa etária de sete anos, no sentido de maior ocorrência de distorção do [s] no grupo GTF. 
Tabela 24. Comparação da ocorrência de distorção e produção correta entre os grupos GSTF e GTF nas provas de nomeação, imitação e fala espontânea nas faixas etária de cinco anos - [s].

\begin{tabular}{|c|c|c|c|c|c|c|c|c|}
\hline & & \multirow{2}{*}{$\frac{\text { GSTF }}{\mathbf{N}}$} & \multirow{2}{*}{$\begin{array}{c}\text { GTF } \\
\%\end{array}$} & \multirow{2}{*}{$\frac{\text { GSTF }}{\mathbf{N}}$} & \multirow{2}{*}{ GTF } & \multicolumn{2}{|c|}{ TOTAL } & \multirow{2}{*}{$\begin{array}{l}\text { Teste qui-quadrado ou Fisher } \\
(\text { p) }\end{array}$} \\
\hline & & & & & & $\mathbf{N}$ & $\%$ & \\
\hline \multirow[t]{3}{*}{ Nomeação } & $\begin{array}{c}\text { Produção } \\
\text { correta } \\
\text { Com }\end{array}$ & 73 & $81,1 \%$ & 34 & $94,4 \%$ & 107 & $84,9 \%$ & \multirow[t]{3}{*}{0,1066} \\
\hline & distorção & 17 & $18,9 \%$ & 2 & $5,6 \%$ & 19 & $15,1 \%$ & \\
\hline & Total & 90 & $100,0 \%$ & 36 & $100,0 \%$ & 126 & $100,0 \%$ & \\
\hline \multirow[t]{3}{*}{ Imitação } & Produção & 73 & $81,1 \%$ & 30 & $83,3 \%$ & 103 & $81,7 \%$ & \multirow[t]{3}{*}{0,9709} \\
\hline & distorção & 17 & $18,9 \%$ & 6 & $16,7 \%$ & 23 & $18,3 \%$ & \\
\hline & Total & 90 & $100,0 \%$ & 36 & $100,0 \%$ & 126 & $100,0 \%$ & \\
\hline \multirow[t]{3}{*}{$\begin{array}{l}\text { Fala } \\
\text { Espontânea }\end{array}$} & $\begin{array}{c}\text { Produção } \\
\text { correta } \\
\text { Com }\end{array}$ & 13 & $76,5 \%$ & 10 & $90,9 \%$ & 23 & $82,1 \%$ & \multirow[t]{3}{*}{0,6587} \\
\hline & distorção & 4 & $23,5 \%$ & 1 & $9,1 \%$ & 5 & $17,9 \%$ & \\
\hline & Total & 17 & $100,0 \%$ & 11 & $100,0 \%$ & 28 & $100,0 \%$ & \\
\hline
\end{tabular}

Legenda: GTF - grupo com transtorno fonológico, GSTF - grupo sem transtorno fonológico.

Tabela 25. Comparação da ocorrência de distorção e produção correta entre os grupos GSTF e GTF nas provas de nomeação, imitação e fala espontânea nas faixas etária de seis anos - [s].

\begin{tabular}{|c|c|c|c|c|c|c|c|c|}
\hline & & \multirow{2}{*}{$\begin{array}{c}\text { GSTF } \\
\mathbf{N}\end{array}$} & \multirow{2}{*}{$\begin{array}{c}\text { GTF } \\
\%\end{array}$} & \multirow{2}{*}{$\frac{\text { GSTF }}{\mathrm{N}}$} & \multirow{2}{*}{$\begin{array}{c}\text { GTF } \\
\%\end{array}$} & \multicolumn{2}{|c|}{ TOTAL } & \multirow{2}{*}{$\begin{array}{c}\text { Teste qui-quadrado ou } \\
\text { Fisher } \\
\text { (p) }\end{array}$} \\
\hline & & & & & & $\mathbf{N}$ & $\%$ & \\
\hline \multirow[t]{3}{*}{ Nomeação } & $\begin{array}{l}\text { Produção } \\
\text { correta }\end{array}$ & 89 & $98,9 \%$ & 63 & $100,0 \%$ & 152 & $99,3 \%$ & \multirow[t]{3}{*}{1,0000} \\
\hline & distorção & 1 & $1,1 \%$ & 0 & $0,0 \%$ & 1 & $0,7 \%$ & \\
\hline & Total & 90 & $100,0 \%$ & 63 & $100,0 \%$ & 153 & $100,0 \%$ & \\
\hline \multirow[t]{3}{*}{ Imitação } & $\begin{array}{l}\text { Produção } \\
\text { correta }\end{array}$ & 89 & $98,9 \%$ & 63 & $100,0 \%$ & 152 & $99,3 \%$ & \multirow[t]{3}{*}{1,0000} \\
\hline & distorção & 1 & $1,1 \%$ & 0 & $0,0 \%$ & 1 & $0,7 \%$ & \\
\hline & Total & 90 & $100,0 \%$ & 63 & $100,0 \%$ & 153 & $100,0 \%$ & \\
\hline \multirow{3}{*}{$\begin{array}{l}\text { Fala } \\
\text { Espontânea }\end{array}$} & $\begin{array}{l}\text { Produção } \\
\text { correta }\end{array}$ & 24 & $100,0 \%$ & 17 & $100,0 \%$ & 41 & $100,0 \%$ & \multirow[t]{3}{*}{1,0000} \\
\hline & $\begin{array}{l}\text { Com } \\
\text { distorção }\end{array}$ & 0 & $0,0 \%$ & 0 & $0,0 \%$ & 0 & $0,0 \%$ & \\
\hline & Total & 24 & $100,0 \%$ & 17 & $100,0 \%$ & 41 & $100,0 \%$ & \\
\hline
\end{tabular}

Legenda: GTF - grupo com transtorno fonológico, GSTF - grupo sem transtorno fonológico. 
Tabela 26. Comparação da ocorrência de distorção e produção correta entre os grupos GSTF e GTF nas provas de nomeação, imitação e fala espontânea nas faixas etária de sete anos - [s].

\begin{tabular}{|c|c|c|c|c|c|c|c|c|}
\hline & & \multirow{2}{*}{$\begin{array}{c}\text { GSTF } \\
\mathbf{N}\end{array}$} & \multirow{2}{*}{$\begin{array}{c}\text { GTF } \\
\%\end{array}$} & \multirow{2}{*}{$\begin{array}{c}\text { GSTF } \\
\mathbf{N}\end{array}$} & \multirow{2}{*}{$\begin{array}{c}\text { GTF } \\
\%\end{array}$} & \multicolumn{2}{|c|}{ TOTAL } & \multirow{2}{*}{$\begin{array}{l}\text { Teste qui-quadrado ou } \\
\text { Fisher } \\
\text { (p) }\end{array}$} \\
\hline & & & & & & $\mathbf{N}$ & $\%$ & \\
\hline \multirow{3}{*}{ Nomeação } & $\begin{array}{l}\text { Produção } \\
\text { correta }\end{array}$ & 60 & $66,7 \%$ & 28 & $77,8 \%$ & 88 & $69,8 \%$ & \multirow{3}{*}{0,3111} \\
\hline & $\begin{array}{c}\text { Com } \\
\text { distorção }\end{array}$ & 30 & $33,3 \%$ & 8 & $22,2 \%$ & 38 & $30,2 \%$ & \\
\hline & Total & 90 & $100,0 \%$ & 36 & $100,0 \%$ & 126 & $100,0 \%$ & \\
\hline \multirow[t]{3}{*}{ Imitação } & $\begin{array}{l}\text { Produção } \\
\text { correta }\end{array}$ & 89 & $98,9 \%$ & 27 & $75,0 \%$ & 116 & $92,1 \%$ & \multirow[t]{3}{*}{$<0,0001 *$} \\
\hline & $\begin{array}{c}\text { Com } \\
\text { distorção }\end{array}$ & 1 & $1,1 \%$ & 9 & $25,0 \%$ & 10 & $7,9 \%$ & \\
\hline & Total & 90 & $100,0 \%$ & 36 & $100,0 \%$ & 126 & $100,0 \%$ & \\
\hline \multirow[t]{3}{*}{$\begin{array}{l}\text { Fala } \\
\text { Espontânea }\end{array}$} & $\begin{array}{l}\text { Produção } \\
\text { correta } \\
\text { Com }\end{array}$ & 24 & $100,0 \%$ & 8 & $61,5 \%$ & 32 & $86,5 \%$ & \multirow[t]{3}{*}{$0,0030 *$} \\
\hline & distorção & 0 & $0,0 \%$ & 5 & $38,5 \%$ & 5 & $13,5 \%$ & \\
\hline & Total & 24 & $100,0 \%$ & 13 & $100,0 \%$ & 37 & $100,0 \%$ & \\
\hline
\end{tabular}

Legenda: GTF - grupo com transtorno fonológico, GSTF - grupo sem transtorno fonológico.

Nas Tabelas 27, 28 e 29 verificam-se a ocorrência de distorção e produção correta entre os grupos GSTF e GTF nas provas de imitação e nomeação e fala espontânea no som [z], nas faixas etárias de cinco, seis e sete anos. Para avaliar esses comparativos foi aplicado teste de quiquadrado ou teste de Fisher conforme a necessidade (n. sig. 0,05). Em nenhuma faixa etária houve diferença significante entre as provas. 
Tabela 27. Comparação da ocorrência de distorção e produção correta entre os grupos GSTF e GTF nas provas de nomeação, imitação e fala espontânea na faixa etária de cinco anos para o som $[\mathrm{z}]$.

\begin{tabular}{|c|c|c|c|c|c|c|c|c|}
\hline & & \multirow{2}{*}{$\frac{\text { GSTF }}{\mathrm{N}}$} & \multirow{2}{*}{$\begin{array}{c}\text { GTF } \\
\%\end{array}$} & \multirow{2}{*}{$\frac{\text { GSTF }}{\mathrm{N}}$} & \multirow{2}{*}{$\frac{\text { GTF }}{\%}$} & \multicolumn{2}{|c|}{ TOTAL } & \multirow{2}{*}{$\begin{array}{l}\text { Teste qui-quadrado ou } \\
\text { Fisher } \\
\text { (p) }\end{array}$} \\
\hline & & & & & & $\mathbf{N}$ & $\%$ & \\
\hline \multirow{3}{*}{ Nomeação } & $\begin{array}{l}\text { Produção } \\
\text { correta }\end{array}$ & 37 & $92,5 \%$ & 15 & $93,8 \%$ & 52 & $92,9 \%$ & \multirow[t]{3}{*}{1,0000} \\
\hline & $\begin{array}{c}\text { Com } \\
\text { distorção }\end{array}$ & 3 & $7,5 \%$ & 1 & $6,3 \%$ & 4 & $7,1 \%$ & \\
\hline & Total & 40 & $100,0 \%$ & 16 & $100,0 \%$ & 56 & $100,0 \%$ & \\
\hline \multirow[t]{3}{*}{ Imitação } & $\begin{array}{l}\text { Produção } \\
\text { correta } \\
\text { Com }\end{array}$ & 20 & $100,0 \%$ & 7 & $87,5 \%$ & 27 & $96,4 \%$ & \multirow[t]{3}{*}{0,2857} \\
\hline & distorção & 0 & $0,0 \%$ & 1 & $12,5 \%$ & 1 & $3,6 \%$ & \\
\hline & Total & 20 & $100,0 \%$ & 8 & $100,0 \%$ & 28 & $100,0 \%$ & \\
\hline \multirow{3}{*}{$\begin{array}{l}\text { Fala } \\
\text { Espontânea }\end{array}$} & $\begin{array}{l}\text { Produção } \\
\text { correta }\end{array}$ & 4 & $100,0 \%$ & 4 & $100,0 \%$ & 8 & $100,0 \%$ & \multirow{3}{*}{1,0000} \\
\hline & $\begin{array}{c}\text { Com } \\
\text { distorção }\end{array}$ & 0 & $0,0 \%$ & 0 & $0,0 \%$ & 0 & $0,0 \%$ & \\
\hline & Total & 4 & $100,0 \%$ & 4 & $100,0 \%$ & 8 & $100,0 \%$ & \\
\hline
\end{tabular}

Legenda: GTF - grupo com transtorno fonológico, GSTF - grupo sem transtorno fonológico.

Tabela 28. Comparação da ocorrência de distorção e produção correta entre os grupos GSTF e GTF nas provas de nomeação, imitação e fala espontânea na faixa etária de seis anos para o som [z].

\begin{tabular}{|c|c|c|c|c|c|c|c|c|}
\hline & & \multirow{2}{*}{$\begin{array}{c}\text { GSTF } \\
N\end{array}$} & \multirow{2}{*}{ GTF } & \multirow{2}{*}{$\frac{\text { GSTF }}{\mathrm{N}}$} & \multirow{2}{*}{ GTF } & \multicolumn{2}{|c|}{ TOTAL } & \multirow{2}{*}{$\begin{array}{l}\text { Teste qui-quadrado ou } \\
\text { Fisher } \\
\text { (p) }\end{array}$} \\
\hline & & & & & & $\mathbf{N}$ & $\%$ & \\
\hline \multirow{3}{*}{ Nomeação } & $\begin{array}{l}\text { Produção } \\
\text { correta }\end{array}$ & 40 & $100,0 \%$ & 28 & $100,0 \%$ & 68 & $100,0 \%$ & \multirow{3}{*}{1,0000} \\
\hline & $\begin{array}{c}\text { Com } \\
\text { distorção }\end{array}$ & 0 & $0,0 \%$ & 0 & $0,0 \%$ & 0 & $0,0 \%$ & \\
\hline & Total & 40 & $100,0 \%$ & 28 & $100,0 \%$ & 68 & $100,0 \%$ & \\
\hline \multirow{3}{*}{ Imitação } & $\begin{array}{c}\text { Produção } \\
\text { correta }\end{array}$ & 20 & $100,0 \%$ & 14 & $100,0 \%$ & 34 & $100,0 \%$ & \multirow{3}{*}{1,0000} \\
\hline & $\begin{array}{c}\text { Com } \\
\text { distorção }\end{array}$ & 0 & $0,0 \%$ & 0 & $0,0 \%$ & 0 & $0,0 \%$ & \\
\hline & Total & 20 & $100,0 \%$ & 14 & $100,0 \%$ & 34 & $100,0 \%$ & \\
\hline \multirow{3}{*}{$\begin{array}{l}\text { Fala } \\
\text { Espontânea }\end{array}$} & $\begin{array}{l}\text { Produção } \\
\text { correta }\end{array}$ & 2 & $100,0 \%$ & 6 & $100,0 \%$ & 8 & $100,0 \%$ & \multirow{3}{*}{1,0000} \\
\hline & $\begin{array}{c}\text { Com } \\
\text { distorção }\end{array}$ & 0 & $0,0 \%$ & 0 & $0,0 \%$ & 0 & $0,0 \%$ & \\
\hline & Total & 2 & $100,0 \%$ & 6 & $100,0 \%$ & 8 & $100,0 \%$ & \\
\hline
\end{tabular}

Legenda: GTF - grupo com transtorno fonológico, GSTF - grupo sem transtorno fonológico. 
Tabela 29. Comparação da ocorrência de distorção e produção correta entre os grupos GSTF e GTF nas provas de nomeação, imitação e fala espontânea na faixa etária de sete anos para o som [z].

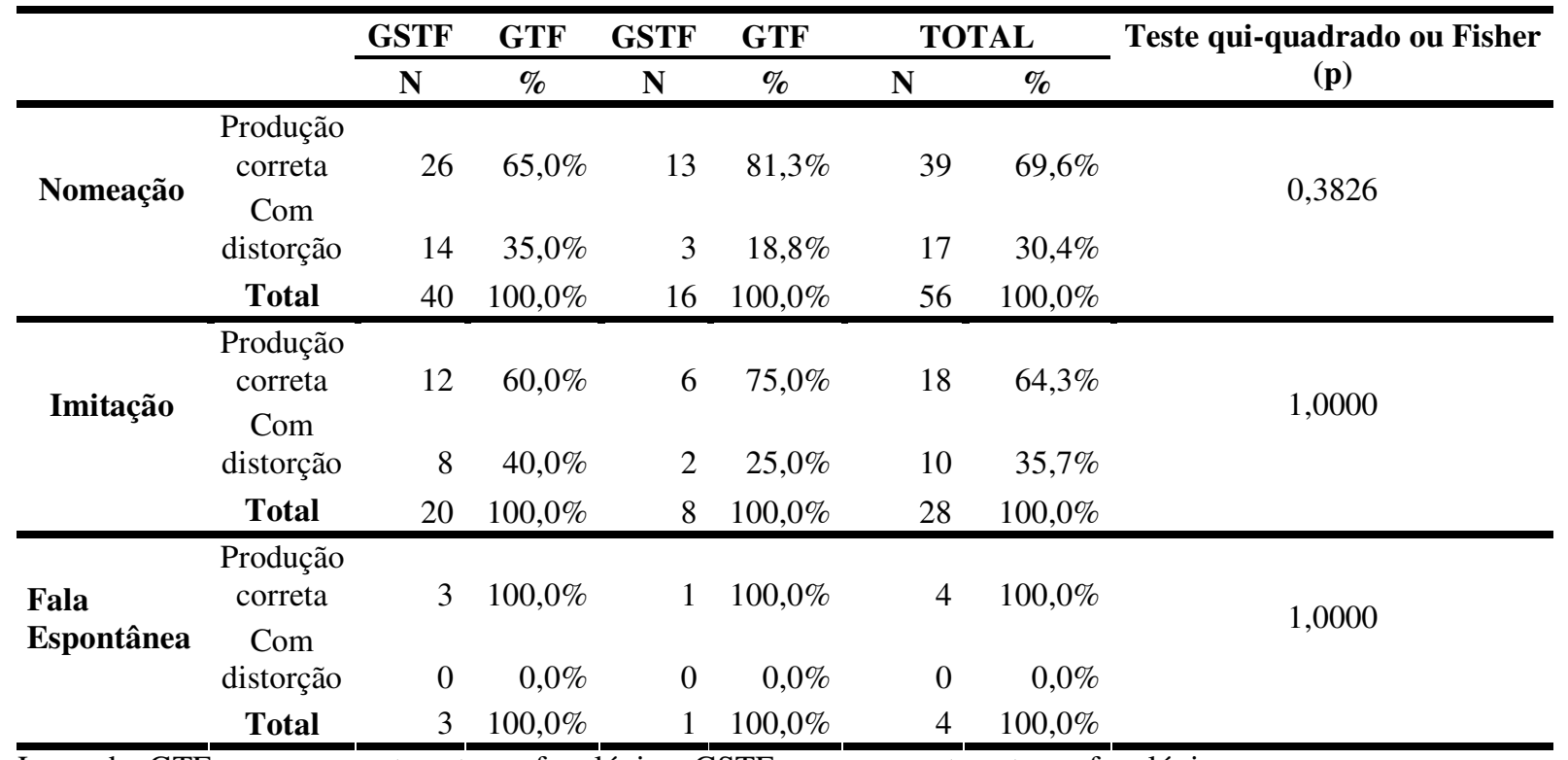

Legenda: GTF - grupo com transtorno fonológico, GSTF - grupo sem transtorno fonológico. 


\section{Descrição das Distorções na Prova Específica para Verificação de Distorção em Sílabas e Palavras}

Grupo Sem Transtorno Fonológico Com Distorção

A Tabela 30 mostra a porcentagem de distorção que cada um dos sujeitos do GSTFCD apresentou na prova específica para verificação de distorção na imitação de sílabas para os sons distorcidos. Em alguns casos a prova de verificação não foi aplicada porque a criança não distorceu o som alvo.

Tabela 30. Ocorrência de distorção do GSTFCD na Prova Específica para Verificação de Distorção - Imitação de Sílabas.

\begin{tabular}{ccccc}
\hline IDADE & {$[\mathbf{s}]$} & {$[\mathbf{z}]$} & {$[\mathbf{S}]$} & {$[\mathbf{l}]$} \\
\hline $5: 3$ & $80,9 \%$ & -- & -- & -- \\
$5: 9$ & $76,1 \%$ & $71,4 \%$ & -- & $76,1 \%$ \\
$6: 2$ & $61,9 \%$ & -- & $76,1 \%$ & -- \\
$7: 0$ & $100 \%$ & $47,6 \%$ & -- & -- \\
$7: 5$ & $100 \%$ & $100 \%$ & -- & -- \\
$7: 7$ & $0 \%$ & $0 \%$ & -- & -- \\
$7: 11$ & $100 \%$ & $76,1 \%$ & -- & $0 \%$ \\
\hline Média & $74,2 \%$ & $59 \%$ & $76,1 \%$ & $38,5 \%$ \\
\hline
\end{tabular}

Legenda: -- - Prova não aplicada

A Tabela 31 mostra a porcentagem de distorção que cada um dos sujeitos do GSTFCD apresentou na prova específica para verificação de distorção na imitação de palavras para os sons distorcidos.

Da mesma maneira que ocorreu na imitação de sílabas, dos sete sujeitos que formaram o GSTFCD, um sujeito, na faixa etária de sete anos, que havia apresentado distorção nos sons [s] e [z] nas provas de imitação e nomeação (WERTZNER, 2004), durante o teste para verificação de distorção não apresentou nenhuma produção distorcida.

Na média de porcentagem de distorção do GSTFCD nesta prova de imitação de palavras, observa-se que independente do número de sujeitos que havia apresentado distorção nas provas de nomeação, imitação e fala espontânea, o [1] foi o som que apresentou maior porcentagem de distorção, seguido pelo [s], [z] e [S]. 
Tabela 31. Porcentagem de distorção do GSTFCD na Prova Específica para Verificação de Distorção - Imitação de Palavras.

\begin{tabular}{ccccc}
\hline IDADE & {$[\mathbf{s}]$} & {$[\mathbf{z}]$} & {$[\mathbf{S}]$} & {$[\mathbf{l}]$} \\
\hline $5: 3$ & $66,6 \%$ & -- & -- & -- \\
$5: 9$ & $83,3 \%$ & $63,6 \%$ & -- & $100 \%$ \\
$6: 2$ & $50 \%$ & -- & $35,7 \%$ & -- \\
$7: 0$ & $72,2 \%$ & $45,4 \%$ & -- & -- \\
$7: 5$ & $100 \%$ & $81,8 \%$ & -- & -- \\
$7: 7$ & $0 \%$ & $0 \%$ & -- & -- \\
$7: 11$ & $100 \%$ & $54,4 \%$ & -- & $58,3 \%$ \\
\hline Média & $67,4 \%$ & $40,8 \%$ & $35,7 \%$ & $79,1 \%$ \\
\hline
\end{tabular}

Legenda: -- - Prova não aplicada

Analisando a média de porcentagem de distorção nas provas de imitação de sílabas e palavras na prova específica para verificação de distorção para o GSTFCD, tem-se que na prova de imitação de sílabas ocorreu mais produção distorcida para os [s], [z] e [S].

O [1] foi o único som em que a média de porcentagem de distorção foi maior na prova de imitação de palavras do que sílabas. Este fato deve-se a um sujeito na faixa etária de sete anos que durante a realização da prova específica em imitação de sílabas não apresentou distorção, mas apresentou na imitação de palavras (Figura 15).

Figura 15. Comparação da média de porcentagem na prova específica para verificação de distorção em sílabas e palavras - GSTFCD.

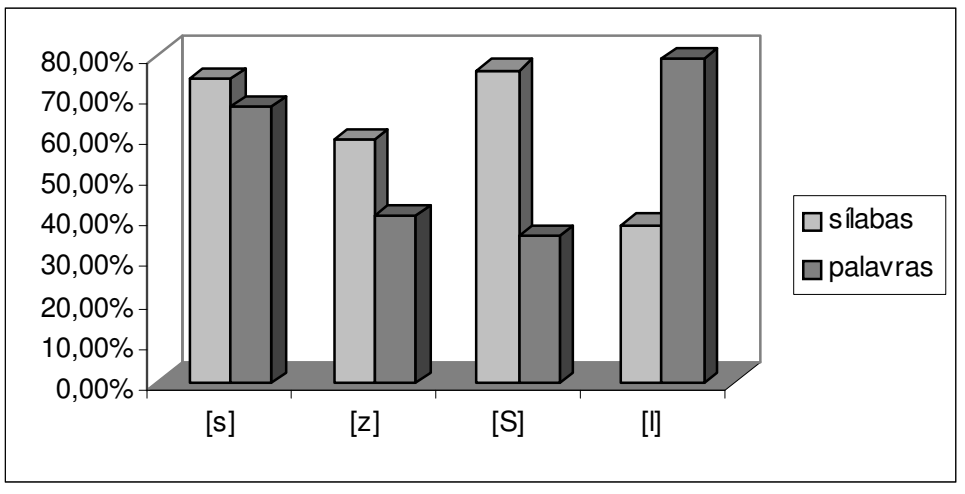

Legenda: $[\mathrm{S}]=\left[\int\right]$.

As Figuras 16 e 17 ilustram a comparação da média de porcentagem na prova específica para verificação de distorção em sílabas e palavras no GSTFCD na faixa etária de cinco, seis e sete anos. 
Figura 16. Comparação da média de porcentagem na prova específica para verificação de distorção em sílabas - GSTFCD na faixa etária de cinco, seis e sete anos.

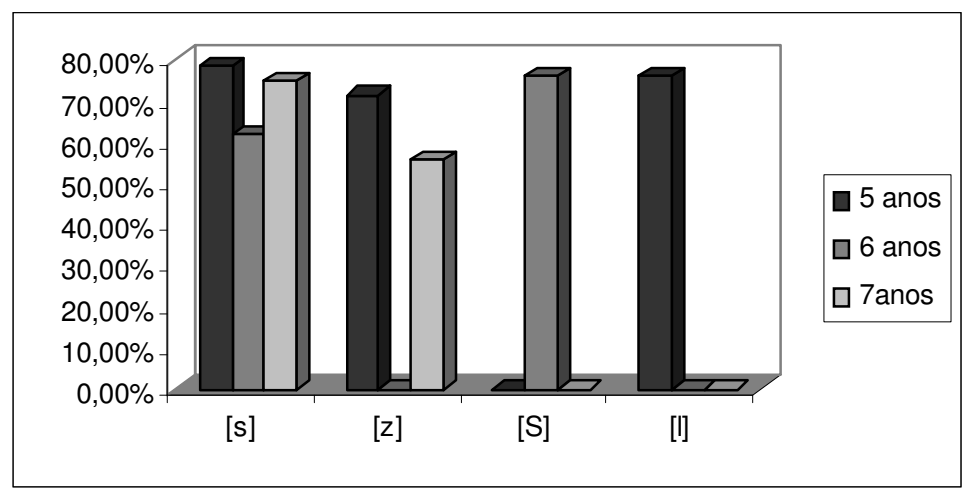

Legenda: $[\mathrm{S}]=\left[\int\right]$.

Figura 17. Comparação da média de porcentagem na prova específica para verificação de distorção em palavras - GSTFCD na faixa etária de cinco, seis e sete anos.

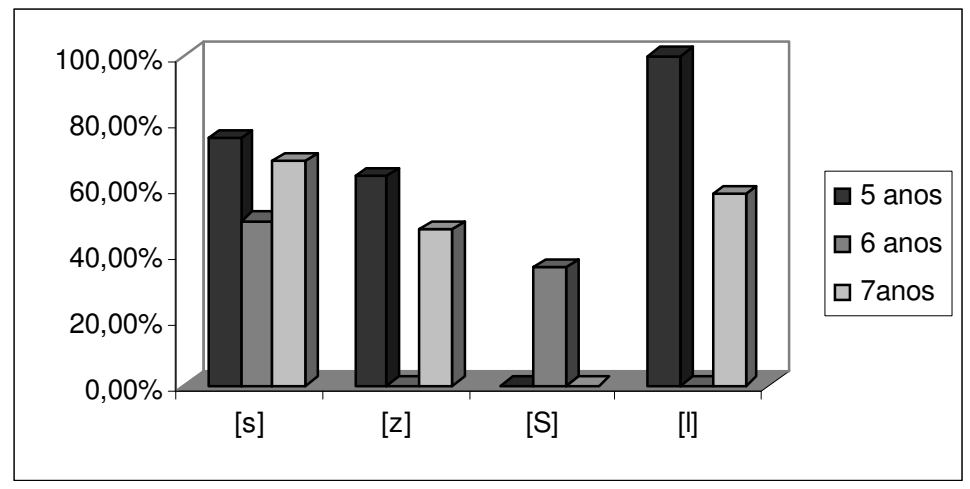

Legenda: $[\mathrm{S}]=\left[\int\right]$.

\section{Grupo Com Transtorno Fonológico Com Distorção}

Dos três sujeitos que formaram o GSTFCD, um sujeito, na faixa etária de cinco anos, que havia apresentado distorção no som [s] nas provas de imitação, nomeação (WERTZNER, 2004) e fala espontânea e no [z] nas provas de imitação, nomeação (WERTZNER, 2004), na prova específica para verificação de distorção tanto em sílabas quanto em palavras não apresentou nenhum tipo de distorção para estes sons, mas realizou $100 \%$ de substituição de ambos os sons para [S]. Além disso, um sujeito na faixa etária de seis anos apresentou duas substituições durante a prova de imitação de sílabas na prova de verificação da distorção do [z] por [3].

A Tabela 32 indica a média da ocorrência de distorção que cada um dos sujeitos do GTFCD apresentou na prova específica para verificação de distorção na imitação de sílabas. 
Nota-se que houve maior porcentagem de distorção para o [r], seguido de [z] e [s]. Deve-se considerar, que a prova de imitação de sílabas para o som [r] foi aplicado para apenas um sujeito.

Tabela 32. Porcentagem de distorção do GTFCD na Prova Específica para Verificação de Distorção - Imitação de Sílabas.

\begin{tabular}{lccc}
\hline \multicolumn{1}{c}{ IDADE } & {$[\mathbf{s}]$} & {$[\mathbf{z}]$} & {$[\mathbf{r}]$} \\
\hline $5: 11$ & $0 \% *$ & $0 \% *$ & -- \\
$7: 2$ & $4,76 \%$ & -- & $100 \%$ \\
$7: 9$ & $71,4 \%$ & $66,6 \% * *$ & -- \\
\hline Média & $25,3 \%$ & $33,3 \%$ & $100 \%$ \\
\hline
\end{tabular}

Legenda: -- Prova não aplicada

* realizou $100 \%$ de substituição por [S]

** realizou duas substituições por [3]

A Tabela 33 indica a média da porcentagem de distorção em que cada um dos sujeitos do GTFCD apresentou na prova específica para verificação de distorção na imitação de palavras. Houve também maior porcentagem de distorção para o [r], seguido de [z] e [s]. Deve-se considerar, que a prova de imitação de palavras para o som [r] foi aplicada para apenas um sujeito.

Tabela 33. Desempenho dos sujeitos do GTFCD na prova de imitação de palavras - porcentagem de distorção.

Legenda: -- Prova não aplicada

\begin{tabular}{lccc}
\hline \multicolumn{1}{c}{ IDADE } & {$[\mathbf{s}]$} & {$[\mathbf{z}]$} & {$[\mathbf{c}]$} \\
\hline $5: 11$ & $0 \% *$ & $0 \% *$ & -- \\
$7: 2$ & $22 \%$ & -- & $100 \%$ \\
$7: 9$ & $72 \%$ & $72,7 \%$ & -- \\
\hline Média & $31,3 \%$ & $36,3 \%$ & $100 \%$ \\
\hline
\end{tabular}

* realizou $100 \%$ de substituição por [S]

Pela média de porcentagem de distorção nas provas de imitação de sílabas e palavras na prova específica para verificação de distorção para o GTFCD, tem-se que a prova de imitação palavras foi a que apresentou maiores porcentagens de distorção para os [s] e [z], enquanto no som [ᄃ] não houve diferenças entre as sílabas e palavras, como demonstrado na Figura 18. 
Figura 18. Comparação da média de porcentagem na prova específica para verificação de distorção em sílabas e palavras - GTFCD.

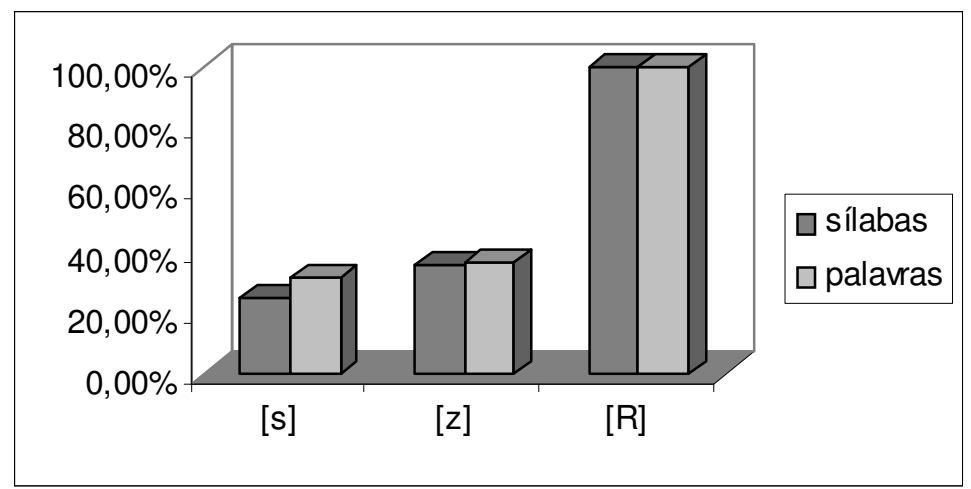

Legenda: $[R]=[\Gamma]$.

Comparação entre a Prova Específica para Verificação da Distorção - GSTFCD e GTFCD

Na Figura 19 verifica-se a comparação das médias de porcentagens dos sons distorcidos na prova para verificação de distorção em sílabas e palavras em sujeitos do GSTFCD e GTFCD.

Figura 19. Comparação das médias dos sons distorcidos na prova para verificação de distorção em sílabas e palavras - GSTFCD e GTFCD.

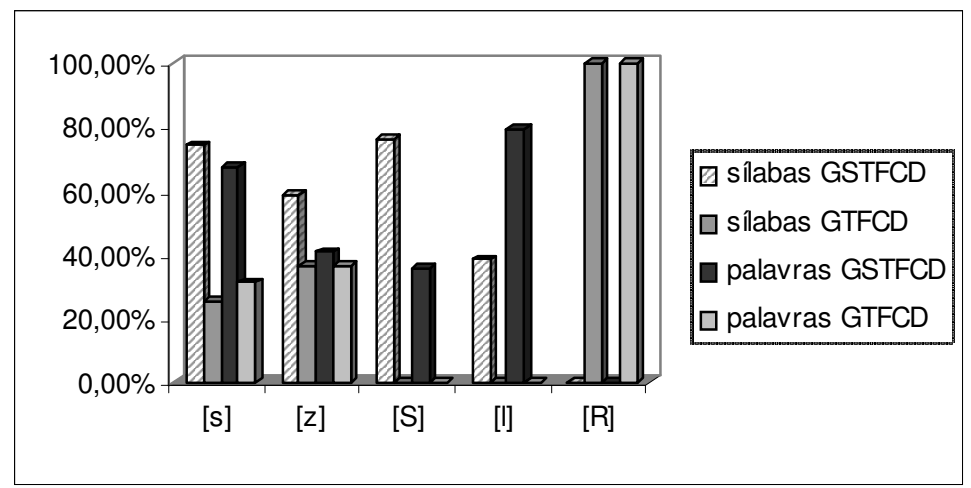

Legenda: GTFSD - grupo com transtorno fonológico sem distorção, GTFCD - grupo com transtorno fonológico com distorção, $[\mathrm{S}]=\left[\int\right],[\mathrm{R}]=[\Gamma]$. 


\section{Classificação Perceptiva das Distorções de Fala na Prova Específica para Verificação de}

Distorções de Sílabas e Palavras

\section{Grupo Sem Transtorno Fonológico Com Distorção}

Todas as distorções encontradas na prova específica para verificação de distorção em imitação de sílabas e palavras foram classificadas auditivamente e/ou visualmente. Em seguida foi feito o cálculo de ocorrência de cada tipo de distorção e divisão pelo número de sílabas ou palavras.

Assim, a Tabela 34 e a Figura 20 indicam a média dos tipos de distorções encontradas em cada um dos sons produzidos pelos sujeitos do GSTFCD na prova específica para verificação de distorção em imitação de sílabas e palavras.

Tabela 34. Média de porcentagem na classificação perceptiva das distorções de fala na prova de imitação de sílabas e palavras - GSTFCD.

\begin{tabular}{cccc|ccc|cc|cc} 
& \multicolumn{4}{c}{$[\mathrm{s}]$} & \multicolumn{4}{c|}{$[\mathrm{z}]$} & \multicolumn{3}{c|}{$[\mathrm{S}]$} & \multicolumn{3}{c}{$[\mathrm{l}]$} \\
\cline { 2 - 13 } & SD\% & PLSD\% & PALCD\% & SD\% & PLSD\% & PALCD\% & SD\% & ECD\% & SD\% & PLSD\% \\
\hline SílABAS & 26,5 & 14,9 & 58,5 & 40 & 34,2 & 15,2 & 23,8 & 76,1 & 59,5 & 40,4 \\
\hline PALAVRAS & 32,5 & 7,9 & 59,5 & 50,9 & 30,8 & 18,1 & 64,2 & 35,7 & 29,1 & 70,8 \\
\hline
\end{tabular}

Legenda: SD - produção correta; PLSD - projeção de língua sem distorção acústica; PALCD - projeção anterior de língua com distorção acústica; ECD - esforço articulatório com distorção acústica, [S] = [S].

Figura 20. Comparação das médias de porcentagem da classificação das distorções em sílabas e palavras da prova específica para verificação de distorção de fala - GSTFCD.

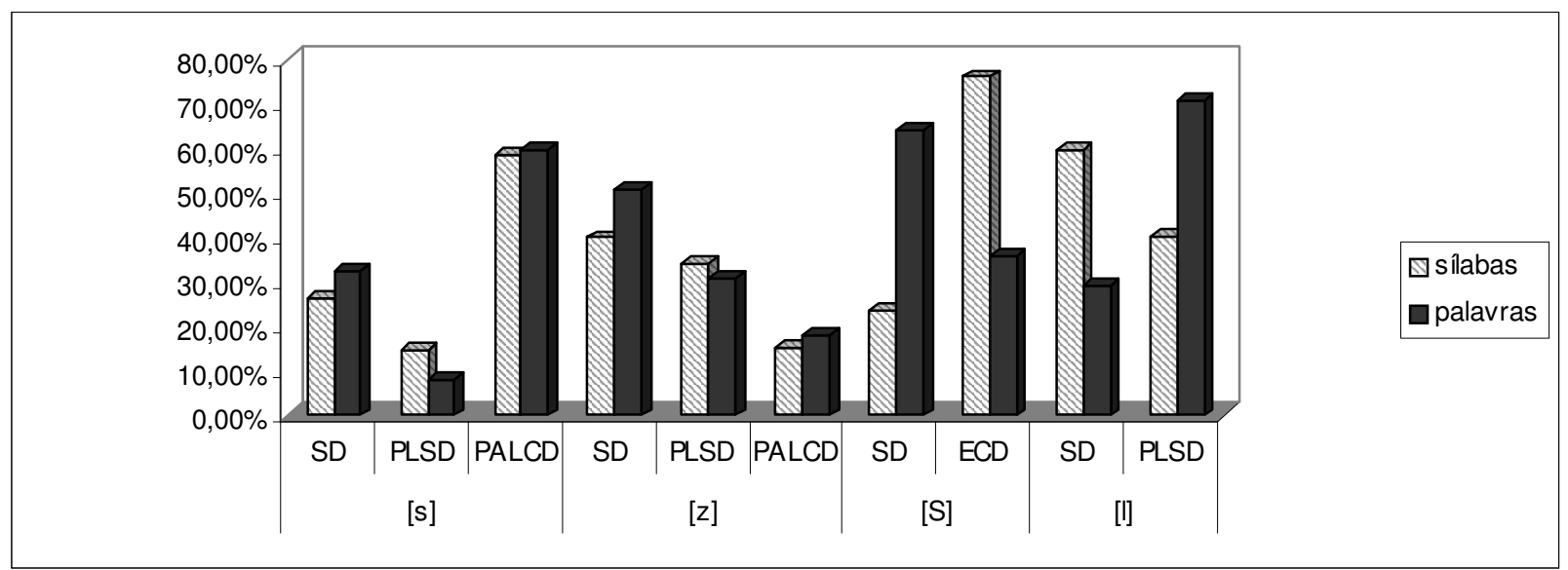

Legenda: SD - produção correta; PLSD - projeção de língua sem distorção acústica; PALCD - projeção anterior de língua com distorção acústica; ECD - esforço articulatório com distorção acústica, [S] = [S]. 
As Tabelas 35 a 37 e a Figura 21 indicam a média de porcentagem da classificação de distorção na prova específica de distorção para imitação de sílabas em cada faixa etária no GSTFCD.

Observa -se que para o som [s] nas três faixas etárias o tipo de distorção que mais ocorre na imitação de sílaba e palavra foi PALCD, sendo que a faixa de seis anos foi a que apresentou maior porcentagem de distorção.

O som [z] foi distorcido apenas na faixa etária de cinco e sete anos, para ambas as faixas o tipo de distorção que mais ocorreu na imitação de sílabas foi PLSD e em palavras PALCD, no entanto para sete anos a porcentagem de produção correta foi superior a produção distorcida.

No [S] que foi distorcido apenas na faixa etária de seis anos foi encontrado tanto em imitação de sílabas quanto de palavras apenas o tipo de distorção ECD.

Por fim, o [1] que foi produzido distorcido nas faixas de cinco e seis anos, teve como único tipo de distorção o PLSD. Na faixa etária de cinco anos a maior porcentagem de sílabas foi produzida produção correta, no entanto, todas as palavras foram produzidas com distorção. $\mathrm{Na}$ faixa de sete anos a maioria das palavras foi produzida corretamente, mas a maior porcentagem das palavras foi produzida com o tipo de distorção PLSD.

Tabela 35. Média de porcentagem na classificação perceptiva das distorções de fala na prova de imitação de sílabas e palavras - faixa etária de cinco anos do GSTFCD.

\begin{tabular}{|c|c|c|c|c|c|c|c|c|c|c|}
\hline & \multicolumn{3}{|c|}{$[\mathrm{s}]$} & \multicolumn{3}{|c|}{$[\mathbf{z}]$} & \multicolumn{2}{|c|}{$\left[\int\right]$} & \multicolumn{2}{|c|}{ [1] } \\
\hline & SD\% & PLSD\% $\%$ & PALCD\% $\%$ & SD\% & PLSD\% $\%$ & PALCD\% & SD\% & ECD\% & SD\% & PLSD\% \\
\hline SÍLABAS & 33,3 & 9,5 & 52,3 & 28,5 & 71,4 & 0 & -- & -- & 95,2 & 14,7 \\
\hline PALAVRAS & 33,3 & 5,5 & 61,1 & 36,6 & 27,2 & 36,6 & -- & -- & 0 & 100 \\
\hline
\end{tabular}

Legenda: SD - produção correta; PLSD - projeção de língua sem distorção acústica; PALCD - projeção anterior de língua com distorção acústica; ECD - esforço articulatório com distorção acústica.

Tabela 36. Média de porcentagem na classificação perceptiva das distorções de fala na prova de imitação de sílabas e palavras - faixa etária de seis anos do GSTFCD.

\begin{tabular}{|c|c|c|c|c|c|c|c|c|c|c|}
\hline & \multicolumn{3}{|c|}{ [s] } & \multicolumn{3}{|c|}{$[z]$} & \multicolumn{2}{|c|}{$\left[\int\right]$} & \multicolumn{2}{|r|}{ [1] } \\
\hline & SD\% & PLSD\% & PALCD \% & SD\% & PLSD\% & PALCD \% & SD\% & ECD\% & SD\% & PLSD\% \\
\hline SÍLABAS & 19 & 0 & 80,9 & -- & -- & -- & 23,8 & 76,1 & -- & -- \\
\hline PALAVRAS & 33,3 & 0 & 66,6 & -- & -- & -- & 23,8 & 76,1 & -- & -- \\
\hline
\end{tabular}

Legenda: SD - produção correta; PLSD - projeção de língua sem distorção acústica; PALCD - projeção anterior de língua com distorção acústica; ECD - esforço articulatório com distorção acústica.

Tabela 37. Média de porcentagem na classificação perceptiva das distorções de fala na prova de imitação de sílabas e palavras - faixa etária de sete anos do GSTFCD. 


\begin{tabular}{|c|c|c|c|c|c|c|c|c|c|c|}
\hline & \multicolumn{3}{|c|}{$[\mathrm{s}]$} & \multicolumn{3}{|c|}{$[\mathbf{z}]$} & \multicolumn{2}{|c|}{ [S] } & \multicolumn{2}{|r|}{ [I] } \\
\hline & SD\% & PLSD\% & PALCD\% & SD\% & PLSD\% & PALCD\% & SD\% & ECD\% & SD\% & PLSD\% \\
\hline SÍLABAS & 25 & 21,4 & 53,5 & 44 & 25 & 30,9 & -- & -- & 23,8 & 76,1 \\
\hline PALAVRAS & 31,9 & 11,1 & 56,9 & 54,5 & 31,8 & 13,6 & -- & -- & 58,3 & 41,6 \\
\hline
\end{tabular}

Legenda: SD - produção correta; PLSD - projeção de língua sem distorção acústica; PALCD - projeção anterior de língua com distorção acústica; ECD - esforço articulatório com distorção acústica.

Figura 21. Comparação das médias de porcentagem da classificação das distorções em sílabas e palavras da prova específica para verificação de distorção de fala - faixas etárias do GSTFCD.

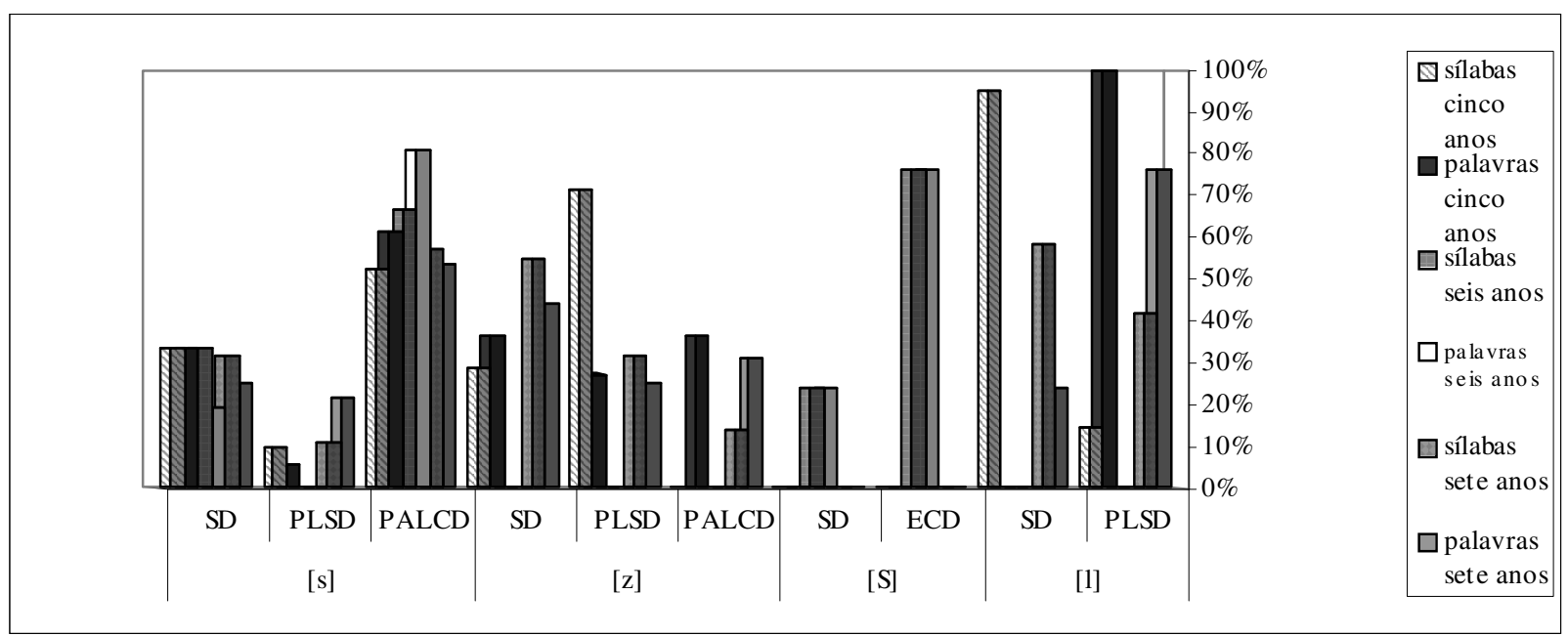

Legenda: SD - produção correta; PLSD - projeção de língua sem distorção acústica; PALCD - projeção anterior de língua com distorção acústica; ECD - esforço articulatório com distorção acústica, $[\mathrm{S}]=\left[\int\right]$.

\section{Grupo Com Transtorno Fonológico Com Distorção}

Para todos os sons somente foram analisados os sujeitos com sete anos, já que nenhum sujeito com seis anos apresentou distorção e o de cinco anos realizou tanto na imitação de sílabas quanto de palavras substituição de [s] e [z] por [S].

A Tabela 38 e a Figura 22 mostram a média de porcentagem na classificação perceptiva das distorções de fala na prova de imitação de sílabas e palavras no GTFCD nos sons [s], [z] e $[r]$.

Observa-se que em média o tipo de distorção que mais ocorreu nas sílabas e palavras nos sons [s] e [z] foi PALCD, apesar da maioria das sílabas e palavras com [s] serem produzidas 
corretamente. No som [ᄃ] 100\% das sílabas e palavras da prova específica foram produzidas com distorção do tipo posteriorização de língua com distorção acústica.

Tabela 38. Média de porcentagem na classificação perceptiva das distorções de fala na prova de imitação de sílabas e palavras - GTFCD.

\begin{tabular}{cccc|ccc|cc} 
& \multicolumn{3}{c|}{$[\mathrm{s}]$} & \multicolumn{3}{c|}{$[\mathrm{z}]$} & \multicolumn{2}{c}{$[\mathbf{r}]$} \\
\cline { 2 - 10 } & SD\% & PLSD\% & PALCD\% & SD\% & PLSD\% & PALCD\% & SD\% & PoCD\% \\
\hline SílLABAS & 61,9 & 2,3 & 35,7 & 23,6 & 0 & 73,6 & 0 & 100 \\
\hline PALAVRAS & 52,7 & 0 & 47,2 & 27,2 & 0 & 72,7 & 0 & 100 \\
\hline
\end{tabular}

Legenda: SD - produção correta; PLSD - projeção de língua sem distorção acústica; PALCD - projeção anterior de língua com distorção acústica; PoCD - posteriorização de língua com distorção acústica.

Figura 22. Comparação das médias de porcentagem da classificação das distorções em sílabas e palavras da prova específica para verificação de distorção de fala - GTFCD.

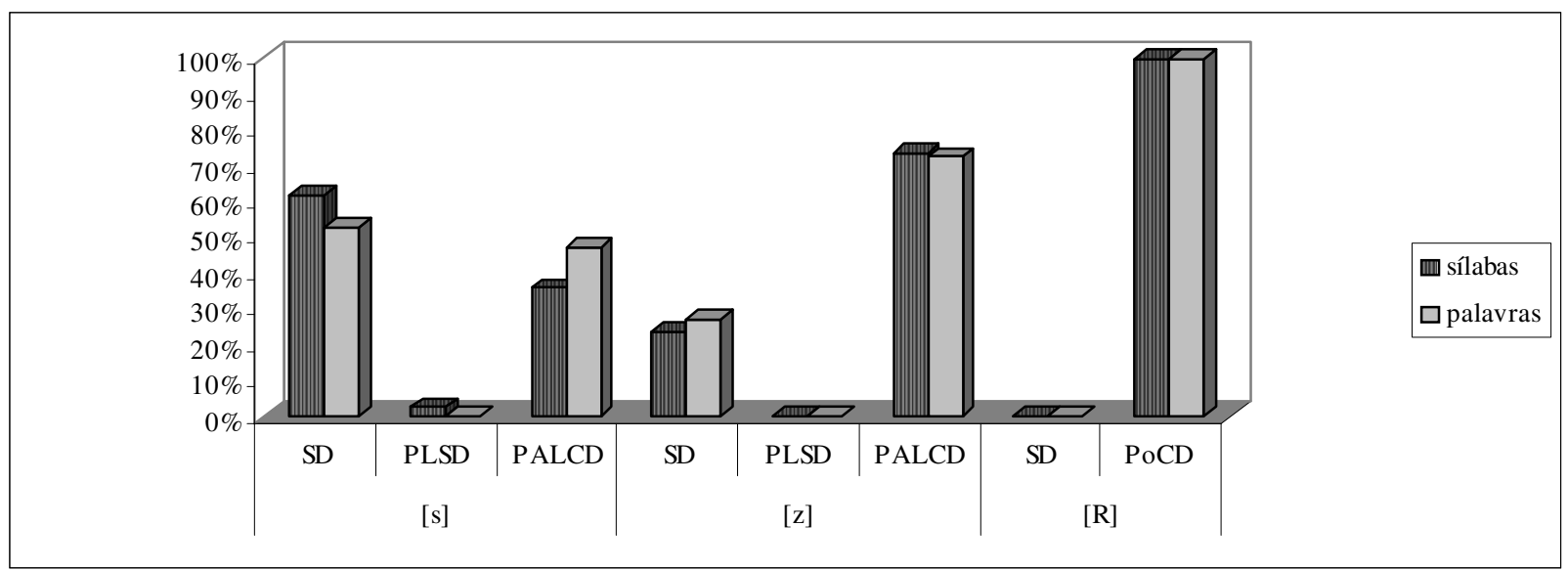

Legenda: SD - produção correta; PLSD - projeção de língua sem distorção acústica; PALCD - projeção anterior de língua com distorção acústica; PoCD - posteriorização de língua com distorção acústica, $[\mathrm{R}]=[\Gamma]$.

Na Figura 23 verifica-se a média dos tipos de distorção que ocorreram na prova específica para distorção em sílabas e palavras para o GSTFCD e GTFCD. Para o som [s], no GTFCD a maioria das produções foi realizada produção correta, o tipo de distorção PALCD foi o que mais ocorreu seguida por PLSD em sílabas e palavras, para o GSTFCD a maioria das produções ocorreram com a distorção do tipo PALCD, mas também ocorreram do tipo PLSD.

No som [z], no GTFCD a maioria das produções em sílabas e palavras ocorreu com PALCD, sendo este o único tipo de distorção encontrada, já para o GSTFCD a maioria das produções foram produzidas produção correta, seguidas por PLSD e PALCD. 
Figura 23. Comparação das médias de porcentagem da classificação das distorções em sílabas e palavras da prova específica para verificação de distorção de fala - GTFCD e GSTFCD.

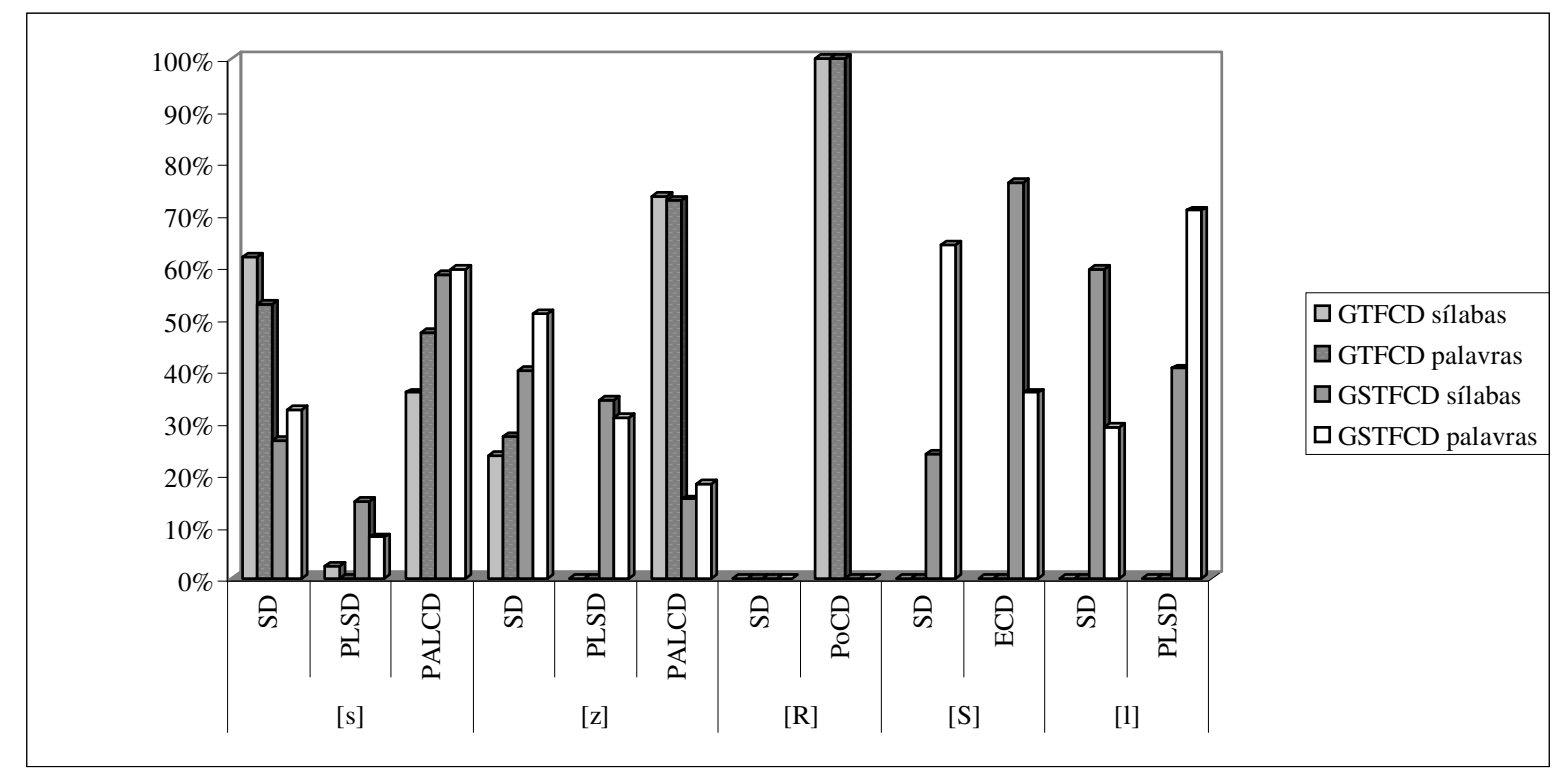

Legenda: SD - produção correta; PLSD - projeção de língua sem distorção acústica; PALCD - projeção anterior de língua com distorção acústica; ECD - esforço articulatório com distorção acústica; PoCD - posteriorização de língua com distorção acústica, GTFSD - grupo com transtorno fonológico sem distorção, GTFCD - grupo com transtorno fonológico com distorção, GSTFSD - grupo sem transtorno fonológico sem distorção, GSTFCD - grupo sem transtorno fonológico com distorção, $[\mathrm{S}]=\left[\int\right],[\mathrm{R}]=[\Gamma]$. 


\section{Análise da Motricidade Orofacial}

Dentre os itens avaliados de motricidade orofacial, o tipo de dentição e a existência de maloclusão foram analisados por terem direta implicação nas produções distorcidas observadas na pesquisa. A Figura 24 ilustra os tipos de dentição encontrados, enquanto a Figura 25 mostra quais os tipos de maloclusões encontrados nos grupos GSTFSD, GSTFCD, GTFSD e GTFCD.

Figura 24. Tipos de dentição do GSTFSD, GSTFCD, GTFSD, GTFCD.

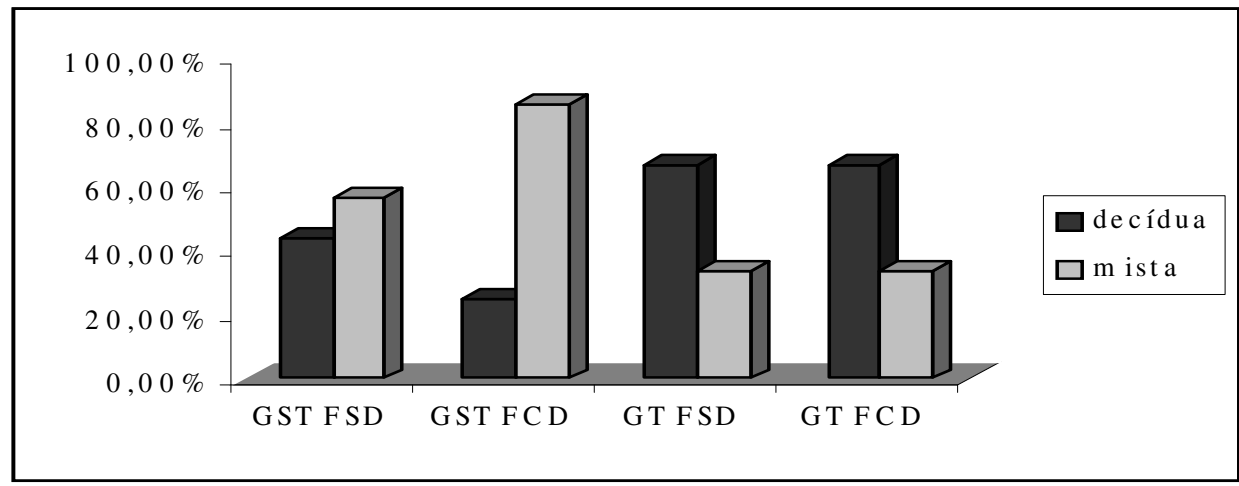

Legenda: GTFSD - grupo com transtorno fonológico sem distorção, GTFCD - grupo com transtorno fonológico com distorção, GSTFSD - grupo sem transtorno fonológico sem distorção, GSTFCD - grupo sem transtorno fonológico com distorção.

Figura 25. Porcentagem média dos tipos de maloclusões - GSTFSD, GSTFCD, GTFSD, GTFCD.

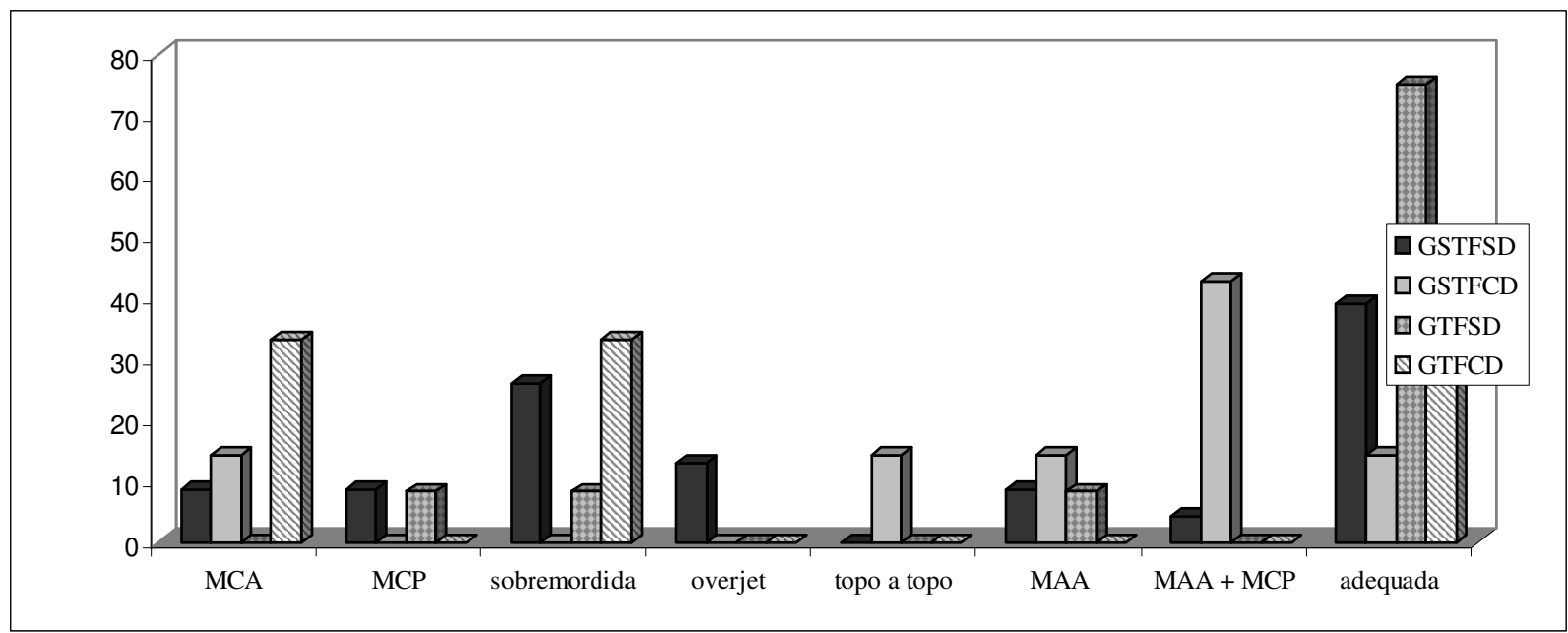

Legenda: MCA - mordida cruzada anterior; MCP - mordida cruzada posterior; MAA - mordida aberta anterior; GTFSD - grupo com transtorno fonológico sem distorção, GTFCD - grupo com transtorno fonológico com distorção, GSTFSD - grupo sem transtorno fonológico sem distorção, GSTFCD - grupo sem transtorno fonológico com distorção. 


\section{Descrição da articulação dos sons líquidos laterais e vibrante simples e fricativos alveolares e palatais pela Palatografia e Linguografia}

Como não há na literatura descrição de palatografias e linguografias de crianças na faixa etária estudada, sem alterações fonológicas e de produção de sons, foi descrita tal análise para dois sujeitos com desenvolvimento típico de fala e linguagem (GSTFSD), nas faixas etárias de cinco e sete anos, para os sons estudados na pesquisa.

O sujeito com cinco anos foi do gênero feminino com 5:10 anos de idade apresentou arcada dentária simétrica, aberta, dentição mista, porém completa; palato duro homogêneo, sem fissuras ou grande rugosidades. As manchas na palatografia e linguografia foram para todos os sons assimétricas, com interrupção e com forte tensão, exceto para o linguograma no som $[\Lambda]$ que ocorreu com fraca tensão.

O sujeito com sete anos também foi do gênero feminino com 7:0 anos de idade, com arcada dentária simétrica, aberta, dentição mista, com ausência do incisivo central superior direito; palato duro homogêneo, sem fissuras ou grandes rugosidades. As manchas na palatografia e linguografia foram para todos os sons assimétricas, com interrupção e com fraca tensão.

Os pontos de contato observados no palatograma e linguograma nos sons estudados nestes dois sujeitos encontram-se no Quadro 6. Observa-se que houve diferença entre os pontos em vários sons.

Por meio da Figura 26 pode se verificar os pontos de contato da palatografia e linguografia do som [s] do sujeito do GSTFSD com 7:0 anos.

As fotos das palatografias e linguografias dos sujeitos do GSTFSD, GSTFCD e GTFCD encontram-se no Anexo 13. 
Figura 26. Palatografia e Linguografia do som [s] - GSTFSD.
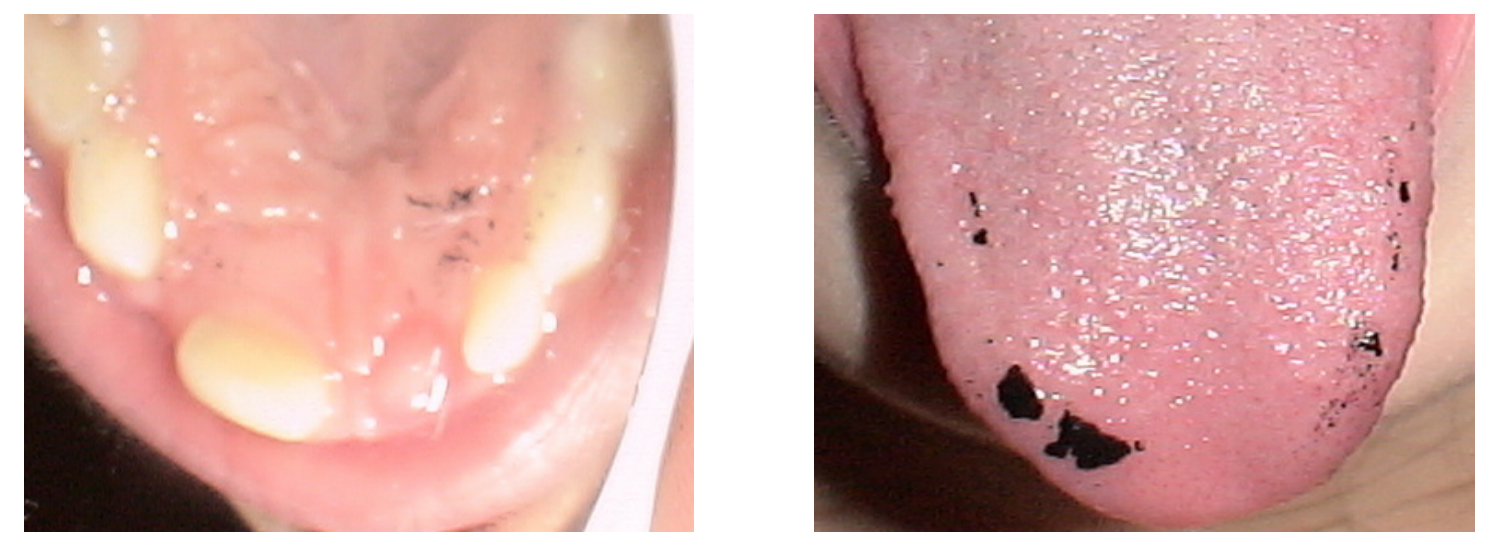

Quadro 6. Descrição dos pontos de contato do palatograma e linguograma nos sons [s], [z] [S], [3], [1], $[\ulcorner]$ e $[\Lambda]$ em sujeitos do GSTFSD nas faixas etárias de cinco e sete anos de idade.

\begin{tabular}{|c|c|c|c|c|c|c|c|c|c|c|}
\hline $\begin{array}{l}\text { Faixa } \\
\text { Etária }\end{array}$ & Análise & {$[\mathbf{s}]$} & {$[z]$} & [3] & {$\left[\int\right]$} & [1] & {$[r]$} & {$[\kappa]$} & Dentição & Oclusão \\
\hline \multirow[t]{2}{*}{5} & Palatografia & A & $\mathrm{A}-\mathrm{P}$ & A-P & $\mathrm{P}$ & A & $\mathrm{D}$ & D-P & Mista & \multirow[t]{2}{*}{ Adequada } \\
\hline & Linguografia & A-L & A-L & A-L & $\mathrm{L}$ & Ap & $\mathrm{L}$ & A-L & & \\
\hline \multirow[t]{2}{*}{7} & Palatografia & $\mathrm{A}$ & $\mathrm{A}$ & $\mathrm{P}$ & A-P & $\mathrm{D}-\mathrm{A}$ & A-P & A-P & Mista & \multirow[t]{2}{*}{ Adequadc } \\
\hline & Linguografia & A-L & A-L & $\mathrm{L}$ & $\mathrm{L}$ & A-L & A-L & A-L & & \\
\hline
\end{tabular}

Legenda: A: alveolar; A-L: ápico-laminar; A-P: alvéolo-palatal; L: lâmina; P: palatal; Ap: ápice; D: dental; D-P: dento-palatal. 


\section{Comparação entre os Pontos de Contato da Articulação na Palatografia e Linguografia e Classificação Perceptiva das Distorções}

Os palatogramas e linguogramas dos sujeitos que apresentaram distorção foram analisados para ambos os grupos juntamente com a classificação perceptiva das distorções. Os dados são apresentados separadamente para cada grupo.

\section{Grupo Sem Transtorno Fonológico com Distorção}

Foram analisados quatro palatogramas e quatro linguogramas do som [s] de sujeitos apenas do gênero masculino com 5:9, 6:2, 7:5 e 7:11 anos de idade, já que um sujeito do gênero feminino de 7:7 anos não apresentou distorção neste som na prova específica para verificação da distorção e dois outros sujeitos fizeram parte da perda amostral.

Em relação à arcada dentária $100 \%$ foram simétricas; $50 \%$ aberta e $50 \%$ estreita; $50 \%$ completa e $50 \%$ incompleta e $75 \%$ dos sujeitos tinham dentição mista, destes, havia ausência do incisivo lateral superior direito e esquerdo (6:2), ausência do incisivo central superior direito (7:5) e dentição mista mas com arcada dentária completa (7:11).

Quanto ao palato duro, 100\% foram homogêneos, nenhuma criança apresentou fissura palatina e $25 \%$ apresentam grande rugosidade, com localização entre os incisivos centrais superiores.

A análise da mancha dos palatogramas mostrou que $100 \%$ foram assimétricas, $100 \%$ com interrupção e $100 \%$ com forte tensão, ou seja, escura. Quanto ao linguograma $50 \%$ foram assimétricas, $50 \%$ com interrupção e $100 \%$ com tensão forte.

Por meio da Figura 27 pode se verificar os pontos de contato da palatografia e linguografia do som [s] do sujeito do GSTFCD com 7:5 anos. O restante das fotos encontra-se no Anexo 13. 
Figura 27. Palatografia e Linguografia do som [s] - GTFCD.
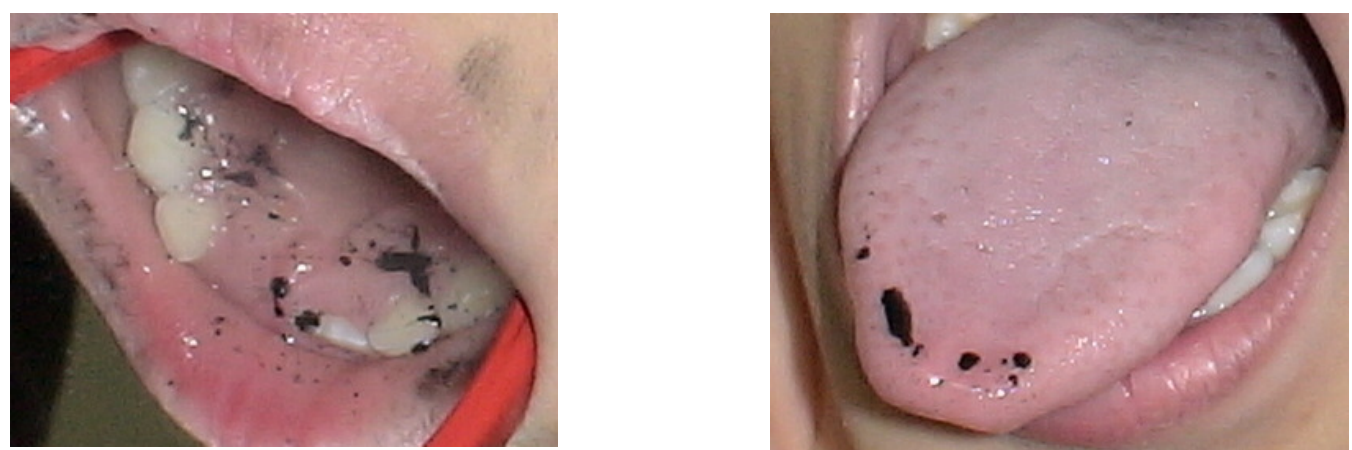

A comparação entre a análise perceptiva da distorção de fala e pontos de contato no palatograma e linguograma no som [s] no GSTFCD encontra-se no Quadro 7.

Quadro 7. Descrição da análise perceptiva da distorção de fala e pontos de contato no palatograma e linguograma no som [s] - GSTFCD.

\begin{tabular}{|c|c|c|c|c|c|}
\hline \multicolumn{2}{|r|}{ ANÁLISE PERCEPTIVA } & \multicolumn{2}{|c|}{ CONTATOS } & DENTIÇÃO & OCLUSÃO \\
\hline \multirow[t]{2}{*}{$5: 9$} & \multirow{2}{*}{$\begin{array}{l}\text { Projeção anterior de língua } \\
\text { com distorção acústica }\end{array}$} & PALATOGRAMA & Dental & \multirow[t]{2}{*}{ Mista } & \multirow[t]{2}{*}{ Topo a topo } \\
\hline & & LINGUOGRAMA & Ápico-laminar & & \\
\hline \multirow[t]{2}{*}{$6: 2$} & \multirow{2}{*}{$\begin{array}{l}\text { Projeção anterior de língua } \\
\text { com e sem distorção acústica } \\
\text { e produção correta }\end{array}$} & PALATOGRAMA & Dento-alveolar & \multirow[t]{2}{*}{ Mista } & \multirow{2}{*}{$\begin{array}{l}\text { Mordida aberta } \\
\text { anterior }\end{array}$} \\
\hline & & LINGUOGRAMA & Lâmina & & \\
\hline \multirow[t]{2}{*}{$7: 5$} & \multirow{2}{*}{$\begin{array}{l}\text { Projeção anterior de língua } \\
\text { com e sem distorção acústica } \\
\text { e produção correta }\end{array}$} & PALATOGRAMA & Dento-alveolar & \multirow[t]{2}{*}{ Mista } & \multirow[t]{2}{*}{ Adequada } \\
\hline & & LINGUOGRAMA & Ápice & & \\
\hline \multirow[t]{2}{*}{$7: 11$} & \multirow{2}{*}{$\begin{array}{l}\text { Projeção anterior de língua } \\
\text { com distorção acústica }\end{array}$} & PALATOGRAMA & Dento-alvéolo-palatal & \multirow[t]{2}{*}{ Mista } & Mordida \\
\hline & & LINGUOGRAMA & Ápico-laminar & & $\begin{array}{c}\text { cruzada } \\
\text { posterior }+ \\
\text { aberta anterior }\end{array}$ \\
\hline
\end{tabular}

Foram analisados três palatogramas e três linguogramas do som [z], de sujeitos apenas do gênero masculino com 5:9, 7:5 e 7:11 anos. Deve ser considerado que um sujeito do gênero feminino de 7:7 anos não apresentou distorção do som [z] na prova específica para verificação da distorção e um outro sujeito fez parte da perda amostral.

Em relação à arcada dentária 100\% foram simétricas; 66,6\% aberta e 33,3\% estreita; $66,6 \%$ completa e $33,3 \%$ incompleta e $66,6 \%$ dos sujeitos tinham dentição mista, mas apenas 33,3\% com ausência de dentes, havia ausência do incisivo lateral superior direito e esquerdo (7:5) e dentição mista mas com arcada dentária completa (7:11). 
Quanto ao palato duro, $100 \%$ foram homogêneos, nenhuma criança apresentou fissura palatina e $25 \%$ apresentam grande rugosidade, com localização entre os incisivos centrais superiores.

A análise da mancha dos palatogramas mostrou que $100 \%$ foram assimétricas, $100 \%$ com interrupção e 100\% com forte tensão, ou seja, escura. Quanto ao linguograma 66,6\% foram assimétricas, $66,6 \%$ com interrupção e $100 \%$ com tensão forte.

O Quadro 8 mostra a descrição da análise perceptiva da distorção de fala e pontos de contato no palatograma e linguograma no som [z] no GSTFCD.

Quadro 8. Descrição da análise perceptiva da distorção de fala e pontos de contato no palatograma e linguograma no som $[\mathrm{z}]$ - GSTFCD.

\begin{tabular}{|c|c|c|c|c|c|}
\hline \multicolumn{2}{|r|}{ ANÁLISE PERCEPTIVA } & \multicolumn{2}{|c|}{ CONTATOS } & DENTIÇÃO & OCLUSÃO \\
\hline \multirow[t]{2}{*}{$5: 9$} & \multirow{2}{*}{$\begin{array}{l}\text { Projeção anterior de língua } \\
\text { com e sem distorção acústica } \\
\text { e produção correta }\end{array}$} & PALATOGRAMA & Dento-palatal & \multirow[t]{2}{*}{ Mista } & \multirow[t]{2}{*}{ Topo a topo } \\
\hline & & LINGUOGRAMA & Ápico-laminar & & \\
\hline \multirow[t]{2}{*}{$7: 5$} & \multirow{2}{*}{$\begin{array}{l}\text { Projeção anterior de língua } \\
\text { com distorção acústica }\end{array}$} & PALATOGRAMA & Dento-alveolar & \multirow[t]{2}{*}{ Mista } & \multirow[t]{2}{*}{ Adequada } \\
\hline & & LINGUOGRAMA & Lâmina & & \\
\hline \multirow[t]{2}{*}{ 7:11 } & \multirow{2}{*}{$\begin{array}{l}\text { Projeção anterior de língua } \\
\text { com distorção acústica }\end{array}$} & PALATOGRAMA & Dento-alveolar & \multirow[t]{2}{*}{ Mista } & \multirow{2}{*}{$\begin{array}{l}\text { Mordida cruzada } \\
\text { posterior }+ \text { aberta } \\
\text { anterior }\end{array}$} \\
\hline & & LINGUOGRAMA & Ápico-laminar & & \\
\hline
\end{tabular}

Foi analisado um palatograma e um linguograma do som [S] de um sujeito do gênero masculino com 6:2 anos, que havia apresentado distorção na prova específica para verificação da distorção para este som.

Em relação à arcada dentária, esta foi simétrica; estreita e mista com ausência do incisivo lateral superior direito e esquerdo e grande diastema entre os incisivos centrais superiores.

O palato duro foi avaliado como homogêneo com grande rugosidade entre os incisivos centrais superiores.

A análise da mancha do palatograma e linguograma mostrou que $100 \%$ foi assimétrica, $100 \%$ com interrupção e $100 \%$ com forte tensão, ou seja, escura.

O Quadro 9 mostra a descrição da análise perceptiva da distorção de fala e pontos de contato no palatograma e linguograma no som [S] no GSTFCD. 
Quadro 9. Descrição da análise perceptiva da distorção de fala e pontos de contato no palatograma e linguograma no som [S] - GSTFCD.

\begin{tabular}{cccccc}
\hline \multicolumn{2}{c}{ ANÁLISE PERCEPTIVA } & \multicolumn{2}{c}{ CONTATOS } & DENTIÇÃO & OCLUSÃO \\
\hline $\mathbf{6 : 2}$ & $\begin{array}{c}\text { Esforço articulatório } \\
\text { produção correta acústica }\end{array}$ & PALATOGRAMA & Dento-palatal & Mista & $\begin{array}{l}\text { Mordida cruzada } \\
\text { posterior } \\
\text { anterior }\end{array}$ \\
\hline
\end{tabular}

Foram analisados dois palatogramas e dois linguogramas do som [1], um de um sujeito do gênero masculino com 5:9 anos, e outro do gênero masculino com 7:11.

Em relação à arcada dentária 100\% foram simétricas; 50\% estreita; 50\% mista, mas sem ausência de dentes.

Quanto ao palato duro, $100 \%$ foram homogêneos, sem fissuras ou grande rugosidade.

A análise da mancha do palatograma e linguograma mostrou que $100 \%$ foram assimétricas, $100 \%$ com interrupção e $100 \%$ com forte tensão, ou seja, escura.

O Quadro 10 realiza a descrição da análise perceptiva da distorção de fala e pontos de contato no palatograma e linguograma no som [1] no GSTFCD.

Quadro 10. Descrição da análise perceptiva da distorção de fala e pontos de contato no palatograma e linguograma no som [1] - GSTFCD.

\begin{tabular}{|c|c|c|c|}
\hline ANÁLISE PERCEPTIVA & CONTATOS & DENTIÇÃO & OCLUSÃO \\
\hline \multirow{2}{*}{$\begin{array}{c}\text { Projeção anterior de língua } \\
\text { sem distorção acústica e } \\
\text { produção correta }\end{array}$} & PALATOGRAMA & \multirow[t]{2}{*}{ Decídua } & \multirow[t]{2}{*}{ Topo a topo } \\
\hline & LINGUOGRAMA & & \\
\hline \multirow{2}{*}{$\begin{array}{c}\text { Projeção anterior de língua } \\
\text { sem } \\
\text { distorção acústica e } \\
\text { produção correta }\end{array}$} & PALATOGRAMA & \multirow[t]{2}{*}{ Mista } & \multirow{2}{*}{$\begin{array}{c}\text { Mordida cruzada } \\
\text { posterior }+ \text { aberta } \\
\text { anterior }\end{array}$} \\
\hline & LINGUOGRAMA & & \\
\hline
\end{tabular}

\section{Grupo Com Transtorno Fonológico Com Distorção}

Foram analisados dois palatogramas e dois linguogramas do som [s], ambos de sujeitos na faixa etária de sete anos, sendo um do gênero feminino com 7:2 anos de idade e um do masculino com 7:9 anos. Um sujeito de cinco anos realizou a substituição de [s] e [z] por [S] tanto na imitação de sílabas quanto de palavras na prova específica para verificação de distorção, desta maneira não foi realizada a palatografia e linguografia. 
Em relação à arcada dentária 100\% foram simétricas; $100 \%$ aberta; $100 \%$ completa e $50 \%$ dos sujeitos tinham dentição mista, porém, com arcada completa e 50\% com dentição decídua.

Quanto ao palato duro, $100 \%$ foram homogêneos, nenhuma criança apresentou fissura palatina ou grande rugosidade.

A análise da mancha do palatograma mostrou que $100 \%$ foram assimétricas, $100 \%$ com interrupção e $100 \%$ com forte tensão. Já para o linguograma $100 \%$ foram assimétricas, $100 \%$ com interrupção e $50 \%$ com tensão forte.

Quadro 11 mostra a descrição da análise perceptiva da distorção de fala e pontos de contato no palatograma e linguograma no som [s] no GTFCD.

Quadro 11. Descrição da análise perceptiva da distorção de fala e pontos de contato no palatograma e linguograma no som $[\mathrm{s}]$ - GTFCD.

\begin{tabular}{|c|c|c|c|c|}
\hline ANÁLISE PERCEPTIVA & CONT & TOS & DENTIÇÃO & OCLUSÃO \\
\hline \multirow{2}{*}{$\begin{array}{l}\text { Projeção anterior de língua } \\
\text { com e sem distorção acústica }\end{array}$} & PALATOGRAMA & Alvéolo-palatal & \multirow[t]{2}{*}{ Decídua } & \multirow[t]{2}{*}{ Sobremordida } \\
\hline & LINGUOGRAMA & Lâmina & & \\
\hline \multirow[t]{2}{*}{$\begin{array}{l}\text { Projeção anterior de língua } \\
\text { com distorção acústica }\end{array}$} & PALATOGRAMA & $\begin{array}{c}\text { Dento-alvéolo- } \\
\text { palatal }\end{array}$ & \multirow[t]{2}{*}{ Mista } & \multirow[t]{2}{*}{ Adequada } \\
\hline & LINGUOGRAMA & Ápico-laminar & & \\
\hline
\end{tabular}

Analisou-se apenas um palatograma e um linguograma do som [z], pois apenas um sujeito do gênero masculino com 7:9 anos de idade do GTFCD apresentou distorção na prova específica para o som $[\mathrm{z}]$.

A arcada dentária foi avaliada como simétrica, aberta e com dentição mista, mas sem ausência de dentes.

O palato duro foi homogêneo e o sujeito não apresentou fissura palatina ou grande rugosidade.

A análise da mancha do palatograma $100 \%$ de assimetria, 100\% com interrupção e $100 \%$ com forte tensão. Para o linguograma $100 \%$ da mancha foi simétrica, $100 \%$ com interrupção e $100 \%$ com tensão forte.

O Quadro 12 faz a descrição da análise perceptiva da distorção de fala e pontos de contato no palatograma e linguograma no som $[z]$ no GTFCD. 
Quadro 12. Descrição da análise perceptiva da distorção de fala e pontos de contato no palatograma e linguograma no som $[z]$ - GTFCD.

\begin{tabular}{cccccc}
\hline \multicolumn{2}{c}{ ANÁLISE PERCEPTIVA } & CONTATOS & DENTIÇÃO & OCLUSÃO \\
\cline { 1 - 4 } 7:9 & $\begin{array}{c}\text { Projeção anterior de língua } \\
\text { com distorção acústica }\end{array}$ & PALATOGRAMA & Dento-alvéolo-palatal & Mista & Adequada \\
\cline { 3 - 4 } & LINGUOGRAMA & Ápico- laminar & & \\
\hline
\end{tabular}

Foi analisado apenas um palatograma e um linguograma do som [ $\varsigma$, já que somente um sujeito do gênero feminino com 7:2 anos de idade apresentou distorção na prova específica para este som.

A arcada dentária foi simétrica, aberta e com dentição decídua.

Em relação ao palato duro, este foi homogêneo e o sujeito não apresentou fissura palatina ou grande rugosidade.

O Quadro 13 mostra a descrição da análise perceptiva da distorção de fala e pontos de contato no palatograma e linguograma no som $[r]$ no GTFCD.

Quadro 13. Descrição da análise perceptiva da distorção de fala e pontos de contato no palatograma e linguograma no som $[\kappa]-$ GTFCD.

\begin{tabular}{|c|c|c|c|c|}
\hline ANÁLISE PERCEPTIVA & CONT & & DENTIÇÃO & OCLUSÃO \\
\hline \multirow{2}{*}{$\begin{array}{l}\text { Posteriorização da língua } \\
\text { com distorção acústica }\end{array}$} & PALATOGRAMA & Velar & \multirow[t]{2}{*}{ Decídua } & \multirow{2}{*}{ Sobremordida } \\
\hline & LINGUOGRAMA & Lâmina & & \\
\hline
\end{tabular}

Os Quadros 14 a 17 descrevem os pontos de contato no palatograma e linguograma, dentição, oclusão e análise perceptiva da distorção de fala nos sons $[\mathrm{s}],[z],[1],\left[\int\right]$ e $[\ulcorner]$ nos grupos GSTFSD, GSTFCD e GTFCD. 
Quadro 14. Descrição dos pontos de contato no palatograma e linguograma, dentição, oclusão e análise perceptiva da distorção de fala no som [s] - GSTFSD, GSTFCD e GTFCD.

\begin{tabular}{ccccccc}
\hline IDADE & GRUPO & $\begin{array}{c}\text { CONTATOS } \\
\text { PALATOGRAMA }\end{array}$ & $\begin{array}{c}\text { CONTATOS } \\
\text { LINGUOGRAMA }\end{array}$ & DENTIÇÃO & OCLUSÃO & $\begin{array}{c}\text { ANÁLISE } \\
\text { PERCEPTIVA }\end{array}$ \\
\hline $5: 10$ & GSTFSD & Alveolar & Ápico-laminar & Mista & Adequada & SD \\
$7: 0$ & GSTFSD & Alveolar & Lâmina & Mista & Adequada & SD \\
\hline $5: 9$ & GSTFCD & Dento-palatal & Ápico- laminar & Mista & Topo a topo & PALCD \\
$6: 2$ & GSTFCD & Dento-alveolar & Lâmina & Mista & MCP + MAA & PLSD, PALCD \\
$7: 5$ & GSTFCD & Dento-alveolar & Ápice & Mista & Adequada & PLSD, PALCD \\
$7: 11$ & GSTFCD & Dento-alvéolo- & Lâmina & Mista & MCP + MAA & PALCD \\
& & palatal & & & & Pecídua \\
$7: 2$ & GTFCD & Alvéolo-palatal & Lâmina & Sobremordida & PLSD, PALCD \\
$7: 9$ & GTFCD & Alvéolo-palatal & Lâmina & Mista & Adequada & PALCD \\
\hline
\end{tabular}

Legenda: GTFCD - grupo com transtorno fonológico com distorção, GSTFSD - grupo sem transtorno fonológico sem distorção, GSTFCD - grupo sem transtorno fonológico com distorção; SD - produção correta; PLSD - projeção de língua produção correta acústica; PALCD - projeção anterior de língua com distorção acústica; MCP - mordida cruzada posterior; MAA - mordida aberta anterior.

Quadro 15. Descrição dos pontos de contato no palatograma e linguograma, dentição, oclusão e análise perceptiva da distorção de fala no som [z] - GSTFSD, GSTFCD e GTFCD.

\begin{tabular}{ccccccc}
\hline IDADE & GRUPO & $\begin{array}{c}\text { CONTATOS } \\
\text { PALATOGRAMA }\end{array}$ & $\begin{array}{c}\text { CONTATOS } \\
\text { LINGUOGRAMA }\end{array}$ & DENTIÇÃO & OCLUSÃO & $\begin{array}{c}\text { ANÁLISE } \\
\text { PERCEPTIVA }\end{array}$ \\
\hline $5: 10$ & GSTFSD & Alvéolo-palatal & Ápico-laminar & Mista & Adequada & SD \\
$7: 0$ & GSTFSD & Alveolar & Ápico-Laminar & Mista & Adequada & SD \\
\hline $5: 9$ & GSTFCD & Dento-palatal & Ápico- laminar & Mista & Topo a topo & PALCD, PLSD \\
$7: 5$ & GSTFCD & Dento-alveolar & Ápice & Mista & Adequada & PALCD \\
$7: 11$ & GSTFCD & Dento-alveolar & Ápico-Laminar & Mista & MCP + MAA & PALCD \\
\hline $7: 9$ & GTFCD & Dento-alvéolo-palatal & Lâmina & Mista & Adequada & PALCD \\
\hline
\end{tabular}

Legenda: GTFCD - grupo com transtorno fonológico com distorção, GSTFSD - grupo sem transtorno fonológico sem distorção, GSTFCD - grupo sem transtorno fonológico com distorção; SD - produção correta; PLSD - projeção de língua produção correta acústica; PALCD - projeção anterior de língua com distorção acústica; MCP - mordida cruzada posterior; MAA - mordida aberta anterior.

Quadro 16. Descrição dos pontos de contato no palatograma e linguograma, dentição, oclusão e análise perceptiva da distorção de fala no som [1] - GSTFSD e GSTFCD.

\begin{tabular}{ccccccc}
\hline IDADE & GRUPO & $\begin{array}{c}\text { CONTATOS } \\
\text { PALATOGRAMA }\end{array}$ & $\begin{array}{c}\text { CONTATOS } \\
\text { LINGUOGRAMA }\end{array}$ & DENTIÇÃO & OCLUSÃO & $\begin{array}{c}\text { ANÁLISE } \\
\text { PERCEPTIVA }\end{array}$ \\
\hline $5: 10$ & GSTFSD & Alveolar & Ápice & Mista & Adequada & SD \\
$7: 0$ & GSTFSD & Alveolar & Ápice & Mista & Adequada & SD \\
\hline $5: 9$ & GSTFCD & Dento-palatal & Ápico- laminar & Mista & Topo a topo & PLSD \\
$7: 11$ & GSTFCD & Dento- palatal & Ápico-laminar & Mista & MCP + MAA & PLSD \\
\hline
\end{tabular}

Legenda: GSTFSD - grupo sem transtorno fonológico sem distorção, GSTFCD - grupo sem transtorno fonológico com distorção; SD - produção correta; PLSD - projeção de língua produção correta acústica; MCP - mordida cruzada posterior; MAA - mordida aberta anterior. 
Quadro 17. Descrição dos pontos de contato no palatograma e linguograma, dentição, oclusão e análise perceptiva da distorção de fala no som [S] - GSTFSD e GSTFCD.

\begin{tabular}{ccccccc}
\hline IDADE & GRUPO & $\begin{array}{c}\text { CONTATOS } \\
\text { PALATOGRAMA }\end{array}$ & $\begin{array}{c}\text { CONTATOS } \\
\text { LINGUOGRAMA }\end{array}$ & DENTIÇÃO & OCLUSÃO & $\begin{array}{c}\text { ANÁLISE } \\
\text { PERCEPTIVA }\end{array}$ \\
\hline $5: 10$ & GSTFSD & Palatal & Lâmina & Mista & Adequada & SD \\
$7: 0$ & GSTFSD & Alvéolo-palatal & Lâmina & Mista & Adequada & SD \\
\hline $6: 2$ & GSTFCD & Dento-palatal & Lâmina & Mista & MCP + MAA & ECD \\
\hline
\end{tabular}

Legenda: GSTFSD - grupo sem transtorno fonológico sem distorção; GSTFCD - grupo sem transtorno fonológico com distorção; SD - produção correta; ECD - esforço articulatório com distorção acústica; MCP - mordida cruzada posterior; MAA - mordida aberta anterior.

Quadro 18. Descrição dos pontos de contato no palatograma e linguograma, dentição, oclusão e análise perceptiva da distorção de fala no som [ᄃ] - GSTFSD e GTFCD.

\begin{tabular}{ccccccc}
\hline IDADE & GRUPO & $\begin{array}{c}\text { CONTATOS } \\
\text { PALATOGRAMA }\end{array}$ & $\begin{array}{c}\text { CONTATOS } \\
\text { LINGUOGRAMA }\end{array}$ & DENTIÇÃO & OCLUSÃO & $\begin{array}{c}\text { ANÁLISE } \\
\text { PERCEPTIVA }\end{array}$ \\
\hline $5: 10$ & GSTFSD & Dental & Lâmina & Mista & Adequada & SD \\
$7: 0$ & GSTFSD & Alveolar & Alvéolo-palatal & Mista & Adequada & SD \\
\hline $7: 4$ & GTFCD & Velar & Lâmina & Decídua & Sobremordida & PoCD \\
\hline
\end{tabular}

Legenda: GTFCD - grupo com transtorno fonológico com distorção; GSTFSD - grupo sem transtorno fonológico sem distorção; SD - produção correta; PoCD - posteriorização de língua com distorção acústica; MCP - mordida cruzada posterior; MAA - mordida aberta anterior. 
Comparação dos Índices de Gravidade nas Provas de Imitação, Nomeação (WERTZNER, 2004) e Fala Espontânea.

Os valores dos índices PCC, PCC-R, PDI, RDI a ACI dos sujeitos do GSTFSD, GTSFCD, GTFSD e GTFCD que serão mostrados foram calculados a partir das provas de nomeação, imitação do teste de fonologia do ABFW Teste de Linguagem Infantil (WERTZNER, 2004) e da fala espontânea.

Pelas Figuras 28, 29 e 30 pode se observar que o GSTFSD foi o grupo que apresentou valores mais homogêneos e mais altos do índice PCC, seguido pelo GSTFCD. Enquanto os subgrupos com transtorno fonológico apresentaram os desempenhos mais baixos.

Figura 28. Boxplot do PCC na Nomeação.

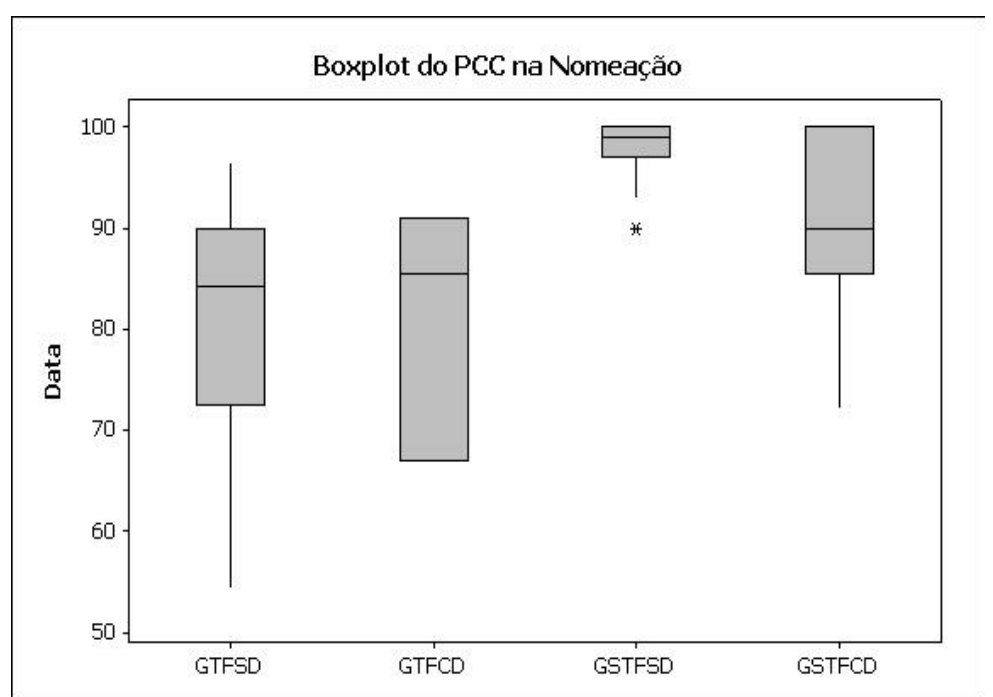

Legenda: GTFSD - grupo com transtorno fonológico sem distorção, GTFCD - grupo com transtorno fonológico com distorção, GSTFSD - grupo sem transtorno fonológico sem distorção, GSTFCD - grupo sem transtorno fonológico com distorção. 
Figura 29. Boxplot do PCC na Imitação.

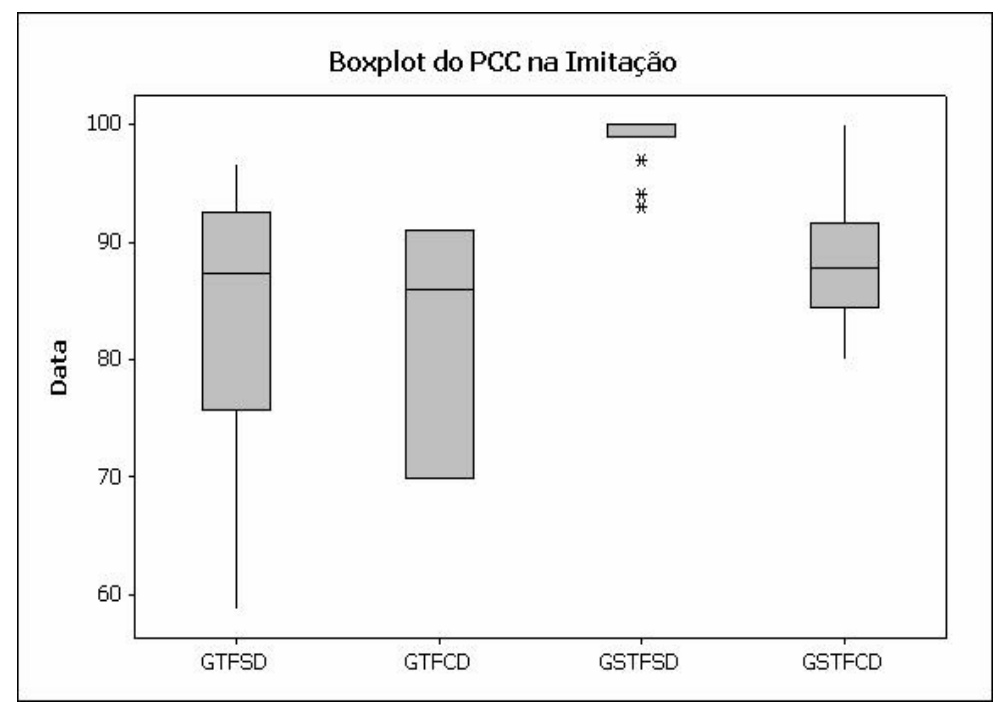

Legenda: GTFSD - grupo com transtorno fonológico sem distorção, GTFCD - grupo com transtorno fonológico com distorção, GSTFSD - grupo sem transtorno fonológico sem distorção, GSTFCD - grupo sem transtorno fonológico com distorção.

Figura 30. Boxplot do PCC na Fala Espontânea.

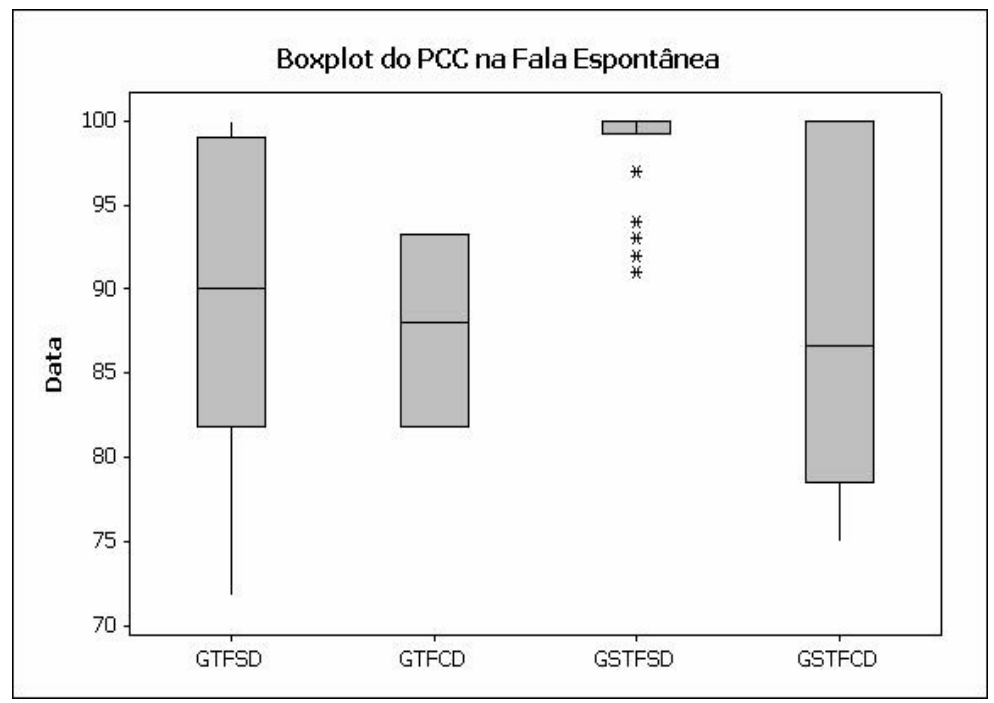

Legenda: GTFSD - grupo com transtorno fonológico sem distorção, GTFCD - grupo com transtorno fonológico com distorção, GSTFSD - grupo sem transtorno fonológico sem distorção, GSTFCD - grupo sem transtorno fonológico com distorção.

As Figuras 31, 32 e 33 mostram o índice PCC-R para os subgrupos GTFSD, GTFCD, GSTFSD e GSTFCD, nas provas de nomeação, imitação e fala espontânea. Neste índice se observa que o GSTFSD apresentou os melhores valores com pequena variação entre o grupo, o GSTFCD foi o segundo melhor índice, além disso, como o PCC-R não considera distorção como erro, os valores foram superiores ao encontrados neste subgrupo para o PCC. Pela observação do 
desempenho dos sujeitos no índice PCC-R nas provas de nomeação, imitação e fala espontânea, nota-se que os melhores desempenhos dos sujeitos ocorreram para o GSTFCD, GSTFSD, GTFCD e por fim GTFSD.

Figura 31. Boxplot do PCC-R na Nomeação.

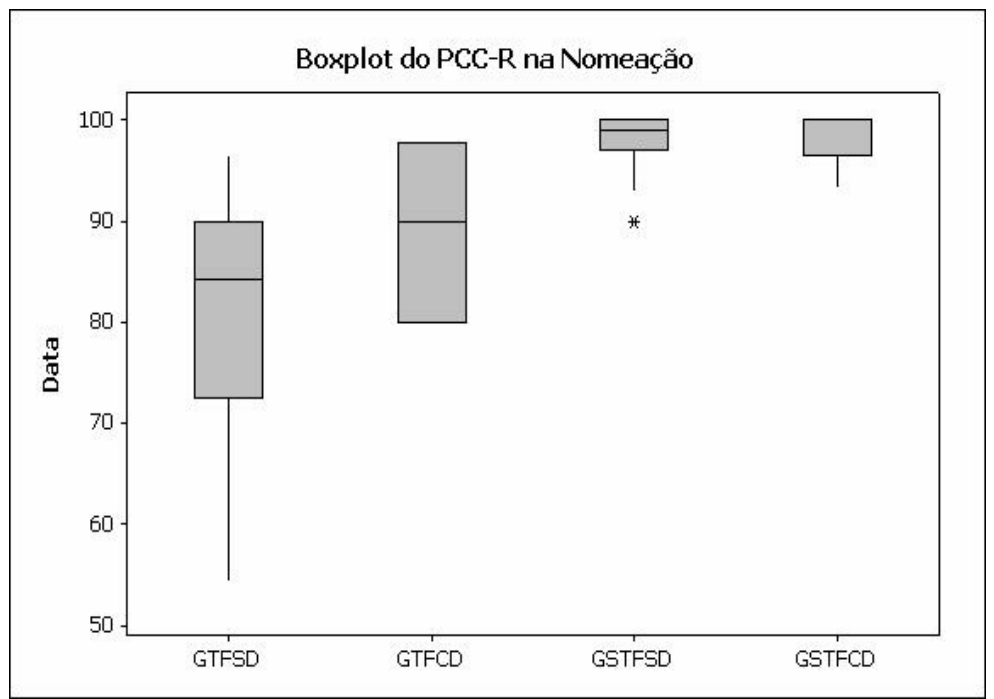

Legenda: GTFSD - grupo com transtorno fonológico sem distorção, GTFCD - grupo com transtorno fonológico com distorção, GSTFSD - grupo sem transtorno fonológico sem distorção, GSTFCD - grupo sem transtorno fonológico com distorção. 
Figura 32. Boxplot do PCC-R na Imitação.

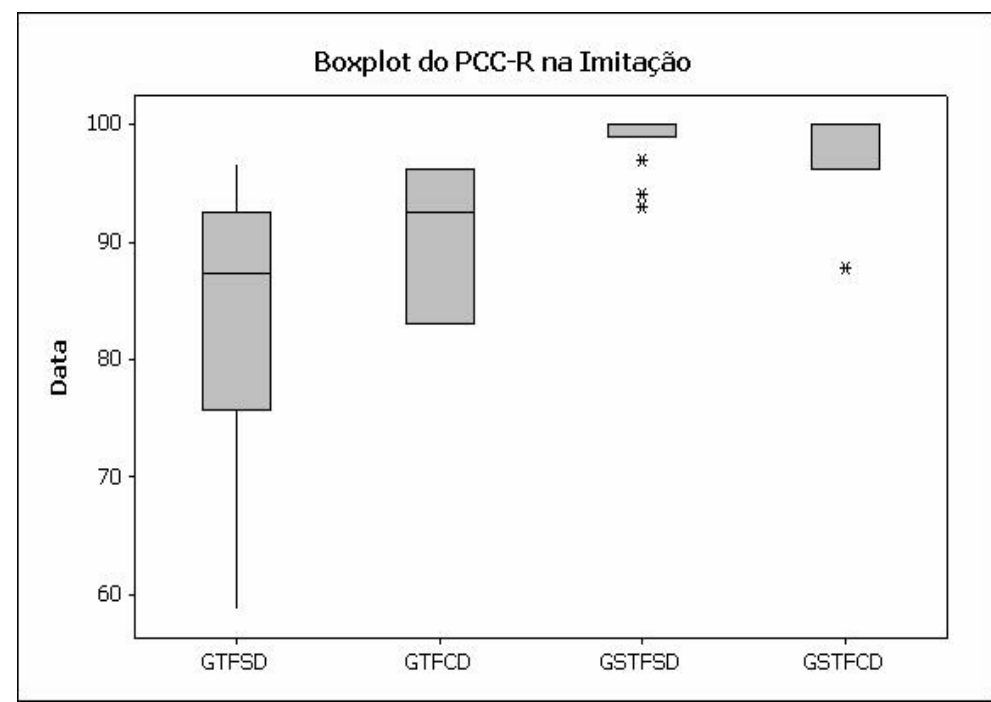

Legenda: GTFSD - grupo com transtorno fonológico sem distorção, GTFCD - grupo com transtorno fonológico com distorção, GSTFSD - grupo sem transtorno fonológico sem distorção, GSTFCD - grupo sem transtorno fonológico com distorção. 
Figura 33. Boxplot do PCC-R na Fala Espontânea.

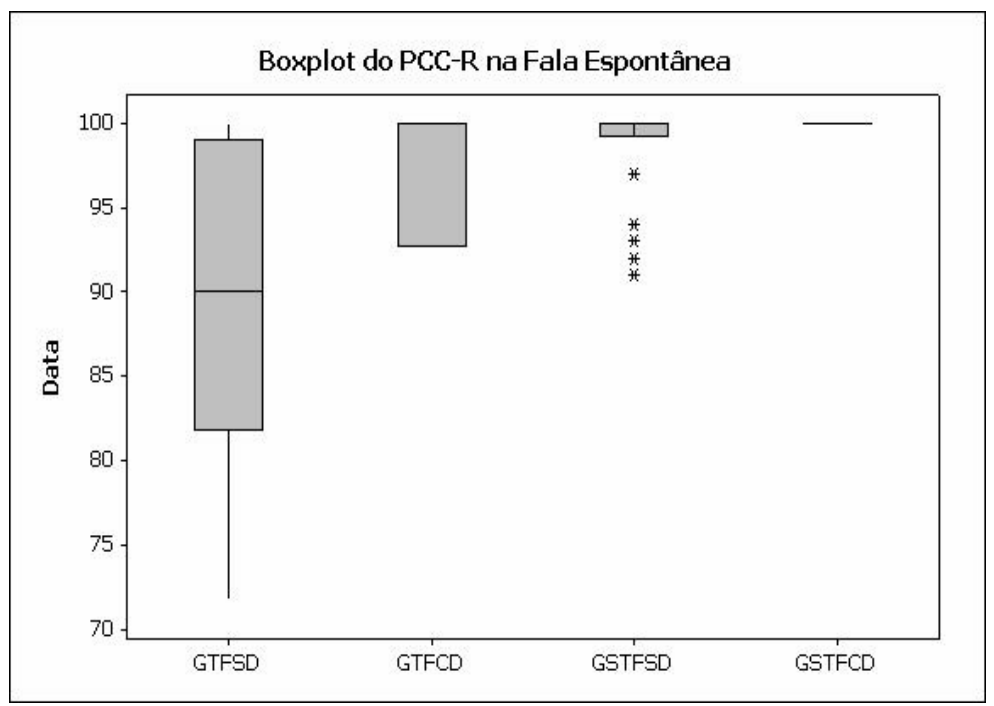

Legenda: GTFSD - grupo com transtorno fonológico sem distorção, GTFCD - grupo com transtorno fonológico com distorção, GSTFSD - grupo sem transtorno fonológico sem distorção, GSTFCD - grupo sem transtorno fonológico com distorção.

As Figuras 34, 35 e 36 mostram os valores do índice PDI nos quatro subgrupos para as provas de nomeação, imitação e fala espontânea. Os valores do índice PDI nas três provas foram menores no GSTFSD, apresentando-se como um grupo homogêneo, o GSTFCD foi o subgrupo que após o GSTFSD apresentou valores mais baixos para este índice.

Figura 34. Boxplot do PDI na Nomeação.

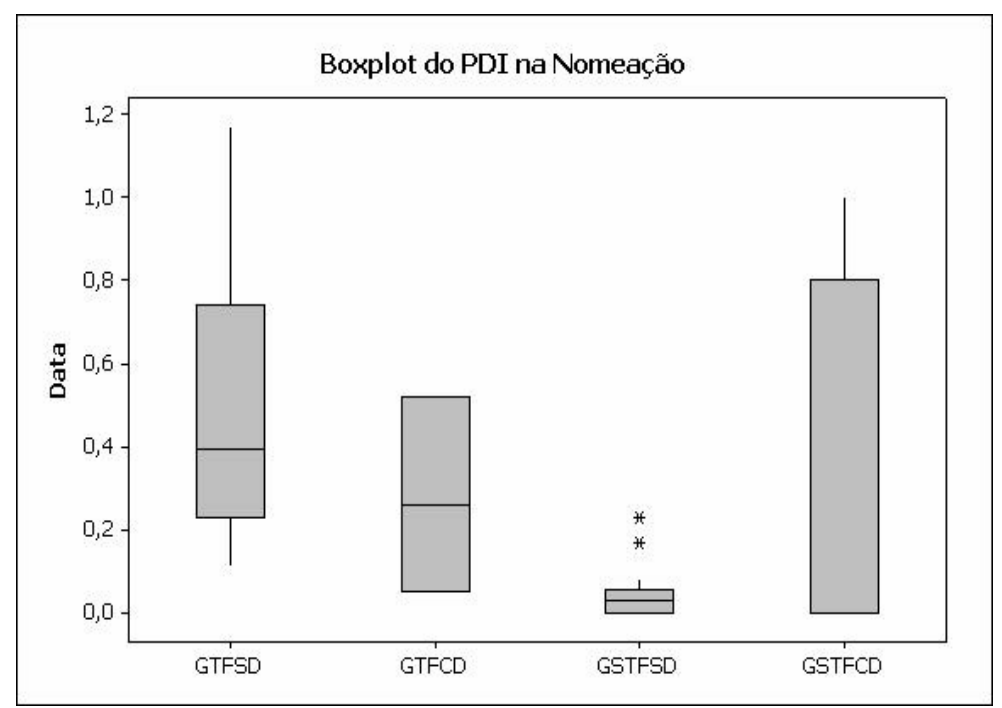

Legenda: GTFSD - grupo com transtorno fonológico sem distorção, GTFCD - grupo com transtorno fonológico com distorção, GSTFSD - grupo sem transtorno fonológico sem distorção, GSTFCD - grupo sem transtorno fonológico com distorção. 
Figura 35. Boxplot do PDI na Imitação.

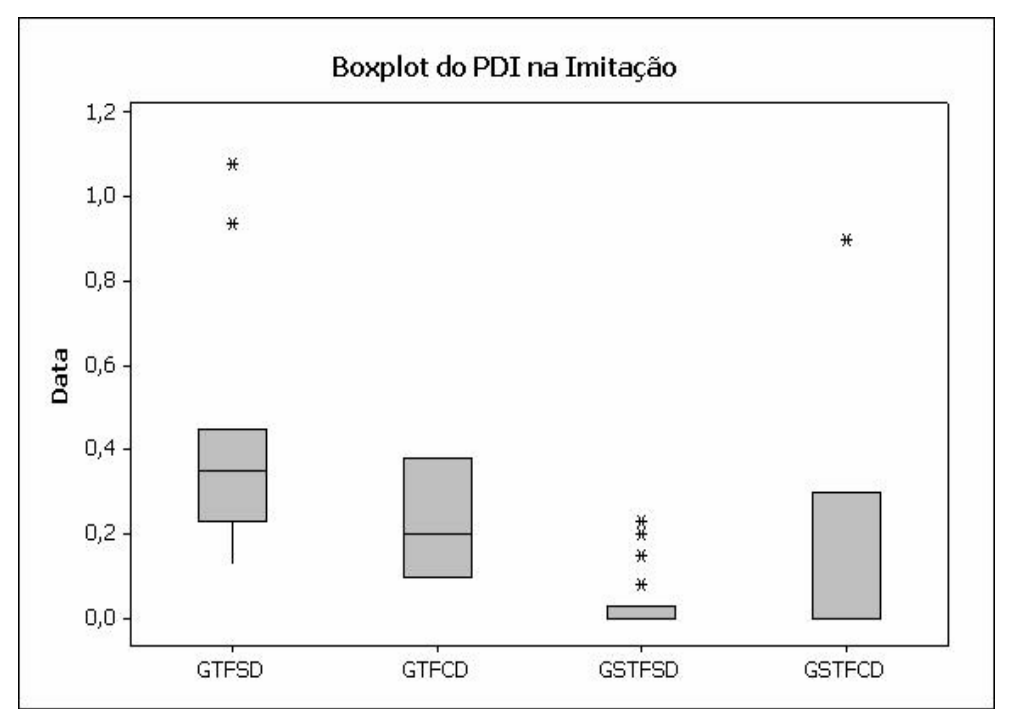

Legenda: GTFSD - grupo com transtorno fonológico sem distorção, GTFCD - grupo com transtorno fonológico com distorção, GSTFSD - grupo sem transtorno fonológico sem distorção, GSTFCD - grupo sem transtorno fonológico com distorção. 
Figura 36. Boxplot do PDI na Fala Espontânea.

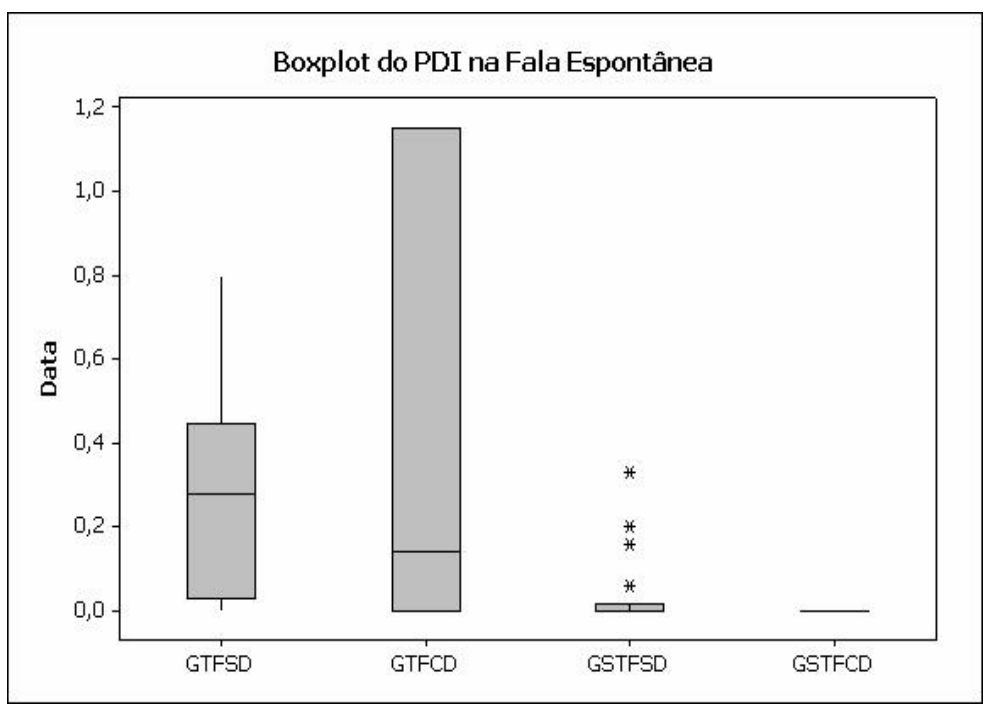

Legenda: GTFSD - grupo com transtorno fonológico sem distorção, GTFCD - grupo com transtorno fonológico com distorção, GSTFSD - grupo sem transtorno fonológico sem distorção, GSTFCD - grupo sem transtorno fonológico com distorção.

Os subgrupos sem distorção (GSTFSD e GTFSD) não apresentaram o índice RDI em nenhuma das provas, já que este índice analisa a ocorrência de distorções. O GSTFCD apresentou valores maiores do índice na prova de nomeação do que o GTFCD (Figuras 37, 38 e 39).

Figura 37. Boxplot do RDI na Nomeação.

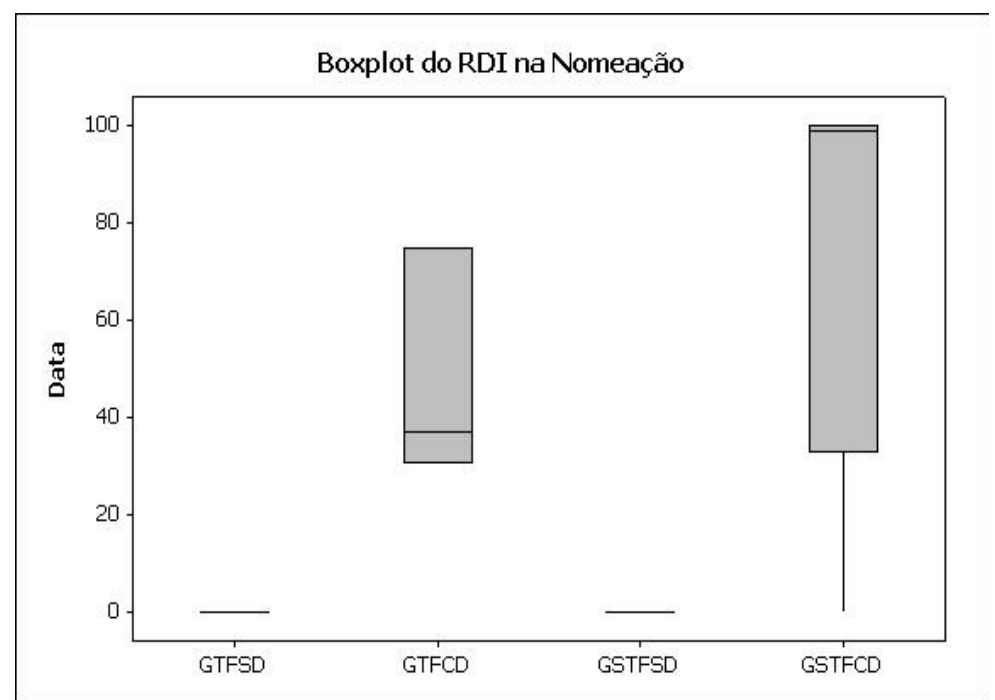

Legenda: GTFSD - grupo com transtorno fonológico sem distorção, GTFCD - grupo com transtorno fonológico com distorção, GSTFSD - grupo sem transtorno fonológico sem distorção, GSTFCD - grupo sem transtorno fonológico com distorção. 
38. Boxplot do RDI na Imitação.

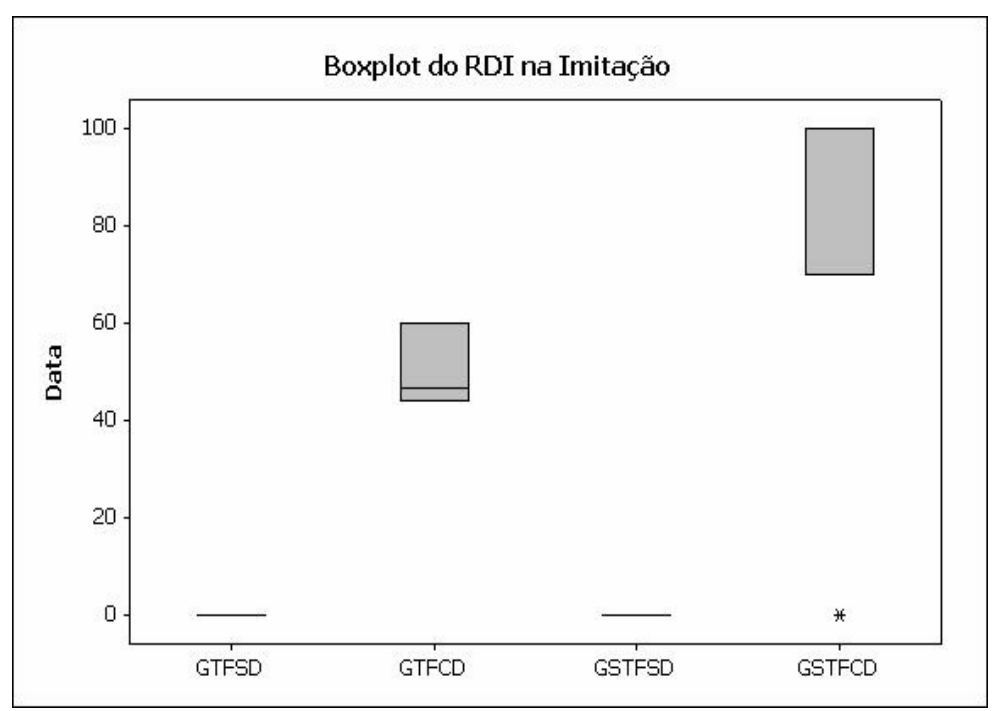

Legenda: GTFSD - grupo com transtorno fonológico sem distorção, GTFCD - grupo com transtorno fonológico com distorção, GSTFSD - grupo sem transtorno fonológico sem distorção, GSTFCD - grupo sem transtorno fonológico com distorção.

Figura 39. Boxplot do RDI na Fala Espontânea.

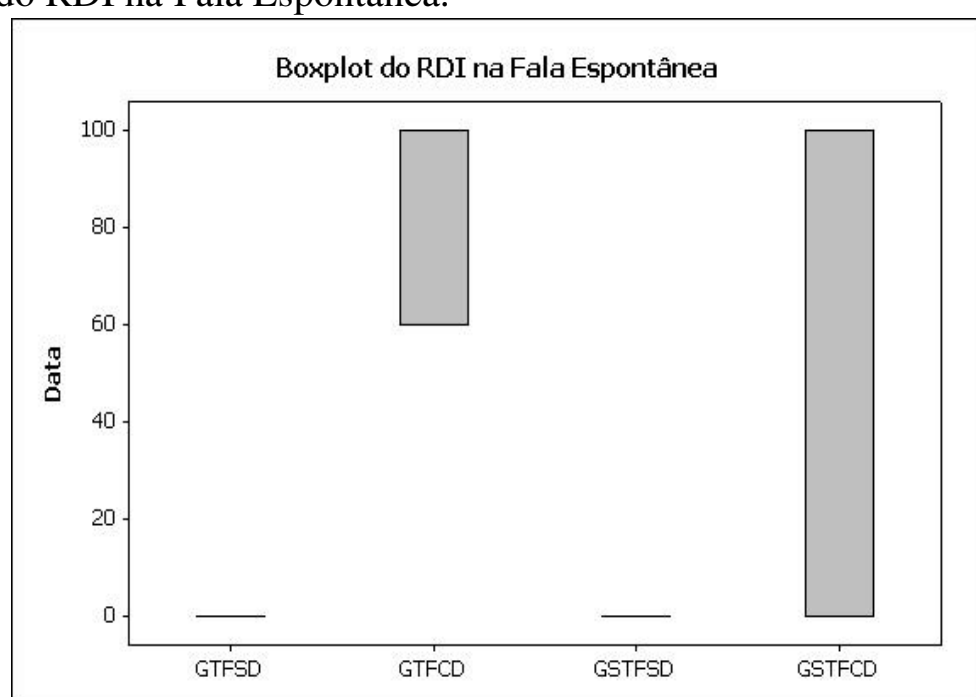

Legenda: GTFSD - grupo com transtorno fonológico sem distorção, GTFCD - grupo com transtorno fonológico com distorção, GSTFSD - grupo sem transtorno fonológico sem distorção, GSTFCD - grupo sem transtorno fonológico com distorção. 
O desempenho dos sujeitos no índice ACI nas provas de nomeação, imitação e fala espontânea pode ser observado nas Figuras 40 a 42. Nota-se que o GSTFSD foi o que apresentou maiores médias, seguido pelo GSTFCD, GTFSD e GTFCD em todas as provas.

Figura 40. Boxplot do ACI - Nomeação.

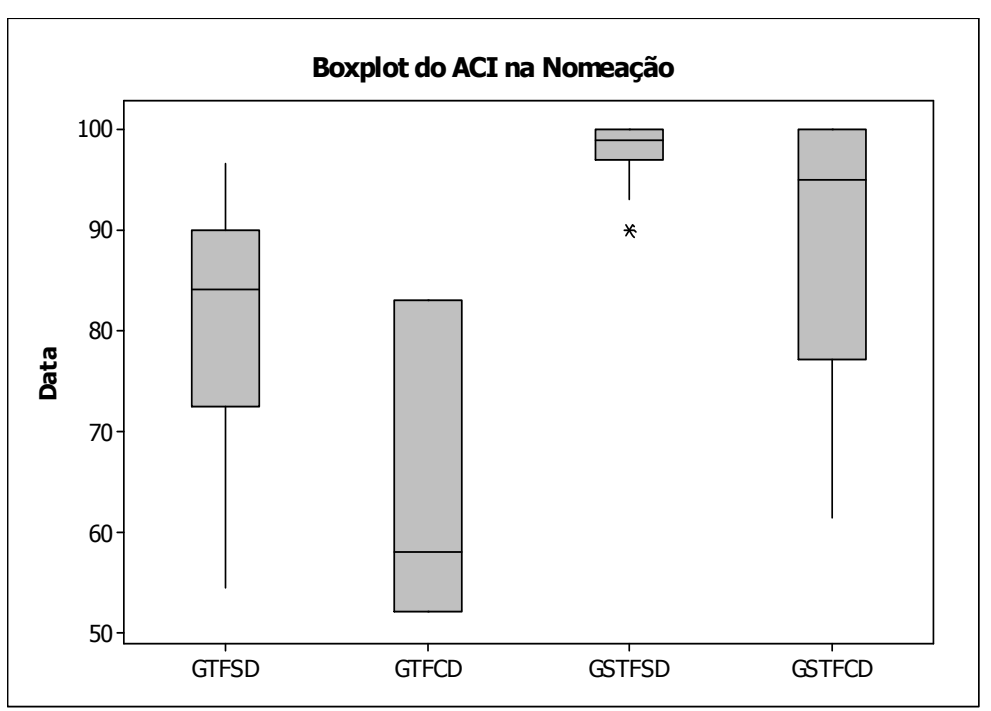

Legenda: GTFSD - grupo com transtorno fonológico sem distorção, GTFCD - grupo com transtorno fonológico com distorção, GSTFSD - grupo sem transtorno fonológico sem distorção, GSTFCD - grupo sem transtorno fonológico com distorção. 
Figura 41. Boxplot do ACI - Imitação.

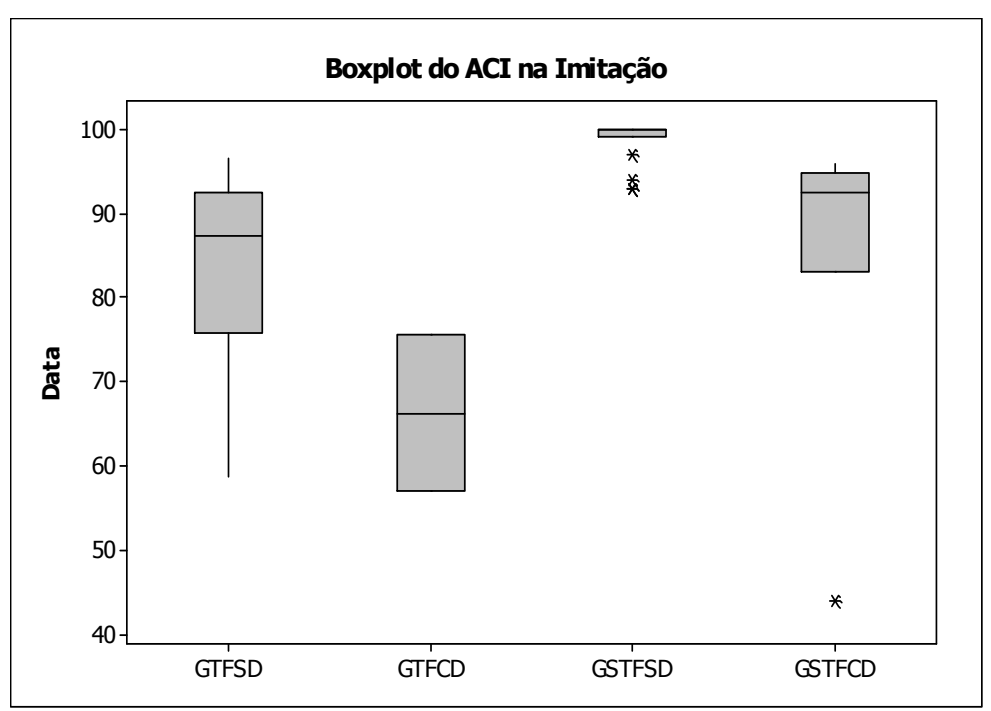

Legenda: GTFSD - grupo com transtorno fonológico sem distorção, GTFCD - grupo com transtorno fonológico com distorção, GSTFSD - grupo sem transtorno fonológico sem distorção, GSTFCD - grupo sem transtorno fonológico com distorção.

Figura 42. Boxplot do ACI - Fala Espontânea.

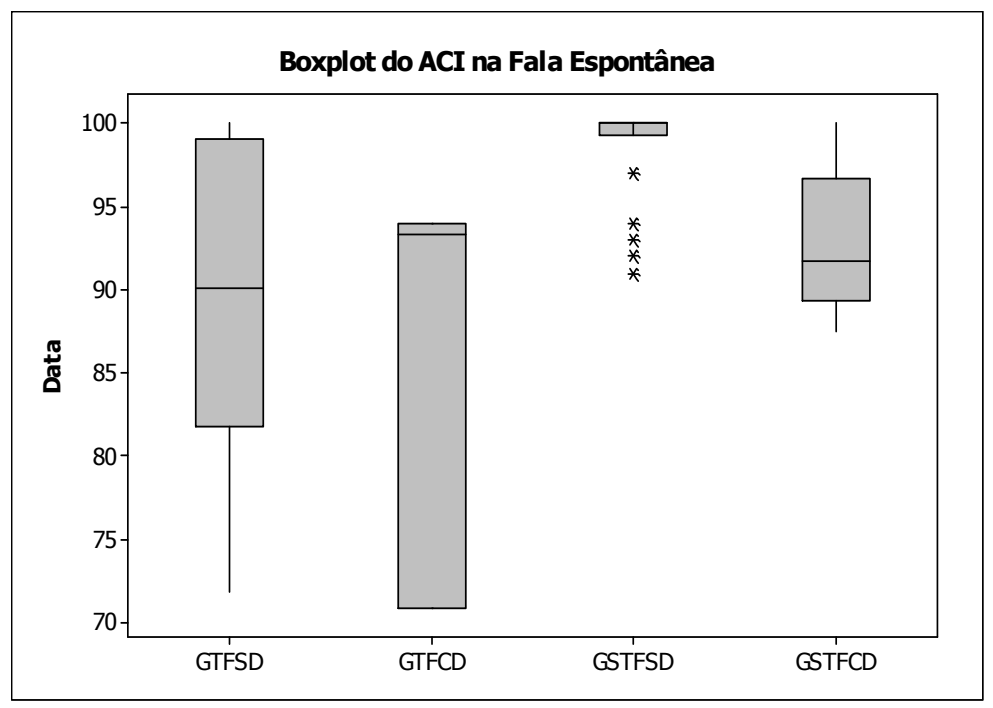

Legenda: GTFSD - grupo com transtorno fonológico sem distorção, GTFCD - grupo com transtorno fonológico com distorção, GSTFSD - grupo sem transtorno fonológico sem distorção, GSTFCD - grupo sem transtorno fonológico com distorção. 
Para comparar as médias dos índices de gravidade nas provas de imitação e nomeação e fala espontânea foi aplicado o teste de ANOVA (n sig 5\%) e foram realizadas as comparações múltiplas pelo método Bonferroni quando se observou diferença entre as diferenças médias dos grupos (Tabelas 39, 40 e 41).

Em alguns índices não são observados todos os grupos no comparativo, o grupo que não aparece no resultado ficou com valor intermediário entre os grupos, ou seja, não se diferiu de nenhum dos outros grupos.

Tabela 39. Comparação dos grupos GTFSD, GTFCD, GSTFCD e GSTFSD nos índices de gravidade na prova de nomeação.

\begin{tabular}{|c|c|c|c|c|c|c|c|}
\hline & & \multicolumn{4}{|c|}{ GRUPOS } & \multirow{2}{*}{$\begin{array}{l}\text { ANOVA } \\
(\mathbf{p})\end{array}$} & \multirow[t]{2}{*}{ Resultado } \\
\hline & & GTFSD & GTFCD & GSTFSD & GSTFCD & & \\
\hline \multirow[t]{3}{*}{ PCC } & Média & 81,68 & 81,17 & 97,95 & 90,10 & \multirow{3}{*}{$<0,001 *$} & \multirow{3}{*}{$\begin{array}{l}\text { GTFSD }=\text { GTFCD }=\text { GSTFCD }< \\
\text { GSTFSD }\end{array}$} \\
\hline & $\begin{array}{l}\text { Desvio- } \\
\text { padrão }\end{array}$ & 11,96 & 12,57 & 2,75 & 9,54 & & \\
\hline & $\mathrm{n}$ & 12 & 3 & 22 & 7 & & \\
\hline \multirow[t]{3}{*}{ PCC-R } & Média & 81,68 & 89,23 & 97,95 & 98,56 & \multirow{3}{*}{$<0,001 *$} & \multirow{3}{*}{ GTFSD $<$ GSTFSD = GSTFCD } \\
\hline & $\begin{array}{l}\text { Desvio- } \\
\text { padrão }\end{array}$ & 11,96 & 8,87 & 2,75 & 2,64 & & \\
\hline & $\mathrm{n}$ & 12 & 3 & 22 & 7 & & \\
\hline \multirow[t]{3}{*}{ PDI } & Média & 0,47 & 0,28 & 0,07 & 0,66 & \multirow{3}{*}{$0,001 *$} & \multirow{3}{*}{ GTFSD $=$ GSTFCD $>$ GSTFSD } \\
\hline & $\begin{array}{l}\text { Desvio- } \\
\text { padrão }\end{array}$ & 0,33 & 0,24 & 0,06 & 0,43 & & \\
\hline & $\mathrm{n}$ & 12 & 3 & 14 & 3 & & \\
\hline \multirow[t]{3}{*}{ RDI } & Média & & 47,57 & & 85,72 & & \multirow{3}{*}{ GTFCD = GSTFCD } \\
\hline & $\begin{array}{l}\text { Desvio- } \\
\text { padrão }\end{array}$ & & 23,97 & & 26,76 & 0,077 & \\
\hline & $\mathrm{n}$ & & 3 & & 6 & & \\
\hline \multirow[t]{3}{*}{ ACI } & Média & 81,68 & 64,47 & 97,95 & 88,93 & & \multirow{3}{*}{$\begin{array}{l}\text { GTFCD }<\text { GTFSD }=\text { GSTFCD }< \\
\text { GSTFSD }\end{array}$} \\
\hline & $\begin{array}{l}\text { Desvio- } \\
\text { padrão }\end{array}$ & 11,96 & 16,31 & 2,75 & 14,36 & $<0,001 *$ & \\
\hline & $\mathrm{n}$ & 12 & 3 & 22 & 7 & & \\
\hline
\end{tabular}

Legenda: GTFSD - grupo com transtorno fonológico sem distorção, GTFCD - grupo com transtorno fonológico com distorção, GSTFSD - grupo sem transtorno fonológico sem distorção, GSTFCD - grupo sem transtorno fonológico com distorção, ACI - Articulation Competence Index, PCC - Percentage of Consonants Correct, PCC-R - Percentage of consonants Correct - Revised, PDI - Process Density Index, RDI - Relative Distortion Index. 
Tabela 40. Comparação dos grupos GTFSD, GTFCD, GSTFCD e GSTFSD nos índices de gravidade na prova de imitação.

\begin{tabular}{|c|c|c|c|c|c|c|c|}
\hline & & \multicolumn{4}{|c|}{ GRUPOS } & \multirow{2}{*}{$\begin{array}{c}\text { ANOVA } \\
(p)\end{array}$} & \multirow[t]{2}{*}{ Resultado } \\
\hline & & GTFSD & GTFCD & GSTFSD & GSTFCD & & \\
\hline \multirow[t]{3}{*}{ PCC } & Média & 83,68 & 82,30 & 98,77 & 88,61 & \multirow{3}{*}{$<0,001 *$} & \multirow{3}{*}{$\begin{array}{l}\text { GTFSD = GTFCD = GSTFCD } \\
<\text { GSTFSD }\end{array}$} \\
\hline & $\begin{array}{l}\text { Desvio- } \\
\text { padrão }\end{array}$ & 12,17 & 10,95 & 2,33 & 6,26 & & \\
\hline & $\mathrm{n}$ & 12 & 3 & 22 & 7 & & \\
\hline \multirow[t]{3}{*}{ PCC-R } & Média & 83,68 & 90,57 & 98,77 & 97,71 & \multirow{3}{*}{$<0,001 *$} & \multirow{3}{*}{$\begin{array}{l}\text { GTFSD }<\text { GSTFSD } \\
\text { GSTFCD }\end{array}$} \\
\hline & $\begin{array}{l}\text { Desvio- } \\
\text { padrão }\end{array}$ & 12,17 & 6,81 & 2,33 & 4,60 & & \\
\hline & $\mathrm{n}$ & 12 & 3 & 22 & 7 & & \\
\hline \multirow[t]{3}{*}{ PDI } & Média & 0,43 & 0,23 & 0,10 & 32,80 & \multirow{3}{*}{0,051} & \multirow{3}{*}{$\begin{array}{l}\text { GTFSD }=\text { GTFCD = GSTFSD } \\
=\text { GSTFCD }\end{array}$} \\
\hline & $\begin{array}{l}\text { Desvio- } \\
\text { padrão }\end{array}$ & 0,29 & 0,14 & 0,09 & 56,46 & & \\
\hline & $\mathrm{n}$ & 12 & 3 & 7 & 3 & & \\
\hline \multirow[t]{3}{*}{ RDI } & Média & & 50,20 & & 92,50 & \multirow{3}{*}{$0,001 *$} & \multirow{3}{*}{ GTFCD < GSTFCD } \\
\hline & $\begin{array}{l}\text { Desvio- } \\
\text { padrão }\end{array}$ & & 8,59 & & 12,55 & & \\
\hline & $\mathrm{n}$ & & 3 & & 6 & & \\
\hline \multirow[t]{3}{*}{ ACI } & Média & 83,68 & 66,23 & 98,77 & 84,81 & \multirow{3}{*}{$<0,001 *$} & \multirow{3}{*}{$\begin{array}{l}\text { GTFCD }<\text { GTFSD }=\text { GSTFCD } \\
<\text { GSTFSD }\end{array}$} \\
\hline & $\begin{array}{l}\text { Desvio- } \\
\text { padrão }\end{array}$ & 12,17 & 9,25 & 2,33 & 18,49 & & \\
\hline & $\mathrm{n}$ & 12 & 3 & 22 & 7 & & \\
\hline
\end{tabular}

Legenda: GTFSD - grupo com transtorno fonológico sem distorção, GTFCD - grupo com transtorno fonológico com distorção, GSTFSD - grupo sem transtorno fonológico sem distorção, GSTFCD - grupo sem transtorno fonológico com distorção, ACI - Articulation Competence Index, PCC - Percentage of Consonants Correct, PCC-R - Percentage of consonants Correct - Revised, PDI - Process Density Index, RDI - Relative Distortion Index. 
Tabela 41. Comparação nos grupos GTFSD, GTFCD, GSTFCD e GSTFSD nos índices de gravidade na prova de fala espontânea.

\begin{tabular}{|c|c|c|c|c|c|c|c|}
\hline & & \multicolumn{4}{|c|}{ Grupos } & \multirow{2}{*}{$\begin{array}{l}\text { ANOVA } \\
(\mathbf{p})\end{array}$} & \multirow[t]{2}{*}{ Resultado } \\
\hline & & GTFSD & GTFCD & GSTFSD & GSTFCD & & \\
\hline \multirow[t]{3}{*}{$\mathbf{P C C}$} & Média & 89,32 & 87,70 & 98,50 & 88,10 & \multirow{3}{*}{$<0,001 *$} & \multirow{3}{*}{$\begin{array}{l}\text { GTFSD }=\text { GTFCD }=\text { GSTFCD }< \\
\text { GSTFSD }\end{array}$} \\
\hline & $\begin{array}{l}\text { Desvio- } \\
\text { padrão }\end{array}$ & 9,41 & 5,76 & 3,00 & 9,99 & & \\
\hline & $\mathrm{n}$ & 12 & 3 & 22 & 7 & & \\
\hline \multirow[t]{3}{*}{ PCC-R } & Média & 89,32 & 97,57 & 98,50 & 100,00 & \multirow{3}{*}{$<0,001 *$} & \multirow{3}{*}{ GTFSD $<$ GSTFSD = GSTFCD } \\
\hline & $\begin{array}{l}\text { Desvio- } \\
\text { padrão }\end{array}$ & 9,41 & 4,21 & 3,00 & 0,00 & & \\
\hline & $\mathrm{n}$ & 12 & 3 & 22 & 7 & & \\
\hline \multirow[t]{3}{*}{ PDI } & Média & 0,40 & 0,65 & 0,19 & 0,09 & \multirow{3}{*}{0,199} & \multirow{3}{*}{$\begin{array}{l}\text { GTFSD }=\text { GTFCD }=\text { GSTFSD }= \\
\text { GSTFCD }\end{array}$} \\
\hline & $\begin{array}{l}\text { Desvio- } \\
\text { padrão }\end{array}$ & 0,22 & 0,71 & 0,10 & . & & \\
\hline & $\mathrm{n}$ & 9 & 2 & 5 & 1 & & \\
\hline \multirow[t]{3}{*}{ RDI } & Média & & 86,67 & & 100,00 & \multirow{3}{*}{0,220} & \multirow{3}{*}{ GTFCD = GSTFCD } \\
\hline & $\begin{array}{l}\text { Desvio- } \\
\text { padrão }\end{array}$ & & 23,09 & & 0,00 & & \\
\hline & $\mathrm{n}$ & & 3 & & 5 & & \\
\hline \multirow[t]{3}{*}{ ACI } & Média & 89,32 & 86,07 & 98,50 & 92,66 & \multirow{3}{*}{$<0,001 *$} & \multirow{3}{*}{ GTFSD $=$ GTFCD $<$ GSTFSD } \\
\hline & $\begin{array}{l}\text { Desvio- } \\
\text { padrão }\end{array}$ & 9,41 & 13,14 & 3,00 & 4,40 & & \\
\hline & $\mathrm{n}$ & 12 & 3 & 22 & 7 & & \\
\hline
\end{tabular}

Legenda: GTFSD - grupo com transtorno fonológico sem distorção, GTFCD - grupo com transtorno fonológico com distorção, GSTFSD - grupo sem transtorno fonológico sem distorção, GSTFCD - grupo sem transtorno fonológico com distorção, ACI - Articulation Competence Index, PCC - Percentage of Consonants Correct, PCC-R - Percentage of consonants Correct - Revised, PDI - Process Density Index, RDI - Relative Distortion Index. 
DISCUSSÃO 
Esta pesquisa buscou estudar as distorções de fala em crianças com transtorno fonológico e com desenvolvimento típico para a produção de sons fricativos alveolares e palatais, bem como líquidos laterais e vibrantes simples, por meio das provas de nomeação, imitação (WERTZNER, 2004), fala espontânea, prova específica para verificação da distorção, palatografia e linguografia e aplicação dos índices de gravidade PCC, PCC-R, PDI, RDI e ACI.

Em relação à faixa etária, pôde-se notar que o GTF foi composto preferencialmente por crianças na faixa de seis anos. Esse fato foi observado em outras pesquisas com crianças falantes do Português Brasileiro e do Inglês, os quais mostraram que o transtorno fonológico é, com freqüência, diagnosticado na faixa etária de cinco e sete anos (SHRIBERG e KWIATKOWSKI, 1982a; DSM-IV, 1995; WERTZNER, 2000, 2002; PAGAN, 2003; CASTRO, 2004).

Independentemente do som distorcido nas provas de nomeação e imitação e fala espontânea, tanto no GSTF como no GTF a faixa etária de sete anos foi a que teve mais ocorrências de distorções. Apesar disso, no primeiro grupo, não houve diferença significante entre as faixas etárias, fato que indica a presença de distorções em crianças no período de aquisição fonológica.

É interessante destacar que as crianças na faixa etária de sete anos estão no final do desenvolvimento fonológico e fonético, no qual omissões e substituições típicas do desenvolvimento já estão superadas, restando apenas alterações fonéticas. Tais alterações podem ainda ocorrer em função do amadurecimento motor dos órgãos da fala, bem como do processamento motor, além das falhas dentárias que tornam as distorções mais evidentes (KENT, 1992; KENT, 2000, GREEN et al., 2000).

$\mathrm{Na}$ literatura são encontrados estudos com crianças com desenvolvimento típico que mostram um contínuo refinamento do desempenho da fala em crianças (GREEN et al., 2000; DODD et al., 2003). Especificamente considerando a presença ou ausência de ceceio anterior, também em crianças com desenvolvimento típico, Fonseca et al. (2005) não observaram relação estatisticamente significante quanto à idade cronológica.

No GTF as distorções não foram observadas em todas as faixas etárias. Percebe-se que estas ocorrem em crianças com desenvolvimento típico, mas podem permanecer por mais tempo e somar-se às demais dificuldades encontradas pela criança. Tal permanência pode estar relacionada a alguma dificuldade motora que ocorre em alguns casos de transtorno fonológico (SHRIBERG et al., 1997; GRUBER, 1999; WERTZNER et al., 2005a).

Considerando o gênero, a análise estatística descritiva evidenciou que no GTF houve predominância do feminino, nas faixas etárias de seis e sete anos, enquanto a faixa de cinco anos 
teve maior ocorrência de meninos. A literatura mostra o contrário, ou seja, o transtorno fonológico acomete mais meninos do que meninas (SHRIBERG et al., 1986; GIERUT, 1998; WERTZNER, 2002; CASTRO, 2004). Ressalta-se que o fato dos sujeitos da pesquisa terem sido selecionados em função dos critérios relativos à idade possa ter contribuído para essa diferença da ocorrência de gênero com os demais trabalhos.

Após a subdivisão do GTF, quanto à presença de distorção de fala nas provas de nomeação e imitação e fala espontânea, foi demonstrado que o GTFCD foi constituído por mais sujeitos do gênero masculino.

Já no GSTFCD, a análise do gênero mostrou que o feminino foi o que mais apresentou distorção. O estudo de Paura et al. (1999) também apontou mais alterações articulatórias em crianças com desenvolvimento típico de linguagem do gênero feminino $(26,20 \%)$ do que no masculino (20,5\%). Outros estudos com crianças com desenvolvimento típico não observaram relação estatisticamente significante entre os gêneros (FONSECA et al., 2005). Outros ainda encontraram predomínio de meninos com distorções de fala em relação às meninas (TOMÉ et al.; 1998 e TOMÉ et al., 2004).

Dodd et al. (2003) concluíram que as meninas geralmente têm melhores desempenhos do que os meninos em funções verbais e lingüísticas, pois os meninos parecem ser biologicamente mais vulneráveis a problemas de linguagem, devido provavelmente a maturação cerebral e dos órgãos de fala e à socialização.

Dessa maneira, a questão da relação entre o gênero e os tipos de erros possíveis no transtorno fonológico apresentado por crianças ainda não apresenta um consenso entre os pesquisadores da área.

As distorções de fala ocorreram em 23\% das crianças do GSTF. Esta proporção, todavia, foi inferior às encontradas em outros estudos, como o de Moura (1994) e o de Tomé et al. (2004). Neste último, detectaram o ceceio anterior em pouco mais da metade das crianças de três a seis anos de idade avaliadas, sem queixa relacionada à fala. Há que se destacar que as idades dos sujeitos da presente pesquisa e a de Tomé et al. (op cit.) são distintas, o que pode explicar a diferença encontrada, na medida em que estudaram faixas etárias mais no início da aquisição fonológica e fonética, na qual esse tipo de erro é mais esperado do que em faixas mais velhas.

Outra pesquisa realizada com crianças com diagnóstico de transtorno fonológico e falantes do Português Brasileiro encontrou que $25 \%$ de sujeitos com desenvolvimento típico de linguagem apresentaram distorção de fala. Nos sujeitos do GTF verificou-se que $20 \%$ apresentaram distorção de fala, contra $75 \%$ de sujeitos com diagnóstico de transtorno fonológico 
(WERTZNER et al. 2005a). Deve-se destacar que no estudo citado foi observada a distorção em qualquer som, ao contrário da presente pesquisa, na qual foram verificados sete sons específicos e em uma faixa etária de quatro a 12 anos. No entanto, os grupos com desenvolvimento típico foram semelhantes quanto à ocorrência de distorções, indicando que as crianças com desenvolvimento típico apresentam menor variação nos sons distorcidos.

A comparação entre os grupos mostrou que de forma geral não houve diferença significante entre a ocorrência de distorção nos sujeitos do GSTF e GTF, evidenciando que para os sons estudados as distorções são esperadas nas faixas etárias estudadas.

A análise dos sons distorcidos nas provas diagnósticas mostrou que os sujeitos do GSFT apresentaram distorção nas provas de nomeação, imitação e fala espontânea nos sons [s], [z], [S] e [1]. Especificamente para a faixa etária de sete anos, o GSTFCD apresentou produção distorcida para $[\mathrm{s}],[\mathrm{z}]$ e [1]; os de seis anos apenas [s] e [S]; e os de cinco anos para [s], [z] e [1]. No entanto, não foi encontrada diferença significante entre as faixas etárias quanto à presença de distorção em cada som.

Para o GTF foram encontradas produções distorcidas para os sons [s], [z] e [r]. Nenhum sujeito com seis anos apresentou distorção de fala, apesar de ser a faixa etária com maior número de sujeitos. Os sujeitos na faixa etária de cinco anos distorceram $[\mathrm{s}] \mathrm{e}[\mathrm{z}]$ e os de sete anos os sons [s], [z] e [ᄃ]. Também não foi encontrada diferença significante entre as faixas etárias quanto à presença de distorção em cada som neste grupo.

Em um estudo realizado com crianças de uma população semelhante ao da presente pesquisa, Wertzner et al. (2005a) verificaram a presença de distorção de fala em crianças com desenvolvimento típico nos sons $[\mathrm{s}, \mathrm{z}, \mathrm{y}, 3, \mathrm{t}]$ e em crianças com diagnóstico de transtorno fonológico nos sons $[\mathrm{s}, \mathrm{z}, \mathrm{y}, 3, \mathrm{~S}, \Lambda, \mathrm{r}, \mathrm{t}, \mathrm{n}, \mathrm{k}, \mathrm{d}, \mathrm{f}, \mathrm{g}]$. Observa-se que, assim como na presente pesquisa, ambos os grupos distorceram os sons $[\mathrm{s}]$ e $[\mathrm{z}]$ e apenas o grupo com transtorno fonológico apresentou distorção no [ $\ulcorner$. Dessa maneira, parece que a distorção do [ $\ulcorner$ ] está mais relacionada ao transtorno fonológico.

Um aspecto observado é que os sons fricativos alveolares apresentam maior ocorrência de distorção nos dois grupos estudados. Tal fato pode decorrer da zona de articulação desses sons, a região alveolar. Alguns estudos referem que em crianças no início da aquisição fonética a produção do som alveolar com projeção da ponta da língua para uma posição mais anterior da cavidade oral, contra os dentes ou até mesmo entre as arcadas dentárias pode ser aceita como 
adequada. Tal articulação tende a ser corrigida sozinha quando a criança refina os movimentos da língua e assim a posiciona de forma a produzir o som alvo adequadamente (SEIFERT et al., 1997; D`ANGELIS, 2000; TOMÉ et al., 2004).

A presença de distorção do som [ $[$ ] apenas no GTF pode ser vinculada ao fato das líquidas serem os últimos fonemas a serem adquiridos, tanto por implicações fonológicas como fonéticas, relacionadas à maturidade da produção motora do som. Isso torna esses sons mais suscetíveis a distúrbios em crianças com atraso na aquisição fonológica (WERTZNER, 1998). Várias pesquisas do Português Brasileiro indicaram que no transtorno fonológico os processos fonológicos mais ocorrentes e de eliminação mais tardia envolvem as líquidas, como os processos de simplificação de líquidas e de simplificação do encontro consonantal (YAVAS e LAMPRECHT, 1990; WERTZNER e OLIVEIRA, 2002; WERTZNER, 2002).

Na medida em que o transtorno fonológico inclui não só casos de simplificações de regras fonológicas, mas também aqueles em que há dificuldade motora para produzir os sons da fala, a avaliação deve ser composta por provas que detectem tanto as alterações fonéticas como fonológicas (WERTZNER, 2003).

A comparação da ocorrência de distorção entre as provas aplicadas indicou que, tanto para o GSTF como para o GTF, as de nomeação e imitação foram as que tiveram maior ocorrência de distorções de fala. Tal resultado pode ser justificado por serem estas provas compostas por palavras foneticamente balanceadas, e a prova de fala espontânea não, pois depende da seleção feita pela criança. Assim sendo, na fala espontânea a criança pode realizar a evitação dos sons que sabe que são produzidos erroneamente. Além disso, as crianças com transtorno fonológico podem ter uma grande variedade de erros e produções variadas para uma mesma palavra (INGRAM, 1976, 2002; GARRET e MORAN, 1992).

No entanto, não foram observados indícios de diferenças significantes quanto à presença de distorções nos sons entre as provas de nomeação, imitação e fala espontânea, tanto no GSTF como no GTF. Tal fato indica que as três provas podem ser utilizadas como instrumentos diagnósticos para detecção de distorção de fala.

Esse resultado concorda com o encontrado por Wertzner et al. (2005a), que ao estudarem a distorção de fala em crianças com e sem transtorno fonológico, concluíram que provas de nomeação, imitação e fala espontânea se mostraram bons métodos de avaliação, já que a correlação estatística entre eles foi alta. 
A comparação entre as provas de nomeação, imitação e fala espontânea quanto ao número de ocorrências de produção correta e de distorção nos sons $[\mathrm{s}],[\mathrm{z}],\left[\int\right]$ e $[1]$ no GSTF e nos sons, $[\mathrm{s}],[\mathrm{z}]$ e $[\ulcorner]$ no GTF mostrou não haver diferenças entre as provas. O que indica que as crianças que realizam distorção de fala as fazem nas três provas, evidenciando que o modelo de repetição único como é feito na prova de imitação não foi suficiente para provocar a resposta adequada nessas crianças. Diferentemente, Castro (2004), ao estudar testes de estimulabilidade específicos para cada som, observou que a prova de imitação de sílabas mostrou diferença estatisticamente significante em relação às provas de nomeação de figuras e imitação de palavras no grupo controle e no grupo com transtorno fonológico.

A comparação entre a ocorrência de distorção entre os grupos GSTF e GTF nas provas de nomeação, imitação e fala espontânea mostrou que a única diferença encontrada foi nas provas de imitação e fala espontânea na faixa etária de sete anos, com maior ocorrência de distorção do [s] no GTF.

Após a análise das provas diagnósticas, foi verificada a presença ou ausência de distorção de fala, para confirmar a presença de distorções nestas provas e averiguar e classificar perceptivamente os tipos de distorções apresentadas. Para tanto, foi aplicada a prova específica para verificação de distorção no som específico que a criança realizou produção distorcida. Esta prova foi composta por imitação de sílabas e palavras, tem a vantagem de ser composta apenas pelo som distorcido, com todas as vogais e em diferentes posições silábicas, o que permite maior precisão no diagnóstico.

Na prova específica para verificação da distorção, o GSTFCD apresentou maior média de distorção para os [s], [z] e [S] em sílabas, enquanto que no GTFCD não foram observadas diferenças entre a média de distorção em sílabas e em palavras. Este fato mostra que a distorção encontrada no GTFCD é mais consistente, não havendo diferenças em relação ao aumento de distorção em contextos variados. Já o GSTFCD aprimorou o som quando contextualizado (INGRAM, 2002; CROSBIES et al., 2005).

O som [1] foi o único no GSTFCD que em média foi mais distorcido na imitação de palavras do que sílabas, provavelmente devido à interferência do contexto, além dos fonemas líquidos serem adquiridos mais tardiamente (WERTZNER, 1992, 1998). Outros aspectos podem estar envolvidos, como a necessidade de movimentos mais precisos da língua, adquiridos à medida que a criança atinge a maturidade (WERTZNER, 2000). 
Para o GTFCD também houve distorção do [r], sendo este o único som em que o sujeito manteve $100 \%$ de distorção nas provas de imitação de sílabas e palavras. Outros estudos do Português Brasileiro com crianças com diagnóstico de transtorno fonológico também observaram maior dificuldade relacionada à líquida vibrante (WERTZNER, 2002; PAGAN, 2003; CASTRO, 2004, WERTZNER et al., 2005a).

A prova específica para verificação da distorção se mostrou sensível, pois um sujeito na faixa etária de sete anos do GSTF, que havia apresentado distorção nos sons [s] e [z] nas provas de imitação e nomeação, nesta prova não apresentou nenhum tipo de distorção para os mesmos sons.

No GTFCD esta prova também foi importante para confirmação da distorção, pois um sujeito na faixa etária de cinco anos, que havia apresentado distorção nos sons [s] nas provas de imitação, nomeação e fala espontânea e no [z] nas provas de imitação e nomeação, não apresentou nenhum tipo de distorção para estes sons na prova específica, mas realizou $100 \%$ de substituição de ambos os sons para [S]. Deve-se considerar que nas provas de nomeação, imitação e fala espontânea a criança havia apresentado inconsistência dos erros fonológicos, com vários processos fonológicos, entre eles a posteriorização para palatal e a frontalização de palatal, que talvez tenham contribuído para a caracterização da presença de distorção durante a transcrição.

Além disso, um outro sujeito na faixa etária de sete anos do GTF, que havia apresentado distorção de fala nas provas diagnósticas nos sons [s] e [z], realizou duas substituições durante a prova de imitação de sílabas na prova de verificação da distorção do [z] por [3], mas em seu sistema fonológico não havia sido observado o processo fonológico de posteriorização de palatal, indicando a instabilidade dos sistemas fonéticos e fonológicos.

A literatura mostra que esses casos não são isolados, pois com freqüência pode ser difícil avaliar a extensão do transtorno fonológico e/ou a dificuldade motora, o que dificulta determinar se um erro é devido a um déficit motor ou fonológico (FOLKINS e BLEILE, 1990).

Em relação aos tipos de distorção encontrados nas provas de imitação de sílabas e palavras, no GSTFCD e no GTFCD, para o som [s] o tipo de distorção que mais ocorreu foi PALCD, para o som [z] foi PLSD para o GSTFCD e PALCD para o GTFCD. Na literatura também existe referência a este tipo de distorção, conhecida como ceceio anterior, explicada pela fisiologia da produção dos sons fricativos alveolares durante o desenvolvimento da criança (SEIFERT et al., 1997; TOMÉ et al., 2004). 
No GSTFCD, além dos sons [s] e [z], também foram observadas distorções no som [ $\left.\int\right]$ do tipo ECD e no som [1] do tipo PLSD. Estas distorções também podem ser justificadas pelo desenvolvimento motor, já que para o [1] há mudança do ponto articulatório, sendo a língua projetada mais anteriormente, assim como nas fricativas alveolares. Já no [ $]$, não há mudança do ponto, mas apenas esforço articulatório, sendo interpretada como uma variação articulatória devido ao desenvolvimento fonético (KENT, 1976).

No GTFCD também foi observada produção distorcida do som [r], com $100 \%$ de distorção nas sílabas e palavras do tipo PoCD enquanto as demais distorções nos sons [s] e [z] foram iguais ao GSTFCD.

Para ambos os grupos houve uma manutenção do tipo de distorção nas provas de imitação de sílabas e palavras, mostrando que as duas provas são importantes para o diagnóstico.

A literatura relata que existe a variabilidade da produção também em produções corretas, mas o ouvinte possui uma tolerância natural quanto a este aspecto. Esta aceitabilidade sofre a influência de vários fatores, sendo a maioria delas devidas à proximidade de sons vizinhos, ou seja, da fonética combinatória, além da posição do som na palavra (MALMBERG, 1954; CORNEAU, 2000; MENN e STOEL-GAMMON, 2001).

Além disso, todas as crianças deste estudo encontram-se em desenvolvimento da fala. A partir desta observação e considerando-se que este desenvolvimento ocorre num período de tempo extenso, há evidências de que as crianças não possuem controle neuromuscular para produzir os sons, e conseqüentemente precisam adotar estratégias para se aproximar do modelo adulto de fala (GREEN et al., 2002). Este mesmo estudo demonstrou que o lábio superior, o inferior e a mandíbula têm programas de desenvolvimentos diferentes, sugerindo que os padrões iniciais de movimentos da mandíbula sustentam a fundação da aquisição de outros padrões que exigem habilidades motoras mais especializadas. Assim, as crianças até seis anos dependem da movimentação da mandíbula para se aproximar do alvo da fala adulta, sendo que esta possibilidade compete com seus inventários fonéticos e as predispõem a produzir erros de fala e distorções previsíveis.

Ainda sobre o desenvolvimento motor da fala, Kent $(1999,2004)$ refere que a partir dos oito anos inicia-se o refinamento da habilidade motora da fala, que se extende até os 16 anos, salientando que a aquisição da fala é um processo multifatorial. Esses dados confirmam os achados do presente estudo, em que crianças na faixa etária de sete anos tanto do GSTF como do GTF ainda apresentaram distorção de fala. 
Em relação à motricidade oral, no GSTF a maioria dos sujeitos se encontrava na fase de dentição mista. No entanto, no GSTFCD houve mais sujeitos nessa fase do que o GSTFSD. No GTF foi observado que a maioria dos sujeitos apresentou dentição decídua e, sendo assim, aparentemente, a ocorrência na porcentagem dos grupos com e sem distorção foi semelhante.

Dessa maneira, os dados sugerem que no GTFCD a fase da dentição não teve influência na presença de distorção. No GSTFCD a dentição mista pode ter influenciado a presença de produção distorcida, fato que concorda com a literatura, a qual refere que crianças com desenvolvimento típico e falantes do Português brasileiro que se encontravam na fase de dentição mista apresentavam maior incidência de ceceio do que em fase de dentição decídua (RODRIGUES et al., 1999), devido à maior facilidade de anteriorização de língua, pela ausência de dentes anteriores.

Outro aspecto observado neste estudo foi que no GSTFSD a maioria dos sujeitos apresentou oclusão adequada. No entanto, ocorreu também mordida aberta anterior, cruzada anterior, cruzada posterior, aberta anterior associada à cruzada posterior, sobremordida e overjet. Já no GSTFCD, a maioria dos sujeitos foram classificados como apresentando maloclusão do tipo mordida aberta anterior associada a posterior. Desta forma, no GSTFCD a presença de mordida aberta anterior pode ter contribuído para a presença de distorção.

Estudos como o de Tomé et al. (2004) também relatam que a presença de alterações oclusais no plano vertical anterior pode representar um risco para o desenvolvimento de ceceio. Por outro lado, Paura et al. (1999) não encontraram relação significante entre a presença de maloclusão e ceceio em crianças com desenvolvimento típico e falantes do Português brasileiro.

Outro instrumento aplicado com o intuito de obter maior precisão no reconhecimento das distorções foi a palatografia e linguografia, já que esses instrumentos não aparecem na literatura como instrumentos de estudo da produção dos sons em crianças, tanto com desenvolvimento típico como no transtorno fonológico. Para ter algum parâmetro de comparação, foram realizadas palatografias em crianças do GSTF sem alterações de motricidade orofacial para os sons estudados na pesquisa.

Dessa forma, a análise mostrou que as duas crianças do GSTFSD que foram analisadas apresentaram dentição mista, sendo que a de sete anos tinha ausência de incisivo central superior direito.

As manchas da palatografia e linguografia foram assimétricas e com interrupção, com tensão fraca para os sujeitos de cinco anos e forte para os de sete anos. Assimetria, interrupção e tensão das manchas podem indicar que essas crianças encontram-se em fase de aperfeiçoamento e 
desenvolvimento do sistema articulatório para os sons verificados. De acordo com Casaes (1990), a intensidade articulatória pode ser real ou não, dependendo da demora na pressão da língua contra o palato durante a realização articulatória. Quanto à assimetria, a sua ocorrência pode não prejudicar a articulação, pois existem condições compensatórias dos órgãos fisiológicos envolvidos na produção.

Quanto às zonas articulatórias, nota-se que as produções dos sons estudados nem sempre ocorreram na mesma região para os dois sujeitos, com exceção do palatograma para o som [s] e linguograma para $[\mathrm{s}],[\mathrm{z}]\left[\int\right]$ e $[\Lambda]$, que foram semelhantes. Não foram observadas diferenças da zona de articulação quando se comparou o palatograma e o linguograma, ou seja, quando a palatografia foi produzida em região mais anterior o linguograma também mostrou contato mais anterior. A diferença dos pontos articulatórios encontrados nos dois sujeitos pode ser explicada pelo processo de maturação do sistema miofuncional oral enquanto mecanismo de produção motora dos sons (MARCHESAN, 1993; WERTZNER, 1997).

Os resultados encontrados nesta pesquisa concordam com a literatura, no sentido de que distúrbios na aquisição e desenvolvimento da função da língua estão associados com a diminuição do movimento entre as diferentes regiões deste órgão, sendo que o grau de independência do movimento poderá delimitar a capacidade da língua para codificar distinções lingüísticas e o tempo do curso da co-articulação (GREEN e WANG, 2003). Gibbon (1999), por meio da palatografia, concluiu que a maioria das crianças com distúrbio de fala apresenta padrões de contato lingual sem clara diferenciação entre o ápice, lâmina e margens laterais.

Em relação à aplicação da palatografia e linguografia, deve ser enfatizado que para a maioria dos sujeitos que foram submetidos à técnica, principalmente para os de menor faixa etária, houve pouca colaboração na realização. Isto pode ser explicado pela aparência da mistura (azeite e carvão), pois a cor escura causou curiosidade e nojo, gerando recusa e até mesmo náusea.

Além disso, em alguns casos, após a aplicação da mistura, as crianças sentiram desconforto com a presença da mistura, sendo necessário que as fotos fossem tiradas rapidamente, não permitindo um posicionamento adequado do fotógrafo, o que dificultou a análise das fotos. Também devido ao desconforto, nem sempre que foi possível o correto posicionamento do espelho entre os molares para refletir a imagem do palato duro, sendo que rapidamente os espelhos ficavam embaçados, comprometendo a qualidade das fotos.

Outro aspecto que comprometeu a execução da palatografia foi o aumento da salivação, dificultando a aplicação homogênea da mistura no palato ou na língua. Uma questão que também 
pode prejudicar a utilização dessas técnicas é a necessidade de ter, além do pesquisador, a presença de um auxiliar para realizar a filmagem e fotografia.

Tais desvantagens já haviam sido descritas na literatura para sujeitos em idade adulta (MALMBERG, 1971; CAGLIARI, 1974; CASAES, 1992; LADEFOGED, 1997). Cayley et al. (2000) também referiram que medidas intra-orais da língua durante as funções são difíceis, no entanto necessárias para a avaliação.

A comparação dos pontos de contato da palatograma e linguograma no GSTFCD para o som [s] (Quadro 7) indicou que todas as produções analisadas no palatograma ocorreram com contato dental juntamente ou não com a região alveolar ou alvéolo-palatal. Apenas para o sujeito de 6:2 anos não houve acordo entre o linguograma e o palatograma, pois o palatograma ocorreu mais em região anterior do trato vocal e o linguograma mais posterior. No entanto, todas as distorções encontradas nestes sujeitos foram do tipo projeção anterior de língua, com ou sem distorção acústica, indicando concordância entre a análise perceptiva e a palatografia e linguografia.

No GSTFCD, para o som [z] também foi observado que a análise perceptiva e a da palato e linguografia foram concordantes, na medida em que a primeira considerou a distorção do tipo PALCD e PLSD e o contato no palatograma ocorreu entre a região dento-alveolar ou dentopalatal. O linguograma também ocorreu com contato anterior da língua (ápice), associado ou não com a região laminar, exceto para o sujeito de 7:5 anos, pois o palatograma ocorreu mais em região anterior do trato vocal e o linguograma mais posterior.

No som [ $\left.\int\right]$, no GSTFCD, o palatograma registrou o ponto esperado para a produção típica, ou seja, palatal, associada à dental, e o linguograma mostrou contato laminar. A análise perceptiva da distorção indicou esforço articulatório. Deve ser lembrado que este sujeito apresentou grandes rugosidades na região alveolar e, conforme já descrito por Casaes (1990), a presença de grandes rugosidades na região alveolar do palato duro poderia levar à produção distorcida, pois o ar comprimido entre a língua e os alvéolos causaria reverberação entre as reentrâncias.

No som [1], no GSTFCD, também houve concordância entre a análise perceptiva e o palatograma e linguograma.

No GTF para os três sons distorcidos houve acordo entre a classificação perceptiva da distorção e os palatogramas e linguogramas.

A análise do som [s] mostrou que as produções consideradas no palatograma ocorreram com contato dento-alvéolo-palatal ou alvéolo-palatal, e no linguograma na região ápico-laminar 
ou em lâmina, todas as distorções encontradas nestes sujeitos foram classificadas perceptivamente como PLSD ou PALCD. No entanto, neste grupo a maioria das produções realizadas durante a imitação de sílabas e palavras do teste para verificação de distorção o somalvo foi produzida sem distorção, indicando, dessa maneira, um acordo entre as análises.

No som [z] também houve acordo entre a análise perceptiva, pois o sujeito foi classificado como apresentando a distorção do tipo PALCD e realizou contato dento-alvéolo-palatal no palatograma e linguograma com contato em região ápico-laminar.

No som [r] a classificação perceptiva foi do tipo PoCD. O palatograma verificou a ocorrência de contato velar e o linguograma região laminar, havendo também acordo entre a análise perceptiva e a objetiva.

A mancha de contato dos palatogramas e linguogramas para a maioria dos contatos realizados pelo GSTFCD e GTFCD foi assimétrica e com interrupção, assim como no GSTFSD, podendo ser justificada pela maturação do sistema fonético (MARCHESAN, 1993; WERTZNER, 1997).

Em relação à comparação dos pontos de contato dos palatogramas e linguogramas do GSTFCD e GTFCD, observa-se em todos os sons grande variabilidade na produção articulatória, não importando se concomitantemente existe o diagnóstico de transtorno fonológico. Esta variabilidade, como já descrita anteriormente, pode ser resultado do amadurecimento geral da criança, tipo de alimentação, crescimento craniofacial e da arcada dentária, além da fase de aquisição e estabilização das fricativas (SHRIBERG et al., 1986; SHRIBERG, 1993; MOURA, 1994; SHRIBERG et al.,1997; PEREIRA et al., 1998; WERTZNER, 2002; FONSECA et al., 2003; PEREIRA et al., 2003).

Deste modo, os resultados mostraram que a palatografia e linguografia apresentam concordância com a análise perceptiva, oferecendo a vantagem de mostrar o local exato da produção e também ajudar a diferenciar o porquê de auditivamente dois sons serem semelhantes, mas em ponto diferente.

Em relação à aplicação dos índices de gravidade,a análise estatística indicou que o PCC e o PCC-R do GSTFSD foram os maiores valores nas provas de nomeação, imitação e fala espontânea. Tal resultado já era esperado, na medida em que este índice verifica o acerto, e as crianças deste grupo não deveriam apresentar nenhum tipo de erro não esperado para a idade. Outros estudos já haviam mostrado que o PCC é um índice preciso de gravidade e muito importante para a avaliação fonoaudiológica, além de auxiliar no diagnóstico, prognóstico e tratamento (GARRET, 1992; SHRIBERG e KWIATKOWSKI, 1994; WERTZNER et al., 2001). 
No índice PDI, que mede a presença de processos fonológicos, ou seja, apenas alterações fonológicas, não houve diferença significante entre os grupos GSTFSD, GSTFCD, GTFSD e GTFCD, exceto na prova de nomeação, em que o GSTFSD apresentou a porcentagem média mais baixa. Tal achado concorda com a literatura, onde existe uma relação inversa entre os índices PCC e PDI, pois o PCC é uma medida de produções corretas, enquanto o PDI de incorretas (WERTZNER et a.l, 2001; WERTZNER e GALEA, 2002; WERTZNER et al., 2004b).

A comparação do GSTFCD e de GTFCD no índice RDI, aplicado apenas nos grupos com distorção, pois é um valor que reflete a proporção de erros de distorção numa amostra de fala, evidenciou diferença na imitação, na qual o GTFCD apresentou valores mais baixos que o GSTFCD. Tal resultado era esperado, já que no GSTFCD foram encontradas somente omissões e substituições esperadas durante o desenvolvimento, enquanto no GTFCD o sistema fonológico estava alterado.

No ACI, que reflete com exatidão as medidas de gravidade de articulação e é baseado no PCC e RDI, para todas as três provas o GSTFSD foi significantemente melhor.

Portanto, tanto no GSTF como no GTF, os sujeitos que não apresentaram distorção obtiveram todos os índices melhores do que os sujeitos com distorção. Além disso, o GSTF diferenciou-se do GTF, por apresentar os melhores valores nos índices que realizam a análise de omissões, substituições e processos fonológicos, corroborando com os achados que indicam a baixa ocorrência de alterações fonológicas no GSTF (WERTZNER, 2004; WERTZNER et al., 2004b).

Apesar das variações encontradas em função das diferentes provas, o índice ACI indicou que o grupo sem transtorno e sem distorção teve o melhor desempenho, mostrando-se um índice adequado para medir a competência articulatória (SHRIBERG, 1993).

Outros estudos do Português Brasileiro também utilizaram diferentes índices para verificar a diferença entre grupos com e sem transtono fonológico, como Wertzner et al. (2004b), que estudaram 20 sujeitos com desenvolvimento típico de fala e linguagem e 20 sujeitos com transtorno fonológico, aplicando-se quatro provas: nomeação, imitação e fala espontânea composta de um discurso e de uma entrevista. Em seguida, calculou-se as medidas PCC, PCC-R e PDI. Os resultados indicaram que existem diferenças entre os dois grupos, há correlação negativa entre as medidas PDI e PCC-R. As médias dos índices PCC-R foram maiores que as médias do PCC nas quatro provas aplicadas. 
Wertzner et al. (2005b) estudaram 20 sujeitos com transtorno fonológico, nos quais também foram aplicadas provas de nomeação, imitação e fala espontânea composta de um discurso e de uma entrevista. Os resultados indicaram que as crianças com maior gravidade no índice PCC foram as que tiveram maior ocorrência média de distorções de fala.

Desta maneira, observa-se que a aplicação dos índices de gravidade foi importante, na medida em que confirmou que a distorção de fala acaba diferenciando os grupos, já que o GSTFSD foi o que apresentou os melhores índices, indicando que as alterações fonéticas são um agravante da gravidade.

A pesquisa realizada indicou que as provas de Fonologia, as provas específicas para verificação da distorção, a palatografia e linguografia, os índices PCC, RDI e ACI podem contribuir para a precisão diagnóstica das alterações fonéticas presentes no transtorno fonológico e planejamento terapêutico.

Contudo, seria interessante aplicar, principalmente, as provas específicas para verificação da distorção, a palatografia e linguografia, os índices PCC, RDI e ACI em um número maior de crianças, ampliando a faixa etária, a fim de complementar as informações obtidas até o presente momento sobre as distorções de fala em crianças com e sem transtorno fonológico. 


\section{CONCLUSÃO}


A população estudada foi composta de crianças com desenvolvimento típico de fala e crianças com diagnóstico de transtorno fonológico, com ou sem distorção de fala, entre cinco e sete anos de idade.

A partir dos resultados obtidos com esta referida população, puderam ser levantadas algumas questões relacionadas a distorções de fala:

As crianças do GSTF apresentaram distorção de fala nas provas de nomeação, imitação e fala espontânea nos sons [s], [z], [S] e [1], enquanto as crianças do GFT apresentaram distorção nos sons $[\mathrm{s}],[\mathrm{z}]$ e $[\ulcorner]$. Não houve evidências de diferença entre o número de sujeitos que apresentaram distorção nos grupos de estudo GSTF e GTF.

No som [s] não houve diferença significante na ocorrência de distorção nas provas de Fonologia no GSTF e no GTF.

Para o GSTF houve diferença significante na prova de nomeação para o som [s] e [z] e para imitação no [s], com maior ocorrência de distorção para a faixa etária de sete anos. No GTF houve indícios de maior ocorrência de distorção do som [s] na faixa etária de sete anos em todas as provas de Fonologia.

Na prova específica para verificação da distorção, o GSTFCD apresentou maior média de distorção para os sons [s], [z] e [S] em sílabas e para o [1] em palavras, enquanto que no GTFCD não foram observadas diferenças entre a média de distorção em sílabas e em palavras nos sons $[\mathrm{s}],[\mathrm{z}]$ e $[\mathrm{r}]$.

No GSTFCD e no GTFCD, para o som [s], o tipo de distorção que mais ocorreu foi PALCD. Para o som [z] foi PLSD para o GSTFCD; e PALCD para o GTFCD. No [S] foi encontrado apenas o tipo de distorção ECD, no [1] PLSD, e no [r] PoCD .

Os achados da palatografia concordam com a análise perceptiva detectada pela prova específica para verificação da distorção. 
O GSTFSD foi o grupo que apresentou os melhores desempenhos de acordo com os índices PCC e ACI.

No índice PCC-R, o GTFSD apresentou os menores valores.

No índice PDI não houve diferença significante entre os grupos, exceto na prova de nomeação, em que o GSTFSD apresentou a porcentagem média mais baixa.

No índice RDI apenas houve diferença na prova de imitação, na qual o GTFCD apresentou valores mais baixos que o GSTFCD.

A partir dos resultados obtidos com esta pesquisa, pôde-se concluir que as distorções de fala ocorrem tanto no desenvolvimento típico como no transtorno fonológico. No entanto, parece que apenas a distorção no som $[\ulcorner]$ está relacionada ao transtorno fonológico, na medida em que as distorções nos outros sons, principalmente nos fricativos alveolares, ocorrem também em crianças normais.

A aplicação das provas de Fonologia, provas específicas para verificação da distorção, palatografia e linguografia e aplicação dos índices PCC, RDI e ACI, mostrou que se trata de instrumentos diagnósticos valiosos para a detecção das distorções de fala em crianças de cinco a sete anos de idade. 
REFERÊNCIAS

BIBLIOGRÁFICAS 
ALABARSE, V.M.; WERTZNER, H.F. Estudo de caso: avaliação e tratamento de um sujeito com alterações fonológicas. Pró-Fono: Revista de Atualização Científica, 10(1): 86-91, 1998.

ANTUNES, R.P.A.; MATSUMOTO, W.; ORSI, I.A; TUNES, F.S.M. Restabelecimento da dimensão vertical: relato de caso clínico. Revista Brasileira de Odontologia, 57 (3): 151-4, 2000.

ANDRADE, C.R.F.; BEFI-LOPES, D.M. ; FERNANDES, F.D.M.; WERTZNER, H.F. ABFW: Teste de Linguagem Infantil nas Áreas de Fonologia, Vocabulário, Fluência e Pragmática. $2^{\mathrm{a}}$ ed., São Paulo: Pró-Fono, 2004.

AVELINO, H.; KIM, S. An articulatory and acoustic study of Pima coronals. Petics Laboratory, UCLA. Disponível em : www.linguistics.ucla.edu/people/grads/havelino/ PIMA. pdf, acessado em: 10 de janeiro de 2006.

BRAGA, G.C.; MACHADO, C.P. Deglutição Atípica. In: PETRELLI, E. Ortodontia para Fonoaudiologia. Curitiba: Lovise, 1992.

BEFI-LOPES, D.M. Vocabulário. In: ANDRADE, C.R.F.; BEFI-LOPES, D.M. ; FERNANDES, F.D.M.; WERTZNER, H.F. ABFW: Teste de Linguagem Infantil nas Áreas de Fonologia, Vocabulário, Fluência e Pragmática. 2a ed., São Paulo: Pró-Fono, 2004.

CAGLIARI, L.C. A Palatização em Português: uma investigação palatográfica. (Dissertação de Mestrado). Departamento de Lingüística do Instituto de Filosofia e Ciências Humanas da Universidade Estadual de Campinas, Campinas, 1974.

CAGLiARI, L.C. Elementos de Fonética do Português Brasileiro. (Tese de Livre Docência). Universidade Estadual de Campinas, Campinas, 1981.

CARVAlHO, C. de. Para Compreender Saussure. 12ª ed., Petrópolis: Vozes, 2003.

CASAES, E.J. Descrição Acústico-Articulatória dos Sons da Voz - para um Modelo dos Sons do Português do Brasil. (Dissertação do Doutorado). Departamento de Linguí́stica da 
Faculdade de Filosofia, Letras e Ciências Humanas da Universidade de São Paulo, São Paulo, 1990.

CASAES, E.J. A Palatografia na Descrição do Português. Boletim Informativo ANPOLL, 17, p. 87, Porto Alegre, 1992.

CASAES, E.J. A Palatografia na Descrição do Português. Anais do VII Encontro Nacional da ANPOLL . Área de Lingüística, v. 2, Goiânia, 1993.

CASTRO, M.M. Estudo da Estimulabilidade de Crianças com Desenvolvimento Típico e com Distúrbio Fonológico para os Fonemas Líquidos Laterais e Vibrantes Simples. (Dissertação de Mestrado). Universidade de São Paulo, Faculdade de Filosofia, Letras e Ciências Humanas, São Paulo, 2004.

CAYLEY, A.S.; TINDALL, A P.; SAMPSON, W.J.; BUTCHER, A R. Electropalatographic and cephalometric assessment of myofunctional therapy in open-bite subjects. Australian Orthodontic Journal, 16(1): 23-33, 2000.

CHANEY, C. Acoustic analysis of correct and misarticulated semivowels. Journal of Speech and Hearing Research, 31:275-87, 1988.

CORNEAU, C. An EPG study of palatalization in French: cross-dialect and inter subject variation. Language Variation and Change, 12: 25-49, 2000.

COSERIU, E. Teoria da Linguagem e Lingüística Geral. Tradução: Agostinho Dias Carneiro. Rio de Janeiro: Editora da Universidade de São Paulo, 1979.

CROSBIES, S.; HOLM, A.; DODD, B. Intervention for children with severe speech disorder: a comparation of two approaches. International Journal of Language Communication Disorder, 40 (4): 467-491, 2005.

CRYSTAL, D. A Lingüística. 2a ed., Lisboa: Dom Quixote, 1977. 
CRYSTAL, D. Dicionário de Lingüística e Fonética. Tradução e adaptação: Maria Carmelita de Pádua Dias. Rio de Janeiro: Jorge Zahar Editor, 2000.

CUNHA, D.A.; SILVA, H.J.; FONTES, M.L.; PAIXÃO, C. Como alterações do sistema estomatognático podem comprometer a fonoarticulação. Jornal Brasileiro de Fonoaudiologia, 4(15): 120-126, 2003.

D’ANGELIS, W. da R. Aquisição do sistema fonológico do Português: correlações opositivas, traços e hierarquização. Cadernos de Estudos Lingüísticos, 39: 23-40, 2000.

DARLEY, F.L.; ARONSON, A.E.; BROWN, J.R. Alteraciones Motrices del Habla. Buenos Aires: Editorial Medica Panamericana, 1978.

DODD, B.; HOLM, A.; HUA, Z.; CROSBIE, S. Phonological development: a normative study of British English-speaking children. Clinical Linguistics \& Phonetic, 17(8): 617-643, 2003.

DOUGLAS, C.R. Patofisiologia Oral: fisiologia normal e patológica aplicada à odontologia e fonoaudiologia. São Paulo: Pancast, 1998.

DSM-IV. Manual Diagnóstico e Estatístico de Transtornos Mentais. Tradução: Dayse Batista. Supervisão da tradução: Alceu Fillmann, Consultoria e Coordenação: Dr. Miguel R. Jorge. $4^{\text {a }}$ ed., Porto Alegre: Artes Médicas, 1995.

EDWARDS, M.L. Clinical Forum: phonological assessment and treatment in support of phonological processes. Language, Speech, and Hearing Services In Schools, 23: 233-240, 1992.

EMMERICH, A.; FONSECA, L.; ELIAS' AM.; DE MEDEIROS, U.V. Relação entre hábitos bucais, alterações oronasofaringianas e mal-oclusões em pré-escolares de Vitória, Espírito Santo, Brasil. Caderno de Saúde Pública, 20(3): 689-697, 2004.

FELICIO, C.M. Fonoaudiologia nos Distúrbios Temporomandibulares. São Paulo: Pancast Editora, 1994. 
FELICIO, C.M.; FERREIRA-JERONYMO, R.R.; FERRIOLLI, B.H.V.M.; FREITAS, R.L.R.G. Análise da sucção, condições miofuncionais orais e fala. Pró-Fono: Revista de Atualização Científica, 2003, 15(1): 31-40.

FOLKINS, J.W.; BLEILE, K.M. Taxonomies in biology, phonetics, phonology, and speech motor control. Journal of Speech and Hearing Research, 55(4): 596-611, 1990.

FONSECA, R.A.; TUCCI, T.A; RODRIGUEZ, R.C.L.; GOMES, I.C.; BIANCHINI, E.M.G. A correlação entre o ceceio frontal e o crescimento infantil. Revista da Sociedade Brasileira de Fonoaudiologia, 10(4):211-7, 2005.

FONSECA, R.P.; DORNELLES, S.; RAMOS, A.P.F. Relação entre a produção de r-fraco e as praxias linguais na infância. Pró-Fono: Revista de Atualização Científica, 15 (3): 229-240, 2003.

FOX, A.V.; DODD, B.; HOWARD, D. Risk factors for speech disorders in children. International Journal of Language Communication Disorders, 37(2): 117-131, 2002.

FURNARI, E. Esconde-Esconde, 9ª ed., São Paulo: Editora Ática, 1999.

GALEA, D.E.S. Análise do sistema fonológico em crianças de 2;1 a 3;0 anos de idade. (Dissertação de Mestrado em Semiótica e Lingüística Geral), Universidade de São Paulo, Faculdade de Filosofia Letras e Ciências Humanas, São Paulo, 2003.

GARRET, K.K.; MORAN, M.J.A. Comparison of phonological severity measures. Language, Speech and Hearing Services in Schools, 23(1): 48-51, 1992.

GIBBON, F.E. Undifferentiated lingual gestures in children with articulation phonological disorders. Journal of Speech and Hearing Research, 42: 382-397, 1999. 
GIERUT, J.A. Treatment efficacy: functional phonological disorders in children. Journal of Speech and Hearing Research, 41(1): 85-100, 1998.

GREEN, J.R.; MOORE, C.A.; HIGASHIKAWA, M.; STEEVE, R.W. The physiologic development of speech motor control: lip and jaw coordination. Journal of Speech and Hearing Research, 43(1): 239-255, 2000.

GREEN, J.R.; MOORE, C.A.; REILY, K. J. The sequential development of jaw and lip control for speech. Journal of Speech and Hearing Research, 45: 66-79, 2002.

GREEN, J.R.; WANG, Y. Tongue-surface movement patterns during speech and swallowing. Journal of Acoustic Society American, 113(5): 2820-2833, 2003.

GRUBER, F.A. Probability estimates and paths to consonant normalization in children with speech delay. Journal of Speech, Language, and Hearing Research, 42: 448-459, 1999.

GURGUEIRA, A.L. Estudo acústico dos fonemas surdos e sonoros do português do Brasil em crianças com distúrbio fonológico apresentando o processo fonológico de ensurdecimento. (Dissertação de Mestrado). Universidade de São Paulo, Faculdade de Filosofia, Letras e Ciências Humanas, São Paulo, 2000.

HERNANDORENA, C.L.M. Introdução à Teoria Fonológica. IN: BISOL, L. Introdução a Estudos de Fonologia do Português Brasileiro, $3^{\mathrm{a}}$ ed., Porto Alegre: EDIPURS, 2001.

INGRAM, D. Phonological disability in children, London: Edwards Arnolds, 1976.

INGRAM, D. The measurement of whole-word productions. Journal Child Language. 29: 713$33,2002$.

ISSÁO, M.; GUEDES-PINTO, A.C. Manual de Odontopediatria, 9ª ed., São Paulo: PancastEditora, 1994. 
KENT, R.D. Anatomical and neuromuscular maturation of the speech mechanism: evidence from acoustic studies. Journal of Speech and Hearing Research, 19: 421-47, 1976.

KENT, R.D. The biology of phonological development. In: FERGUSON, C. A; MENN, L.; STOEL-GAMMON, C. Phonological development: models, research, implications. Timonium, Maryland: York Press, 1992.

KENT, R.D. Development, pathology and remediation of speech. Sound to Sense at MIT, june 11-13, 2004.

KENT, R.D. Motor control: neurophysiology and functional development. In: CARUSO, A.; STRAND, E. Clinical management of Motor Speech Disorders in Children. New York: Thieme Medical Publishers, 1999.

KENT, R.D. Research on speech motor: control and its disorders: a review and prospective. Journal of Communication Disorders, 33: 391-428, 2000.

LADEFOGED, P. A Course in Phonetics. $3^{\text {a }}$ ed., New York: Harcourt Brace Jovanovich, 1993.

LADEFOGED, P. Instrumental Techniques for Linguistic Phonetic Fieldwork. In: HARDCAStle, W.J.; LAVER, J. The Handbook of Phonetics Sciences. Blackweel Publishers, 1997.

LADEFOGED, P. Vowels and Consonants: an introduction to the sounds of language. Blackwell Publishing, 2001.

LAUNAY, C.; BOREL-MAISONNY, S. Distúrbios de Linguagem, da Fala e da Voz na Infância. São Paulo: Roca, p. 278-300, 1989.

LOWE, R.J. Fonologia: Avaliação e Intervenção: aplicações na patologia da fala. Tradução Marcos A. G. Domingues. Porto Alegre: Artes Médicas, 1996. 
MALMBERG, B. A Fonética: no mundo dos sons da linguagem. Tradução de Oliveira Figueiredo. Lisboa: Edição Livros do Brasil Lisboa, 1954.

MALMBERG, B. As Novas Tendências da Lingüística: uma orientação a lingüística moderna. Tradução de Francisco da Silva Borba. São Paulo: Nacional, 1971.

MARCHESAN, I.Q. Avaliação e terapia dos problemas da respiração. Disponível em http://www.ibemol.com.br/ciodf2001/003.asp, acessado em 10 de julho de 2005.

MARCHESAN, I.Q. Frênulo de Língua: classificação e interferência na fala. Revista Cefac, 5: 341-345, 2003.

MARCHESAN, I.Q. Motricidade Oral. São Paulo: Pancast, 1993.

MAXWELL, D.L.; SATAKE, E. Research and Statistical Methods in Communication Disorders. Baltimore: Williams \& Wilkins.1997.

MENN, L.; STOEL-GAMMON, C. Phonological development: learning sounds and sounds patterns. In.: GLEASON, J.B. The Development of Language. $5^{\text {a }}$ ed., Needham Heights: A Pearson Education Company, 2001.

MESSNER, A.H.; LALAKEA, M.L. The effect of ankyloglossia on speech in children. Otolaryngology - Head and Neck Surgery, 127(5): 539-45, 2002.

MESSNER, A.H.; LALAKEA, M.L. Ankyloglossia: the adolescent and adult perspective. Otolaryngology - Head and Neck Surgery, 128(5): 746-52, 2003.

MOTA, V.A.; GUEDES, Z.C.F. Análise da fala de crianças pré-escolares pertencentes à escola da rede pública do município de São Paulo. Fono Atual, 3(13): 48-56, 2000.

MOURA, A.L.L. O ceceio anterior em crianças de 03 a 07 anos. In: MARCHESAN I.Q. (Org.) Tópicos em Fonoaudiologia, São Paulo: Lovise: 321-238, 1994. 
OLIVEIRA, M.M.F.; WERTZNER, H.F. Estudo do distúrbio fonológico em crianças. Revista da Sociedade Brasileira de Fonoaudiologia. 7(1): 68-75, 2000.

PAGAN, L.O. Estudo das Líquidas Laterais e Vibrantes em Crianças com Distúrbio Fonológico: Análise Acústica e Articulatória. (Dissertação de Mestrado). Universidade de São Paulo, Faculdade de Filosofia, Letras e Ciências Humanas, São Paulo, 2003.

PAIS, C.T. Introdução à Fonologia. Global Editora: São Paulo, 1981.

PAIS, C.T. Palatografia. (Aula ministrada na disciplina de Fonética para o Curso de Graduação em Fonoaudiologia da FMUSP). São Paulo: Faculdade de Filosofia, Letras e Ciências Humanas da Universidade de São Paulo, 1999.

PAURA, A.C.; MOSCA-GIROTO, C.R.; CASAGRANDE, G.B.; VANCINE, F.A. A relação entre mordida aberta anterior e ceceio anterior em crianças de 5 a 6 anos. In: Congresso Internacional de Fonoaudiologia, IV Encontro Ibero-Americano de Fonoaudiologia, 3, 1999, São Paulo. Anais... São Paulo: [s.n], 1999, p. 245.

PENAA-BROOKS, A.; HEDGE, M.N. Assessment and treatment of articulation and phonological disorders in children. Austin: Pro-ed., 2000.

PEREIRA, L.F.; SILVA, A.M.T.; CECHELLA, C. Ocorrência de hábitos orais viciosos e distúrbios fonoarticulatórios em indivíduos portadores de deglutição atípica. Pró-Fono: Revista de Atualização Científica, 10(1): 56-60, 1998.

PEREIRA， P.M.M.B.; BIANCHINI， E.M.G.; CARVALHO， G.G.T; JARDIM， Z.M.G Investigação da Ocorrência e Caracterização de Distorções do [s] em crianças de 3 anos. Revista da Sociedade Brasileira de Fonoaudiologia, 8(1): 10-17, 2003.

PETERSON, G.E.; SHOUP, J.E. A phisiological theory of phonetics. Journal of Speech and Hearing Research, 9: 5-67, 1966. 
RODRIGUES, P.M.T.; CARVALHO, E.L.L.; RODRIGUES, S.A.; BURGUETTI, F.A.R. Relação entre mordida aberta anterior e sigmatismo. In: Anais do VII Congresso Brasileiro e IV Encontro Ibero-Americano de Fonoaudiologia. São Paulo: Sociedade Brasileira de Fonoaudiologia, 1999, p. 321.

SAUSSURE, F. Curso de Lingüística Geral. São Paulo: Editora Cultrix, 1969.

SEIFERT, E.; RUNTE, C.; NESEN, A. Dentristy and speech production. Correlations between the morphology of jhe articulation zone and acoustics exemplified in /s/ articulation. Journal of Orofacial Orthopedic, 58(4): 224-231, 1997.

SHRIBERG, L.D. Four New Speech and Prosody-Voice measures for Genetics Research and Other Studies in Developmental Phonological Disorders. Journal of Speech and Hearing Research, 36: 105-140, 1993.SHRIBERG, L.D. Phenotype markers for genetically transmitted speech sound disorder. The $10^{\text {th }}$ Symposium of the International Clinical Phonetics and Linguistics Association, Lafayette, Louisiana, february 25-28, 2004.

SHRIBERG, L.D.; AUSTIN, B.A.; McSWEENY, S.L.; WILSON, D.L. The Percentage of Consonants Correct (PCC) Metric: Extensions and Reliability Data. Journal of Speech, Language and Hearing Research, 40: 708-722, 1997.

SHRIBERG, L.D.; KWIATKOWSKI, J. Phonological Disorders I: A Diagnostic Classification System. Journal of Speech and Hearing Disorders, 47: 226-241, 1982a.

SHRIBERG, L.D.; KWIATKOWSKI, J. Phonological Disorders III: A Procedure for Assessing Severity of Involvement. Journal of Speech and Hearing Disorders, 47: 256-270, 1982b.

SHRIBERG, L.D.; KWIATKOWSKI, J. Developmental phonological disorders I: a clinical profile. Journal of Speech and Hearing Research, 37(5): 1100-26, 1994.

SHRIBERG, L.D.; KWIATKOWSKI, J.; BEST, S.; HENGST, J.; TERSELIC-WEBER, B. Characteristics of Children with Phonologic Disorders of Unknown Origin. Journal of Speech and Hearing Disorders, 51: 140-161, 1986. 
SILVA, T.C. Fonética e Fonologia do Português: roteiro de estudos e guia de exercícios. São Paulo: Editora Contexto, 2001.

SPAJIC, S.; LADEFOGED, P.; BHASKARARAO, P. The rhotics of Toda. Fieldworks Studies of Targeted Languages II, UCLA Working Papers in Phonetics, 87, 1993.

STOEL-GAMMON, C.; DUNN, C. Normal and Disordered Phonology in Children, Texas: Pro- Ed, 1985.

TOMÉ, M.C.; FARIAS, S.R.; ARAÚJO, S.M.; SCHIMITT, B.E. Ceceio interdental e alterações em crianças de 03 a 06 anos. Pró-Fono: Revista de Atualização Científica, 16(1): 19-30, 2004.

TOMÉ, M.C.; GUEDES, Z.C.F.; SILVA, A.M.T. da; CECHELLA, C. Estudo da ocorrência de alterações da deglutição e da oclusão dentária em crianças com queixa de falar errado. Pró-Fono: Revista de Atualização Científica, 10(1): 61-65, 1998.

TROIA Jr., M.G.; FRAGOSO, W.S.; MESQUITA, M.F.; HENRIQUES, G.E.P.; NÓBILO, M.A.A. Uso da palatografia na reabilitação fonética de paciente desdentado total portador de apraxia ideomotora. III Congresso Brasileiro de Odontologia e XII Jornada Odontológica de $\begin{array}{llll}\text { Piracicaba. } & \text { Piracicaba: } & \text { UNICAMP, } & \text { Disponível }\end{array}$ em:http://www.fop.unicamp.br/congresso/inscricao/aprovados.php?pageNum=3\&totalRows=83 $\underline{\text { pesquisa }=\& \text { tipo }=\& \mathrm{t}=\mathrm{o}}$, acessado em 15 de novembro de 2005.

WERTZNER, H.F. Articulação: aquisição do sistema fonológico dos 3 aos 7 anos. (Dissertação de Mestrado). Universidade de São Paulo, Faculdade de Filosofia, Letras e Ciências Humanas, São Paulo, 1992.

WERTZNER, H.F. Aquisição da articulação: um estudo em crianças de três a sete anos. Estudos de Psicologia, 11(1): 11-21, 1994. 
WERTZNER, H.F. Articulação e suas alterações. In: KUDO, AM.; MARCONDES, E.; LINS, L.; MORIYAMA, L.Y.; GUIMARÃES, M.L.L.; JULIANI, R.C.Y.P.; PIERRI, S. A (coord). Fisioterapia, Fonoaudiologia e Terapia Ocupacional em Pediatria, $2^{\text {a }}$ ed., São Paulo: Sarvier, 1997.

WERTZNER, H.F. Typical substitutions on liquid phonemes in the phonological acquisition of brazilian children. School of Speech and hearing Science, Western Australia, p. 175-181, 1998.

WERTZNER, H.F. Fonologia. In: ANDRADE, C.R.F.; BEFI-LOPES, D.M.; FERNANDES, F.D.M.; WERTZNER, H.F. ABFW: Teste de Linguagem Infantil nas Áreas de Fonologia, Vocabulário, Fluência e Pragmática. São Paulo: Pró-Fono, 2000.

WERTZNER, H.F. O Distúrbio Fonológico em Crianças Falantes do Português: Descrição e Medidas de Severidade. (Tese de Dissertação de Livre Docência). Faculdade de Medicina da Universidade de São Paulo, São Paulo, 2002.

WERTZNER, H.F. Procedimentos de avaliação e tratamento do distúrbio fonológico. In.: LIMONGI, S.C.O. Fonoaudiologia Informação para Formação: procedimentos terapêuticos para linguagem. Rio de Janeiro: Guanabara-Koogan, 2003.

WERTZNER, H.F. Fonologia. In: ANDRADE, C.R.F.; BEFI-LOPES, D.M.; FERNANDES, F.D.M.; WERTZNER, H.F. ABFW: Teste de Linguagem Infantil nas áreas de Fonologia, Vocabulário, Fluência e Pragmática. $2^{\text {a }}$ ed., São Paulo: Pró-Fono, 2004.

WERTZNER, H.F; AMARO, L; RAMOS, A C.; SOTELO, M. B. Relação entre índice de gravidade e distorção de fala em crianças com transtorno fonológico. In: XII Congresso Brasileiro de Fonoaudiologia, 2005, Santos. Anais... Santos: [s.n], 2005 b.

WERTZNER, H.F; AMARO, L; TERAMOTO, S.S. Determinant Factors of severity Rating of Phonological Disorder. Pró-Fono: Revista de Atualização Científica. 16(2): 139-150, 2004a. 
WERTZNER, H.F; GALEA, D. E. S. Porcentagem de Consoantes Corretas - Revisada (PCC-R) e Índice de Densidade Fonológica (PDI) na aquisição fonológica. Revista da Sociedade Brasileira de Fonoaudiologia, 8(2): 233-8, 2001.

WERTZNER, H.F.; HERRERO, S.F.; PIRES, S.C.F.; IDERIHA, P.N. Classificação do distúrbio fonológico por meio de duas medidas de análise: porcentagem de consoantes corretas (PCC) e índice de ocorrência de processos (PDI). Pró-Fono: Revista de Atualização Científica, 13 (1): 90-97, 2001.

WERTZNER, H.F.; OLIVEIRA, M.M.F. Semelhanças entre os sujeitos com distúrbio fonológico. Pró-Fono: Revista de Atualização Científica. 14(2): 143-152, 2002.

WERTZNER, H.F.; RAMOS, AC.O; AMARO, L. Índices Fonológicos Aplicados ao Desenvolvimento Fonológico Típico e ao Transtorno Fonológico. Revista da Sociedade Brasileira de Fonoaudiologia, 9(4): 199-204, 2004b.

WERTZNER, H.F.; SOTELO, M.B.; AMARO, L. Analysis of Distortions in Children with and without Phonological Disorders. Clinics. 60 (2), 93-102, 2005 a.

YAVAS, M.S.; LAMPRECHT, R.R. O s processos e a inteligibilidade na fonologia com desvios. In: YAVAS, M.S. Desvios fonológicos em crianças: teoria, pesquisa e tratamento. Porto Alegre: Mercado Livre, 1990. 
ANEXOS 
Anexo 1. Aprovação do Comitê de Ética para Análise de Projetos de Pesquisa-CAPPesq.

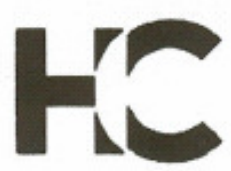

\section{APROVACÃO}

A Comissão de Ética para Análise de Projetos de Pesquisa - CAPPesq da Diretoria Clínica do Hospital das Clínicas e da Faculdade de Medicina da Universidade de São Paulo, em sessão de 27.01.05, APROVOU o Protocolo de Pesquisa $n^{\circ}$ 1090/04, intitulado: "Descrição de distorções dos sons da fala em crianças com e sem transtorno fonológico" apresentado pelo Departamento de FISIOTERAPIA, FONOAUDIOLOGIA E TERAPIA OCUPACIONAL, inclusive o Termo de Consentimento Livre e Esclarecido.

Cabe ao pesquisador elaborar e apresentar à CAPPesq, os relatórios parciais e final sobre a pesquisa (Resolução do Conselho Nacional de Saúde n 196 , de 10.10.1996, inciso IX.2, letra "c").

Pesquisador(a) Responsável: Profa. Dra. Haydée Fiszbein Wertzner Pesquisador(a) Executante: Dra. Luciana Amaro

CAPPesq, 27 de Janeiro de 2005.

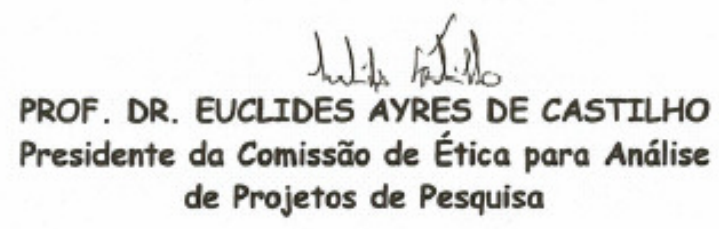


Anexo 2. Questionário sobre o desenvolvimento neuropsicomotor do GSTF.

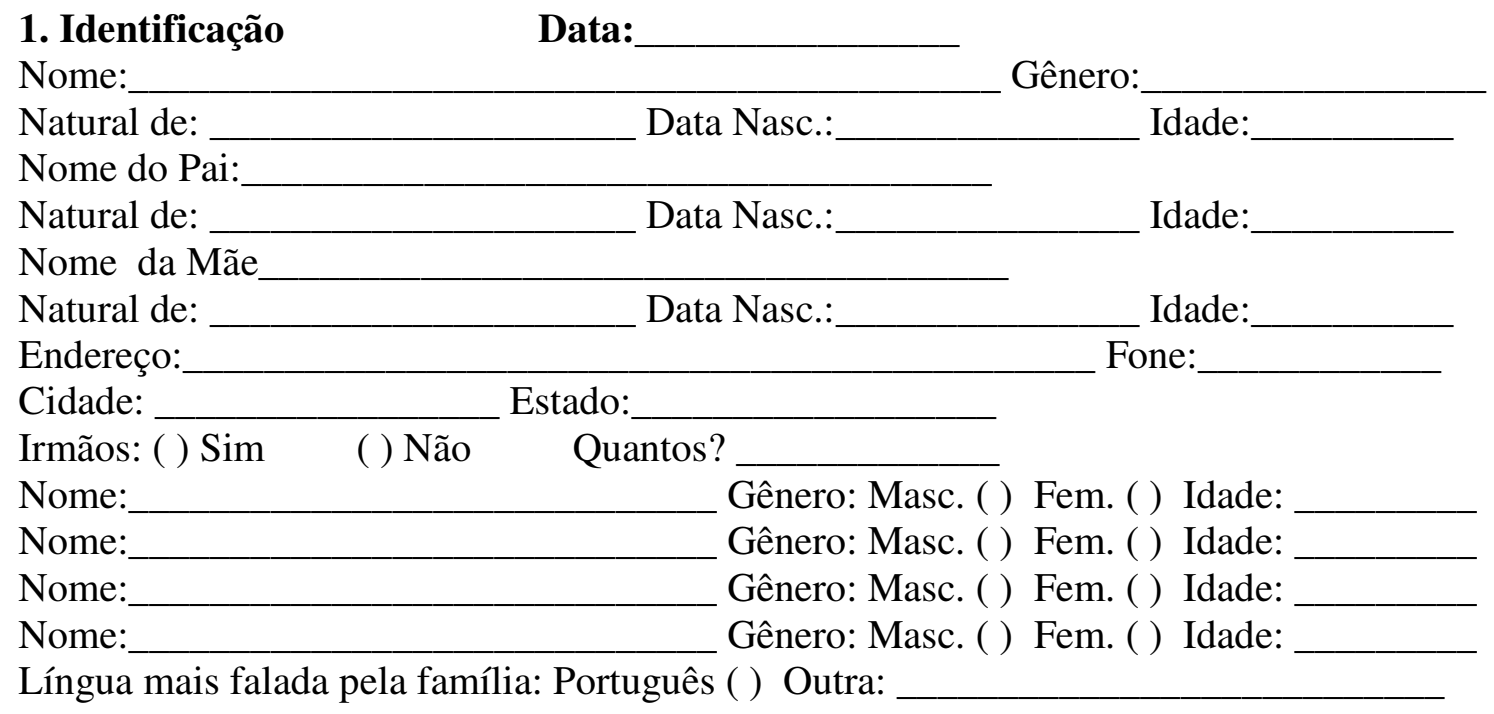

\section{Antecedentes Orgânicos}

Teve algum problema durante a gestação? Sim ( ) Não ( ) Qual?

Teve algum problema no nascimento? Sim ( ) Não ( ) Qual?

Quando começou a andar? Até 1 ano ( ) Até 1 ano e 2 meses ( ) Até 1 ano e meio ( )

Tem ou teve problemas de coordenação motora? Sim ( ) Não ( )

Tem ou teve dificuldades nas atividades de vida diária? (alimentar-se-se, vestir-se)

Sim ( ) Não ( )

\section{Antecedentes familiares}

Há casos de alterações de linguagem na família? Sim ( ) Não ( )

Grau de parentesco: Pai ( ) Mãe ( ) Irmãos ( ) Tios ( ) Primos ( )

Qual o problema? Troca sons na fala ( ) Troca letras na escrita ( ) Audição ( ) Alteração de voz

( ) Gagueira ( ) Outros

\section{Antecedentes físicos}

\section{Alimentação}

Recebeu aleitamento natural (seio)? Sim ( ) Não ( ) Até que idade?

Fez uso de mamadeira? Sim ( ) Não ( ) Até que idade?

Tem ou teve dificuldades para se alimentar? Sim ( ) Não( )

\section{Dentição}

Tem ou teve problemas de dentição? Sim ( ) Não ( )

Tem hábitos orais? Sim ( ) Não ( ) qual? Ranger dentes ( ) Sugar dedo ( ) Chupeta ( )

\section{Dados de audição}

Tem ou teve episódios de otites? Sim ( ) Não ( )

Já realizou avaliação de audição? Sim ( ) Não ( )

Resultado: Normal ( ) Alterado ( ) Quando? Onde? 
6. Desenvolvimento da linguagem

Quando falou as primeiras palavras? Antes de andar ( ) Depois de andar ( )

Era compreendido quando começou a falar? Sim ( ) Não ( )

Por quem? Pais ( ) Pessoas próximas ( ) Estranhos ( )

Atualmente é compreendido? Sim ( ) Não (

Tem ou teve alterações de fala? Sim ( ) Não ( )

Qual alteração? Linguagem ( ) Voz ( ) Leitura/Escrita ( ) Outra?

Já realizou tratamento fonoaudiológico? Sim ( ) Não ( )

\section{Evolução clínica:}

Tem ou teve problemas de saúde? Sim ( ) Não ( ) Qual ?

Faz ou já fez tratamento médico? Sim ( ) Não ( ) Qual ?

Tem ou teve problemas respiratórios? Sim ( ) Não ( ) Qual ?

\section{Tratamento Fonoaudiológico:}

Já realizou anteriormente tratamento fonoaudiológico?

Qual o motivo?

\section{Atual}

Sono

O sono é tranquilo? Sim ( ) Não ( )

Dorme durante o dia? Sim ( ) Não ( )

\section{Escolaridade}

Tem ou teve problemas de adaptação? Sim ( ) Não ( )

Tem ou teve dificuldades de aprendizagem? Sim ( ) Não ( )

Nome da Escola:

Queixas escolares: Sim ( ) Não ( ) Quais?

\section{Socialização}

Gosta de que tipo de brincadeira? Jogos ( ) Bola ( ) TV ( ) Outros

Brinca com outras crinaças? Sim ( ) Não ( )

Prefere brincar: Com crianças da mesma idade ( ) Com crianças maiores ( )

Com crianças menores ( ) Sozinha ( ) 
Anexo 3. Termo de Consentimento Pós-Informação: Grupo Sem Transtorno Fonológico.

\section{HOSPITAL DAS CLÍNICAS \\ DA FACULDADE DE MEDICINA DA UNIVERSIDADE DE SÃO PAULO TERMO DE CONSENTIMENTO LIVRE E ESCLARECIDO}

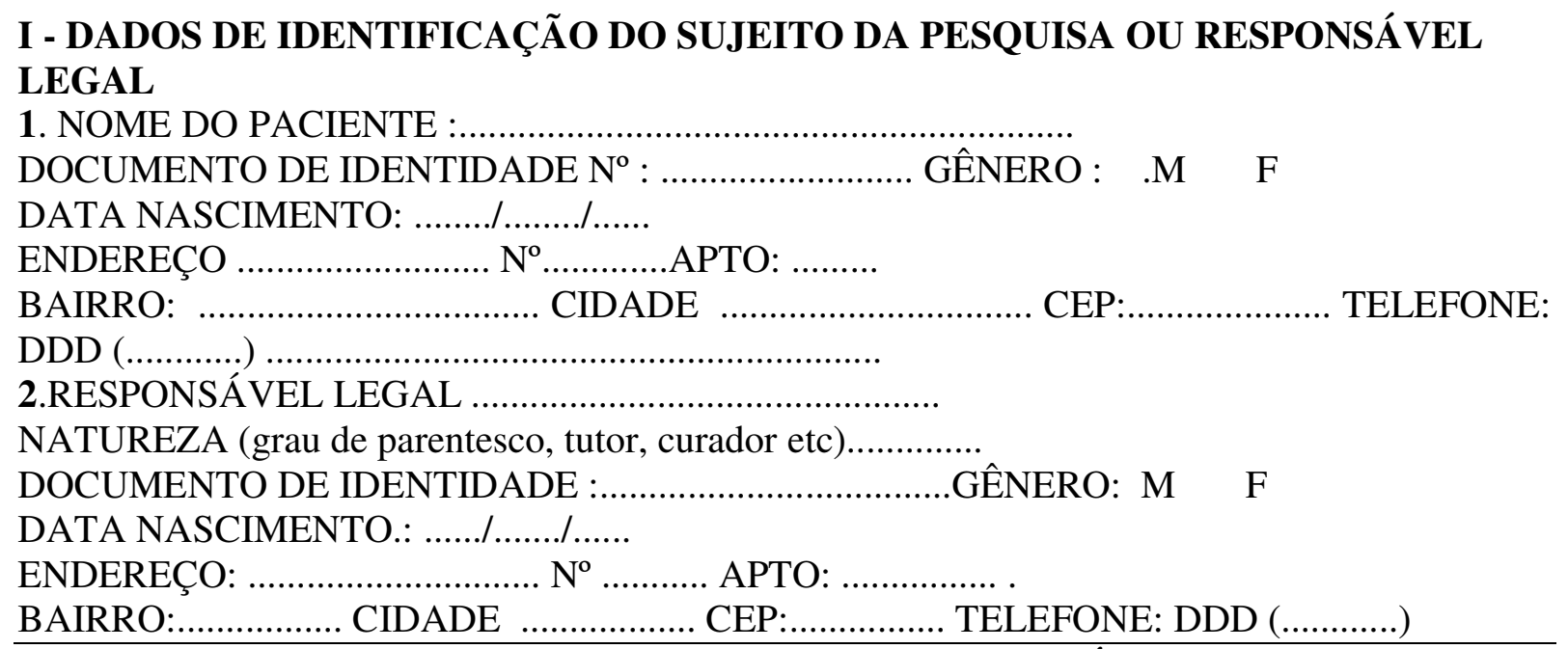

\section{II - DADOS SOBRE A PESQUISA CIENTÍFICA}

1. TÍTULO DO PROTOCOLO DE PESQUISA: Descrição de distorções de fala em crianças com e sem transtorno fonológico.

PESQUISADOR: Haydée Fiszbein Wertzner CARGO/FUNÇÃO:Profa.Livre Docente

INSCRIÇÃO CONSELHO REGIONAL N ${ }^{\circ}$ CRF $^{a} 0941$

UNIDADE DO HCFMUSP: Departamento de Fisioterapia, Fonoaudiologia e Terapia Ocupacional

3. AVALIAÇÃO DO RISCO DA PESQUISA:

$\begin{array}{lcc}\text { SEM RISCO } \square & \text { RISCO MÍNIMO } & \text { X } \\ \text { RISCO BAIXO } & \text { RISCO MÉDIO }\end{array}$

4.DURAÇÃO DA PESQUISA : 17 meses

III - REGISTRO DAS EXPLICAÇÕES DO PESQUISADOR AO PACIENTE OU SEU REPRESENTANTE LEGAL SOBRE A PESQUISA CONSIGNANDO:

É muito comum na população infantil ocorrer alteração de linguagem e fala, que é um atraso ou desvio na aquisição dos sons de fala. As crianças com esta alteração trocam ou não produzem alguns sons e também podem distorce-los, ou seja, produzi-los de maneira errada. É muito importante que seja feito um bom diagnóstico para que o tratamento seja eficiente, para isso são usadas algumas técnicas.

O objetivo desta pesquisa é verificar a ocorrência de distorções em crianças com e sem alteração de linguagem e fala.

Para atingir este objetivo necessitamos avaliar seu filho que não apresenta alteração de linguagem e fala e que participa do grupo controle, para poder ser comparado com as crianças que têm esta alteração. Inicialmente, será feita uma entrevista como os senhores pais, para saber como foi desenvolvimento de seu filho, logo após, a criança será avaliada por meio de provas de linguagem composta por imitação de palavras, nomeação de figuras e fala espontânea, onde irá contar uma história a partir de figuras de um livro. Serão analisadas a postura e movimentação dos lábios, dentes, língua, bochechas, paredes superior e inferior da boca, além de verificar o tipo de mordida.

Caso seja detectada na prova de linguagem alguma distorção de fala, será aplicada uma prova composta de imitação de sílabas e palavras que contenham os sons distorcidos. Para verificar quais os pontos que a lingua de seu filho toca na parede superior da boca durante a produção do som distorcido, a língua será coberta por uma pasta de azeite de oliva e carvão (esta mistura não tem cheiro nem gosto), enquanto 
ocorre a produção do som serão tiradas fotografias e filmada, para posterior análise. Estes sons distorcidos serão analisados também por um programa de computador.Todas as provas serão gravadas e filmadas. Não é esperado nem desconforto e risco mínimo para a criança durante a aplicação dessas provas.

Com as respostas de seu filho, será possível verificar e caracterizar as distorções de crianças com transtorno fonológico, o que possibilitará o oferecimento de melhores condições de conduzir a avaliação, diagnóstico e tratamento das crianças com transtorno fonológico.

Como a linguagem e os órgãos fonoarticulatórios de seu filho serão avaliadas, caso seja necessário ele será encaminhado para tratamento específico.

IV - ESCLARECIMENTOS DADOS PELO PESQUISADOR SOBRE GARANTIAS DO SUJEITO DA PESQUISA CONSIGNANDO:

1. acesso, a qualquer tempo, às informações sobre procedimentos, riscos e benefícios relacionados à pesquisa, inclusive para dirimir eventuais dúvidas. A qualquer momento o responsável pela criança poderá procurar a pesquisadora para tirar quaisquer dúvidas quanto às provas usadas na testagem, bem como às gravações realizadas.

2. liberdade de retirar seu consentimento a qualquer momento e de deixar de participar do estudo, sem que isto traga prejuízo à continuidade da assistência. A qualquer momento o responsável pela criança poderá decidir não fazer parte do estudo.

3. salvaguarda da confidencialidade, sigilo e privacidade. Os dados da criança serão utilizados somente para a pesquisa e ensino, sendo mantido o sigilo e a privacidade da mesma.

4. disponibilidade de assistência no HCFMUSP, por eventuais danos à saúde, decorrentes da pesquisa. Não é esperado nenhum dano à saúde com a aplicação das provas anteriormente citadas. $\mathrm{O}$ tratamento fonoaudiológico estará garantido caso seja diagnosticada qualquer alteração de linguagem ou fala na criança.

5. viabilidade de indenização por eventuais danos à saúde decorrentes da pesquisa. Não é esperado nenhum dano à saúde com a aplicação das provas anteriormente citadas.

V. INFORMAÇÕES DE NOMES, ENDEREÇOS E TELEFONES DOS RESPONSÁVEIS PELO ACOMPANHAMENTO DA PESQUISA, PARA CONTATO EM CASO DE INTERCORRÊNCIAS CLÍNICAS E REAÇÕES ADVERSAS.

Prof ${ }^{a}$ Dr $^{a}$ Haydée Fiszbein Wertzner: Rua Cipotãnea, 51 - Cidade Universitária - Butantã - São Paulo Fone: 30917455 e 30917452

\section{OBSERVAÇÕES COMPLEMENTARES:}

\section{VII - CONSENTIMENTO PÓS-ESCLARECIDO}

Declaro que, após convenientemente esclarecido pelo pesquisador e ter entendido o que me foi explicado, consinto em participar do presente Protocolo de Pesquisa.

São Paulo, de de 20

assinatura do sujeito da pesquisa ou responsável legal 
Anexo 4. Roteiro de Avaliação da Motricidade Orofacial.

Nome

Data Nasc. Idade

Data do Exame

\section{Postura em Repouso}

Lábios:

Língua:

2. Mobilidade

Lábios: ( ) protrusão ( ) retração lateral D ( ) retração lateral E ( ) retração lateral simétrica () vibração ( ) contração

Língua: ( ) lateralização interna D ( ) lateralização interna E ( ) elevação

( ) lateralização externa D ( ) lateralização externa E ( ) abaixamento

( ) protrusão em ponta ( ) retração

3. Tonicidade

Lábios: ( ) hipotonia ( ) hipertonia ( ) adequado

Língua: ( ) hipotonia ( ) hipertonia ( ) adequado

4. Freios

Labial: ( ) adequado ( ) Longo

Lingual: ( ) adequado ( ) Longo

5. Palato Duro
( ) adequado
( ) alto
( ) estreito

6. Palato Mole e Úvula

Aspecto: ( ) adequado ( ) desviado

Mobilidade: ( ) sim ( ) não

7. Dentição

Higiene: () boa () regular () ruim

Cáries: ( ) sim ( ) não

Ausência de dentes: ( ) sim ( ) não

8. Tipo de Oclusão

( ) adequada ( ) cruzada ( ) aberta ( ) overjet ( ) prognatismo ( ) sobremordida

9. Mastigação

Mandíbula: ( ) rotação ( ) abertura ( ) fechamento

Contração de masseteres: ( ) forte () fraca

Contração de temporais: () forte () fraca

Uso preferncial de um lado:( ) direito ( ) esquerdo

10. Deglutição

Interposição de Língua Participação da musc oral Contração masseteres

Líquido

( )

Saliva

( )

( )

( )

Sólidos

( )

( )

()

11. Respiração
( ) oral
( ) nasal
( ) mista 
Anexo 5a. Protocolo de Registro da Prova Específica para Distorção de Fala em Sílabas e Palavras $[\mathrm{s}]$.

Nome:

Idade:

Data:

Escola:

Grupo: ( ) sem Transtorno Fonológico ( ) com Transtorno Fonológico

SÍlABAS E PALAVRAS PARA PROVA DE DISTORÇÃO [s]

\begin{tabular}{|c|l|l|l|l|l|}
\hline & Transcrição & $\begin{array}{c}\text { Classificação } \\
\text { da Distorção }\end{array}$ & & Transcrição & $\begin{array}{c}\text { Classificação } \\
\text { da Distorção }\end{array}$ \\
\hline SAPO & & & SA & & \\
\hline CENA & & & SO & & \\
\hline SETA & & & SÓ & & \\
\hline CIDADE & & & SE & & \\
\hline SOPA & & & SA & & \\
\hline SÓLIDO & & & SI & & \\
\hline SUCO & & & SO & & \\
\hline PASSARO & & & SA & & \\
\hline PÊSSEGO & & & SU & & \\
\hline INSETO & & & SI & & \\
\hline BICICLETA & & & SU & & \\
\hline PROFESSORA & & & SE & & \\
\hline CAÇULA & & & SÉ & & \\
\hline PAÇOCA & & & SE & & \\
\hline CABEÇA & & & SÓ & & \\
\hline DOCE & & & SU & & \\
\hline SACI & & & SÉ & & \\
\hline URSO & & & SÉ & & \\
\hline & & & SÓ & & \\
\hline & & & SI & & \\
\hline & & & & \\
\hline
\end{tabular}

Classificação: 0 - sem distorção, 1- PLSD: Projeção de língua sem distorção acústica, 2 - PALCD: Projeção anterior de língua com distorção acústica, 3- PLLCD: Projeção lateral de língua com distorção acústica. 
Anexo 5b. Protocolo de Registro da Prova Específica para Distorção de Fala em Sílabas e Palavras $[\mathrm{z}]$.

\section{Nome:}

Idade:

Data:

Escola:

Grupo: ( ) sem Transtorno Fonológico ( ) com Transtorno Fonológico

SÍlABAS E PALAVRAS PARA PROVA DE DISTORÇÃO [z]

\begin{tabular}{|c|c|c|c|l|l|}
\hline & Transcrição & $\begin{array}{c}\text { Classificação da } \\
\text { Distorção }\end{array}$ & Transcrição & $\begin{array}{c}\text { Classificação } \\
\text { da Distorção }\end{array}$ \\
\hline ZABUMBA & & & ZÉ & & \\
\hline ZEBRA & & & ZA & & \\
\hline ZUNIDO & & & ZU & & \\
\hline CASACO & & ZU & & \\
\hline DESENHO & & & ZÓ & & \\
\hline CASINHA & & & ZA & & \\
\hline CASA & & & ZO & & \\
\hline VASO & & & ZÉ & & \\
\hline & & & ZÓ & & \\
\hline & & & ZE & & \\
\hline & & & ZI & & \\
\hline & & & ZE & & \\
\hline & & & ZO & & \\
\hline & & & ZÓ & & \\
\hline & & & ZE & & \\
\hline & & & ZI & & \\
\hline & & & ZÉ & & \\
\hline & & & & & \\
\hline & & & & & \\
\hline & & & & & \\
\hline
\end{tabular}

Classificação: 0 - sem distorção, 1- PLSD: Projeção de língua sem distorção acústica, 2 - PALCD: Projeção anterior de língua com distorção acústica, 3- PLLCD: Projeção lateral de língua com distorção acústica. 
Anexo 5c. Protocolo de Registro da Prova Específica para Distorção de Fala em Sílabas e Palavras [3].

Nome:

Idade:

Data:

Escola:

Grupo: ( ) sem Transtorno Fonológico ( ) com Transtorno Fonológico

SÍlABAS E PALAVRAS PARA PROVA DE DISTORÇÃO [3]

\begin{tabular}{|c|c|c|c|c|c|}
\hline & Transcrição & $\begin{array}{c}\text { Classificação } \\
\text { da Distorção }\end{array}$ & & Transcrição & $\begin{array}{c}\text { Classificação } \\
\text { da Distorção }\end{array}$ \\
\hline JANELA & & & JÉ & & \\
\hline GELADEIRA & & & JÓ & & \\
\hline JIPE & & & JE & & \\
\hline JOGO & & & JO & & \\
\hline JUBA & & & JÉ & & \\
\hline PIJAMA & & & JÓ & & \\
\hline OBJETO & & & JE & & \\
\hline MÁGICO & & JA & & \\
\hline TIJOLO & & & JO & & \\
\hline JUJUBA & & & JI & & \\
\hline LARANJA & & & JÚ & & \\
\hline HOJE & & & JU & & \\
\hline ANJO & & & JO & & \\
\hline CAJU & & & JÁ & & \\
\hline & & & JI & & \\
\hline & & & JE & & \\
\hline & & & JU & & \\
\hline & & & JÓ & & \\
\hline & & & & & \\
\hline
\end{tabular}

Classificação: 0 - sem distorção, 1 - ESD: Esforço articulatório sem distorção acústica, 2 ECD: Esforço articulatório com distorção acústica. 
Anexo 5d. Protocolo de Registro da Prova Específica para Distorção de Fala em Sílabas e Palavras $\left[\int\right]$.

Nome:

Idade:

Data:

Escola:

Grupo: ( ) sem Transtorno Fonológico ( ) com Transtorno Fonológico

SÍlABAS E PALAVRAS PARA PROVA DE DISTORÇÃO [S]

\begin{tabular}{|c|c|c|c|c|c|}
\hline & Transcrição & $\begin{array}{c}\text { Classificação } \\
\text { da Distorção }\end{array}$ & & Transcrição & $\begin{array}{c}\text { Classificação } \\
\text { da Distorção }\end{array}$ \\
\hline XALE & & & XI & & \\
\hline CHEGADA & & & XÓ & & \\
\hline CHEFE & & & XE & & \\
\hline CHINELO & & & XE & & \\
\hline CHUVA & & & XÓ & & \\
\hline ENXADA & & & XA & & \\
\hline BEXIGA & & & XI & & \\
\hline CACHORRO & & & XÉ & & \\
\hline CAIXOTE & & & XE & & \\
\hline CAIXA & & & XU & & \\
\hline PEIXE & & & XÓ & & \\
\hline & & & XA & & \\
\hline ABACAXI & & & XÉ & & \\
\hline BICHO & & & XO & & \\
\hline & & & XU & & \\
\hline & & & XÉ & & \\
\hline & & & XA & & \\
\hline & & & XI & & \\
\hline & & & & & \\
\hline & & & & & \\
\hline & & & & & \\
\hline
\end{tabular}

Classificação: 0 - sem distorção, 1 - ESD: Esforço articulatório sem distorção acústica, 2 - ECD: Esforço articulatório com distorção acústica. 
Anexo 5e. Protocolo de Registro da Prova Específica para Distorção de Fala em Sílabas e Palavras $[\ulcorner]$.

Nome:

Idade:

Data:

Escola:

Grupo: ( ) sem Transtorno Fonológico ( ) com Transtorno Fonológico

SÍlABAS E PALAVRAS PARA PROVA DE DISTORÇÃO [ []

\begin{tabular}{|c|c|c|c|c|c|}
\hline & Transcrição & $\begin{array}{l}\text { Classificação } \\
\text { da Distorção }\end{array}$ & & Transcrição & $\begin{array}{l}\text { Classificação } \\
\text { da Distorção }\end{array}$ \\
\hline GIRAFA & & & $\mathrm{RE}$ & & \\
\hline COROA & & & RI & & \\
\hline CORUJA & & & $\mathrm{RO}$ & & \\
\hline CADEIRA & & & RÉ & & \\
\hline ARVORE & & & $\mathrm{RA}$ & & \\
\hline JACARE & & & $\mathrm{RO}$ & & \\
\hline CHUVEIRO & & & $\mathrm{RE}$ & & \\
\hline \multirow[t]{15}{*}{ CANGURU } & & & $\mathrm{RO}$ & & \\
\hline & & & RÉ & & \\
\hline & & & RÓ & & \\
\hline & & & $\mathrm{RU}$ & & \\
\hline & & & RA & & \\
\hline & & & $\mathrm{RO}$ & & \\
\hline & & & $\mathrm{RU}$ & & \\
\hline & & & RÉ & & \\
\hline & & & RI & & \\
\hline & & & $\mathrm{RE}$ & & \\
\hline & & & RÓ & & \\
\hline & & & $\mathrm{RU}$ & & \\
\hline & & & RÓ & & \\
\hline & & & RI & & \\
\hline & & & $\mathrm{RA}$ & & \\
\hline
\end{tabular}

Classificação: 0 - sem distorção, 1- PoCD: Posteriorização com distorção acústica. 
Anexo 5f. Protocolo de Registro da Prova Específica para Distorção de Fala em Sílabas e Palavras [1].

Nome:

Idade:

Data:

Escola:

Grupo: ( ) sem Transtorno Fonológico ( ) com Transtorno Fonológico

SÍlABAS E PALAVRAS PARA PROVA DE DISTORÇÃO [l]

\begin{tabular}{|c|l|l|l|l|l|}
\hline & Transcrição & $\begin{array}{c}\text { Classificação da } \\
\text { Distorção }\end{array}$ & & Transcrição & $\begin{array}{c}\text { Classificação } \\
\text { da Distorção }\end{array}$ \\
\hline LATA & & & LO & & \\
\hline LEÃO & & & LÉ & & \\
\hline LEQUE & & LU & & \\
\hline LIXO & & & LI & & \\
\hline LOBO & & LÓ & & \\
\hline LOJA & & & LA & & \\
\hline LUA & & & LE & & \\
\hline POLEGAR & & LU & & \\
\hline GALINHA & & LA & & \\
\hline JANELA & & & LÉ & & \\
\hline XALE & & & LE & & \\
\hline CAVALO & & & LÓ & & \\
\hline & & & LI & & \\
\hline & & & LO & & \\
\hline & & & LÁ & & \\
\hline & & & LÉ & & \\
\hline & & & LI & & \\
\hline & & & LU & & \\
\hline & & & LO & & \\
\hline & & & LE & & \\
\hline
\end{tabular}

Classificação: 0 - sem distorção, 1- PLSD: Projeção de língua sem distorção acústica. 
Anexo 5g. Protocolo de Registro da Prova Específica para Distorção de Fala em Sílabas e Palavras $[\Lambda]$.

Nome:

Idade:

Data:

Escola:

Grupo: ( ) sem Transtorno Fonológico ( ) com Transtorno Fonológico

SÍlABAS E PALAVRAS PARA PROVA DE DISTORÇÃO $[\Lambda]$

\begin{tabular}{|c|c|c|c|c|c|}
\hline & Transcrição & $\begin{array}{l}\text { Classificação } \\
\text { da Distorção }\end{array}$ & & Transcrição & $\begin{array}{l}\text { Classificação } \\
\text { da Distorção }\end{array}$ \\
\hline PALHACCO & & & LHE & & \\
\hline FOLHINHA & & & LHI & & \\
\hline TOALHA & & & LHA & & \\
\hline VERMELHO & & & LHO & & \\
\hline \multirow[t]{17}{*}{ FILHOTE } & & & LHE & & \\
\hline & & & LHÓ & & \\
\hline & & & LHI & & \\
\hline & & & LHU & & \\
\hline & & & LHA & & \\
\hline & & & LHÓ & & \\
\hline & & & LHU & & \\
\hline & & & LHE & & \\
\hline & & & LHO & & \\
\hline & & & LHÉ & & \\
\hline & & & LHÓ & & \\
\hline & & & LHI & & \\
\hline & & & LHA & & \\
\hline & & & LHÉ & & \\
\hline & & & LHU & & \\
\hline & & & LHO & & \\
\hline & & & LHÉ & & \\
\hline
\end{tabular}

Classificação: 0 - sem distorção 1- RM: Ruído molhado (ruído de saliva). 
Anexo 6. Termo de Consentimento Pós-Informação: Grupo Com Transtorno Fonológico.

\section{HOSPITAL DAS CLÍNICAS \\ DA FACULDADE DE MEDICINA DA UNIVERSIDADE DE SÃO PAULO TERMO DE CONSENTIMENTO LIVRE E ESCLARECIDO}

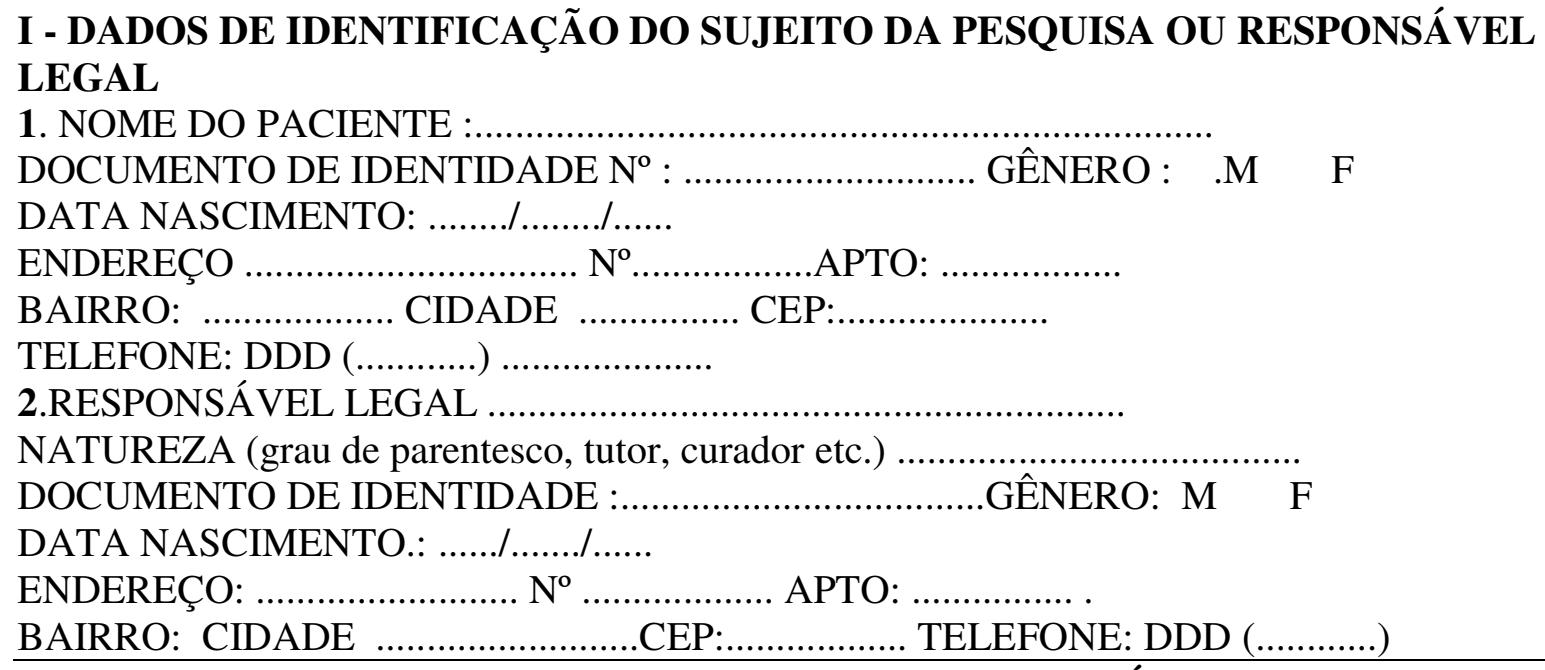

\section{II - DADOS SOBRE A PESQUISA CIENTÍFICA}

1. TÍTULO DO PROTOCOLO DE PESQUISA: Descrição de distorções de fala em crianças com e sem transtorno fonológico.

PESQUISADOR: Haydée Fiszbein Wertzner CARGO/FUNÇÃO:Profa.Livre Docente INSCRIÇÃO CONSELHO REGIONAL N ${ }^{\circ}$ CRF $^{a} 0941$

UNIDADE DO HCFMUSP: Departamento de Fisioterapia, Fonoaudiologia e Terapia Ocupacional

3. AVALIAÇÃO DO RISCO DA PESQUISA:

$\begin{array}{lcc}\text { SEM RISCO } \square & \text { RISCO MÍNIMO } & \text { X } \\ \text { RISCO BAIXO } & \text { RISCO MÉDIO }\end{array}$

4.DURAÇÃO DA PESQUISA : 17 meses

III - REGISTRO DAS EXPLICAÇÕES DO PESQUISADOR AO PACIENTE OU SEU REPRESENTANTE LEGAL SOBRE A PESQUISA CONSIGNANDO:

É muito comum na população infantil ocorrer alteração de linguagem e fala, que é um atraso ou desvio na aquisição dos sons de fala. As crianças com esta alteração trocam ou não produzem alguns sons e também podem distorcê-los, ou seja, produzi-los de maneira errada. É muito importante que seja feito um bom diagnóstico para que o tratamento seja eficiente, para isso são usadas algumas técnicas.

O objetivo desta pesquisa é verificar a ocorrência de distorções em crianças com e sem alteração de linguagem e fala.

Para atingir este objetivo necessitamos avaliar seu filho que apresenta alteração de linguagem e fala e que participa do grupo com transtorno fonológico, para poder ser comparado com as crianças que não têm esta alteração. Inicialmente, será feita uma entrevista como os senhores pais, para saber como foi desenvolvimento de seu filho, logo após, a criança será avaliada por meio de provas de linguagem composta por imitação de palavras, nomeação de figuras e fala espontânea, onde irá contar uma história a partir de figuras de um livro. Serão analisadas a postura e movimentação dos lábios, dentes, língua, bochechas, paredes superior e inferior da boca, além de verificar o tipo de mordida. 
Caso seja detectada na prova de linguagem alguma distorção de fala, será aplicada uma prova composta de imitação de sílabas e palavras que contenham os sons distorcidos. Para verificar quais os pontos que a língua de seu filho toca na parede superior da boca durante a produção do som distorcido, a língua será coberta por uma pasta de azeite de oliva e carvão (esta mistura não tem cheiro nem gosto), enquanto ocorre a produção do som serão tiradas fotografias e filmada, para posterior análise. Estes sons distorcidos serão analisados também por um programa de computador.Todas as provas serão gravadas e filmadas.

Não é esperado nem desconforto e risco mínimo para a criança durante a aplicação dessas provas. Com as respostas de seu filho, será possível verificar e caracterizar as distorções de crianças com transtorno fonológico, o que possibilitará o oferecimento de melhores condições de conduzir a avaliação, diagnóstico e tratamento das crianças com transtorno fonológico.

IV - ESCLARECIMENTOS DADOS PELO PESQUISADOR SOBRE GARANTIAS DO SUJEITO DA PESQUISA CONSIGNANDO:

1. acesso, a qualquer tempo, às informações sobre procedimentos, riscos e benefícios relacionados à pesquisa, inclusive para dirimir eventuais dúvidas. A qualquer momento o responsável pela criança poderá procurar a pesquisadora para tirar quaisquer dúvidas quanto às provas usadas na testagem, bem como às gravações realizadas.

2. liberdade de retirar seu consentimento a qualquer momento e de deixar de participar do estudo, sem que isto traga prejuízo à continuidade da assistência. A qualquer momento o responsável pela criança poderá decidir não fazer parte do estudo.

3. salvaguarda da confidencialidade, sigilo e privacidade. Os dados da criança serão utilizados somente para a pesquisa e ensino, sendo mantido o sigilo e a privacidade da mesma.

4. disponibilidade de assistência no HCFMUSP, por eventuais danos à saúde, decorrentes da pesquisa. Não é esperado nenhum dano à saúde com a aplicação das provas anteriormente citadas. O tratamento fonoaudiológico estará garantido caso seja diagnosticada qualquer alteração de linguagem ou fala na criança.

5. viabilidade de indenização por eventuais danos à saúde decorrentes da pesquisa. Não é esperado nenhum dano à saúde com a aplicação das provas anteriormente citadas.

V. INFORMAÇÕES DE NOMES, ENDEREÇOS E TELEFONES DOS RESPONSÁVEIS PELO ACOMPANHAMENTO DA PESQUISA, PARA CONTATO EM CASO DE INTERCORRÊNCIAS CLÍNICAS E REAÇÕES ADVERSAS.

Prof $^{a}{ }{ }^{a}{ }^{a}$ Haydée Fiszbein Wertzner: Rua Cipotãnea, 51 - Cidade Universitária - Butantã - São Paulo

Fone: 30917455 e 30917452

\section{OBSERVAÇÕES COMPLEMENTARES:}

\section{VII - CONSENTIMENTO PÓS-ESCLARECIDO}

Declaro que, após convenientemente esclarecido pelo pesquisador e ter entendido o que me foi explicado, consinto em participar do presente Protocolo de Pesquisa.

São Paulo, de de 20

assinatura do sujeito da pesquisa ou responsável legal

assinatura do pesquisador

Prof $^{a}$ Dra. Haydée Fiszbein Wertzner 
Anexo 7. Protocolo para registro dos índices de gravidade.

\begin{tabular}{|c|c|c|}
\hline \multirow[b]{3}{*}{ Imitação = } & $P C C=$ total de consoantes corretas & \multirow[b]{2}{*}{$x 100 \%$} \\
\hline & total consoantes da prova & \\
\hline & & \\
\hline Nomeação = & & \\
\hline Fala Espontânea = & & \\
\hline
\end{tabular}

\begin{tabular}{|c|c|c|}
\hline \multirow[b]{3}{*}{ Imitação = } & \multicolumn{2}{|l|}{$P C C-R=$ total de consoantes corretas } \\
\hline & total consoantes da prova & $x 100 \%$ \\
\hline & & \\
\hline Nomeação $=$ & & \\
\hline Fala Espontânea = & & \\
\hline
\end{tabular}

\begin{tabular}{|l|c|}
\cline { 2 - 2 } \multicolumn{1}{c|}{} & \multicolumn{2}{c|}{$P D I=$ número total de processos fonológicos } \\
\cline { 2 - 2 } & \\
\hline Imitação $=$ & número total de palavras \\
\hline Nomeação $=$ & \\
\hline Fala Espontânea $=$ & \\
\hline
\end{tabular}

\begin{tabular}{|l|c|}
\cline { 2 - 2 } \multicolumn{1}{c|}{} & \multicolumn{2}{c|}{ RDI = número total de erros de distorção } \\
Imitação $=$ & número total de erros da fala \\
\hline Nomeação $=$ & \\
\hline Fala Espontânea $=$ & \\
\hline
\end{tabular}

\begin{tabular}{|l|c|}
\cline { 2 - 2 } \multicolumn{1}{c|}{} & \multicolumn{2}{|c|}{$A C I=P C C+R D I$} \\
Imitação $=$ & $\frac{2}{2} \times 100 \%$ \\
\hline Nomeação $=$ & \\
\hline Fala Espontânea $=$ & \\
\hline
\end{tabular}


Anexo 8a. Carta de Encaminhamento à Escola de Ensino Fundamental.

Sra. Angela

Diretora da EMEF "Guilherme de Almeida"

Prezada Sra.

Conforme explicado em contato anterior, estamos realizando pesquisa para verificar a ocorrência de distorções em crianças com e sem transtorno fonológico, desta forma, necessitamos de crianças normais de ensino fundamental para formarem o grupo controle. Esperamos que esta pesquisa possa contribuir para um diagnóstico preciso e objetivo, colaborando assim, para melhores procedimentos terapêuticos para crianças com o diagnóstico deste transtorno.

Solicitamos sua colaboração e autorização formal para que a pesquisa possa ser realizada com os alunos de sua escola.

Colocamo-nos à disposição para eventuais esclarecimentos.

Atenciosamente,

Prof $^{\mathrm{a}}$ Dr $^{\mathrm{a}}$ Haydée F. Wertzner

Curso de Fonoaudiologia da Faculdade de Medicina da USP 
Anexo 8b. Carta de Encaminhamento à Escola de Ensino Infantil.

Sra. Márcia

Coordenadora da EMEI “José Rubens Perez Fernandes"

Prezada Sra. Márcia

Coordenadora Pedagógica da EMEI “Prof. José Rubens Perez Fernandes”.

Conforme explicado em contato anterior, estamos realizando pesquisa para verificar a ocorrência de distorções em crianças com e sem transtorno fonológico, desta forma, necessitamos de crianças normais de pré-escola com desenvolvimento típico de fala e linguagem entre 5:00 e 6:11 anos de idade de ambos os gêneros para formarem o grupo controle. Esperamos que esta pesquisa possa contribuir para um diagnóstico preciso e objetivo, colaborando assim, para melhores procedimentos terapêuticos para crianças com o diagnóstico deste transtorno.

Solicitamos sua colaboração e autorização formal para que a pesquisa possa ser realizada com os alunos de sua escola.

Colocamo-nos à disposição para eventuais esclarecimentos.

Atenciosamente,

Prof $^{\mathrm{a}}$ Dr $^{\mathrm{a}}$ Haydée F. Wertzner

Curso de Fonoaudiologia da Faculdade de Medicina da USP 
Anexo 9. O Processo de Construção da Prova de Sílabas e Palavras para a Verificação de Distorção de Sons.

Para compor a prova para verificação de distorção, foi realizado o levantamento de palavras, substantivos preferencialmente concretos e simples, que continham os fonemas fricativos /s/, /z/, /3/ e /S/ da Língua Portuguesa e que freqüentemente são utilizados por crianças de 5:0 a 7:11 anos. As palavras que compuseram a prova para verificação de distorção dos sons em sílabas e palavras em sons líquidos laterais e vibrantes simples foram retiradas do Teste de Estimulabilidade (CASTRO, 2004).

A seleção dos estímulos para os fonemas fricativos seguiu os mesmos critérios do Teste de Estimulabilidade (CASTRO, 2004). Deste modo, foram usados três instrumentos para selecionar os estímulos com os quatro fonemas fricativos estudados, os instrumentos foram: entrevista com crianças, consulta a livros de histórias infantis e livros didáticos usados a partir da Pré-Escola.

Primeiramente realizou-se uma entrevista com 15 crianças de 5:0 a 8:11 anos (língua falada) da entidade filantrópica "Casa Comunitária Sagrada Família", localizada na Zona Leste da cidade de São Paulo, que atende crianças de baixa renda. A entrevista foi composta por perguntas fechadas e abertas, tais como: nome, idade, se tinha irmãos, escola que freqüentava, o que a criança achava do Natal, nomes de animais, frutas e meios de transporte. Todas as entrevistas foram gravadas em fita cassete e transcritas pela pesquisadora.

O segundo instrumento contou com o levantamento de substantivos preferencialmente concretos e simples presentes em livros de histórias infantis, escritos por autores brasileiros. Optou-se pela escolha desta fonte, por ser o mais freqüente contato que crianças desta faixa etária têm com histórias infantis, lidas ou contadas para elas (língua falada) ou lida pela própria criança (língua escrita). Foram selecionados seis diferentes autores (FRANÇA E FRANÇA, 1986; BELINSKY, 1988; COELHO; MUNIZ, 1988; ANDRADE, 1995; ZIRALDO, 1996), com o propósito de permitir variação no léxico e evitar a influência de outra língua, que não o Português Brasileiro (Tabela A). 
Tabela A. Relação de livros de história pesquisados.

\begin{tabular}{|l|l|l|l|l|l|}
\hline Nome do Livro & Autor & Editora & Publicação & Edição & Cidade \\
\hline O Bronzeado da Zebra & ANDRADE, T. G. C. & Paulus & 1995 & $1^{\text {a }}$ & São Paulo \\
\hline $\begin{array}{l}\text { A Alegre Vovó Guida } \\
\text { que é um Bocado Distraída }\end{array}$ & BELINSKY, T. & $\begin{array}{l}\text { Editora do } \\
\text { Brasil }\end{array}$ & 1988 & $1^{\text {a }}$ & São Paulo \\
\hline A Laranja Colorida & COELHO, R. S. & Editora Lê & Sem data & $1^{\text {a }}$ & Belo Horizont \\
\hline O Jabuti & $\begin{array}{l}\text { FRANÇA, M.; } \\
\text { FRANÇA, E. }\end{array}$ & Ática & 1992 & $1^{\text {a }}$ & São Paulo \\
\hline O Jogo do Pega Pega & MUNIZ, F. & FTD & 1988 & $1^{\text {a }}$ & São Paulo \\
\hline $\begin{array}{l}\text { Um, Dois, Feijão } \\
\text { com Arroz }\end{array}$ & ZIRALDO & Melhoramentos & 1996 & $1^{\text {a }}$ & São Paulo \\
\hline
\end{tabular}

A terceira fonte de pesquisa foi constituída por nove livros didáticos (CASTRO, 1986; LIMA, 1987; GONDIM, 1993 a; GONDIM, 1993 b; GONDIM, 1995 a; GONDIM, 1995 b; DE NICOLA E CHIARION, 1996; PASSOS, FERREIRA e SILVA; PASSOS e SILVA) utilizados a partir da fase pré-escolar, já que a faixa etária desta pesquisa iniciou-se aos 5;01 anos.

Tabela B. Relação de livros didáticos pesquisados

\begin{tabular}{|c|c|c|c|c|c|}
\hline Nome do Livro & Autor & Editora & Publicação & Edição & Cidade \\
\hline Caminho Feliz & CASTRO, M A P & IBEP & 1986 & $1^{\mathrm{a}}$ & São Paulo \\
\hline $\begin{array}{l}\text { Cartilha Caminho } \\
\text { Novo }\end{array}$ & $\begin{array}{l}\text { DE NICOLA, J.; } \\
\text { CHIARION, R. }\end{array}$ & Scipione & 1996 & $1^{\mathrm{a}}$ & São Paulo \\
\hline $\begin{array}{l}\text { Lápis na Mão: L } \\
\text { Íngua Portuguesa } 2\end{array}$ & GONDIM, M S A & FTD & $1993 \mathrm{a}$ & $1^{\mathrm{a}}$ & São Paulo \\
\hline $\begin{array}{l}\text { Lápis na Mão: L } \\
\text { Íngua Portuguesa } 3\end{array}$ & GONDIM, M S A & FTD & $1993 \mathrm{~b}$ & $1^{\mathrm{a}}$ & São Paulo \\
\hline $\begin{array}{l}\text { Lápis na Mão: } \\
\text { Matemática } 3\end{array}$ & GONDIM, M S A & FTD & $1995 \mathrm{a}$ & $1^{\mathrm{a}}$ & São Paulo \\
\hline $\begin{array}{l}\text { Lápis na Mão: } \\
\text { Matemática } 4\end{array}$ & GONDIM, M S A & FTD & $1995 \mathrm{~b}$ & $1^{\mathrm{a}}$ & São Paulo \\
\hline Caminho Suave & LIMA, B. A & $\begin{array}{l}\text { Ed. Caminho } \\
\text { Suave }\end{array}$ & 1987 & $27^{a}$ & São Paulo \\
\hline $\begin{array}{l}\text { Conceitos Básicos, } \\
\text { Percepção Visual, } \\
\text { Auditiva, } \\
\text { Coordenação Motora, } \\
\text { Orientação } \\
\text { Temporo-Espacial }\end{array}$ & $\begin{array}{l}\text { PASSOS, C.; } \\
\text { FERREIRA, M.; } \\
\text { SILVA, Z }\end{array}$ & $\begin{array}{l}\text { Cia Editora } \\
\text { Nacional }\end{array}$ & Sem data & $1^{\mathrm{a}}$ & São Paulo \\
\hline $\begin{array}{l}\text { Eu gosto de ler e } \\
\text { Escrever }\end{array}$ & $\begin{array}{l}\text { PASSOS, C.; } \\
\text { SILVA, Z. }\end{array}$ & $\begin{array}{l}\text { Editora } \\
\text { Nacional }\end{array}$ & Sem data & $1^{\mathrm{a}}$ & São Paulo \\
\hline
\end{tabular}

Para cada um dos três instrumentos analisou-se as ocorrências dos quatro fonemas estudados buscando-se as palavras mais freqüentes e portanto familiares no vocabulário infantil. Selecionou-se todos os substantivos simples e com vogais abertas, compostas preferencialmente com estrutura silábica do tipo CV (consoante vogal), nas posições silábicas inicial, medial e final. Em seguida, agrupou-se a palavra de acordo com a vogal, a posição silábica do fonema na palavra (inicial, medial ou final) e a extensão da palavra (dissílabos, trissílabos ou polissílabos). 
Foram escolhidos preferencialmente os di ou trissílabos, pois além de serem mais freqüentes na língua não apresentam influência da extensão vocabular. Como pode ser notado não foi possível encontrar palavras que pudessem preencher todos os quesitos para todos os fonemas, sendo, portanto variável o número de palavras em função do fonema.

Os vocábulos selecionados foram os que apresentaram maior número de ocorrência nas entrevistas, livros infantis e didáticos.

As Tabelas a seguir mostram a ocorrência dos vocábulos nos três instrumentos pesquisados, além de indicar a posição do fonema na sílaba.

Tabela C. Entrevistas - ocorrência do fonema /s/.

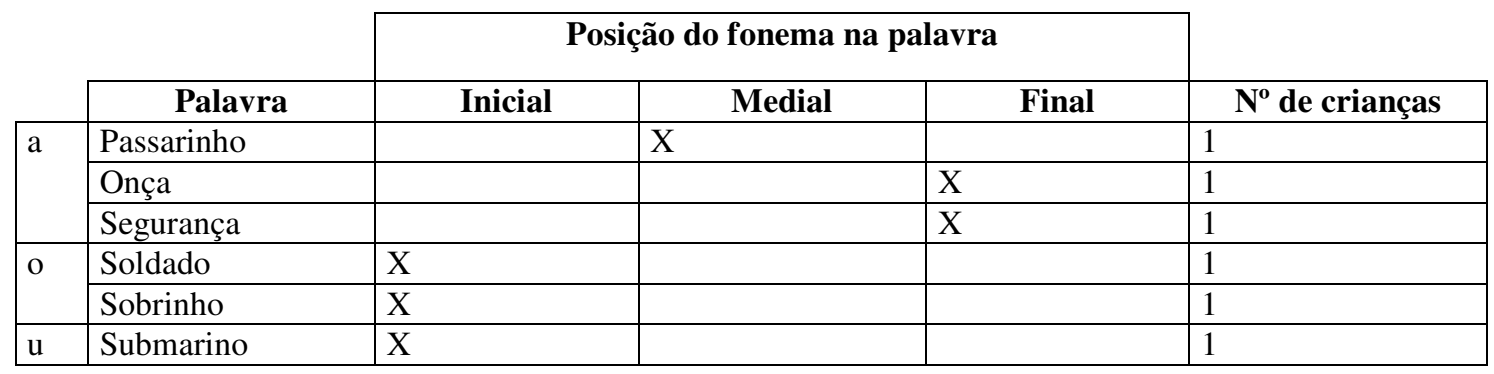

Tabela D.Entrevistas - ocorrência do fonema /z/.

\begin{tabular}{|l|l|l|l|l|l|}
\cline { 3 - 6 } \multicolumn{2}{c|}{} & \multicolumn{2}{c|}{ Posição do fonema na palavra } & \multicolumn{1}{c}{ Final } & \multicolumn{1}{c|}{$\mathbf{N}^{0}$ de crianças } \\
\cline { 2 - 6 } \multicolumn{1}{c|}{ Palavra } & Inicial & Medial & & 1 \\
\hline a & Rosa & & X & & 1 \\
\hline i & Casinha & & X & X & 1 \\
\hline u & Azul & & & \\
\hline
\end{tabular}


Tabela E. Entrevistas - ocorrência do fonema / $/$.

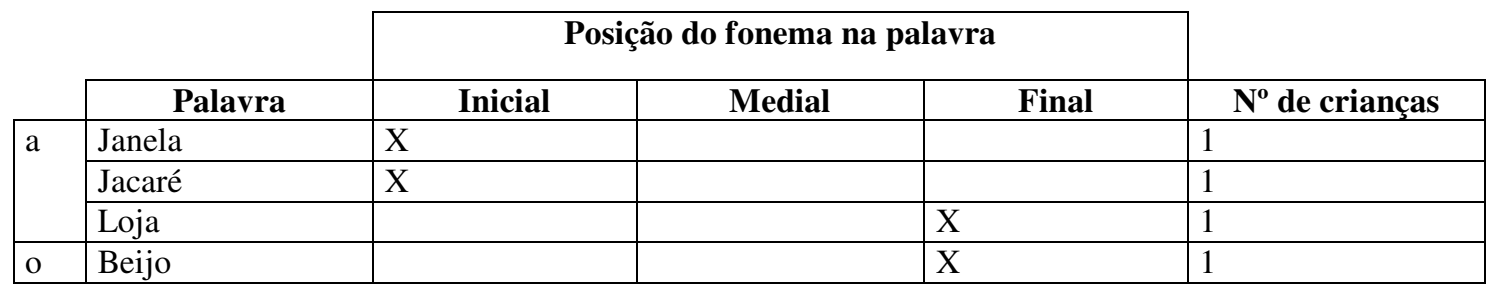

Tabela F. Entrevistas - ocorrência do fonema /3/.

\begin{tabular}{|c|c|c|c|c|c|}
\hline & & \multicolumn{3}{|c|}{ Posição do fonema na palavra } & \multirow[b]{2}{*}{$\mathrm{N}^{0}$ de crianças } \\
\hline & Palavra & Inicial & Medial & Final & \\
\hline \multirow[t]{2}{*}{$\mathrm{a}$} & Prancha & & & $\mathrm{X}$ & 1 \\
\hline & Lagartixa & & & $\mathrm{X}$ & 3 \\
\hline \multirow[t]{2}{*}{ o } & Cachorro & & $\mathrm{X}$ & & 1 \\
\hline & Roxo & & & $\mathrm{X}$ & 1 \\
\hline $\mathrm{u}$ & Chuva & $\mathrm{X}$ & & & 1 \\
\hline
\end{tabular}

Tabela G. Livros Infantis - ocorrência do fonema /s/.

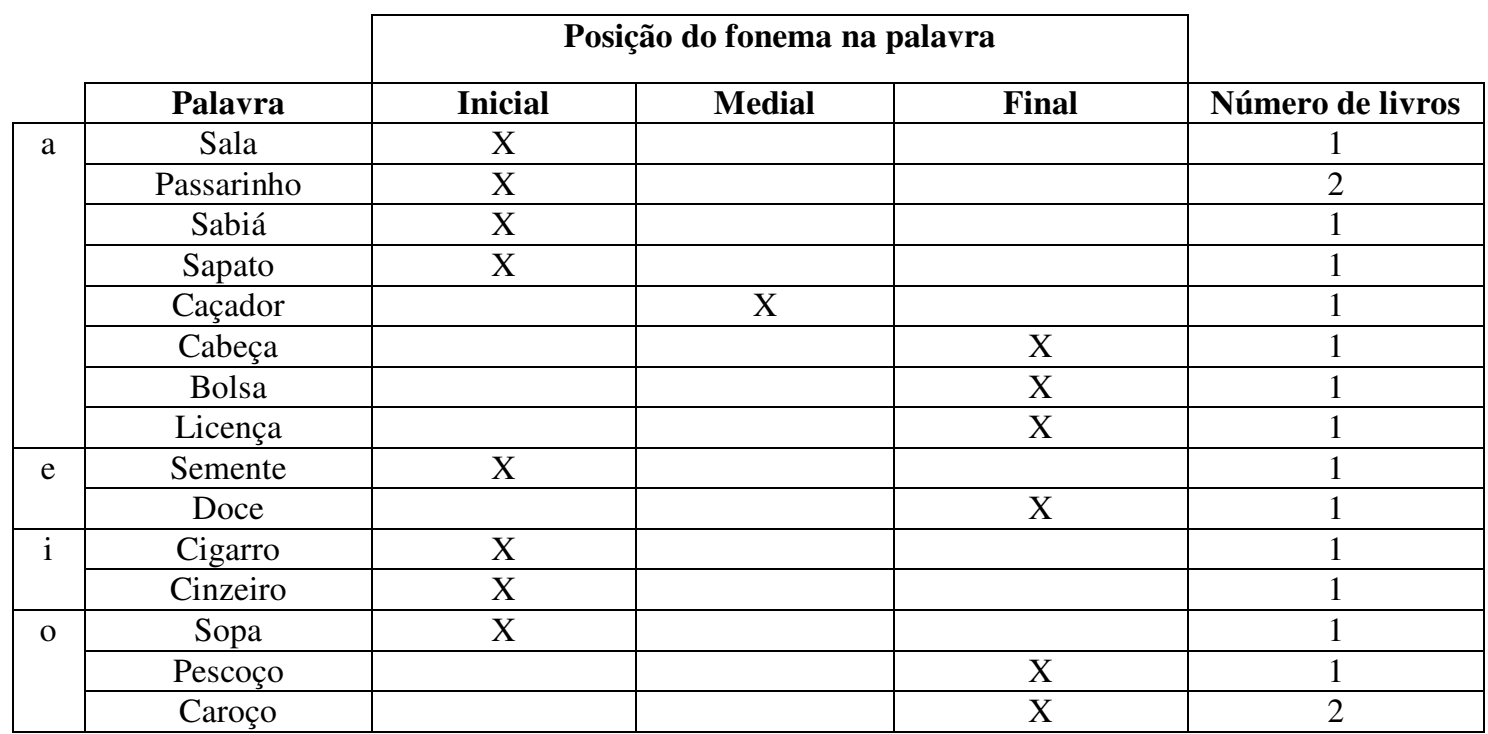


Tabela H. Livros Infantis - ocorrência do fonema /z/.

\begin{tabular}{c|c|c|c|c|c|}
\cline { 3 - 6 } \multicolumn{1}{c}{} & \multicolumn{3}{c|}{ Posição do fonema na palavra } & \multicolumn{1}{c}{} \\
\cline { 2 - 6 } \multicolumn{1}{c|}{} & Palavra & Inicial & Medial & Final & Número de livros \\
\hline \multirow{2}{*}{ a } & Cinza & & & $X$ & 1 \\
\cline { 2 - 6 } & Mesa & & & $X$ & 1 \\
\cline { 2 - 6 } & Asa & & $X$ & & 1 \\
\hline e & Zebra & $\mathrm{X}$ & $\mathrm{X}$ & 1 \\
\cline { 2 - 6 } & Bronzeador & & $\mathrm{X}$ & & 1 \\
\hline i & Cozinha & & & & 1 \\
\hline
\end{tabular}

Tabela I. Livros Infantis - ocorrência do fonema /S/.

\begin{tabular}{|c|c|c|c|c|c|}
\cline { 3 - 6 } \multicolumn{1}{c|}{} & \multicolumn{3}{c|}{ Posição do fonema na palavra } & \multicolumn{1}{c}{ Final } & Número de livros \\
\cline { 2 - 6 } \multicolumn{1}{c|}{} & Palavra & Inicial & Medial & & 1 \\
\hline $\mathrm{a}$ & Jabuti & $\mathrm{X}$ & & & 1 \\
\hline $\mathrm{e}$ & Jenipapo & $\mathrm{X}$ & & & 1 \\
\hline$\varepsilon$ & Tigela & & $\mathrm{X}$ & & 1 \\
\hline $\mathrm{i}$ & Girafa & $\mathrm{X}$ & & $\mathrm{X}$ & 1 \\
\hline $\mathrm{o}$ & Queijo & & & & 1 \\
\hline
\end{tabular}

Tabela J. Livros Infantis - ocorrência do fonema / $/$ /.

\begin{tabular}{|c|c|c|c|c|c|}
\cline { 3 - 6 } \multicolumn{1}{c|}{} & \multicolumn{3}{c|}{ Posição do fonema na palavra } & \multicolumn{1}{c}{} \\
\cline { 2 - 6 } \multicolumn{1}{c|}{} & Palavra & Inicial & Medial & Final & Número de livros \\
\hline i & Chique & $\mathrm{X}$ & & $\mathrm{X}$ & 1 \\
\hline $\mathrm{o}$ & Bicho & & & 2 \\
\hline
\end{tabular}


Tabela L. Livros Didáticos - ocorrência do fonema /s/.

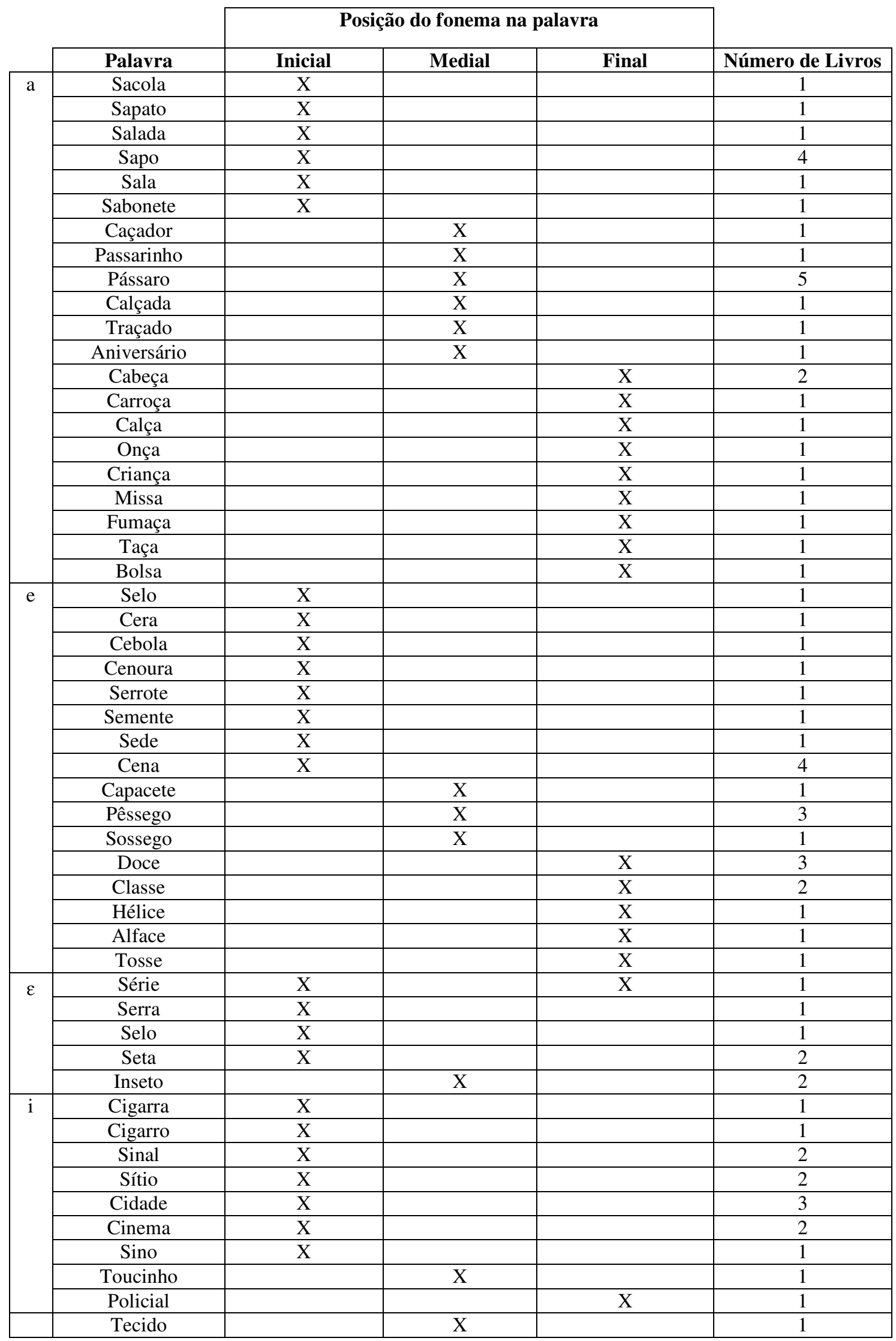




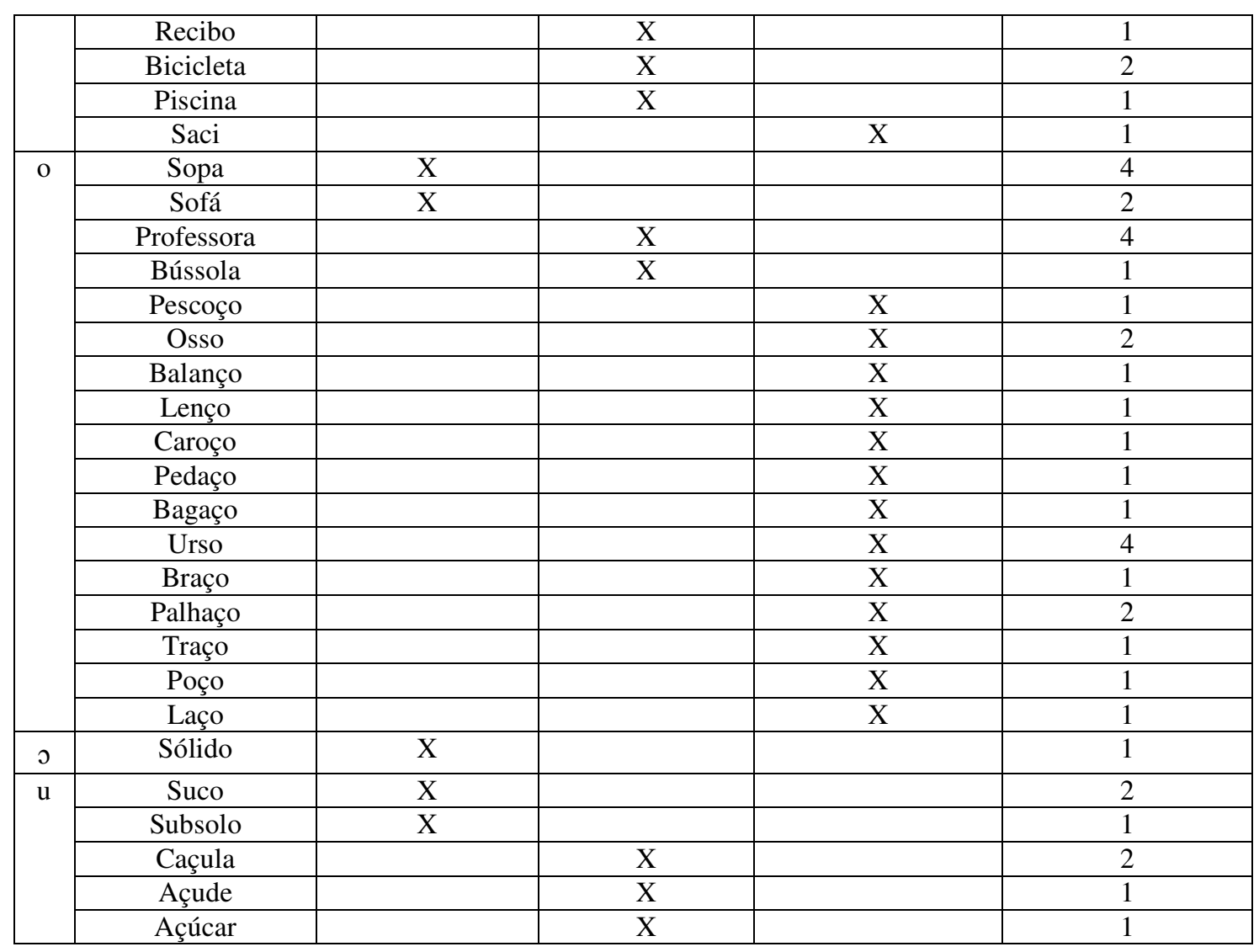


Tabela M. Livros Didáticos - ocorrência do fonema /z/.

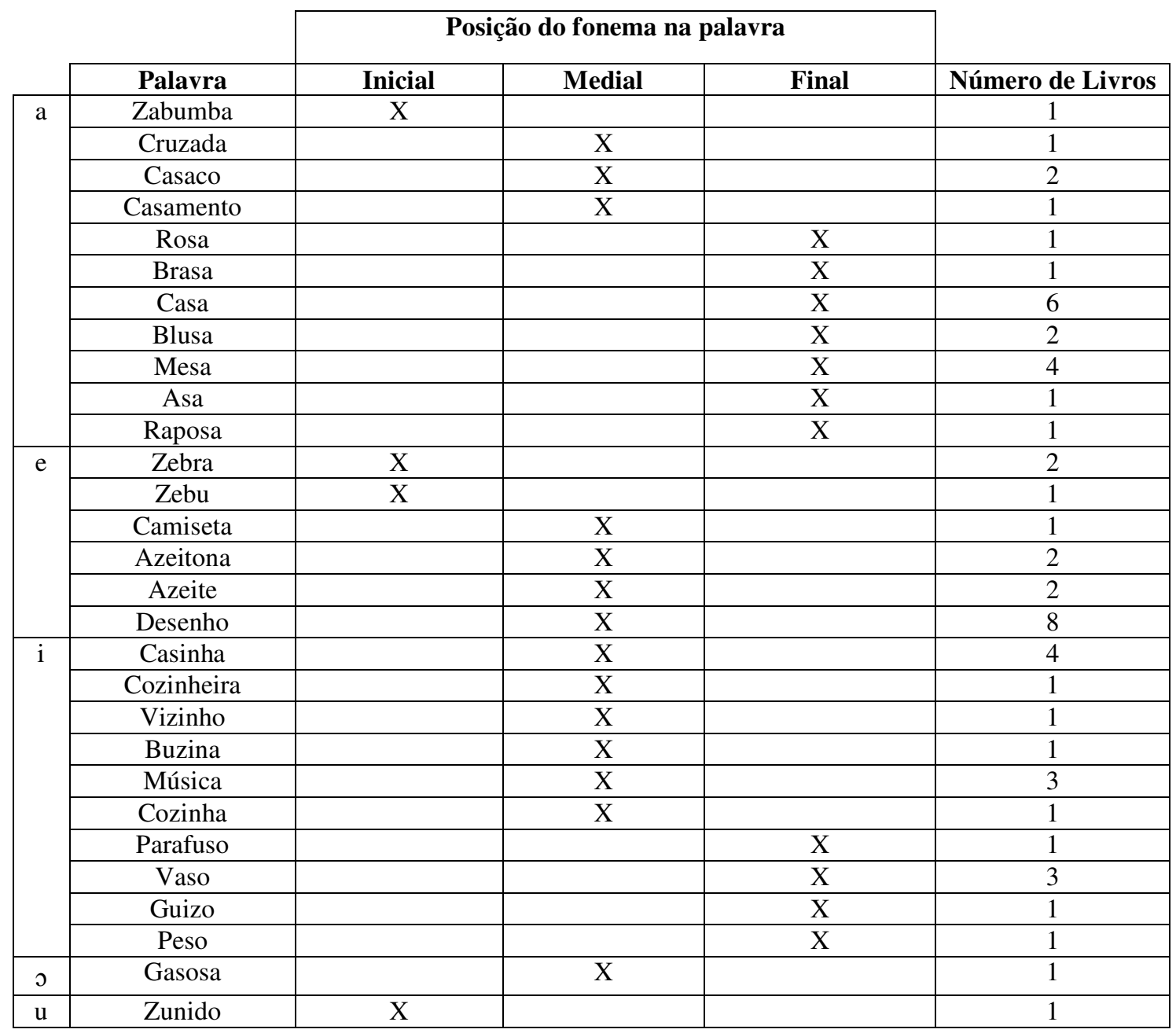


Tabela N. Livros Didáticos - ocorrência do fonema /S/.

\begin{tabular}{|c|c|c|c|c|c|}
\hline & & \multicolumn{3}{|c|}{ Posição do fonema na palavra } & \multirow[b]{2}{*}{$\begin{array}{l}\text { Número de } \\
\text { Livros }\end{array}$} \\
\hline & Palavra & Inicial & Medial & Final & \\
\hline \multirow[t]{16}{*}{$\mathrm{a}$} & Xarope & $\mathrm{X}$ & & & 5 \\
\hline & Chave & $\mathrm{X}$ & & & 2 \\
\hline & Chapéu & $\mathrm{X}$ & & & 4 \\
\hline & Chá & $\mathrm{X}$ & & & 3 \\
\hline & Xale & $\mathrm{X}$ & & & 7 \\
\hline & Chaminé & $\mathrm{X}$ & & & 1 \\
\hline & Charrete & $\mathrm{X}$ & & & 2 \\
\hline & Chácara & $\mathrm{X}$ & & & 1 \\
\hline & Machado & & $\bar{X}$ & & 1 \\
\hline & Enxada & & $\mathrm{X}$ & & 2 \\
\hline & Ameixa & & & $\mathrm{X}$ & 1 \\
\hline & Caixa & & & $\mathrm{X}$ & 3 \\
\hline & Colcha & & & $\mathrm{X}$ & 1 \\
\hline & Borracha & & & $\mathrm{X}$ & 1 \\
\hline & Bolacha & & & $\mathrm{X}$ & 2 \\
\hline & Ficha & & & $\mathrm{X}$ & 1 \\
\hline \multirow[t]{5}{*}{ e } & Chegada & & & $\mathrm{X}$ & 4 \\
\hline & Feixe & & & $\mathrm{X}$ & 1 \\
\hline & Peixe & & & $\mathrm{X}$ & 7 \\
\hline & Fantoche & & & $\mathrm{X}$ & 2 \\
\hline & Guache & & & $\mathrm{X}$ & 1 \\
\hline$\varepsilon$ & Chefe & $\mathrm{X}$ & & & 2 \\
\hline \multirow{7}{*}{$\mathrm{i}$} & Chita & $\mathrm{X}$ & & & 1 \\
\hline & Xícara & $\mathrm{X}$ & & & 2 \\
\hline & Xilofone & $\mathrm{X}$ & & & 1 \\
\hline & Chinelo & $\mathrm{X}$ & & & 2 \\
\hline & Bexiga & & $\mathrm{X}$ & & 2 \\
\hline & Carochinha & & $\mathrm{X}$ & & 1 \\
\hline & Abacaxi & & & $\mathrm{X}$ & 2 \\
\hline \multirow[t]{7}{*}{ o } & Chocolate & $\mathrm{X}$ & & & 2 \\
\hline & Cachorro & & $\mathrm{X}$ & & 3 \\
\hline & Lixo & & & $\mathrm{X}$ & 3 \\
\hline & Cacho & & & $\mathrm{X}$ & 3 \\
\hline & Roxo & & & $\mathrm{X}$ & 1 \\
\hline & Bicho & & & $\mathrm{X}$ & 4 \\
\hline & Queixo & & & $\mathrm{X}$ & 1 \\
\hline & Caixote & & $\mathrm{X}$ & & 1 \\
\hline 0 & & & & & \\
\hline \multirow[t]{5}{*}{$\mathrm{u}$} & Chuva & $\mathrm{X}$ & & & 3 \\
\hline & Chuveiro & $\mathrm{X}$ & & & 2 \\
\hline & Chupeta & $\mathrm{X}$ & & & 2 \\
\hline & Chuchu & $\mathrm{X}$ & & & 2 \\
\hline & Machucado & & $\bar{X}$ & & 1 \\
\hline
\end{tabular}


Tabela O. Livros Didáticos - ocorrência do fonema /3/.

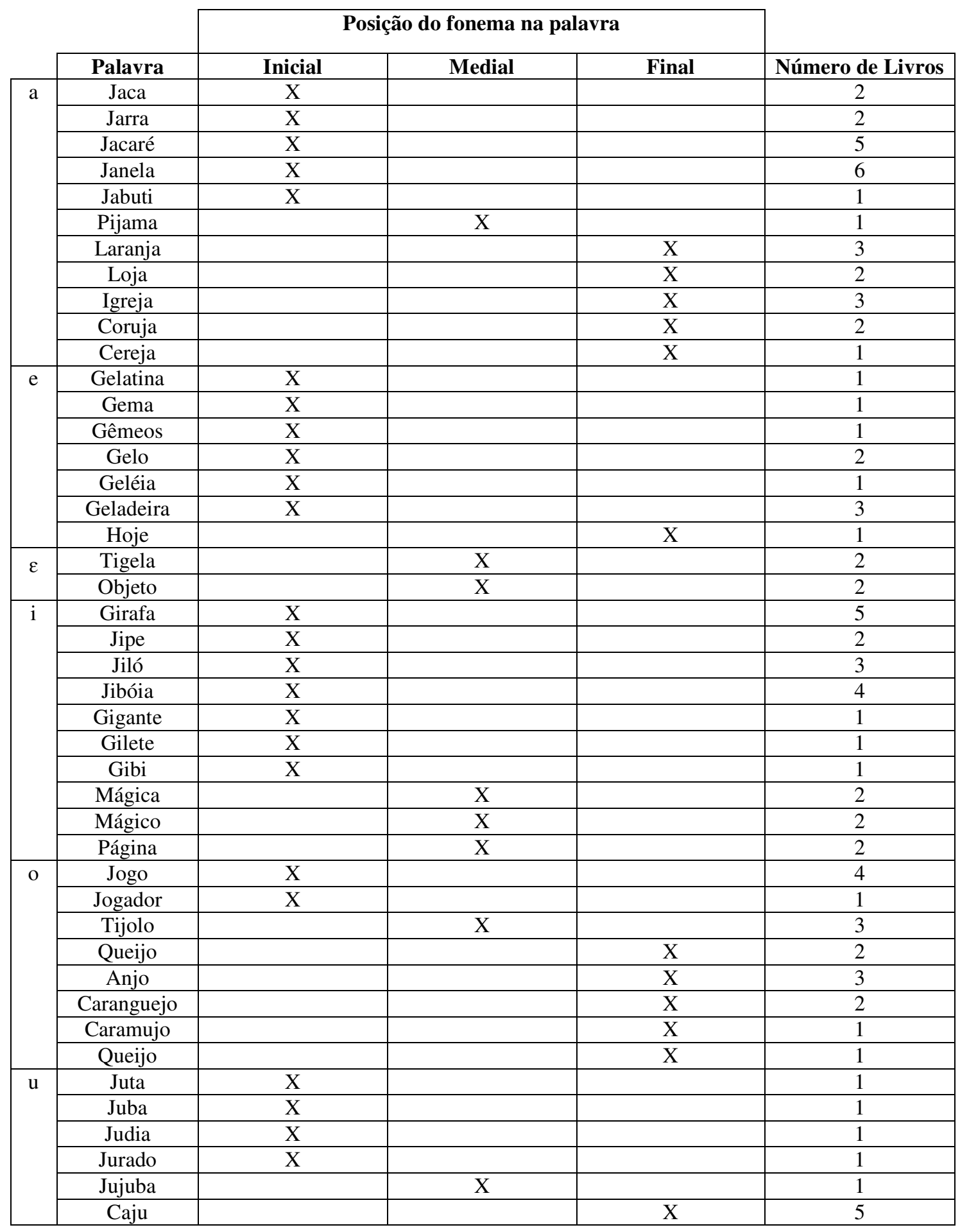


Anexo 10. Proporção de distorção nos $[\mathrm{s}],[\mathrm{z}],\left[\int\right]$ e [l] nas provas de nomeação, imitação e fala espontânea no GSTF.

Tabela P. Proporção de distorção nos [s], [z], [S] e [1] nas provas de nomeação, imitação e fala espontânea no GSTF.

\begin{tabular}{|c|c|c|c|c|}
\hline PROVAS & {$[\mathbf{s}]$} & {$[\mathbf{z}]$} & {$[$ [S] } & {$[$ [] } \\
\hline Imitação & $48 / 270$ & $8 / 60$ & $1 / 90$ & $2 / 240$ \\
\hline Nomeação & $48 / 270$ & $17 / 120$ & $1 / 90$ & $4 / 240$ \\
\hline Fala espontânea & $8 / 58$ & $0 / 9$ & $0 / 7$ & $0 / 7$ \\
\hline
\end{tabular}


Anexo 11. Proporção de distorção nos $[\mathrm{s}],[\mathrm{z}]$ e $[\ulcorner]$ nas provas de nomeação, imitação e fala espontânea no GTF.

Tabela Q. Proporção de distorção nos $[\mathrm{s}],[\mathrm{z}]$ e $[\ulcorner]$ nas provas de nomeação, imitação e fala espontânea no GTF.

\begin{tabular}{|c|c|c|c|}
\hline PROVAS & {$[\mathbf{s}]$} & {$[\mathbf{z}]$} & {$[\boldsymbol{c}]$} \\
\hline Imitação & $15 / 135$ & $3 / 30$ & $0 / 195$ \\
\hline Nomeação & $10 / 135$ & $4 / 60$ & $2 / 210$ \\
\hline Fala espontânea & $6 / 41$ & $0 / 11$ & $0 / 31$ \\
\hline
\end{tabular}


Anexo 12. Proporção de distorção nos $[\mathrm{s}],[\mathrm{z}]$ e $[\ulcorner]$ nas provas de nomeação, imitação e fala espontânea no GTF e GSTF nas faixas etárias de cinco, seis e sete anos.

Tabela R. Proporção de distorção nos $[\mathrm{s}],[\mathrm{z}]$ e $[\ulcorner]$ nas provas de nomeação, imitação e fala espontânea no GTF e GSTF nas faixas etárias de cinco, seis e sete anos.

\begin{tabular}{|c|c|c|c|c|c|c|c|c|c|c|c|}
\hline & & \multicolumn{2}{|c|}{$[\mathrm{s}]$} & \multicolumn{2}{|c|}{ [z] } & \multicolumn{2}{|c|}{ [S] } & \multicolumn{2}{|c|}{ [1] } & \multicolumn{2}{|c|}{ [ᄃ] } \\
\hline & & GSTF & GTF & GSTF & GTF & GSTF & GTF & GSTF & GTF & GSTF & GTF \\
\hline \multirow{3}{*}{$\begin{array}{c}5 \\
\text { anos }\end{array}$} & Nomeação & $17 / 90$ & $2 / 36$ & $3 / 40$ & $1 / 16$ & $0 / 30$ & $0 / 12$ & $0 / 60$ & $0 / 18$ & $0 / 140$ & $0 / 56$ \\
\hline & Imitação & $17 / 90$ & $6 / 36$ & $0 / 20$ & $1 / 8$ & $0 / 30$ & $0 / 12$ & $1 / 80$ & $0 / 32$ & $0 / 130$ & $0 / 52$ \\
\hline & $\begin{array}{c}\text { Fala } \\
\text { espontânea }\end{array}$ & $4 / 17$ & $1 / 11$ & $0 / 4$ & $0 / 4$ & $0 / 5$ & $0 / 2$ & $0 / 2$ & $0 / 5$ & $0 / 4$ & $0 / 8$ \\
\hline \multirow[t]{3}{*}{6 anos } & Nomeação & $1 / 90$ & $0 / 63$ & $0 / 40$ & $0 / 28$ & $1 / 30$ & $0 / 21$ & $0 / 60$ & $0 / 42$ & $0 / 140$ & $0 / 98$ \\
\hline & Imitação & $1 / 90$ & $0 / 63$ & $0 / 20$ & $0 / 14$ & $1 / 30$ & $0 / 21$ & $0 / 80$ & $0 / 56$ & $0 / 130$ & $0 / 91$ \\
\hline & $\begin{array}{c}\text { Fala } \\
\text { espontânea }\end{array}$ & $0 / 24$ & $0 / 17$ & $0 / 2$ & $0 / 6$ & $0 / 2$ & $0 / 1$ & $0 / 4$ & $0 / 11$ & $0 / 19$ & $0 / 15$ \\
\hline \multirow{3}{*}{$\begin{array}{c}7 \\
\text { anos }\end{array}$} & Nomeação & $30 / 90$ & $8 / 36$ & $14 / 40$ & $3 / 16$ & $0 / 30$ & $0 / 12$ & $4 / 60$ & $0 / 18$ & $0 / 140$ & $2 / 56$ \\
\hline & Imitação & $30 / 90$ & $9 / 36$ & $8 / 20$ & $2 / 8$ & $0 / 30$ & $0 / 12$ & $1 / 80$ & $0 / 32$ & $0 / 130$ & $0 / 52$ \\
\hline & $\begin{array}{c}\text { Fala } \\
\text { espontânea }\end{array}$ & $4 / 17$ & $5 / 13$ & $0 / 3$ & $0 / 1$ & $0 / 0$ & $0 / 0$ & $0 / 2$ & $0 / 2$ & $0 / 13$ & $0 / 8$ \\
\hline
\end{tabular}


Anexo 13. Palatografia e Linguografia dos sujeitos do GSTFSD, GSTFCD e GTFCD.

Figura A. Palatografia e Linguografia [s] - GSTFSD 5:10 anos.
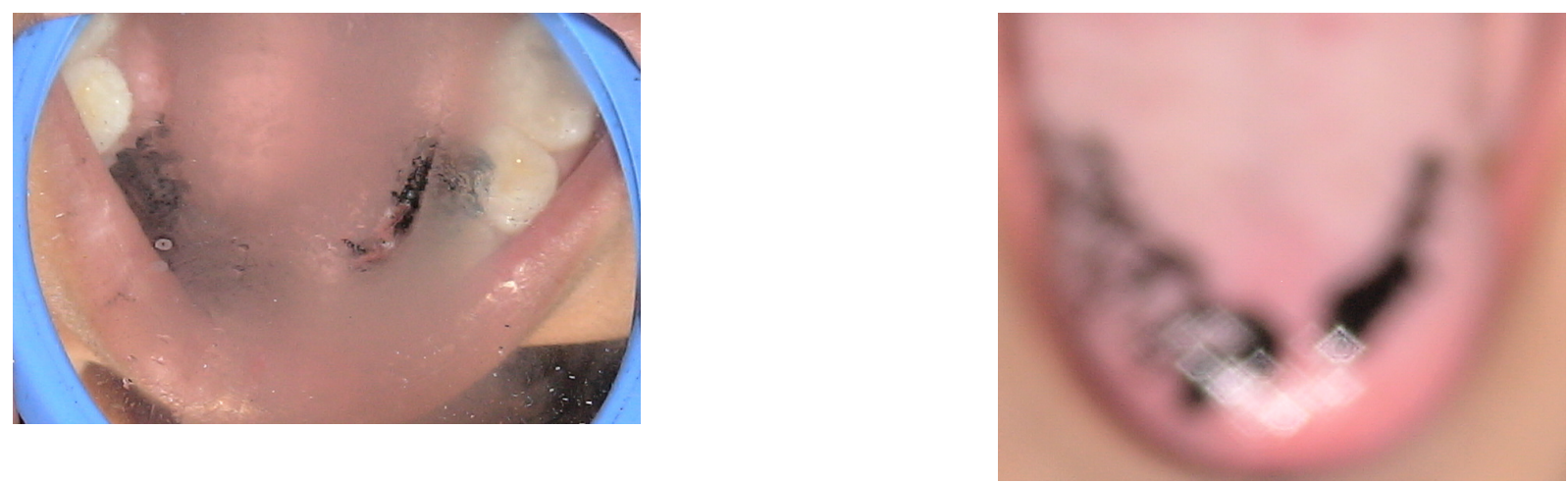

Figura B. Palatografia e Linguografia [z] - GSTFSD 5:10 anos.
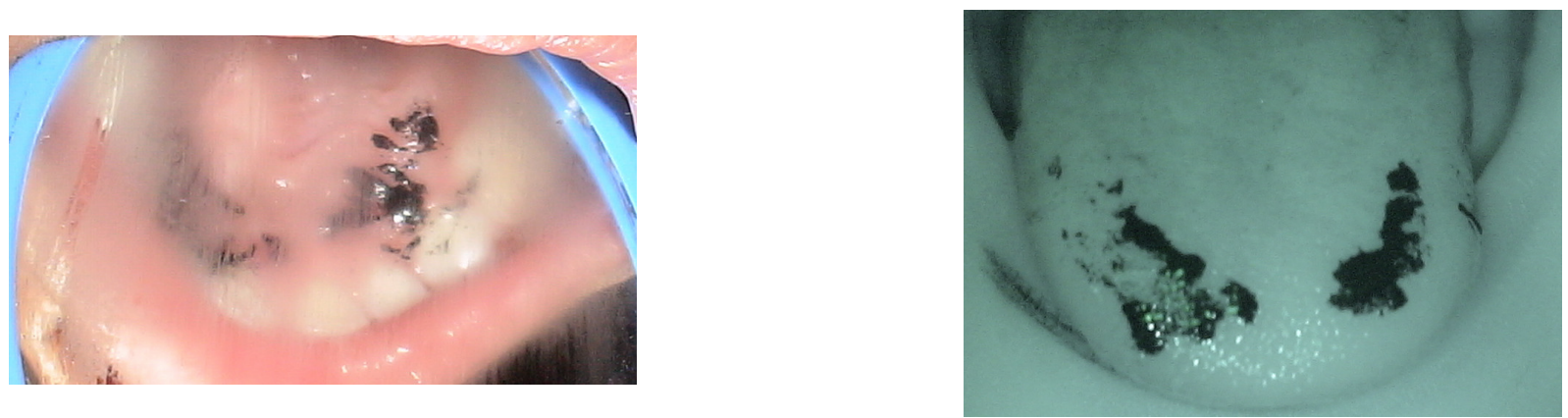

Figura C. Palatografia e Linguografia [S] - GSTFSD 5:10 anos.
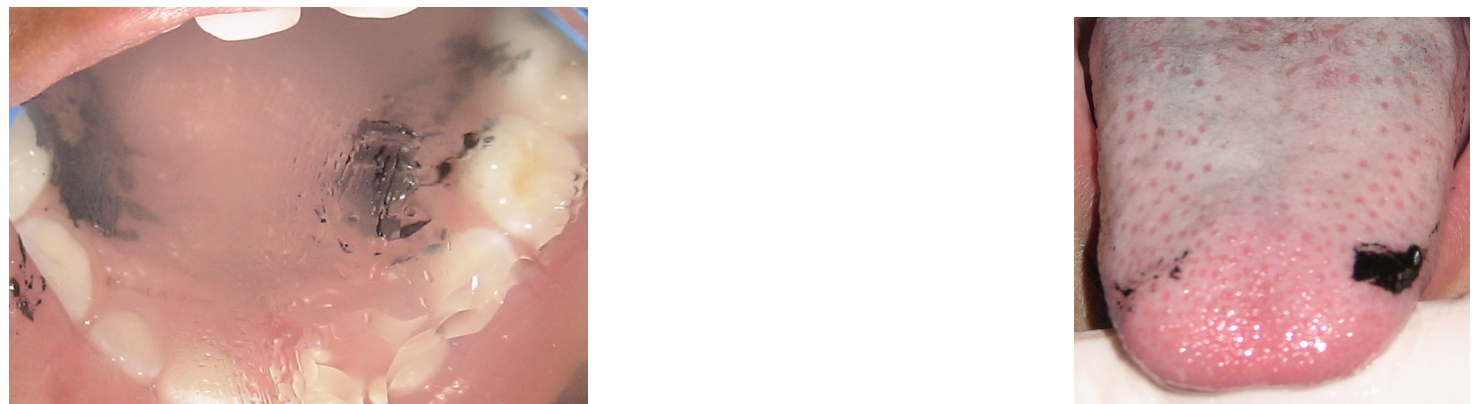
Figura D. Palatografia e Linguografia [3] - GSTFSD 5:10 anos.
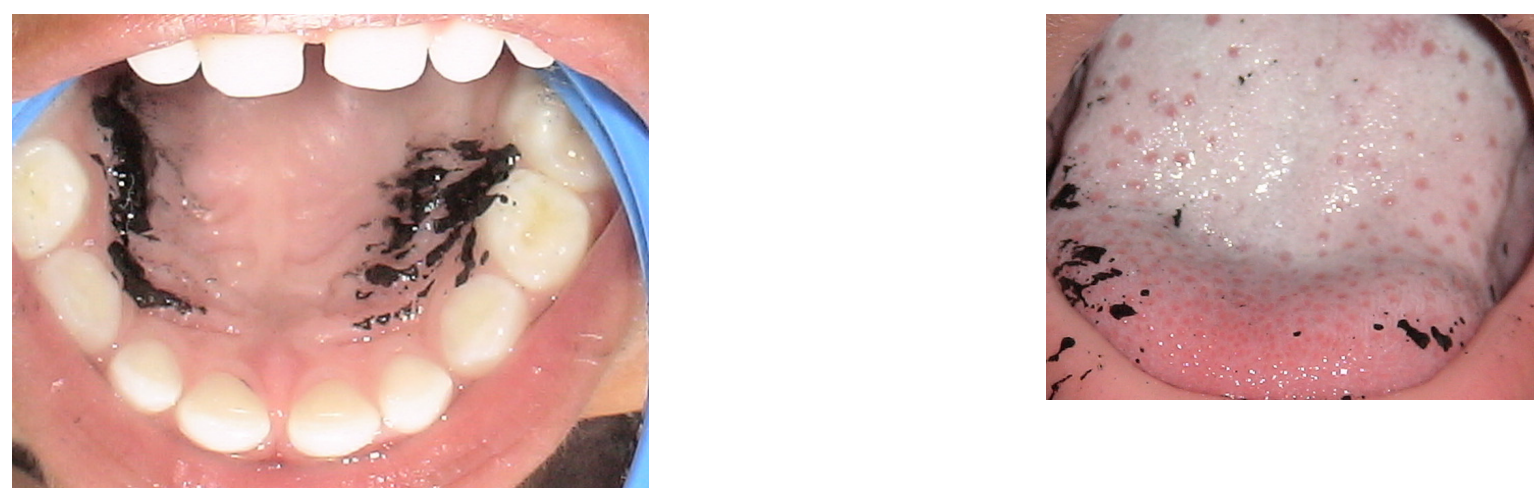

Figura E. Palatografia e Linguografia [1] - GSTFSD 5:10 anos.
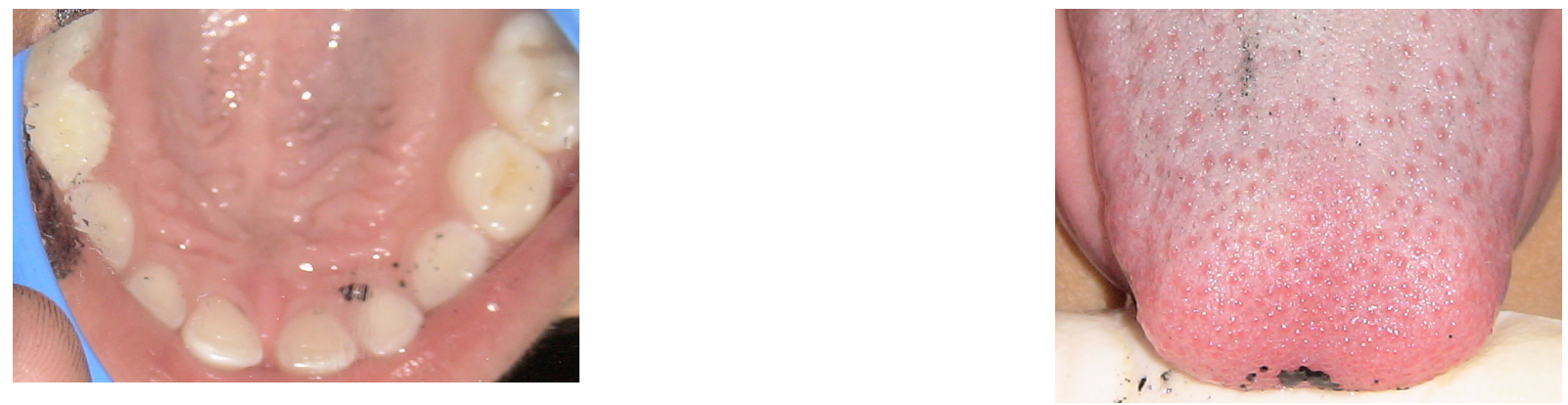

Figura F. Palatografia e Linguografia $[\Lambda]$ - GSTFSD 5:10 anos.
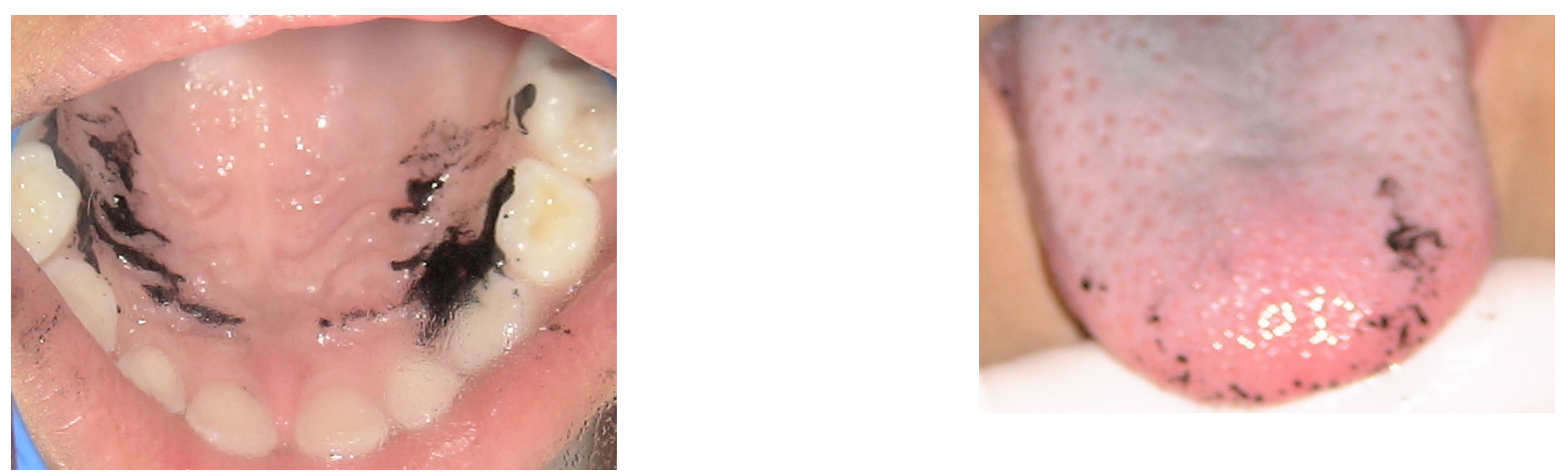
Figura G. Palatografia e Linguografia [ $\varsigma$ ] - GSTFSD 5:10 anos.
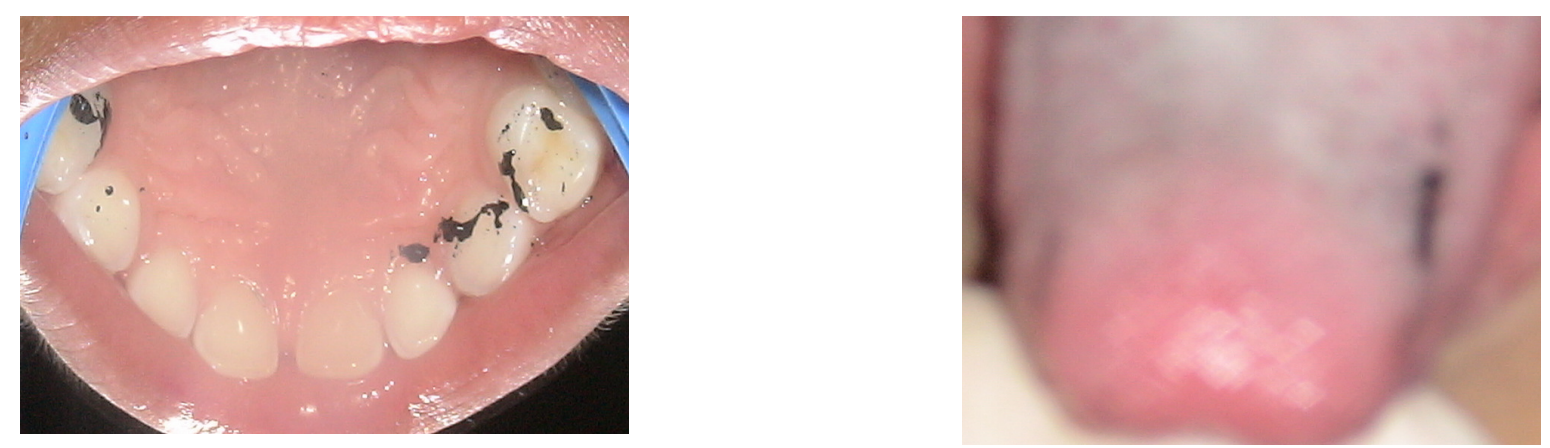

Figura H. Palatografia e Linguografia [s] - GSTFSD 7:00 anos.
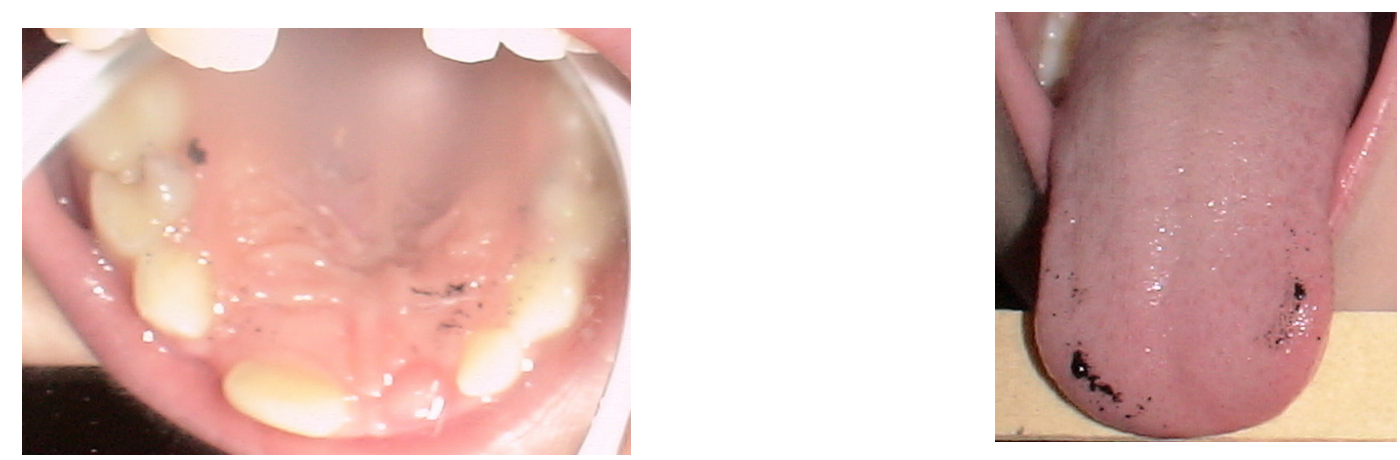

Figura I. Palatografia e Linguografia [z] - GSTFSD 7:00 anos.
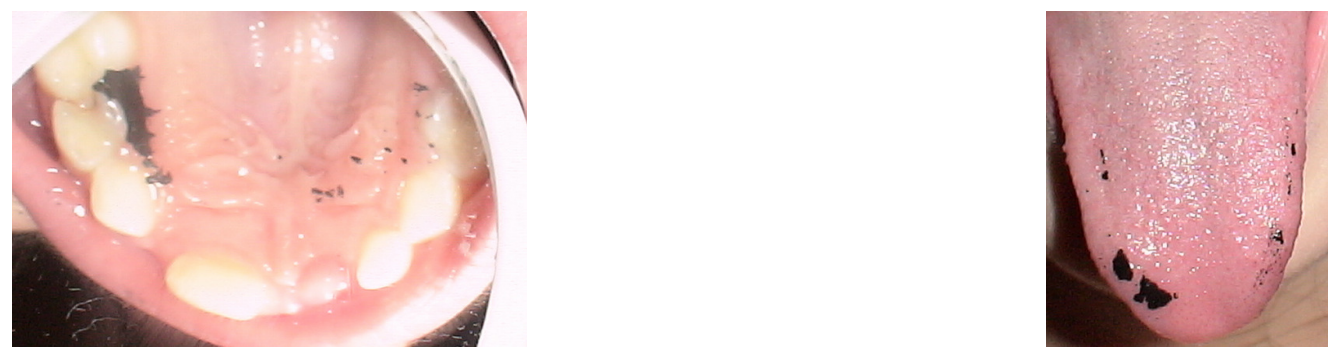
Figura J. Palatografia e Linguografia [S] - GSTFSD 7:00 anos.
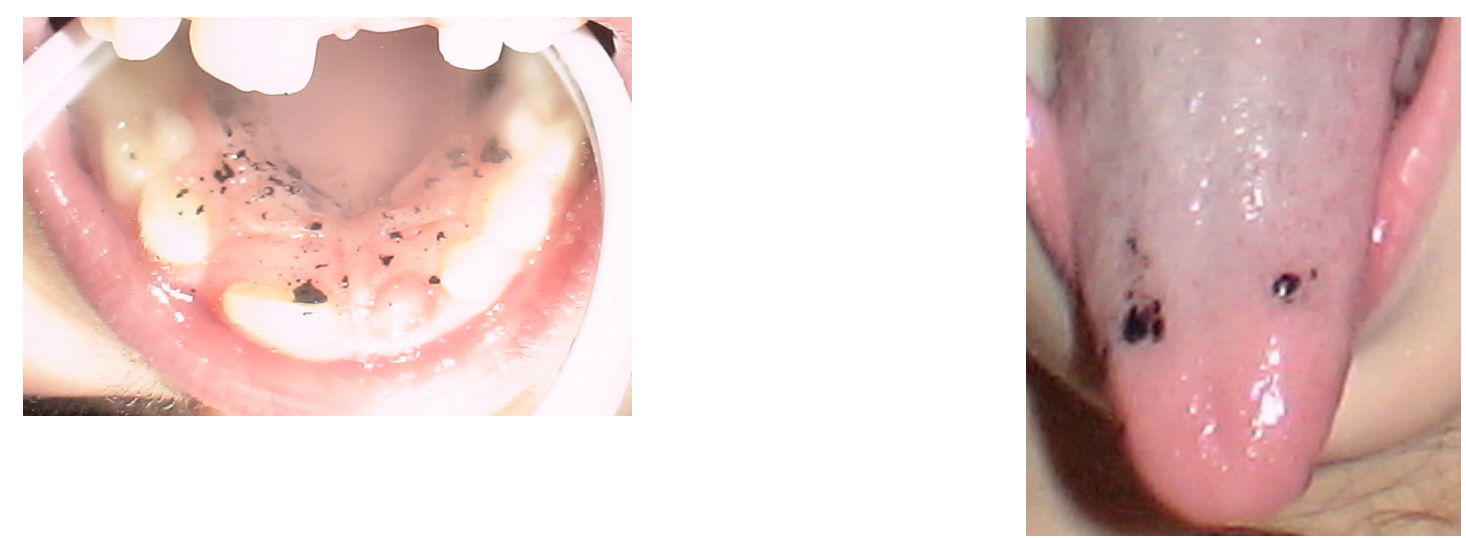

Figura L. Palatografia e Linguografia [3] - GSTFSD 7:00 anos.
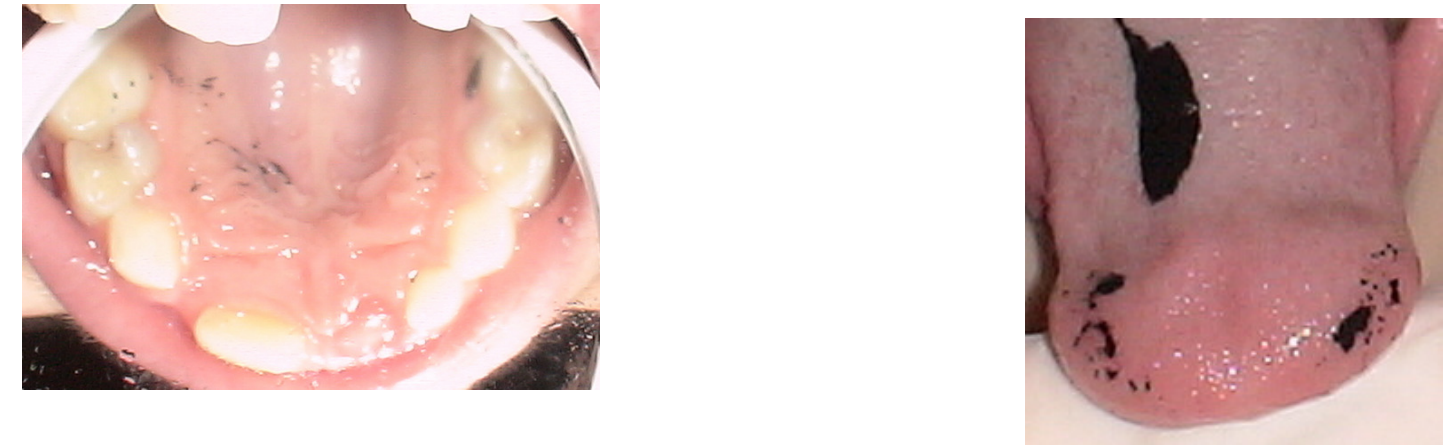

Obs.: durante a aplicação da mistura para obtenção da linguografia do [3], houve contato do pincel com a região laminar posterior.

Figura M. Palatografia e Linguografia [1] - GSTFSD 7:00 anos.
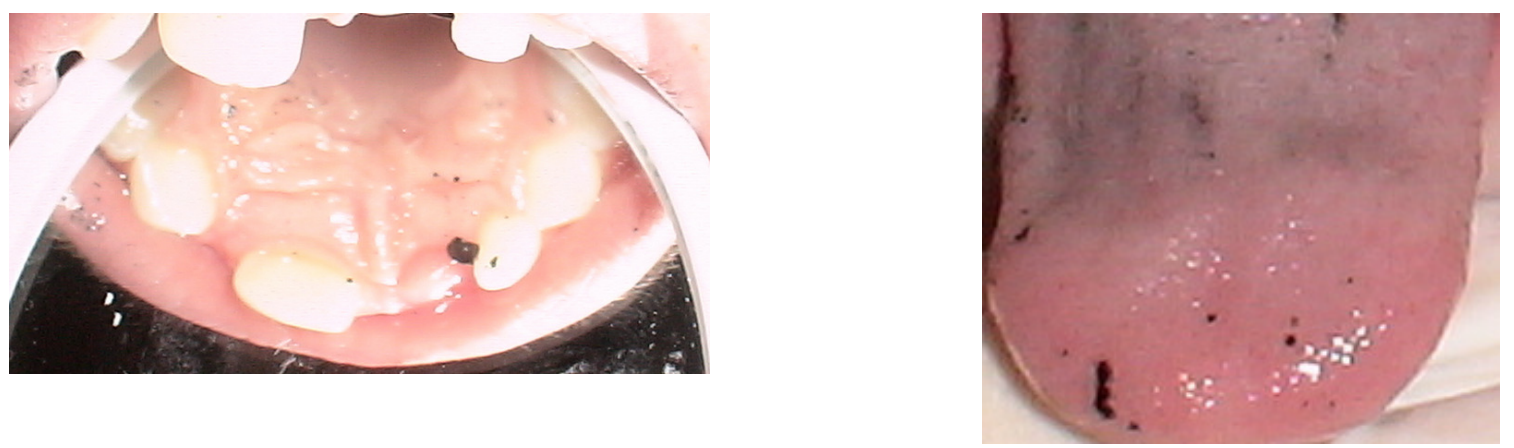
Figura N. Palatografia e Linguografia $[\Lambda]$ - GSTFSD 7:00 anos.
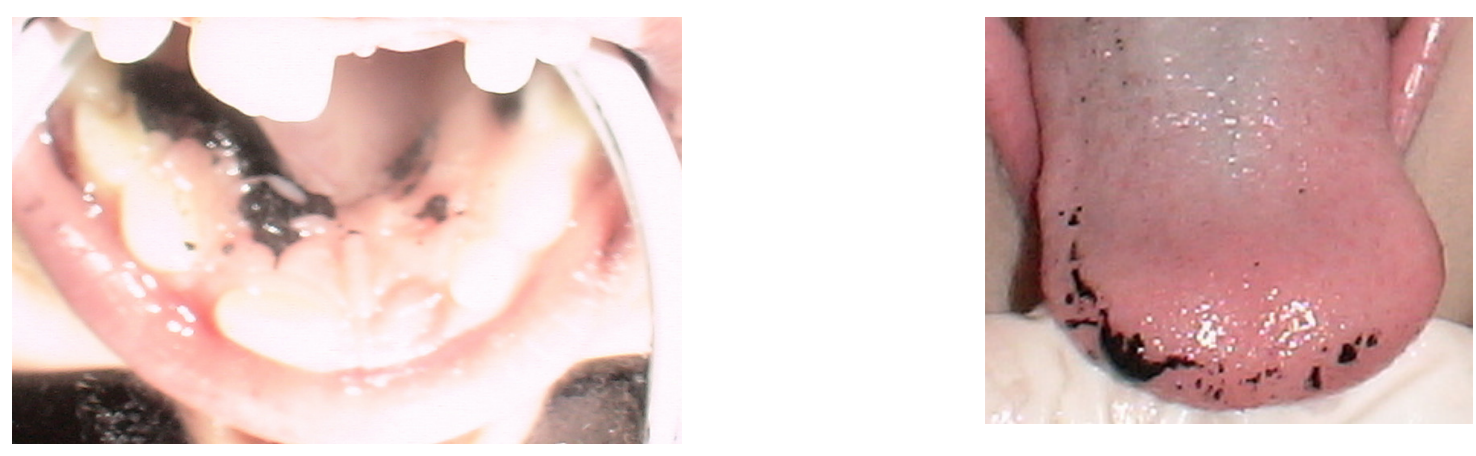

Figura O. Palatografia e Linguografia [ $\ulcorner$ - GSTFSD 7:00 anos.
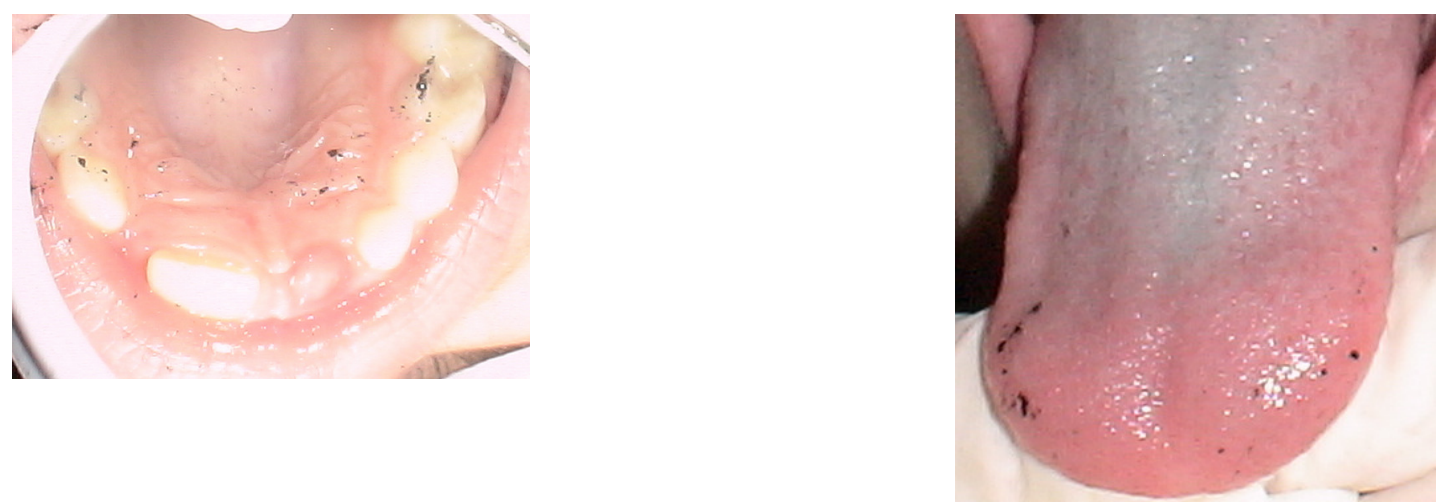

Figura P. Palatografia e Linguografia [s] - GSTFCD 5:09 anos.
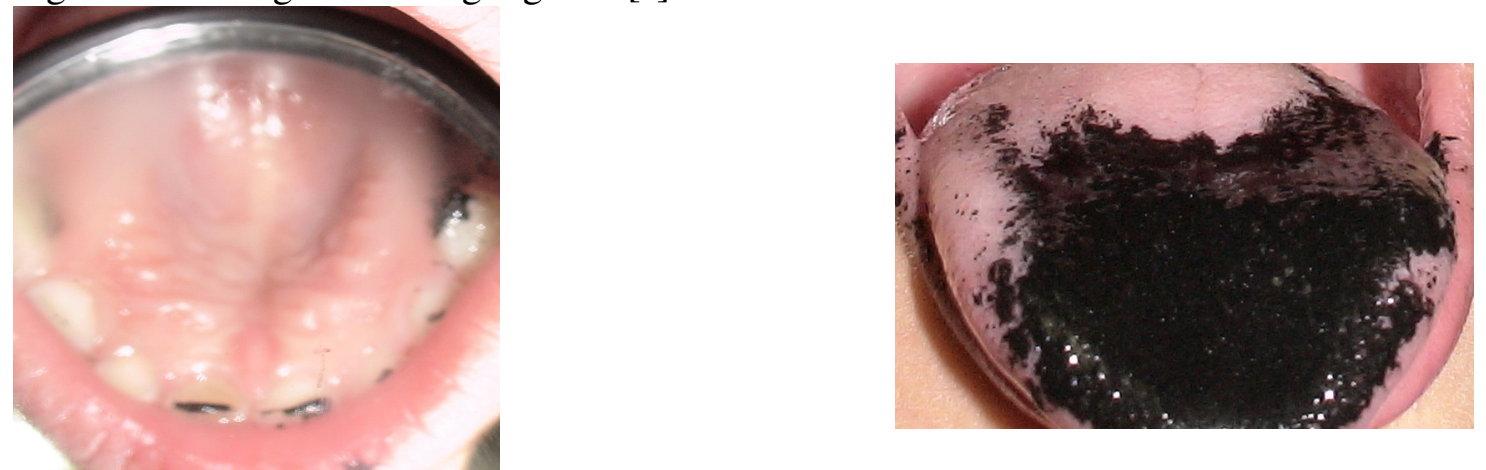
Figura Q. Palatografia e Linguografia [s] - GSTFCD 6:02 anos.
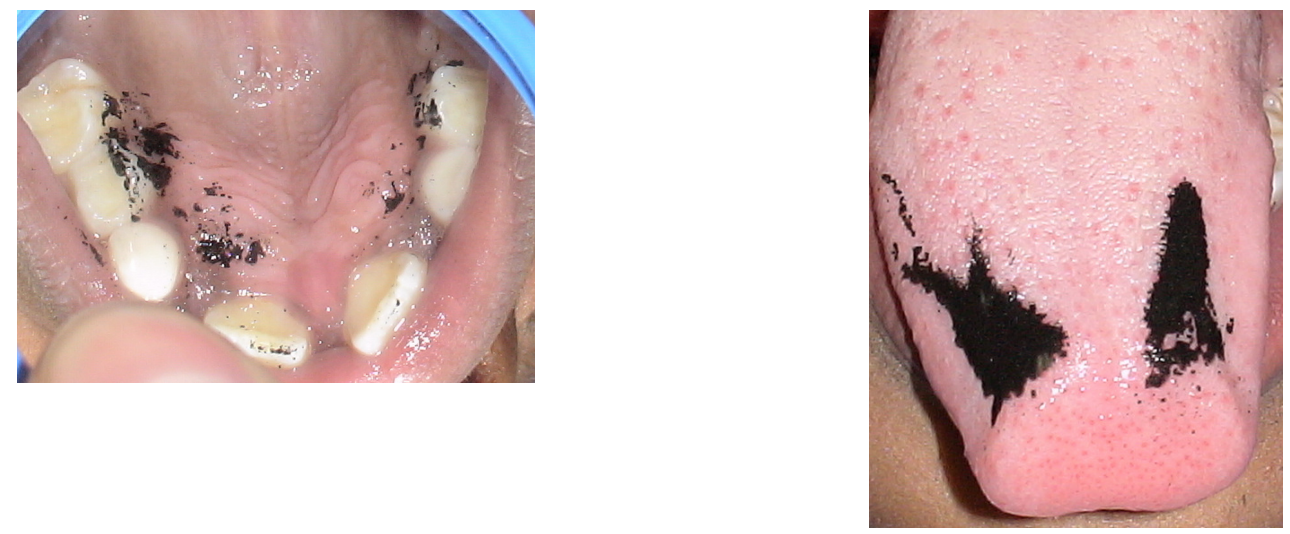

Figura R. Palatografia e Linguografia [s] - GSTFCD 7:05 anos.
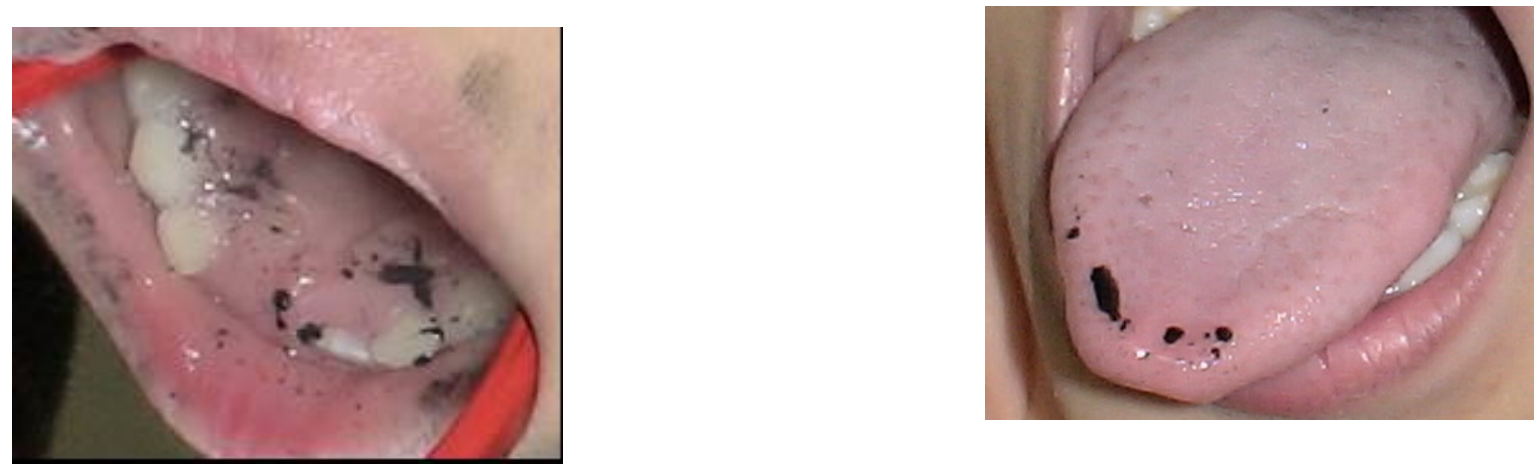

Figura S. Palatografia e Linguografia [s] - GSTFCD 7:11 anos.

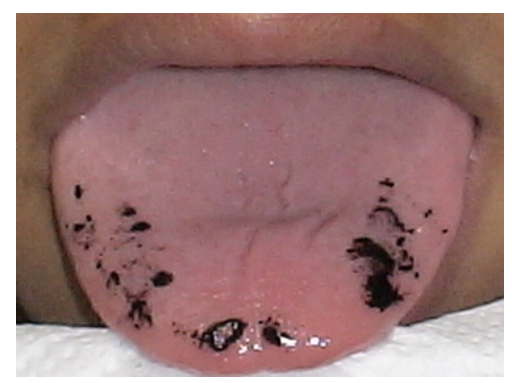

Figura T. Palatografia e Linguografia [z] - GSTFCD 5:09 anos. 

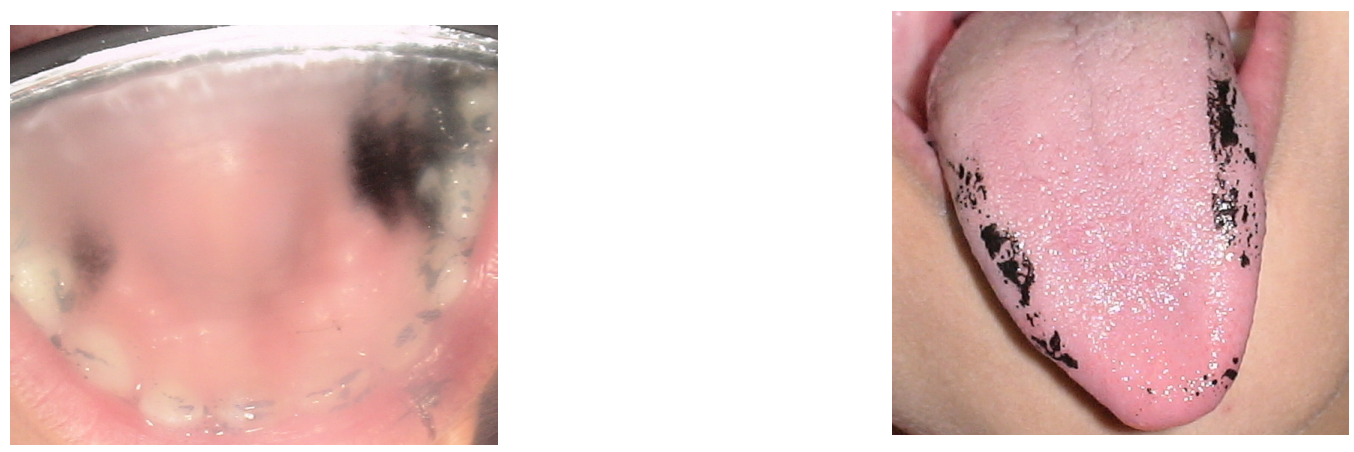

Figura U. Palatografia e Linguografia [z] - GSTFCD 7:05 anos.
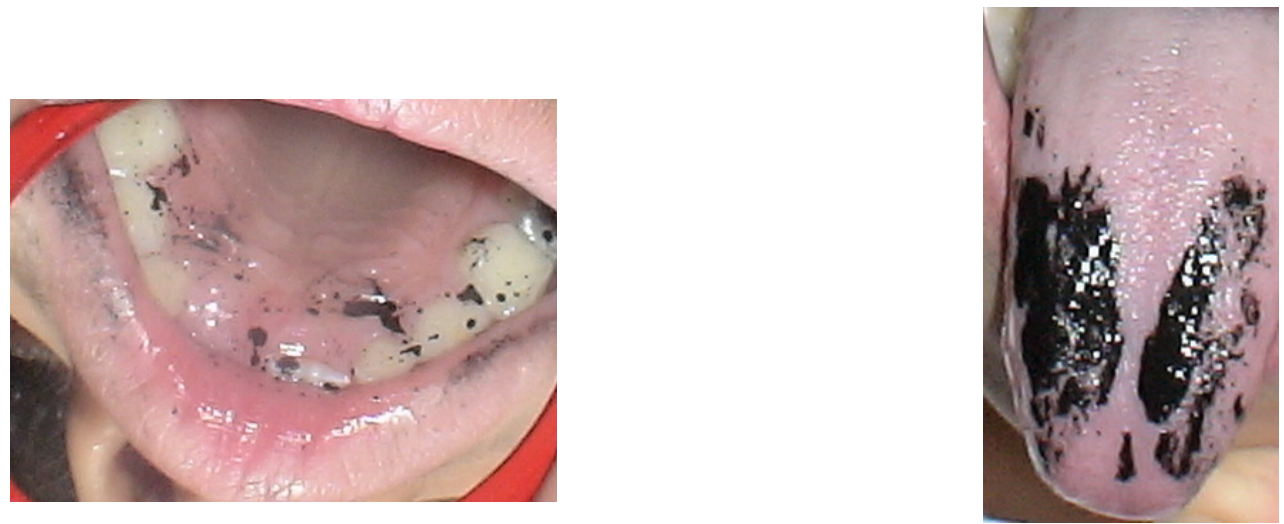

Figura V. Palatografia e Linguografia [z] - GSTFCD 7:11 anos.
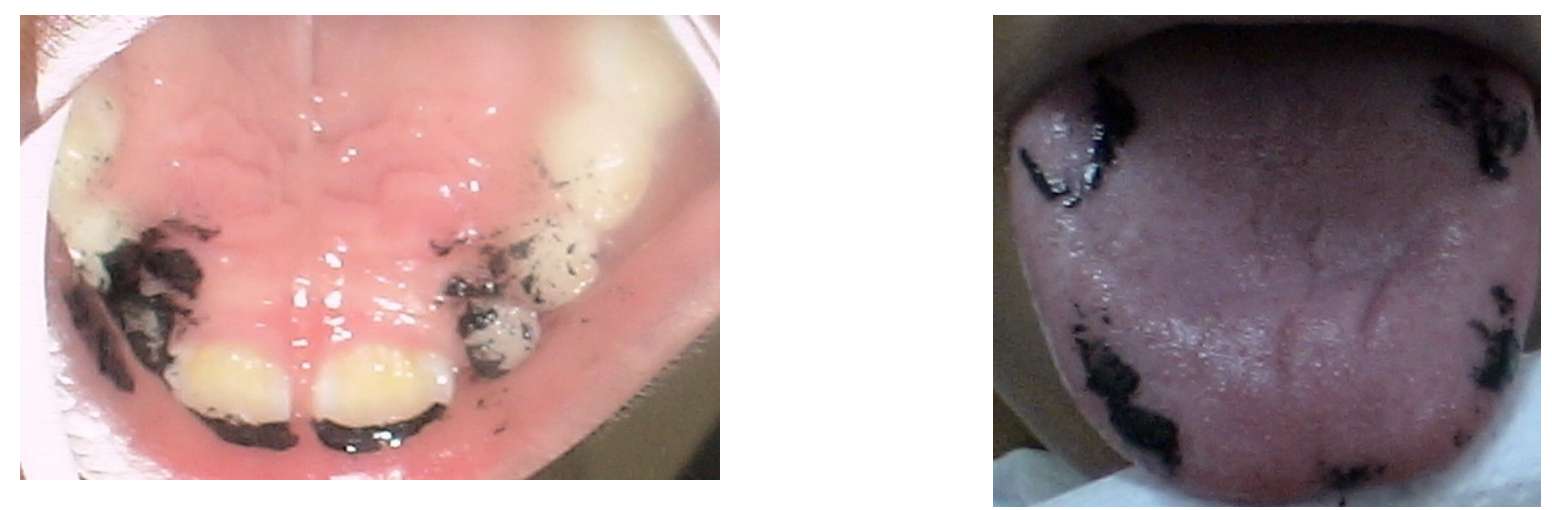

Figura X. Palatografia e Linguografia [S] - GSTFCD 6:02 anos. 

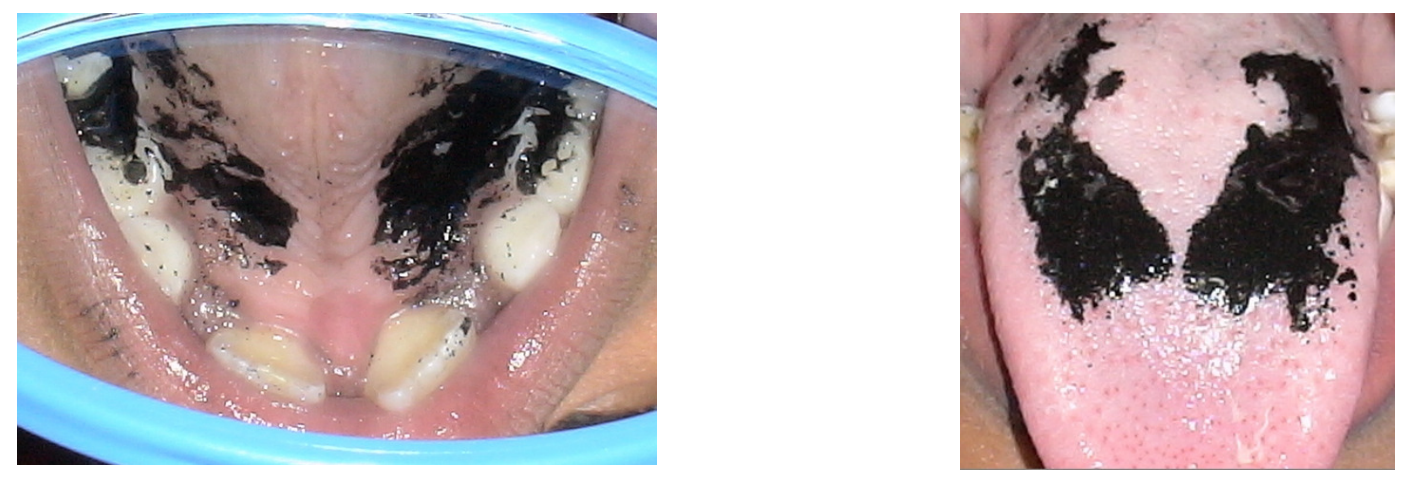

Figura Z. Palatografia e Linguografia [1] - GSTFCD 5:09 anos.
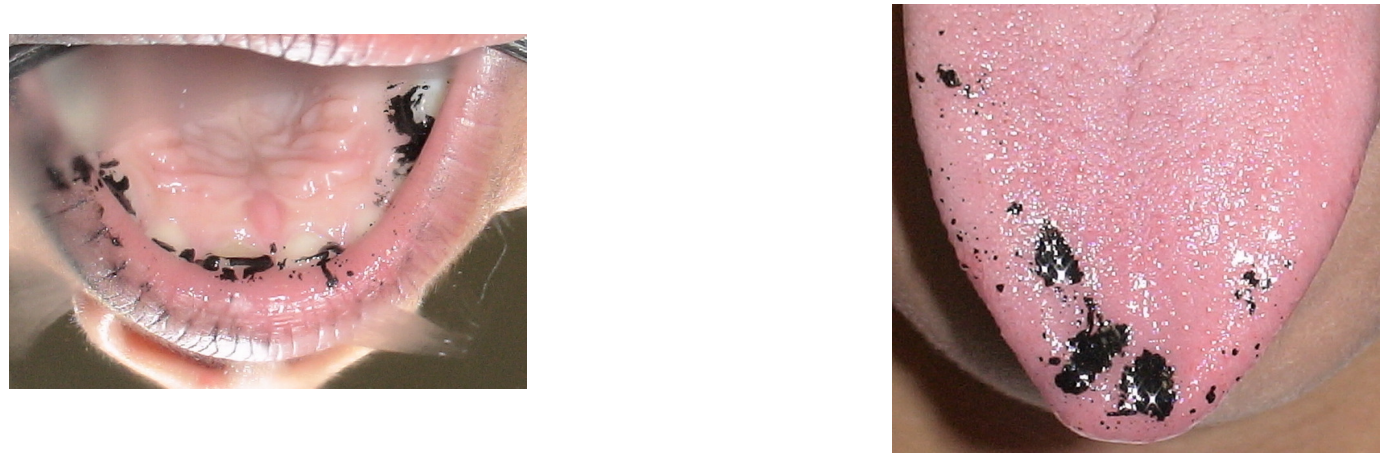

Figura AA. Palatografia e Linguografia [1] - GSTFCD 7:11 anos.
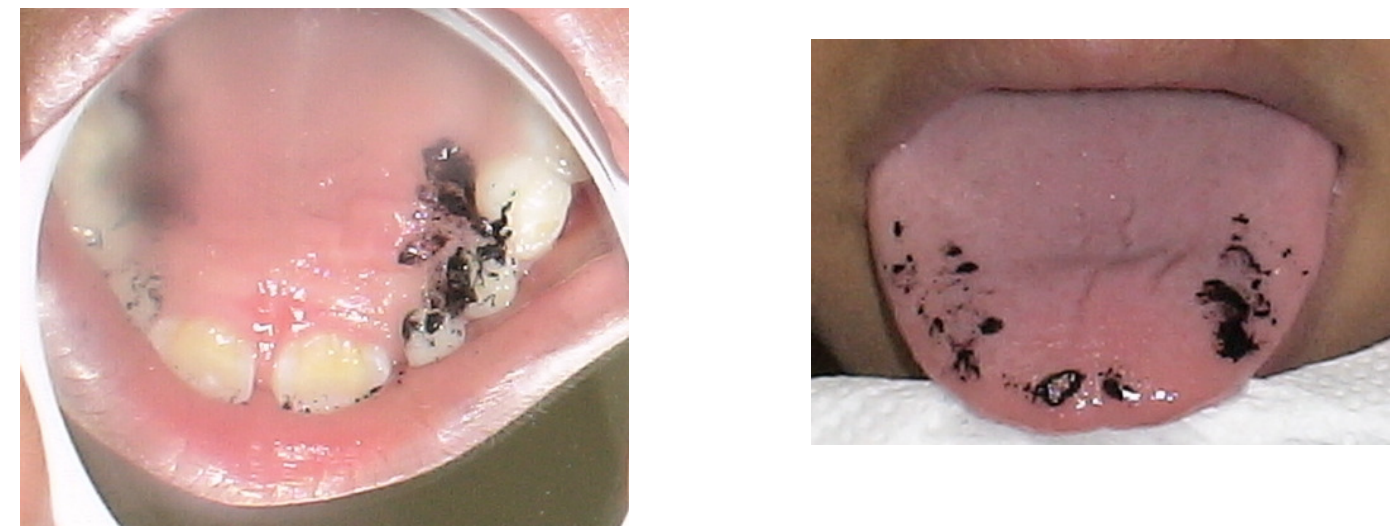

Figura AB. Palatografia e Linguografia [s] - GTFCD 7:04 anos. 

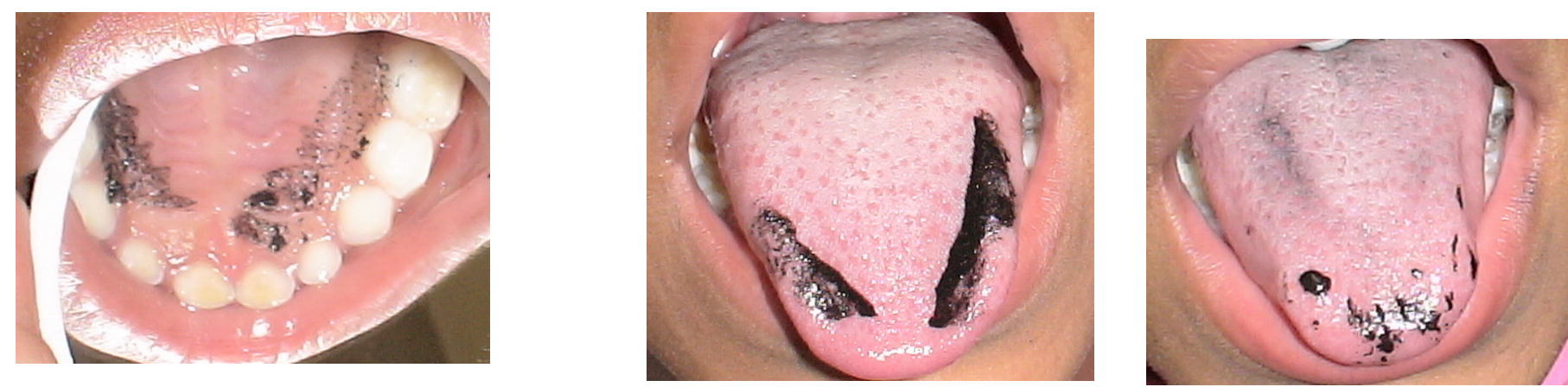

Figura AC. Palatografia e Linguografia [s] - GTFCD 7:09 anos.
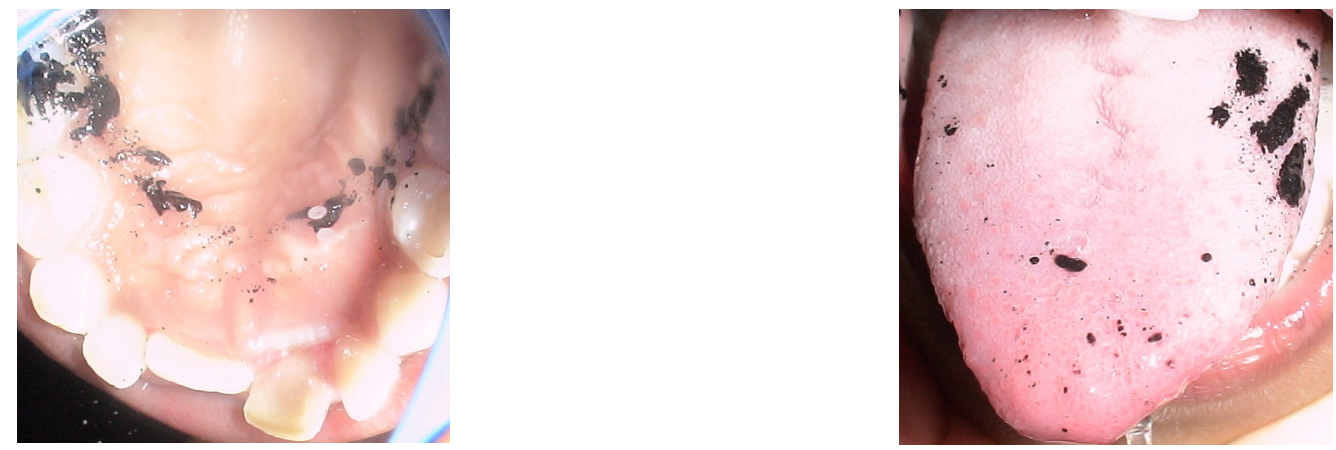

Figura AD. Palatografia e Linguografia [z] - GTFCD 7:09 anos.
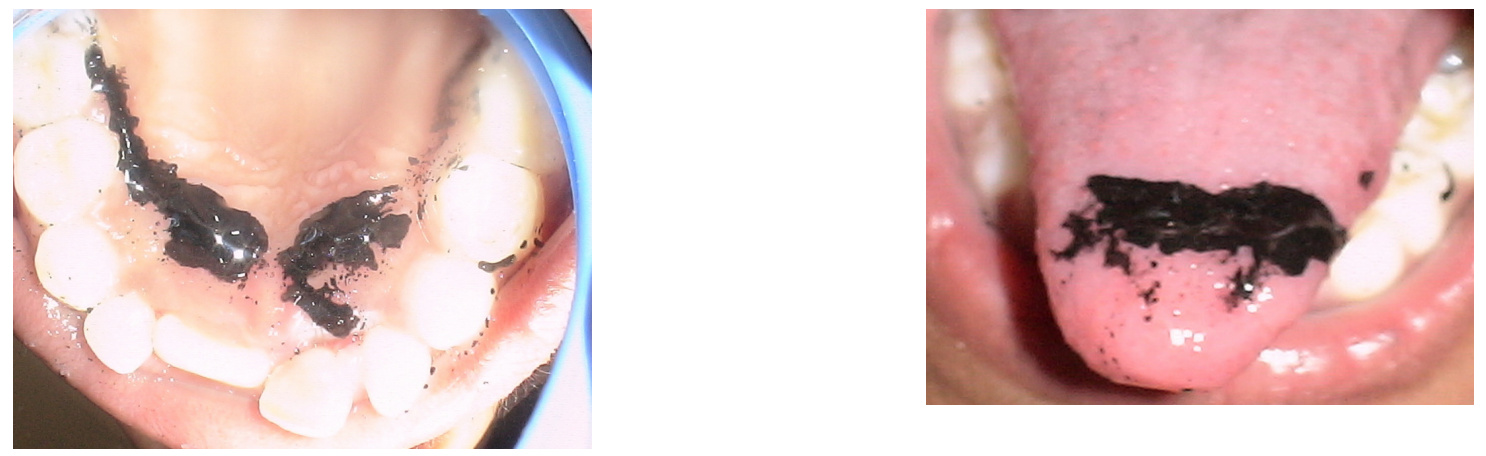
Figura AE. Palatografia e Linguografia [ᄃ] - GTFCD 7:04 anos.
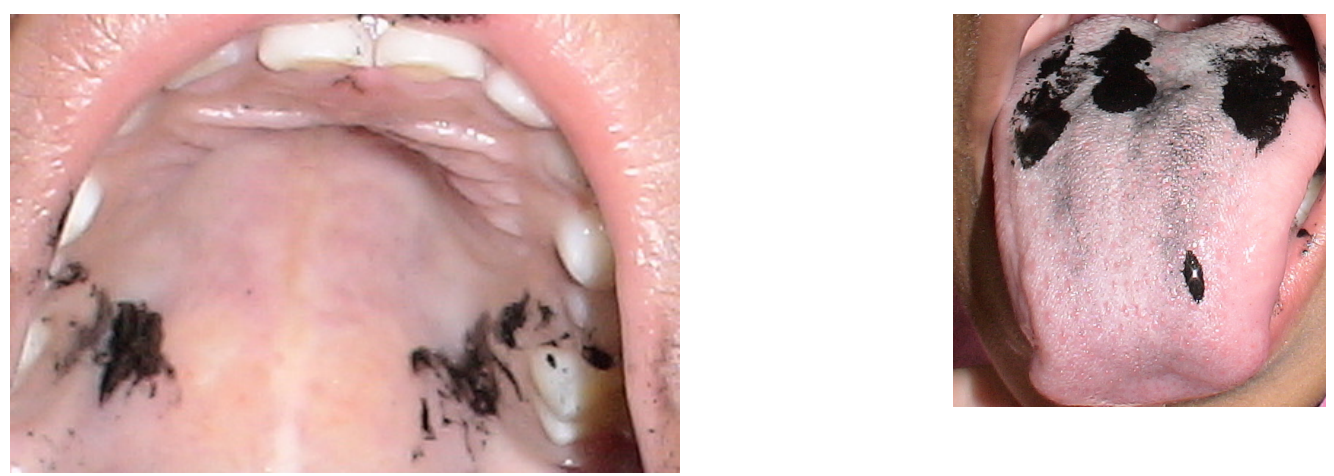
